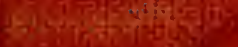

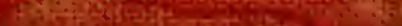
Theng

SCIENTIFIC FEEDING OF ANIMALS

* kELLNer 


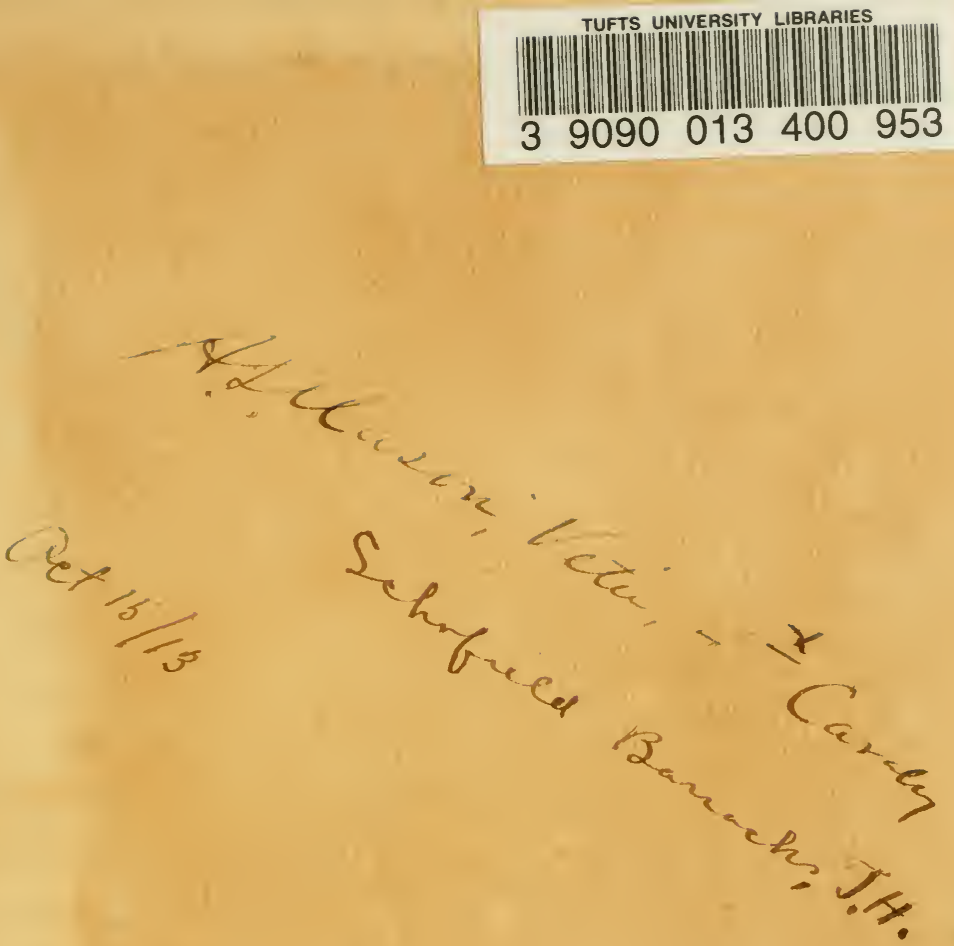

Webser Family Litsany of Veteringry Medicine Cumming Scincl of Werthary Piediche at 





\section{THE SCIENTIFIC FEEDING OF ANIMALS}





\section{THE \\ SCIENTIFIC FEEDING OF ANIMALS}

BY

PROFESSOR O. KELLNER

AUTHORISED TRANSLATION BY

WILLIAM GOODWIN, B.Sc., Ph.D.

Lecturer on Agricultural Chemistry, and Head of the Chemical

Department, South-Eastern Agricultural College

(University of London)

Wye, Kent.

NEW YORK.

THE MACMILLAN COMPANY

I 9 I 3 


\section{First Impression . . 1909 \\ Second Impression . . I9r3 \\ All Rights Reserved}

PRINTED BY WILLIAM BRENDON AND SON, LTD. PLYMOUTH, ENGLAND. 


\section{PREFACE TO THE ENGLISH EDITION}

THE scientific foundations upon which the 1 principles of animal nutrition rest are, like all other experimentally derived data, of general applicability and not restricted to one country alone. It is true that climate influences the weights of crops and the nutrients contained in them, but the laws governing digestion, metabolism, effect of foods in the production of flesh, fat, milk, wool, or utilisable energy are the same whether the animals are kept in the north or south, east or west. Any facts therefore which are brought to light in Germany or France are practically applicable to Great Britain, the United States, Canada, Australia, etc., for in temperate climates the differences of heat or cold only influence to a very small degree the needs of an animal for a given purpose. For this reason anybody who is well acquainted with the general laws which underlie the feeding of animals will always have an advantage over one who relies upon ruleof-thumb, and will be able to raise animals more cheaply than a competitor who follows the practices of his grandfather. 
As there is not at the present time an English book which gives concisely and clearly the information which a farmer or agricultural student ought to possess, I have gladly agreed to the following translation being made by Dr. Goodwin. In Part I will be found the main principles upon which the theory of feeding is based, then follows in Part II a short descriptive account of the different feeding-stuffs, in which more attention has been paid to the suitability and uses of the various classes than to the percentage amounts of nutrients which they contain. This second part also includes the methods used in the conservation and preparation of feedingstuffs, and is followed in Part III by the conditions which should be observed in the feeding of the different kinds of domestic animals. The tables needed for the calculation of rations, with a few remarks upon the method of using them, are placed in the Appendix.

I sincerely trust that this edition will gain as favourable a verdict as the original has done both from practical men and from students of agriculture and veterinary science.

Dr. O. KeLLNER.

Agricultural Experimental Station,

Möckern, Near Leipzig,

December, igos. 


\section{TRANSLATOR'S PREFACE}

T HAVE made no attempt to rearrange Professor

1 Kellner's valuable little work so that it should be more in accordance with English practice, for I believe that in its original form the main points are quite clear and that where there are differences between German practice and our own they will perhaps serve to suggest methods worth a trial here. It is hoped that in this way the book will have something of the value of a visit to a foreign country, which is so beneficial in arousing a spirit of critical observation with regard to the practices in vogue there. As the author says in the Preface which he has kindly written for this edition, the main principles of feeding apply equally well in all countries possessing a moderate climate.

That Professor Kellner has succeeded in giving to the world a book which was needed is proved by the fact that it is now appearing in seven languages, and the original is in its second edition.

I have purposely not converted all weights, temperatures, etc. into those used in this country, for the student will prefer to have them in the original; where, however, it has seemed preferable to give the 
viii

\section{PREFACE}

practical man the weights and measures to which he is accustomed this has been done. In any case the relation between the two systems hardly requires a greater knowledge than that I kilogram (kg.) = 2.2 lbs.; I litre $=I \frac{3}{4}$ pints; I oz. $=28$ grms. (g.).

\section{W. Goodwin.}

South-Eastern Agricultural College,

Wye, Kent. 


\section{CONTENTS}

PART I

THE COMPOSITION, DIGESTION, AND UTILISA- PAGE TION OF FEEDING-STUFFS . • . . . I

\section{CHAPTER I}

The Composition of Feeding-Stuffs

I. Water .

2. The proteins

3. Non-protein nitrogenous substances

4. The fats and oils

5. Crude fibre

6. The nitrogen-free extract

7. Mineral substances or ash

- 3

- 4

- 5

- 8

- 10

- 12

- 14

- 15

\section{CHAPTER II}

The Digestion of the Food

I. Mastication

2. The processes of digestion

- 18

3. The determination of the digestibility of foods

- 18

- $2 \mathrm{I}$

4. The exient of digestion under various conditions

- 27

- $3 \mathrm{I}$

CHAPTER III

The Utilisation of Digested Nutrients in the

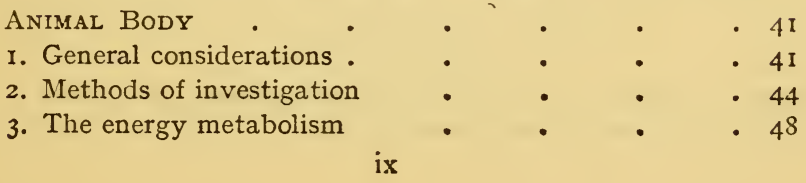




\section{CHAPTER IV}

Metabolism .

I. Fasting metabolism . $\quad$. $\quad$. $5 \mathrm{I}$

2. Insufficient feeding . $\quad . \quad$. $\quad . \quad 55$

3. Abundant food supply-formation of fat and flesh . 58

a. The effect of protein . $\quad$. $\quad$. $\quad$. 59

b. The effect of non-protein nitrogenous substances 65

c. The effect of nitrogen-free nutrients . . 69

d. The action of nitrogen-free nutrients upon the protein and fat metabolism . . . 7 I

e. Formation of body fat from food fat . . 74

f. Formation of body fat from carbohydrates $\quad 77$

g. The utilisation of complete foods . • . 82

$h$. The effect of mineral substances . . . 93

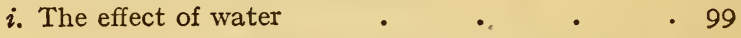

\section{CHAPTER V}

The Utilisation of Food and Energy in Muscular Work-LAWS OF Production OF ENERgy . . 104

I. The sources of muscular energy a . . 104

a. Protein as a source of muscular energy . . I04

$b$. The nitrogen-free nutrients (fats and carbohydrates) as a source of muscular energy - 106

c. Storage of protein in consequence of muscular work . . . . . . 108

2. The relation between metabolism and muscular work : I09

\section{PART II}

THE FEEDING-STUFFS - THEIR PROPERTIES, CONSERVATION, PREPARATION, AND APPLICABILITY .
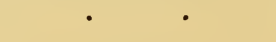

\section{CHAPTER I}

The Nutrient Contents, Palatableness, and DurABILIty of the Feeding-Stuffs 
CHAPTER II

Conservation of Feeding-Stuffs

I. The making of hay

2. Sour fodder and silage .

3. The storage of cereal grains

4. The keeping of roots and tubers

5. The artificial drying of feeding-stuffs

\section{CHAPTER III}

Preparation of Feeding-Stuffas .

I. Chopping and grinding

2. Moistening with cold water

3. Cooking and steaming .

4. Roasting

5. Steeping in water

6. Heating under pressure with caustic soda

- 137

- 137

- 140

- 140

. 142

. 142

. 144

7. Heating under pressure with hydrochloric acid

. I 44

8. Malting and preparation of sweet mashes

. 145

9. Artificial digestion of foods

Io. Fermentation .

II. Sour fodder

12. Feeding loaves .

\section{CHAPTER IV}

Description OF the Feeding-Stuffs

I. Green fodder and hay .

2. Chaif and straw

3. Roots and tubers

4. Grains and seeds

5. By-products from flour mills .

. 146

- 147

. 147

. 148

6. Residues from oil mills

7. Residues from the manufacture of starch

8. By-products from the manufacture of sugar

- 150

. 169

- 173

. 180

- 190

. 195

. 204

- 207

9. Residues from fermentation processes .

. 213

10. Feeding-stuffs of animal origin

. 217

II. Cattle powders . 


\section{PART III}

THE FEEDING OF DOMESTIC ANIMALS UNDER THE CONDITIONS USUALLY FOUND IN PRACTICE

PAGE

\section{CHAPTER I}

General Considerations - Experimental Trials in Practice .

\section{CHAPTER II}

Maintenance Ration for Oxen at Rest

\section{CHAPTER III}

Maintenance Ration for Sheep-The Production of Wool

\section{CHAPTER IV}

The Fattening of Full-grown Animals • . 253

I. The fattening of grown ruminants . . . $26 \mathrm{I}$

2. The fattening of grown pigs . • . 268

\section{CHAPTER V}

The Feeding of Working Animals

I. The feeding of draught oxen .

2. The feeding of horses .

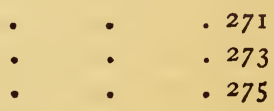

\section{CHAPTER VI}

The Feeding of Growing Animals for Breeding or

FATTENing

I. The feeding of calves :

2. The feeding of lambs

. 283

• $\quad . \quad$ • 294

3. The feeding of growing pigs . $\quad$. $\quad .296$ 


\section{CHAPTER VII}

The Femping OF MiLch CATTLe

The Feeding of Milch Cattle • • • • 306

I. The formation of milk . $\quad . \quad$. $\quad . \quad 306$

2. The influence of the constitution of the animal upon the formation of milk $\quad . \quad$. $\quad . \quad 308$

a. Breed and individuality . . . . . 308

b. The period of lactation . . . . . 310

c. The age of the cow . . . . 3II

3. The influence of other factors on the formation of milk 3 I I

$a$. The frequency and manner of milking . . 3II

b. Performance of work by cows . . . 3I4

c. Other influences: treatment and care . . 316

4. Methods for ascertaining the effect of food on the secretion of milk $\quad \cdot \quad \cdot \quad \cdot \quad \cdot \quad \cdot 317$

a. The period system $\quad . \quad . \quad . \quad .317$

b. The group system . . . . . 3I9

5. The effect of food on the milk production . . 32I

a. General considerations . . . . 32I

b. The effect of the quantity of food on the milk secretion. $. \quad . \quad . \quad 323$

c. The effect of food-protein on the production of milk . . . . . . . 325

d. The effect of non-protein nitrogenous substances 327

$e$. The effect of non-nitrogenous nutrients . . 329

$f$. The so-called specific effects of the food-stuffs . 334

g. The effect of food-stuffs injurious to health $\cdot 33^{8}$

6. Food for milch cattle . $\quad . \quad . \quad . \quad .338$

\section{APPENDIX}

Tables for the Calculation of Rations • 353

Method of using the Tables . . . . $\quad .353$

TABle I-Composition, Digestibility, and Starch Equivalents of various Feeding-Stuffs • . 360 Table II-The Digestibility of the Feeding-Stuffis (Digestibility COEfFicients) From EXPeriments ON Animals TABle III-Standard Rations INDEX 



\section{PART I}

THE COMPOSITION, DIGESTION, AND UTILISATION OF FEEDING-STUFFS 



\section{THE SCIENTIFIC FEEDING OF ANIMALS}

\section{CHAPTER I}

THE COMPOSITION OF FEEDING-STUFFS

THE natural products of the animal and vege1 table kingdoms which serve for the nourishment of domestic animals have a very varied composition. There is hardly one of them that contains less than thirty to forty different components, and to this number additions are continually being made. In order to get an insight into this crowded department it is necessary to group together those materials which resemble one another in their properties, or in their nutritive value. The chemical examination of a food-stuff is for this reason generally confined to a determination of the quantity of (I) water, (2) protein, or albuminoids, (3) non-protein substances, such as amides and amino acids, (4) fat, or oil, (5) crude fibre, (6) nitrogen-free extract substances, or carbohydrates, (7) ash and sand, which it contains. 


\section{(I) Water.}

That portion of a food which disappears on drying is called the water, or moisture. If the percentage of water in a food-stuff, such as grass or hay, had to be determined, it would not be sufficient to dry a sample at ordinary temperatures in the air, for in this way the whole of the water would not be driven off. A portion would still remain, varying from II $-20 \%$ of the total weight, and the sample would only be "air dried." Water can only be completely driven off by drying the finely ground sample of food for a considerable time at $100^{\circ} \mathrm{C}$. Usually this is continued until the weight of the substance remains constant, and this is the method adopted when an exact chemical analysis is being made. Many feeding-stuffs, particularly those that have been acted upon by bacteria or moulds, e.g. silage, as well as the plants and seeds containing ethereal oils, lose some other substances in addition to water when heated at $100^{\circ}$. These volatile materials, such as acetic acid, lactic acid, butyric acid, some ethereal oils, ammonia, etc., necessitate special precautions being taken when the water has to be estimated in a food in which they are present.

That which is left after complete desiccation in the manner described above is called the "dry matter." 
The tábles in the Appendix of this volume show clearly how considerably the amount of water in the various feeding-stuffs varies. Those which contain the most water are fresh slices of beetroot, with $93 \%$ water; then the roots and tubers, with $68-90 \%$; followed by the green fodders, with $70-90 \%$. Hay and straw contain about I2-I7\%, cereal grains II-I5\%, whilst oil cakes and oil cake meals have only $9-13 \%$. As a rule oily seeds $(7-9 \%)$ and dried by-products, such as brewers' grains $(7-12 \%)$, contain the least amount of moisture.

A knowledge of the quantity of water in a foodstuff is of great importance, not only as an indication of its feeding value, but also in respect to its keeping properties. Most meals and cakes easily undergo decomposition if they contain more than $\mathrm{I} 4 \%$ of water.

\section{(2) The Proteins.}

The proteins are a group of substances which vary a good deal in their properties, but agree in containing nitrogen. White of egg (albumin), the casein of milk, lean meat, wheat gluten, are amongst the best-known of these substances. In spite of the variations which they show in chemical composition there is sufficient agreement to enable them to be placed in one class. The proteins contain from $50 \cdot 6-55 \cdot 2 \%$ of carbon, $15 \cdot 0-18 \cdot 4 \%$ of nitrogen, $6 \cdot 5-7 \cdot 3 \%$ of hydrogen, $20 \cdot 8-23 \cdot 6 \%$ of 


\section{SCIENTIFIC FEEDING OF ANIMALS}

oxygen, along with $0 \cdot 3-2 \cdot 3 \%$ of sulphur. In some cases phosphorus is found, and in others a little iron.

When the proteins are pure and dry they form a horny substance, which melts in the flame and then burns to a black coal-like mass. At the same time fumes, which have the smell of burning hair, are given off. The products of such decomposition vary considerably in their properties, according to the substance which is heated.

The proteins are further distinguished by the ease or difficulty with which they dissolve in various solvents, such as water, alcohol, salt solution, caustic soda solution. They may be also characterised by another set of properties, e.g. coagulation on heating, precipitation from solution by metallic salts or tannic acid, distinctive colouration when acted upon by various reagents.

It was thought for a long time that all the nitrogen which is found in feeding-stuffs was present in the form of albumin. For this reason, and also on account of the impossibility of obtaining the proteins from the plant or the animal in a sufficiently pure state to be weighed, it has been the custom to estimate the amount of nitrogen in a food, and then calculate from this the percentage of protein matter. The proteins were supposed to contain on an average $16 \%$ of nitrogen, so by multiplying the amount of nitrogen found by $6 \cdot 25$ the weight of 
proteins was obtained. It was known that this method was not quite correct, for nitrogenous substances of a non-protein nature had already been found in different parts of the plant. The amount of these non-protein materials was considered, though, to be so small as to be negligible. The products obtained in this way by calculation from the nitrogen found in the food were called "crude protein," or " nitrogenous substances."

It was not until comparatively recently (I879) that the nitrogenous substances of a non-protein nature were shown to be widely distributed in the plant and animal kingdoms, and to be present in considerable quantities in some food-stuffs. This led to a distinction being made between "crude protein," which expresses all the nitrogen-containing compounds, and "pure protein," or, as it is named in some places, "the proteids." When making an analysis of a feeding-stuff advantage is taken of the property which proteins possess of combining with metallic salts or tannic acid, whereas nonproteins do not. In this way protein can be separated from non-protein and the quantities of each determined. For the analysis the finelyround food-stuff is treated with warm water, and the substance to be used for precipitation is added. The proteins are in this way precipitated, and the nitrogen can then be determined either in the solution which is left after the precipitation, or in the 


\section{SCIENTIFIC FEEDING OF ANIMALS}

precipitate itself. By this method proteins are isolated from non-proteins, and by using the same factor, $6 \cdot 25$, the amount of either, or both, can be got.

Dried animal residues, such as meat- or fish-meal, or the gluten of wheat, contain the highest proportion of crude protein. Next come various oil cakes, dried brewers' grains, leguminous and oily seeds, whilst hay made from leguminous crops, cereal grains and their by-products follow. Hay made from grass, dried potatoes and green fodders are poorer in protein, whilst, as is seen in the tables in the Appendix, straw and chaff contain least of all.

(3) Nitrogen-containing substances of non-protein nature.

These non-protein substances, often called amides or amino compounds, show very great differences in their properties. They all agree, though, in containing nitrogen, but are not of a protein or albumin nature. In this class may be placed ammonia, which is found in small quantities in silage ; asparagine, which is a crystalline substance, first found in asparagus and later in many young shoots and quickly growing green plants; glutamine, an easily soluble substance, which can be got from the beetroot; and, lastly, lecithine, which resembles fat, and consists of the nitrogenous material combined with free fatty acid, glycerine, 
and phosphoric acid. In addition to the abovementioned there are many other similar compounds found in animal and vegetable products. The greater portion of the non-protein nitrogenous compounds arise from the decomposition of protein matter in the living plant, particularly in the parts where rapid growth is taking place. Another portion of the non-proteins are intermediate products formed in the building up of proteins from simpler substances, for the nitrogenous matter (nitric acid and ammonia) taken in by the roots first forms non-proteins, and these are further elaborated and become proteins. Where bacteria or moulds flourish it is found as a rule that decomposition of proteins is taking place with the formation of non-proteins.

The chief points to be noted with regard to the formation and distribution of non-protein substances are :-

(I) The quicker the rate of growth of a plant, that is, the younger and tenderer it is, the richer it tends to be in non-proteins. In young shoots, meadow grass, germinated seeds, etc., fairly large quantities are to be found.

(2) The nearer the plant approaches maturation the less does the amount of non-protein nitrogen become. Ripe grain or straw are comparatively poor in non-protein matter.

(3) The richer the plants, or parts of plants, are in water so much greater is the percentage of 


\section{Io SCIENTIFIC FEEDING OF ANIMALS}

amide nitrogen. This is well seen in root crops, in plants of the melon order, in berries, and in juicy fruits, where the greater part of the nitrogen is not in the form of proteins.

(4) Feeding-stuffs which have undergone acid fermentation, or have been acted upon by bacteria or moulds, contain more non-protein substance than they did in their original condition.

As already stated, crude protein includes protein and non-protein, or amides. If the amount of pure protein in a food be deducted from the crude protein, then the nitrogenous compounds left are in the non-protein or amide form.

The tables in the Appendix do not distinguish between the protein and non-protein, but this can easily be done by subtracting the digestible protein from the total digestible crude protein. As these amido compounds are all of them readily soluble in water, and easily pass through animal membrane, they are regarded as being perfectly digestible.

\section{(4) The fats and oils.}

Fats and oils are compounds of glycerine with various fatty acids, such as stearic, palmitic, and oleic. In each fat or oil several of these acids are present, and it depends upon the proportions of these whether the fat is liquid, semi-solid, or solid. If stearic or palmitic acids predominate, then a 
solid fat, similar to tallow, is the result. If, on the other hand, oleic acid is the chief acid present, then the fat at ordinary temperatures has a more or less fluid form, and is generally called an oil. In this book the word fat will be used to denote all substances of this class, whether solid or liquid. Many oils, e.g. linseed, hemp, sunflower seed, take up oxygen when exposed to the air, and when spread in a thin layer become solid. They are called on this account drying oils. In most fats free fatty acids are found in addition to the compounds formed from fatty acids and glycerine. Fats freshly extracted from the animal body, or from new ripe seeds, contain only small amounts of these free fatty acids. Where, however, oily seeds are not fully ripe, or where, owing to bad weather at the time of harvesting, they have sprouted, large quantities of free fatty acids are to be found.

When feeding-stuffs rich in fats are stored it is also found that the percentage of free fatty acids rises, particularly if there is much moisture present. Such food-stuffs soon acquire a sour taste and smell, and in time become quite rancid, owing to the further decomposition of the free fatty acids.

In order to determine the quantity of fat in a feeding-stuff a finely ground sample is extracted with some solvent that will dissolve the fat. Ether is generally used for the extraction, and the residue left after distilling off the ether is dried and weighed. 


\section{SCIENTIFIC FEEDING OF ANIMALS}

By this means, unfortunately, not only the fat but other substances-such as wax, colouring matters, and in some cases organic acids, which are soluble in ether-are weighed along with the fat. The separation of these compounds from the fat is not easy, so in order to indicate that the fat is not pure it is customary to call it " crude fat" or " ether extract." Oily seeds and waste animal products, such as greaves and tallow refuse, are amongst the food-stuffs containing the most fat. Then come the oil cakes, oil cake meals, brewers' grains, and other by-products from distilleries, flour mills, and starch manufactories. The cereal grains, such as oats and maize, and the leguminous seeds, such as soja beans or lupines, take the next place, whilst roots, tubers, green fodders, hay and straw are amongst the poorest in fat.

\section{(5) Crude fibre.}

If a small quantity of finely-ground food material be boiled successively with given quantities of dilute sulphuric acid, water, dilute caustic potash, and again with water, a residue is left, which, after washing with alcohol and ether, may be dried and weighed. This residue consists principally of crude fibre along with a little crude protein and mineral substances, and if these last two are estimated separately in a portion of the residue, and their weight deducted from the total weight, then the 
true quantity of crude fibre is obtained. Crude fibre obtained in the above manner is free from nitrogen, and consists of a mixture of cellulose pentosans, lignin, and cutin.

Cellulose is closely related to starch in its chemical composition, and is found in an almost pure state in cotton-wool which has been freed from fat. Like all the components of the crude fibre it is insoluble in water and dilute acids and alkalies. Strong acids (sulphuric, hydrochloric), on the other hand, attack it and convert it into glucose.

The pentosans have not yet been prepared in a pure form. Their presence in crude fibre is inferred from the fact that on boiling this portion of the plant with dilute acid, characteristic pentose sugars, such as xylose, are formed. The pentosans must be regarded as being the mother substance of these sugars.

Cellulose and the pentosans have the same percentage composition ( $44.4 \%$ carbon), whilst lignin and cutin, which are less well known, are richer in carbon, the former having $55-60 \%$, and the latter $68-70 \%$. The components of the crude fibre are so intermingled that the particles of cellulose and the pentosans may be embedded in the cutin and lignin. These two compounds are often grouped together as "incrusting materiàls." The higher the percentage of lignin and cutin in the crude fibre the closer does it approach wood in its pro- 


\section{I4 SCIENTIFIC FEEDING OF ANIMALS}

perties. The various kinds of straw, the awns and husks of grains, and the varieties of hay, etc., are richest in crude fibre, as is seen in Table I of the Appendix. On the other hand, roots and tubers, awnless seeds of cereals, and most of the seeds freed from husks, contain only a little. Foods of animal origin, and also molasses, are practically free from fibre.

\section{(6) The nitrogen-free extract.}

Under the above designation are included all those constituents of feeding-stuffs which do not belong to any of the groups already mentioned, or are not mineral substances. The percentage amount of nitrogen-free extract in any food is therefore found by adding together the percentage of water, crude protein, fat, crude fibre, and ash, and subtracting them from Ioo. It is impossible, owing to the great differences found amongst the nitrogen-free extract substances, to determine them directly. In this group it is usual to include (I) carbohydrates, (2) pentosans, (3) incrusting materials, (4) organic acids. The carbohydrates, which are the chief representatives of the nitrogenfree extract substances, include glucose or grape sugar, levulose or fruit sugar, saccharose or cane sugar, lactose or milk sugar, starch, and the dextrines. All members of the group which are not already classified as sugars are converted into them by boiling with dilute acids, grape sugar or fruit 
sugar being the usual sugars formed. The pentosans and the incrusting material, both of which have already been mentioned, may be separated into two portions. One remains undissolved, as was seen in the preparation of the crude fibre, whilst the second and greater portion goes into solution, and must therefore be reckoned as nitrogenfree extract.

The organic acids are generally only present in small quantities in the natural food-stuffs. They may be there partly in the free state and partly combined with potash, soda, or lime to form salts. The chief representatives in the vegetable kingdom are malic, tartaric, citric, and oxalic acids. Those feeding-stuffs which have undergone acid fermentation contain fairly large quantities of lactic acid along with butyric and acetic acids, which are the results of bacterial activity.

Roots, tubers, and by-products of these-such as potato slump, slices of sugar-beet, molasses-are distinguished by the quantity of nitrogen-free extract which they contain. The cereal grains and the meals made from them take the next place, whilst some products of the animal kingdom-meatand fish-meal, dried blood, etc.-come last.

\section{(7) The mineral substances'or ash.}

To determine the amount of mineral matter or ash in a feeding-stuff, a known quantity of it is 


\section{I6 SCIENTIFIC FEEDING OF ANIMALS}

burnt, and the ash which is left is ignited until it becomes white. When prepared in this way the ash generally contains small particles of unburnt carbon. If there is much lime or potash in the food the ash may contain carbon dioxide as well, and in many cases this has combined so firmly with the constituents of the ash that it cannot be driven off by ignition. For this reason it is usual to call the residue left, after ignition of a sample of a feedingstuff, "the crude ash." For most purposes a determination of the crude ash suffices, but if more exact figures are required, the carbon and carbon dioxide have to be specially estimated, and the amount of these deducted from the crude ash, leaving what is termed the " pure ash."

If from the total dry matter of any food which has been analysed the ash is deducted, then the quantity of organic substance present is obtained. This "organic matter" consists of all the combustible portion of the food-crude protein, crude fat, nitrogen-free extract.

The ash from vegetable food-stuffs contains mineral matter, the most common substances present being potash, soda, lime, magnesia, compounds of iron and manganese, alumina, phosphoric acid, silica, chlorine, all of which have been taken up by the roots from the soil. In addition to these there are small particles of other incombustible substances, such as sand, earth, dust, etc., which 
have adhered to the plant, and so got into the ash. In commercial feeding-stuffs gypsum, chalk, fine earth or sand, are sometimes found. They may be there by accident, or they may have been wilfully added for purposes of adulteration. Injurious substances-such as arsenic, copper, lead, zinc, etc.may also get into the ash either by sticking to the plant in the form of dust or small particles of earth, or else by way of the plant roots. Where it is a question of solid matter adhering to the plant, the injurious substance may come from particles of slag, or from sewage water, or if absorbed by the roots the manure is usually the source.

The quantity of mineral substances found in fodder plants depends not only upon the kind and size of the plant, but also upon the soil, manure, and weather. As a rule a rich soil, or the application of plenty of mineral manures, raises the ash content of the plant. Periods of drought decrease the amount of mineral substances in the plant, particularly as regards lime and phosphoric acid. 


\section{CHAPTER II}

THE DIGESTION OF THE FOOD

EROM the moment that the food is taken into 1 the mouth up to the time it leaves the body as fæces, it is subjected to a continuous series of changes. The food is first masticated, that is, ground up into small pieces by the teeth, and is then subjected to the action of the various digestive juices which renders the food capable of absorption into the body.

(I) Mastication.

Mastication begins at once while the food is being eaten. During this process a number of glands in the mouth pour out saliva which saturates the food and assists the work of mastication.

Animals such as the horse and pig which have a simple stomach do not remasticate their food as the ruminants do. This latter group of animals have, as is well known, four divisions in the stomach, and the food is at first only chewed sufficiently to allow of it being swallowed. Each mouthful passes to the first two divisions of the stomach-the 
rumen and the reticulum-which may be simply regarded as store places for the food. In these two compartments of the stomach the food is thoroughly mixed with the saliva and any water which may have been drunk, the walls of the stomach assisting in the process of mixing. Some time after eating, small portions of the softened food are brought up again (regurgitated) into the mouth, where they are masticated and salivated for a second time. The return of the food to the mouth is performed by the help of special muscles aided by gases, such as carbon dioxide and marsh gas, which arise from the food. After remastication the food passes chiefly to the third stomach (omasum, manyplies, or psalterium) by way of the œsophageal groove. The cavity of the omasum is divided by means of leaf-like extensions of the mucous membrane provided with special muscles, giving a sievelike structure. By the slow contraction of the walls of the omasum and by the rubbing together of the leaf-like membranes, the food is still further kneaded and ground up. When it is sufficiently fine it passes to the fourth division of the ruminant stomach-the abomasum or rennet, which is the real digestive stomach, and resembles the simple stomach of other animals. The abomasum and the succeeding portion of the alimentary canalthe small and large intestines-undergo peculiar movements when food is in them. From the 


\section{SCIENTIFIC FEEDING OF ANIMALS}

similarity of these movements to those of a worm they have been called the vermicular movements, and they serve to further disintegrate the food and mix it with the digestive juices.

From the above description it will be seen that the ruminants possess a much more perfect arrangement for the grinding of food than do animals with a simple stomach. Cattle, sheep, and goats, thanks to their compound stomachs, are better able to utilise the coarser and harder food-stuffs than are horses and pigs in which the first three stomachs are absent. Horses usually chew their food with care, but if they are rapid eaters chopped hay should be mixed with the food to ensure proper mastication. If this is not done, then considerable quantities of the corn pass unused through the alimentary canal of the animal and so their nutritive value is lost. Molasses feeds and similar articles which are usually eaten quickly should be treated in the same way and mixed with chopped hay, or else given after the corn has been eaten. Animals with faulty teeth ought to have their corn either crushed, coarsely ground, or soaked. Pigs chew their food very slightly and should therefore get all hard or coarse feeding materials in a soaked, steamed, or boiled condition.

When an animal masticates a hard food-stuff containing a large quantity of crude fibre, it has to perform a considerable amount of work. As 
the energy required for the performance of such work has to come from the food it is easy to see that the value of such a food-stuff must be less on account of the work of mastication. At a later stage this subject will be further discussed.

\section{(2) The processes of digestion.}

Under the term digestion are included all those processes by which the substances contained in the food are converted into a form suitable for assimilation, or absorption. Grape sugar, fruit sugar, organic acids, and many mineral substances require no such conversion, they are absorbed directly if dissolved in a sufficient quantity of water. On the other hand, those nutrients which cannot pass through the walls of the intestine, or are insoluble in water, must first undergo some chemical change before they can enter the cells of the alimentary canal. The change usually takes the form of a cleavage or splitting up into some simpler substances which are capable of absorption. The majority of changes of this kind are carried out by means of the ferments or enzymes present in the digestive juices. Bacteria which get into the alimentary canal from the food, water, or air, also take part in the process of digestion and multiply rapidly. A few remarks as to the nature of enzymes may fitly be mentioned here. They are classed along with the albumens and have the property, 


\section{SCIENTIFIC FEEDING OF ANIMALS}

within certain limits of temperature, of transforming large quantities of material into simpler substances without themselves undergoing any change as far as can be proved. The enzyme diastase, for example, which is found in malt, is able to convert starch, in the form of paste, into maltose (malt sugar) and dextrine. Another enzyme, zymase, which is found in the yeast of beer, splits up maltose into alcohol and carbon dioxide.

These enzymes, or ferments, are widely distributed in the animal and vegetable kingdoms, and the effects which they produce are all based upon natural changes which the materials undergo. It can be truly said that without these enzymes life would be impossible.

The digestive fluids act, then, by reason of the enzymes which they contain. In the digestion of the food five different juices may act upon it during its passage through the alimentary canal : (I) saliva, (2) gastric juice, (3) bile, (4) pancreatic juice, (5) intestinal juice.

The chief work performed by the saliva seems to consist in making the dry food-stuff soft and slimy, and so rendering mastication and swallowing easy. Where such a process is not necessary, as with roots, distillery waste, milk, etc., only a little saliva is secreted. The digestive action which it has upon the food is limited almost entirely to the starch, which is changed by the ferment ptyalin into 
dextrine, maltose, and grape sugar. In the case of cooked or steamed foods, the ptyalin begins to act in a quarter to half a minute, whilst the starch of the coarse fodders only begins to be changed after the saliva has acted for two to three minutes. Saliva contains another ferment which splits up proteins, but it appears to exercise very little influence. In the fourth stomach (abomasum) of ruminants and in the simple stomach of other mammals, a second digestive fluid, the gastric juice, is poured out upon the mass of food. This gastric juice is acid, for it contains free hydrochloric acid and also lactic acid, and acts upon the proteins and fats of the nutrients. Under the action of the pepsin of the gastric juice the proteins are changed into albumoses and peptones, both of which are soluble and can easily enter into the blood and lymph of the animal. Many proteins, such as the casein of milk, are coagulated by another ferment (rennet) present in the gastric juice before being digested in the manner already mentioned. A third fermentlipase-acts upon the fats, splitting them up into free fatty acids and glycerine (see p. Io). The other nutrients of the food are not appreciably acted upon by the acid gastric juice.

The partly-digested food passes from the stomach into the small intestine, where it is mixed with two other digestive fluids-the bile and the pancreatic juice. The first of these, the bile, plays an import- 


\section{SCIENTIFIC FEEDING OF ANIMALS}

ant part in the digestion of the fats, for it dissolves a large quantity of the fatty acids coming from the stomach, as well as emulsifying, that is, dividing into minute drops, the unchanged fat of the food. The bile also stimulates the muscles of the small intestine and increases its movements.

The pancreatic juice is a clear, colourless liquid without smell, and exerts a powerful digestive action upon the proteins as well as upon the fats and starch. The enzyme which acts upon the proteins is known as trypsin, and it converts them not only into albumoses and peptones, as was the case with gastric juice, but into simpler non-protein substances. The action of pancreatic juice upon the fats is similar to that in the stomach, but more energetic, whereas the starch is changed almost instantly, substances similar to those formed by the saliva in the mouth being the result. The partially digested food next meets the intestinal juice, the effect of which is to change any remaining protein or starch in a manner similar to that exercised by the pancreatic juice.

To the action of these various digestive fluids must be added that of the bacteria which play an important part in the large intestine and in the vermiform appendix. In the ruminants bacterial action begins even in the first stomach. The bacteria break down portions of the food and use it for their own nutrition. They are also capable 
of splitting up the proteins into simpler compounds, transforming in various ways the soluble nitrogenfree parts of the food, and attacking the crude fibre which is unacted upon by the various digestive juices, and would otherwise undergo no change.

Lactic and butyric acids are amongst the substances which result from the activity of the bacteria upon the nitrogen-free extract and crude fibre. In addition to these acids certain gaseous products, such as carbon dioxide, marsh gas, and hydrogen, are also formed. With fattening cattle and milch cows the quantity of marsh gas formed daily is considerable, as much as 700 litres ( $\mathrm{I}$ litre $=\mathrm{I} \frac{3}{4}$ pints) having been collected from one animal. The bacterial decomposition of the crude fibre renders available many substances which would otherwise not be acted upon by the digestive juices and so would be lost. Bacteria, then, are of considerable service in this respect, and they can be also very useful to the animal in other ways. Some bacteria have the power of forming proteins from certain non-protein substances, probably with the assistance of nitrogen-free extract substances; and such protein matter can be utilised exactly in the same way as are the proteins of the food. Most probably this transformation only takes place in the case of the ruminants, for in this class the activity of the bacteria is far greater than with animals which have only a simple stomach like the horse or pig. 


\section{SCIENTIFIC FEEDING OF ANIMALS}

This brief outline of the changes which the food undergoes on digestion shows that the process is not limited to one organ. The proteins are digested not only in the stomach, but also in the intestine, the fats are acted upon by the gastric juice as well as by the secretions from the pancreas, the gall bladder, and the intestine, and the solution and digestion of starch takes place in the several portions of the alimentary canal. It is clear, therefore, that the various digestive organs assist one another materially, and the work of one can be partly or wholly taken over by another.

The undigested portions of the food, along with the remains of the digestive juices, are expelled by the animal from time to time. The period during which the food remains in the body depends upon the quantity of undigested matter and the size of the digestive apparatus, considerable differences being shown by the various domestic animals.

In the case of the ox the alimentary canal is twenty times as long as its body, in sheep and goats it is twenty-seven times, in pigs fourteen times, whilst in the horse and donkey it is only eleven to twelve times the body-length. Similar differences are also to be noted in the capacity of the stomach and intestines, for the ox can hold on an average 365 kilograms (I kilo $=2 \cdot 2 \mathrm{lbs}$.), the horse, $2 \mathrm{II}$ kilos, and the pig, 23-3I kilos. Thus it follows that the length of time which elapses before the 
undigested part of the food is expelled as fæces varies considerably. With cattle and sheep it takes on an average three to four days, whilst with pigs thirty-six hours suffice.

(3) The determination of the digestibility of foods.

To learn what substances in a food-stuff are digested and taken up by the animal body, it is usual to undertake digestibility experiments with animals. For this purpose the food under examination is first carefully analysed and a weighed portion given to the animal, generally a sheep ; afterwards the dung is analysed and the quantity of undigested material which it contains is determined. As it is some time before the residues from the previous feeding are expelled completely from the digestive organs, the food to be tested must be given for a period of some days before the analysis of the fæces begins. Ruminants and horses are usually allowed six to eight days and pigs four to six days.

Owing to the differences in the composition of the fæces, even when the supply and quality of the food is constant, it is essential to collect them for at least eight days when experimenting with oxen, and at least six days for pigs. Each day an aliquot part, say, one-tenth or one-fifth of the well-mixed fæces, is taken, at once dried, and then after being left exposed to the air to render it " air dry" it is analysed in exactly the same way as the food. 


\section{SCIENTIFIC FEEDING OF ANIMALS}

During the period of experiment the animals are kept in specially constructed stalls or boxes, and the dung collected in bags lined with india-rubber and attached to the body in such a way that the solid and liquid excreta are kept separate. The urine passes by means of an india-rubber funnel and tube to a bottle underneath the stall. The part of the food which has been digested is then found by deducting the ingredients of the fæces from those of the original food. An example will serve to make this clear. An ox was fed daily with 9 kilos meadow hay, which contained $8 \mathrm{I} \cdot 22 \%$ dry matter, and during the fifteen days which the experiment lasted there was an average daily yield of $x 8.008$ kilos dung which contained $I 7 \cdot 43 \%$ dry matter.

The chemical analysis gave the following percentage composition for the dry matter of the hay and of the fæces-

\begin{tabular}{|c|c|c|c|c|c|}
\hline & $\begin{array}{c}\text { Crude } \\
\text { protein. }\end{array}$ & $\begin{array}{l}\text { Nitrogen-free } \\
\text { extract. }\end{array}$ & Crude & Crude & $\begin{array}{l}\text { Pure } \\
\text { ash. }\end{array}$ \\
\hline Meadow ha & $\begin{array}{r}9.36 \\
-\quad 10.80\end{array}$ & $\begin{array}{l}52.05 \\
46.28\end{array}$ & $\begin{array}{l}2 \cdot 10 \\
2.75\end{array}$ & $29 \cdot 8 I$ & 6.68 \\
\hline
\end{tabular}

The amounts digested are calculated to be-

\begin{tabular}{|c|c|c|c|c|c|c|}
\hline Meadow hay & $\begin{array}{l}\text { Dry } \\
\text { matter. } \\
\text { kilos. } \\
7 \cdot 303\end{array}$ & $\begin{array}{c}\text { Organic } \\
\text { matter. } \\
\text { kilos. } \\
6.8 \text { I } 5\end{array}$ & $\begin{array}{c}\text { Crude } \\
\text { protein. } \\
\text { kilos. } \\
0.684\end{array}$ & $\begin{array}{l}\text { Nitrogen-free } \\
\text { extract. } \\
\text { kilos. } \\
3 \cdot 80 \text { I }\end{array}$ & $\begin{array}{c}\text { Crude } \\
\text { fat. } \\
\text { kilos. } \\
0.153\end{array}$ & $\begin{array}{c}\text { Crude } \\
\text { fibre. } \\
\text { kilos. } \\
2 \cdot 177\end{array}$ \\
\hline Dung & $6 \cdot 91$ & $2 \cdot 792$ & 0.342 & $I \cdot 453$ & 0.086 & O.9I I \\
\hline Digested & $4 \cdot 164$ & 4.023 & 0.342 & $2 \cdot 348$ & 0.067 & $I \cdot 266$ \\
\hline
\end{tabular}

Amount digested per Ioo parts-

$\begin{array}{lllll}57^{\circ} \mathrm{O} & 59^{\circ} \mathrm{O} & 50^{\circ} \mathrm{O} & 61.8 & 43^{\circ}\end{array}$




\section{DIGESTION OF THE FOOD}

These last figures are termed the "Coefficients of Digestibility."

If the digestibility of the protein is to be calculated, then the non-protein substances (in this case $\mathrm{I} \cdot 35 \%=0.099$ kilos) have to be deducted from the crude protein in the food and from that in the dung. This would be in the above experiment $0.684-0.099=0.585$ kilos for the protein in the food, and $0.342-0.099=0.243$ kilos digested, which equals $4 \mathrm{I} \cdot 5 \%$ digestible protein.

From what has been said it will be seen that the assumption is made that the dung consists only of undigested food. This assumption, however, is not quite correct, for the fæces are always mixed with small quantities of substances which come from the digestive organs and which are termed the products of metabolism. At present there are no methods by which these can be separated from the dung, so the supposition has to be made that all which is found in the dung is undigested food.

If digestion experiments have to be made with easily digested foods such as roots, cereal grain meals, oil cakes, etc., which cannot be fed alone to ruminants or horses, then some coarse fodderhay or straw-the digestibility of which has previously been determined, must be given at the same time.

From these two experiments all the data neces- 


\section{SCIENTIFIC FEEDING OF ANIMALS}

sary for calculating the digestibility of both of the foods are obtained.

Investigations of this kind are known as availability determinations and are very important, because they are the only means by which a knowledge of the way any given food is utilised by the animal body can be obtained. All the efforts which have been made to separate the digestible portion of a food from the indigestible by chemical methods have only been successful in the case of crude protein. This has been done by artificial digestion in acid gastric juice, and has served to determine the total quantity of crude protein which is digestible. No method, however, has yet been devised for estimating the digestibility of other constituents of the food-nitrogen-free extract, crude fibre, fat, etc. Attempts have also been made to calculate from the chemical composition what proportion of a food-stuff would be digested, but without any great success. In the case of fodder plants, harvested at the time of flowering, and also with straw of various kinds, it has been found that the total amount of nitrogen-free extract in the food is in many cases equal to the crude fibre and nitrogen-free extract substances which have been digested. With young plants this does not, however, hold good, for in that case the figure obtained for the undigested portion is too low. 
Results of availability determinations made with domestic animals are to be found in Table II of the Appendix.

\section{(4) The extent of digestion under various}

\section{conditions.}

(a) The influence of the nature of the animal upon the digestion of the food.

I. Animals of different species do not always digest the same quantity of any given food. The greatest digestive power is undoubtedly possessed by the ruminants, oxen being somewhat better than sheep as regards the digestion of straw or coarse hay. With medium quality hay these differences are less marked, and with other foods the digestive power of the ox and the sheep seems to be about equal.

Compared to the ruminants the horse has a somewhat inferior digestive power, as is seen from Table II of Appendix. Investigations carried out on this point have shown that the horse digests almost the same amount of crude protein from the various food-stuffs as do the ruminants. It is in the crude fibre and crude fat that the greatest differences are seen, and in a less measure in the nitrogen-free extract. In the case of such a difficultly digestible material as straw, the peculiarity of the horse as compared to a ruminant is clearly shown, for the former utilises only about half of 


\section{SCIENTIFIC FEEDING OF ANIMALS}

what the latter does. When it comes to the different varieties of grass, the horse is found to digest only $20-25 \%$ less nitrogen-free extract and crude fibre than does the sheep. With clover hay, or lucerne hay the differences are again less, being at most ro \%, whilst the digestibility of the grains is about equal for each class of animal, except as regards the crude fat.

The pig digests coarse fodders considerably worse than does the horse. Only $23 \%$ of the organic matter of wheat chaff is digested by the pig, whereas the ox digests $36 \%$. These differences, which are clearly shown in Table II of the Appendix, hold also for the digestion of green fodder. With oil cakes and grains these differences are less pronounced, and practically vanish with such foods as mangels and potatoes. There are, however, many byproducts, such as dried brewers' grains and various other refuse materials from the brewery and distillery, which the pig digests very badly.

All these differences are mainly due to the kind of digestive apparatus possessed by the animal, for in function, length, and capacity there are considerable variations in the different species. The action of the digestive fluids and of the bacteria upon the food is also subject to variations and alters the conditions very materially.

2. Different breeds of the same species of animal possess an equal digestive power. Investigations 
carried out upon various breeds of sheep have proved this. The experiment was performed with five different rations, and the coefficients of digestibility were found in no case to exceed a maximum difference of $3-4 \%$. This might quite well be due to individual peculiarities of the animal, combined with unavoidable experimental errors.

3. Between individual members of the same breed, small variations, usually traceable to some slight physical weakness on the part of the animal, may occasionally be noticed. Generally faulty teeth, too rapid eating, nervousness, disturbances of the digestive organs, sometimes also intestinal worms, are the causes. Defects of this kind may usually be detected by the condition of the fæces, for in animals with weak digestion these are often moister than is the case with those digesting the same foods in the normal way. Where the differences are not due to serious disease of the stomach or intestine the percentage error seldom exceeds $3-4 \%$ of the ingested organic matter.

4. The age of the animal does not influence the digestibility of the food, but until the first stomach of the ruminant is fully developed, the coarse, harder particles of the food will not be as well digested as at a later period.' Growing sheep, which were given the same food from the age of six to fourteen months, were found to digest what 


\section{SCIENTIFIC FEEDING OF ANIMALS}

they received just as well at six months as they did eight months later.

5. Whether the animal is working or at rest seems to have little effect upon the digestion of the food, even where the work is hard. The rate, however, at which such work is done does have an influence, for it has been noticed that cab-horses working at a quick trot did not digest their food as well as they did when at rest; there was a noticeable, but not large, decrease in digestibility. In one case, where a constant ration was given, it was found that $60 \%$ of the organic matter was digested when the horse was at rest in the stall, $62 \%$ when he was walking, and when trotting $61 \%$. When working at a walk $6 \mathrm{I} \%$ of the organic matter was digested, when working at a trot $57 \%$, and when drawing a cart $57 \%$.

Oxen used for draught purposes must get enough time (3-4 hours) for the rumination of the food, for although working at a slow rate does not entirely stop rumination, it is not properly performed, and so more or less serious derangement of the digestive processes can result.

6. Alterations in the conditions under which the animals are placed are also without influence upon the digestibility of the food, provided violent excitement and disturbance of health are avoided. Changes in the temperature, lighting, or other conditions of the stable, have no appreciable effect 
upon the extent of digestion. Nor has it been shown that the removal of the coat in clipping or shearing has any influence in that direction.

(b) Influence of the quantity and mixing of the food upon digestion.

I. If coarse fodder is the only food-stuff given, then smaller or larger quantities do not affect digestion, as has often been shown. To quote one example : $6 \mathrm{I}-62 \%$ of the organic matter of lucerne hay was digested by sheep whether the daily ration was $0 \cdot 8, I \cdot 0$, or $I \cdot 2$ kilos ( $\mathrm{I}$ kilo $=2 \cdot 2 \mathrm{lbs}$.).

2. Varyingly large rations, in which the ratio between coarse and concentrated foods is kept constant, seem to be digested to a less degree the larger the daily ration is. Four successive digestibility trials were made with a mixture of meadow hay, molasses feed, rye bran, and cotton-seed cake. When the dry matter of the daily ration was I0.84 kilos, $76 \%$ of the organic matter was digested; when it was I3.OI kilos, $74.7 \%$; when I5. I 8 kilos, $72.8 \%$; and again, when the dry matter was I0.84 kilos, the digestibility coefficient rose to $75.8 \%$. The diminution of food digested in the case of the larger ration was equally evident in the various constituents, except the crude fat.

Although the depression of digestibility is not as a rule large, still, in the total daily rations, it may mean considerable quantities. In the experiments 


\section{SCIENTIFIC FEEDING OF ANIMALS}

just quoted about I lb. less organic matter was digested when the largest ration was given. It is easy to see that by the consumption of large quantities of food the passage through the alimentary canal is more rapid, although this organ possesses a certain extensibility, and so digestion may not be perfect. When large quantities of easily digestible food are consumed it is possible that the intestine is not able to cope with it, and so some of the nutrients escape unabsorbed. Over-feeding of animals for these and other reasons is to be avoided.

3. The one-sided addition of digestible carbohydrates to a food causes, under certain conditions, a greater or less depression of digestibility. This fact has been constated by numerous experiments on ruminants and pigs. One of these, with an ox, may be quoted. It was found that after the addition of $\mathrm{I} \cdot 66$ kilos of dry starch to a daily ration of 9 kilos meadow hay, the digestion of the crude protein decreased by 63 grams ( 28 grams $=\mathrm{I}$ oz.), the nitrogen-free extract by III grams, and the crude fibre by 133 grams. When the quantity of added starch was raised to 2.87 kilos, then a decrease of I 20 grams crude protein, 252 grams nitrogen-free extract, and 167 grams crude fibre was found in the amounts digested. This depression of digestibility, due to the starch, was also observed when other carbohydrates, such as sugar or cellulose, were added to the hay. Similarly, when foods rich in 
carbohydrates-potatoes, mangels, etc.-are added to a ration poor in crude protein, the digestibility of the various components of the food is diminished.

As regards the explanation of this phenomenon, it is known that after the addition of such materials as have been mentioned, the fæces of the animal are considerably richer in nitrogenous substances. These do not come from the food, but from the digestive juices and from the mucous membrane of the intestines. On analysing such fæces more crude protein is found than when the basal ration is given without any additions. As the calculation of the quantity of digested crude protein is made by subtracting that found in the dung from that present in the food, the difference in crude protein is less where additions of the kind mentioned have been made. The depression of the digestibility of crude protein by the addition of starch, etc., would accordingly only be an apparent one, and would be explained by the presence of waste nitrogenous products of metabolism in the fæces. Further, it may be supposed that the bacteria, which are present in large quantities in partly digested food, nourish themselves on the easily digestible substances, such as starch or sugar, when these are added, whilst the constituents of the food are acted upon in a less degree. The addition of starch or sugar to hay would protect the latter from dissolution and decomposition by bacteria. In conse- 
quence of this, more of the nutrients of the hay would pass into the fæces, that is, less would be digested than when hay alone was fed. Be that as it may, the fact remains that the digestibility of a food poor in protein is diminished when large quantities of easily digestible nitrogen-free substances of the kind already mentioned are mixed with it.

4. The addition of fat or oil does not alter the digestibility of a food, provided the added material is in a finely divided form, and moderate quantities (not more than I lb. per Iooo lbs. body weight) only are given. If, however, large quantities of oil or melted fat are poured over the food, its digestibility is diminished. This is due to the difficulty with which the digestive juices penetrate the particles of food which are coated with oil. In the natural food-stuffs the oils and fats are always present in the form of microscopically small globules.

5. The increase of crude protein in a food causes not only no depression of digestibility of the other components, but, on the contrary, minimises the depressing effect of large quantities of nitrogenfree substances. If, for example, ruminants are being fed with a mixture of hay or straw and a lot of potatoes, then, as has been shown (p. 36), the nitrogen-free substances are not completely digested, in fact, part of the easily digestible starch passes into the fæces. When a food rich in protein- 
say, cotton-seed cake meal-is added to the ration, no traces of starch are found in the dung, for digestion has been complete. The addition of nonprotein nitrogenous substances (amides and amino acids, etc.) acts similarly to the protein, and raises the digestibility when it is depressed by large doses of carbohydrates. After thorough investigation of this phenomenon it has been proved that a complete digestion of all constituents of the food is assured if the total ration contains 8-Io parts of digestible nitrogen-free substance to each part of crude protein. This ratio applies particularly to ruminants; for pigs less protein is necessary, and may be placed at I part to I2 parts nitrogen-free extract. If the proportion of carbohydrates is in excess of these figures, then some of the otherwise digestible material passes into the fæces.

6. The only other substances whose action upon the digestibility has been tested are lactic acid, calcium carbonate, and common salt. With all these, however, no influence, favourable or unfavourable, has been noticed. With regard to lactic acid, which is present in considerable quantities (up to $3 \%$ ) in acid food-stuffs, such as silage, it is known that continued feeding of large quantities of this material injures the teeth, and so mastication becomes imperfect. Disturbances of the digestive organs are also liable to arise, and so the food is not properly utilised, which means loss. Without 


\section{SCIENTIFIC FEEDING OF ANIMALS}

doubt salt increases the secretion of the digestive juices, but in the form in which it is usually given it has not got the power of rendering the food more available. Very large quantities of salt act as a purgative, and so diminish the digestibility.

All owners of cattle have been told of the wonderful power which some particular condiment has in increasing the digestibility and value of the food. Impartial experiments which have been made with these "condiments" have shown that they do not in any way improve the effect of the food. The animal organism is much too perfect to need assistance in such a way. 


\section{CHAPTER III}

THE UTILISATION OF DIGESTED NUTRIENTS

IN THE ANIMAL BODY

(I) General considerations.

$7 \mathrm{HE}$ body temperature of a living, warm-

1 blooded animal lies between $37-40^{\circ} \mathrm{C}$. (99$\mathrm{I0} 4^{\circ} \mathrm{F}$.), and so, as a rule, is higher than the temperature of the surrounding atmosphere. On this account animals are continually losing heat, and must have some source from which the loss can be made good.

The movements which take place during respiration, the work performed by the heart, the changes in shape of the digestive organs, the movements of the voluntary and involuntary muscles, etc., all use up energy, which must be replaced if life is to continue. It is impossible to prevent the loss of animal heat, as will be seen later (Chap. IV), even if the surrounding temperature is raised. The same holds good, also, in the case of dissipation of energy. Energy can be brought into a machine in various ways, but there is only one way of bringing 
it into the animal body, and that is in the food. It is, in fact, an essential condition of life that heat and energy should be generated in the body itself, and it is in the living cells of the organism that they are produced from the digested nutrients which are brought in the blood supply to all parts of the body, and there taken up by the cells. Heat and energy, then, are only generated in the animal body by the decomposition and combustion of organic materials which the cells have received from the blood. The combustion is preceded as a rule by a splitting up of the compounds, probably under the influence of enzymes. Simpler substances are obtained in this way, and they are oxidised by means of the oxygen in the blood. The fine bloodvessels of the lungs take up the oxygen, which is drawn in with each breath of air, and transport it in the blood through the whole body.

Whenever energy or heat are to be generated this oxygen unites with the substances which have been prepared for the combination by a preliminary cleavage. The nitrogen-free substances-such as carbohydrates, fats, and organic acids-yield thereby carbon dioxide and water, which are the same products as those formed when ordinary combustion takes place outside the body.

In a similar manner to that by which oxygen is brought to the cells, but in the opposite sense, the carbon dioxide is dissolved in the blood, reaches 
the lungs, and is there given out to the air, only a small proportion being excreted by the skin and intestine. The proteins and amides also give carbon dioxide and water on decomposition, as well as nitrogenous waste products, of which urea is the chief. The latter, together with soluble salts and some of the water, are brought in the blood to the kidneys, and from there pass in the form of urine to the bladder. There are other ways, too, in which water, whether from the food, drink, or the combustion of organic substances in the cells, leaves the body. Some is exhaled as gas from the lungs and skin, whilst the rest is got rid of in fluid form in the urine or fæces.

The materials taken up by the blood from the alimentary canal are not always split up and oxidised, but when the food supply is liberai they are changed into body tissue or milk. Hereby there arise as a rule many waste products, which are capable of further oxidation with the formation of the final products already mentioned.

All these changes, which take place from the entrance of the digested compounds of the food into the blood up to the excretion of the final products, are grouped under the term " metabolism." Every constituent of the food which can yield heat or energy, or can serve for the production of body tissue, is called a nutrient. 


\section{(2) Methods of investigation.}

To ascertain whether any given susbtance is a nutrient in the above sense a careful examination of the quantity and nature of the food and fæces has to be made. The same method is employed for finding out what quantity of the nutrient material is necessary for an animal under certain conditions, and, further, under what circumstances a gain or loss of body tissue takes place.

I. The increase of body tissue, or flesh, can be reckoned from the amount of nitrogen which is retained in the animal body when a known ration is fed. It is true that the growth of hair, horns, hoofs, etc., also claims a little nitrogen, but this amount is so small as to be negligible, except in the case of sheep. The computation of the quantity of nitrogen which an animal retains in its body is relatively simple, owing, in the first instance, to animals not having the power to make use of the nitrogen of the atmosphere. The air coming from the lungs contains the same amount of nitrogen that it did when taken in. Secondly, the nitrogenous components of the food do not split off free nitrogen, for all the nitrogen which is not stored in the body passes into the urine or fæces in the form of organic compounds. The amount of nitrogenous matter which leaves the body through the skin in the form of perspiration is 
too small to be considered. It suffices, then, in an estimation of the increase of flesh to determine how much nitrogen is taken into the body in the food, and how much leaves it in the urine and fæces. If, then, the output of nitrogen is subtracted from the income, it is easy to calculate the amount of flesh that has been stored, for dry flesh, free from fat and mineral matter, contains $I 6.67 \%$ of nitrogen. Fresh lean meat contains, further, $77 \%$ of water. In a certain sense, then, the additions of nitrogen and of flesh are the same.

Although the food of an animal may contain more or less nitrogen or even none at all, it is always found that a certain quantity is present in the urine. This comes from the decomposition of the constituents of the food or of the body tissue, and so the nitrogen in the urine is a measure of the nitrogen metabolism in the body. In investigations relative to vital changes which take place in the organism, particularly in relation to its food supply, the quantity of nitrogen in the urine plays a very important part. Experiments on the formation of body tissue are in general carried out in the same way as those on the digestibility of food (p. 27), only here, in addition to the fæces, the urine must be collected without loss for a certain length of time. The minimum time of collection should be eight to ten days, and careful analyses of the urine are necessary. During the drying of fæces small 


\section{SCIENTIFIC FEEDING OF ANIMALS}

quantities of nitrogen-containing substances volatilise, so it is generally preferable to analyse the fresh dung. The previous feeding of the animal exercises considerable influence on the excretion of urine, so care must be taken that the nitrogen in the urine is constant before the real experiment begins.

2. A determination of the increase of fat in an animal body is only possible when, in addition to the nitrogen, all the carbon that goes into and leaves the body is known. As the animal gives out large quantities of carbon-containing substances (carbon dioxıde and marsh gas principally) from the lungs, skin and rectum, it is essential to determine these gaseous products in addition to the solids. The analysis of the gases usually takes place in the Pettenkofer respiration chamber which will be described later. An example will show what can be learnt from such investigations. An ox was given the following amounts of nitrogen and carbon in the food and water daily: 186.47 gr. nitrogen and 5564.5 gr. carbon; excreted in urine, dung, and breath I79.24 gr. nitrogen and $4892 \cdot 0$ gr. carbon; remaining in body $7 \cdot 23$ gr. nitrogen and $672.5 \mathrm{gr}$. carbon.

Pure dry flesh contains $16.67 \%$ nitrogen and $52.54 \%$ carbon, so the addition of $7 \cdot 23 \mathrm{gr}$. nitrogen equals $43.4 \mathrm{gr}$. of dry flesh containing $22.8 \mathrm{gr}$. of carbon. For the increase of fat there remain, 
therefore, $672 \cdot 5-22 \cdot 8=649 \cdot 7$ gr. carbon over. With the exception of fat the other nitrogen-free carbon compounds in the body are only formed in very small quantities, so it is permissible to reckon all the added carbon-649.7 gr. as fat. It is known that Ioo parts beef suet contain $76.5 \%$ carbon, so that $649 \cdot 7$ gr. of carbon $=849 \cdot 3$ gr. (nearly 2 lbs.) of fat added each day.

Investigations of this kind are carried out exactly as was described in the case of increase of flesh, but the animal must become used not only to having no litter, but also to the respiration chamber, before the experiment begins. Such an experiment takes at least twelve to fourteen days, during which time the fæces and urine must be collected daily without loss. The products of respiration are estimated three or four times for periods of twenty-four hours exactly. In such investigation the digestibility of the food is naturally determined in addition to the nitrogen and carbon metabolism.

As has already been stated, the digested nutrients not only supply material for the formation of flesh, fat, wool, milk, etc., but they also serve as carriers of heat and energy, both of which are required by the body. Investigations on the energy relations of the body are most important, and it will be well to briefly note the mèthods by which the energy metabolism of an animal is ascertained. 


\section{(3) The energy metabolism.}

The simplest measure of the amount of energy that can be obtained from any substance is the heat which is produced when it undergoes complete combustion. When, for instance, starch is burnt in a bomb calorimeter filled with compressed oxygen, a certain amount of heat is generated. If the bomb is immersed in a known quantity of water the rise in temperature of the water can be measured by a very sensitive thermometer, and from the observed increase of temperature of the water, the amount of heat present in the starch can be calculated.

The unit of energy, expressed as heat, is the large calorie (Cal.), which is the amount of heat sufficient to raise I kilogram of water $\mathrm{I}^{\circ} \mathrm{C}$. (or $\mathrm{I} \mathrm{lb}$. of water $4^{\circ} \mathrm{F}$.). Sometimes the small calorie (Cal.) is employed, which is only a thousandth part of the large calorie. When it is stated that the heat value of I gram of starch ( $\frac{1}{28}$ th of an oz.) is $4 \cdot 1825$ Cal., it is understood that this is a direct measure of the energy in the starch. In the same way, when it is said that an ox weighing 600 kilograms (about $\mathrm{II} \frac{1}{2} \mathrm{cwt}$.) requires a daily supply of $\mathrm{I} 2,780 \mathrm{Cal}$., it is clear what is meant. It has already been seen that many digestible components of the food yield waste products which, like marsh gas and urea, are combustible and so contain heat, or energy. 
When the real available energy or availability of the digested material is to be given, then the heat value of the waste products must be deducted from the total heat value contained in the digested material. Thus from Ioo grams of starch it has been found by experiment on the ox that $3 \cdot I 7$ grams of marsh gas are formed, I gram of which has the high heat value of 13,344 cal. When this is calculated on I gram of starch it is seen that there is a loss of $422 \mathrm{cal}$., so that the net heat value is $4 \mathrm{I} 83$ cal. $-422 \mathrm{cal}$. $=376 \mathrm{I}$ cal. or $3 \cdot 76 \mathrm{I}$ Cal. instead of $4 \cdot I 83$ Cal. The available energy of I gram of starch is then only $89.90 \%$.

The investigation of the energy metabolism can be made in two ways, either direct or indirect. In the first case the heat which is given off from the animal is measured directly. For this purpose special forms of apparatus-the so-called respiration calorimeters are necessary. The commonest form is built upon the principle of an ordinary air thermometer, the bulb of which encloses the animal. These calorimeters usually serve at the same time as a respiration chamber. In the second case where the determination is an indirect one all the income and outgo of the animal in food, fæces, urine, and the products of respiration must be determined, as was done in the experiments on storage of flesh and fat (pp. 44-47). In addition, the heat values of all materials eaten or excreted 


\section{SCIENTIFIC FEEDING OF ANIMALS}

must be accurately estimated by direct experiments. When this has been done the energy content of the food and of the excretory products is calculated, and it is found what amount of energy expressed in heat units has been at the disposal of the animal. Further, from the increase in flesh and fat the energy which has remained in the body can be calculated. In this way all the data essential for a clear insight into the metabolism of material and of energy are obtained. The following experiment on a well-fed ox will serve as an example of an energy-metabolism investigation-

Income of energy in food . • . 52929 Cal. Expenditure ," , fæces I59I6 Cal.

" , " ", $\quad$ ", marsh gas 3383 ,"

Total amount of available energy . 3I944 Cal. For maintenance of the animal, determined from other experiments Amount of available energy left for production Stored in flesh 246 Cal., in fat 8069 Cal. Percentage storage of available energy $56.9 \%$ 


\section{CHAPTER IV}

\section{METABOLISM}

\section{(I) Fasting metabolism.}

ATHOUGH an animal is entirely deprived A of food, it continues to live for some time. During the period of starvation most of the organs of the body, as well as the fatty tissue, decrease in weight. In the excreta-fæces, urine, and products of respiration-there are, nevertheless, the same substances found as when food was being taken.

An examination of the excreta shows that by complete withdrawal of food the body loses protein (flesh) as well as nitrogen-free substances (principally fat), and mineral compounds. For example, a rabbit which weighed 234I gr. (about $5 \mathrm{lbs}$.) was found, after starving for eighteen days, to weigh only I388 gr., a loss of 953 , which is $40.7 \%$ of the original body weight. From the excreta of this animal it was calculated that the following quantities of body protein and body fat had been destroyed- 
I-2 days of hunger 9.75 gr. protein and - gr. fat.

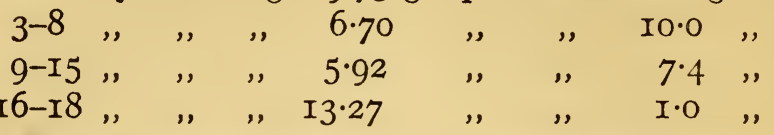

It is the need of heat and energy which causes the continued decomposition of tissues and which ceases only with the death of the animal. All the energy which is utilised for any form of work, be it in a machine or in the animal body, is finally converted into heat. The total heat, then, that an animal gives off when starving can be regarded as a reliable measure of the energy required for the maintenance of life.

The loss of heat which a body suffers in surroundings of a lower temperature depends upon the surface of the warm body and not upon the weight. If two pieces of metal of equal weight are taken, and one of them made into a ball and the other beaten into a thin sheet, then if both are heated to $100^{\circ} \mathrm{C}$. and allowed to cool the sheet becomes cold more quickly than the ball; the larger surface radiates more heat than the smaller. This law has often been shown to hold good also for the living animal. An investigation on the energy metabolism of seven starving dogs of different weights gave the following results-

Body weight in kilograms : $31 \cdot 2,24 \cdot 0,19 \cdot 8,18 \cdot 2$, $9 \cdot 6,6 \cdot 5,3 \cdot 2$.

Body surface in sq. centimetres: I0,750, 8805 , $7500,7662,5286,3724,2423$. 
Loss of heat-

Per I kg. body weight : $36 \cdot 6,40 \cdot 9,45 \cdot 9,46 \cdot 2,65 \cdot 2$, 66.I, 88. I.

Per I sq. cm. body surface: I036, III2, I207, I097, II83, II53, I2I2.

Reckoned upon I kilo body weight the smaller animals used up far more heat than the large ones, whereas when the calculation is made upon the loss of heat from an equal body surface only small differences are seen. It is thus possible to say that the total exchange of energy, and with it naturally the consumption of material, depend upon the surface of the body.

There is another factor that influences these relations, and that is the surrounding temperature. In an experiment two dogs, one of which (A) had long hair and the other (B) was clipped, were kept at different temperatures with the following results, the loss of heat at $30^{\circ}$ being taken as Ioo, and the other temperatures calculated on that basis-

(A)

At a temperature of $30^{\circ} \mathrm{C}$. IOO

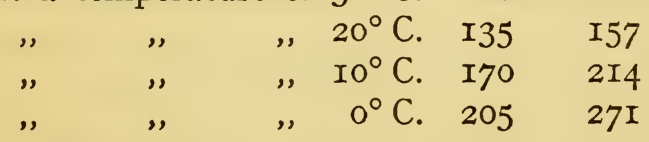

It is thus seen that by warming the surrounding atmosphere a considerable diminution in loss of heat is obtained, for compared with $0^{\circ} \mathrm{C}$. the saving was- 


\section{(A)}

$$
\begin{aligned}
& \text { At } 10^{\circ} \mathrm{C} . \quad 26 \% \\
& \text {, } 20^{\circ} \mathrm{C} .4 \mathrm{I} \% \\
& \text {, } 30^{\circ} \mathrm{C} .5 \mathrm{I} \%
\end{aligned}
$$

$63 \%$

The loss of heat, or what is the same, the consumption of tissue which takes place at $0^{\circ}$ can be diminished by $50-60 \%$ when the surrounding temperature is raised to $30^{\circ} \mathrm{C}$. In this respect the results of the experiment given above teach a great deal. They show that the using up of tissue in a fasting animal is in close and regular relation to changes of the surrounding temperatures. Other investigations confirm this and differences of $\mathrm{I}^{\circ} \mathrm{C}$. have in fact been clearly reflected in the loss of heat. Animals cannot, however, stand higher temperatures, such as $30-35^{\circ} \mathrm{C}$., for the body becomes overheated and a condition of fever sets in.

If a comparison is made between the behaviour of the two dogs in the above experiment, it is seen that the clipped $\operatorname{dog}$ (B) lost considerably more heat at the lower temperatures, and that in its case the raising of the temperature prevented more loss of heat than with the long-coated $\operatorname{dog}(\mathrm{A})$. The importance of a covering of hair on animals is clearly shown in this way.

In the production of heat in the fasting animal it has been seen that both the body protein and the body fat take part. The fatter the animal is the 
greater the part played by the fat in the production of heat.

It has been found with a dog experimented upon in various stages of fatness that when starving the production of heat was divided between the protein and the fat in the following proportions-

Condition of

the animal.

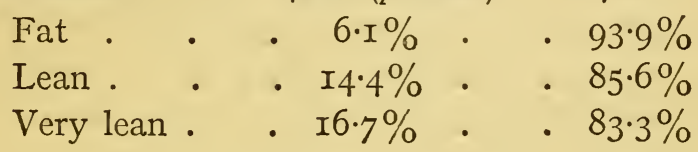

During the period of starvation the fat disappears by degrees, and then the body proteins are called upon to furnish heat. However fat though the animal may be, the protein metabolism never completely ceases, for protein plays a part which cannot be performed by fat.

Observations on fasting animals give a clearer insight into the metabolism of the body than can be the case where food is given, and therefore they have found a place here.

\section{(2) Insufficient feeding.}

In the preceding section it has been shown that a starving animal lives upon the materials of its body. The amount of heat which it gives out serves as an exact measure of the requirements of the body in material and energy. If such an animal is given 


\section{SCIENTIFIC FEEDING OF ANIMALS}

food, which brings heat and energy, it is clear that body tissue equal in quantity to the heat which is liberated from the food in the body will be saved. Various investigations with carnivorous animals and rabbits have confirmed this.

In order to prevent a loss of Ioo gr. of body fat it is necessary, according to calculations based upon the heat values (p. 48), to give 235 gr. cane sugar. An experiment on a fasting dog which received only cane sugar showed that 234 gr. of that substance can take the place of Ioo gr. of body fat. Other experiments with lean or extracted flesh, starch, grape sugar, etc., lead to the same conclusion. This proves accordingly that the several nutrients can mutually replace one another in proportion to the amount of heat which is set free when they decompose in the body. This law, however, only holds good where the total quantity of food consumed does not yield more heat than the animal gives off during starvation, that is, it applies only to a maintenance ration. In the fasting animal part of the energy arising from the decomposition of the nutrients does not immediately take the form of heat, but is first utilised for work and afterwards manifests itself as heat. With carnivorous animals it has been possible to determine that portion of the energy of the food which serves for work, and it was thereby shown that only a portion of this-never the whole-undergoes conversion in the animal 
body. From protein this portion was $7 \mathrm{I} \cdot 3 \%$, from fat $87.3 \%$, and from cane sugar $94 \%$, the remainders, $18.7 \%, 12.7 \%$, and $6 \%$ respectively, appear under all circumstances in the form of heat, and cannot be used for work by the animal or its organs. Thus there are two forms of energy to be considered, the one which takes the form of work and is called "dynamic" energy, and the other which takes the form of heat and is known as "thermic" energy.

The portion of dynamic energy which comes to herbivorous animals from their food is much less than the amounts given above for carnivorous animals receiving pure nutrients. A considerable proportion of the food of ruminants and horses is coarse and hard, and some part of it must always be used up to furnish energy for the work of mastication and digestion. In addition, some of the food materials undergo so much bacterial decomposition in the stomach and intestines that the products which thereby arise hardly yield anything but heat. Experiments relative to these conditions have shown that when timothy-hay is fed at least $40 \%$ of the digestible nutrients reappear in the form of heat only, and in coarsely ground maize the percentage is still considerable-22\%.

With pigs it is different, for they get much less coarse food, and with them bacterial activity is weaker. In these animals a much greater proportion of the energy of the digested nutrients re- 


\section{SCIENTIFIC FEEDING OF ANIMALS}

appears in the dynamic form than is the case with ruminants.

The distinction between dynamic and thermic energy is of great importance, for a proper understanding of the action of different foods on the various species of animals.

It must be clearly understood that the animal body possesses no power of converting heat into work or other form of energy. Whatever part of the food has taken the form of heat has passed beyond the influence of the body; it has lost the property which the digested nutrients possess of being applied to various purposes. Heat, once it is manifested, can only act as such, and under some conditions-high temperature, etc.-it finds no further useful application in the body.

\section{(3) Abundant food supply-Formation of fat and flesh.}

If an animal gets an abundant supply of food, it uses part of it for maintenance. The excess can go to increase the body substance or serve for the production of useful muscular work. A ration which yields more food than an animal requires for maintenance can, therefore, be divided into two parts; the one maintains life, the other serves for the production of tissue. The former is called the maintenance ration and the latter the productive 
part of the ration. A ration can be complete or one-sided according to whether it brings to the animal all the nutrients which it requires, or whether some are present in insufficient quantities, or not at all. A food which contained too little protein or mineral matter would be termed one-sided. An animal receiving such a ration, even in large quantities, would be obliged to draw protein, or mineral substances, from its own body, and would suffer from " protein " or " mineral " hunger.

In the following sections the action of the nutrients, either alone or mixed with one another, will be discussed, and then the complete food-stuffs themselves.

\section{(a) The effect of protein.}

I. The metabolism of protein and fat when only protein is given.

Through the action of ferments and bacteria in the digestive organs the food proteins are changed for the most part into simpler substances-albumoses, peptones (pp. 23, 24). These are of a nonprotein character, and are easily taken up by the cells of the alimentary canal. A small portion o1 the food protein is, however, absorbed without undergoing this preliminary change. Most probably the simpler substances which are absorbed are changed again into protein in the walls of the stomach and intestines, for although the intestine 


\section{SCIENTIFIC FEEDING OF ANIMALS}

may be filled with the products of protein digestion there are none of these substances to be detected in its walls even after the absorption of all the contents of the intestines. These changes may be said to be effected by the help of enzymes, and the proteins which result closely resemble those of the animal body. The splitting up of the different food proteins by the digestive fluids yields in this way the material from which the body protein is built up. So it is clear that the food proteins, which differ considerably from the tissue proteins, are nevertheless essential materials for the building up of them. In the above metabolic changes waste products are formed, as they are in the process of digestion.

Numerous feeding experiments have shown that no animal can live unless it gets a certain quantity of protein. All other nutrients may be there in abundance, but if protein fails, partially or entirely, the animal draws daily upon its own body for a supply, and finally dies from protein starvation.

The way in which this takes place when different amounts of protein are given is seen from the following experiment.

A fully-grown dog which weighed $30 \mathrm{~kg}$. (66 lbs.) used up the following quantities of body protein and body fat when fasting and when being fed with lean meat, which is almost pure protein. 
Loss (-) or gain (+) of tissue.

Daily Food.

Flesh.

Fat.

Fasting . . - - 65 gr. . - -95 gr.

500 gr. flesh . -99 gr. . . -47 gr.

I000 gr. flesh. - 79 gr. . . - r9 gr.

I500 gr. flesh . $\quad$ o gr. . +4 gr.

Thus it is seen that the loss of body protein, or body fat, is smaller the larger the amount of protein in the food. When the daily supply of flesh reached I500 gr. the body did not require to provide any protein, and a condition of "protein," or "nitrogen equilibrium," was established. The proteins of the food are, therefore, able to protect the body proteins from consumption. Exactly the same results are obtained when the animal is fed with artificially prepared peptone or with the products which arise from artificial digestion of protein by means of gastric juice and which contain no traces of protein or peptones. Gelatine, which is usually classed along with the proteins, has a much less favourable effect and does not appear to contain the substances essential for building up body proteins. Fed to dogs which received no other food, gelatine was only able to replace at most $37 \%$ of the protein which was used up during fasting. Dogs which were in a position of nitrogen equilibrium and so got enough protein to make withdrawal from their own tissue unnecessary, only maintained this equilibrium when 


\section{SCIENTIFIC FEEDING OF ANIMALS}

not more than one-fifth of the protein nitrogen was replaced by gelatine nitrogen.

If a fully-grown animal is given more protein than it metabolises, when in a state of hunger, it soon puts itself in equilibrium with the amount given, that is, as much protein is destroyed as is present in the food. Where the amount of protein given exceeds that in the preceding feeding the animal, for a time, lays on protein tissue before equilibrium is reached. When, on the other hand, the food has been richer in protein, the reverse is seen, for tissue is lost, until after some time the intake and output become equal.

Fully-grown animals have clearly not the power of increasing their store of protein, or flesh, beyond certain limits. An examination of the fibres of flesh shows that it is only in youth that they can increase, and that a limit to the increase in thickness is also set. In other ways, too, it is clear that the store of flesh in an animal can only be increased to a small extent.

The work of which an animal is capable depends in general upon the number of living cells in the body, and if these were intimately dependent upon the supply of food the increase or decrease of body tissue would vary rapidly according to any change of food which might occur. This, of course, would be entirely opposed to the regular performance of work and resistance to various in- 
fluences which are shown by the animal. The animal organism, therefore, breaks up the greater part of the surplus proteins and uses them in place of other material for the production of heat, work, or the formation of fat. This last serves then as a reserve which can be drawn upon in times of insufficient food supply, and it does not to any extent impair the capabilities of the animal.

It has been proved that a large excess of protein given to an adult animal causes respiration to be more rapid and the supply of blood to the skin to increase. Sometimes also the body temperature rises. All these symptoms indicate increased metabolism of material and of energy and lead to the decomposition of more protein. This may, in fact, go so far that the body fat is also included in the increased decomposition.

Animals whose limit of growth is not yet reached behave quite differently with regard to the greater part of the excess of the food proteins. They utilise them in the body for development of the organs without the effects noted above being observed, as is the case with adult animals.

For example, full-grown sheep retain as a rule Io gr., at most I5 gr., of protein daily in the body, most of this, if not the whole, going to form wool. Lambs, on the other hand, in spite of the smaller body weight, are able to store $40-50 \mathrm{gr}$. daily. Investigations with sucking calves have 


\section{SCIENTIFIC FEEDING OF ANIMALS}

shown that these animals are able to utilise $72 \%$ of the protein of the milk for the formation of flesh, which is a very high percentage.

2. Formation of fat from protein.

Various investigations point to the conclusion that in the splitting up of protein (p. 42) in the animal cells, sugar is formed, along with nitrogenous substances. In a healthy animal the sugar is at once utilised, but if the body has lost this power, as in diabetic diseases, then sugar appears in considerable quantities in the urine, although the food may consist only of lean meat.

It will shortly be seen that under certain conditions fat can be formed from sugar in the body, so it may he concluded that protein can take part in the formation of fat. Investigations on carnivorous animals which were given lean meat in large quantities fully confirm this. With herbivorous animals such investigations are impossible, for they cannot subsist on a diet of pure protein, without other foods being given. It is possible though to arrange experiments so that the increase of fat can be determined when a known weight of protein is added to a basal ration. From a number of such investigations it has been found that on an average I kilogram of vegetable protein (wheat gluten) gives a maximum addition of $235 \mathrm{gr}$. fat. It was further found that only $35 \%$ of the energy of the protein went to form fat, I9\% was lost in the 
urine and $46 \%$ dissipated as heat. Before the above-mentioned investigations were made it was calculated from the composition of the proteins and of the urea formed from it that roo parts of protein could yield $5 \mathrm{I} \cdot 4$ parts of fat. This number -Henneberg's number as it is called-plays an important part in many investigations, but it is certainly too high, for in arriving at it, it was assumed that all the nitrogen of the protein formed urea, and that the formation of fat is not accompanied by any development of heat. Neither of these assumptions is quite correct, for waste products richer in carbon than urea are formed, and so less of this element remains for the production of fat. Also there is always some heat developed during metabolism, as was stated on page 56 . Henneberg's number, or factor, will be frequently mentioned later, and it is now seen by what methods it was obtained.

(b) The effect of non-protein nitrogenous substances.

These substances are soluble in water, and can pass through the walls of animal cells; they are usually assumed to be completely digestible. Asparagine may be taken as a typical member of the group, and where it was fed to carnivorous animals it was not able to replace protein, but behaved like large doses of salt and increased the decomposition 


\section{SCIENTIFIC FEEDING OF ANIMALS}

of protein. Omnivorous animals, such as rats, died from protein starvation when a complete food in which protein had been replaced by asparagine was given. It was also immaterial whether asparagine was added to the food or not; death occurred in the same time in both cases. With ruminants it was different, for the addition of asparagine to a food rich in carbohydrates but poor in protein effected a considerable saving in the latter; a similar effect was noticed also when ammonium acetate was added to the food. In experiments with lambs which received the same basal ration the daily increase of protein was as follows-

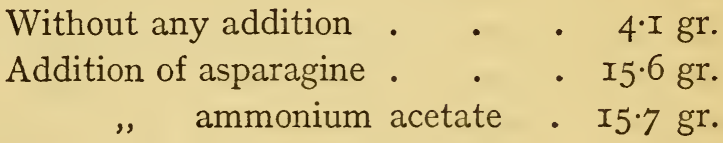

Ruminants then behave differently to the carnivora and herbivora as regards the non-protein of the food. Fundamental differences in the way in which the nutrients are treated in the body cells are in any case not to be expected. The various species, however, do differ in the way in which the work of the alimentary canal is performed, and it is here that an explanation must be sought. Most probably the differences are caused by the bacteria, for ammonia and asparagine are known to be excellent foods for them. It may be that 
these micro-organisms, with the assistance of the nitrogen-free substances, form proteins in one part of the intestines, which are again digested in another part. On the other hand, it is possible that when the bacteria can get such an acceptable food as asparagine or ammonia they destroy less protein, and so leave more available for the real enzyme digestion (p. 22). In this way more protein would be placed indirectly at the disposal of the animal. Bacteria are present in large quantities in the partly digested food of ruminants, whereas considerably fewer are found in that of carnivorous animals. This would explain how the former class are able to make better use of the non-protein nitrogenous substances.

It has not yet been clearly shown whether other substances besides asparagine and ammonia can act similarly ; for the present it is only possible to say that amido compounds can be utilised by ruminants in the way described.

For the non-protein compounds in molasses it has been proved that they are not in a position to maintain ruminants in a position of protein equilibrium, to say nothing of causing an increase of protein tissue. Experiments have also shown that the nonprotein nitrogen substances of potatoes and mangels are as valueless for the nourishment of rabbits as asparagine is for flesh-eating animals. The products which arise on boiling protein with strong 


\section{SCIENTIFIC FEEDING OF ANIMALS}

acids have also shown themselves unable to replace food protein when fed with large quantities of nitrogen-free substance to dogs, rats, and mice. Dnly with those substances which result from the decomposition of protein by pancreatic juice, and which contain therefore all that is in the protein, has the effect on carnivora been shown to be the same as with proteins themselves. Many investigators have prematurely concluded from this that the amides of the food, if fed together and not alone, must give results similar to those from the proteids. That, however, could only be the case if the mixture of amido substances in each food contained the materials from which protein could be built up, as the products of digestion just mentioned do. The above experiments with the amides of potatoes and mangels prove this assumption to be incorrect. It will be remembered that even gelatine, which stands in very close relation to protein and is, in fact, put in that class, cannot take the place of the true proteins in the case of carnivorous animals (p. 6I).

-Investigations as to the part which non-protein nitrogenous compounds play in the formation of fat have so far only been made with asparagine. Upon sheep it has been shown that these materials cannot be changed into body fat. This agrees perfectly with the fact that asparagine, where it is not changed by the bacteria of the intestines, possesses 
no protein-saving action. All food nutrients, then, which are capable of conversion into fat in the body possess at the same time the power of economising protein. Whether the nitrogen compounds of nonprotein nature which contain more carbon than asparagine can take part in the formation of fat has not yet been decided. In fact, the whole question as to the position of these materials in the food supply requires more investigation. As far as has been proved, it may be said that ruminants receiving a food poor in protein, but rich in non-protein, can utilise the latter to make flesh, but not fat, the change being brought about by help of the bacteria in the partly digested food. Some further experiments on this subject will be given in the chapter on the feeding of milch cattle.

(c) The effect of nitrogen-free nutrients.

The different nitrogen-free constituents of the food-the fats, the nitrogen-free extract, and the crude fibre, exercise in general the same effect. The fats are the most concentrated form of nutrient; on digestion they suffer no severe loss, for they are not apparently acted upon by bacteria or the digestive juices, except that the latter split them up into free fatty acids and glycerine. Immediately after entrance into the fluids of the body, these components are again formed into fat. 


\section{SCIENTIFIC FEEDING OF ANIMALS}

Fats, like protein and amides, undergo no marsh gas fermentation. Only those parts of the crude fat (p. I2) which are true fats undergo digestion; the wax-like substances, chlorophyll, resins, etc., are excreted undigested. The heat, or energy, content of the fats is unsurpassed by any other digestible food material, the vegetable fat of oily seeds or oil cakes yielding 9300-9500 cal. from I gr., whilst the fat from coarse fodder has an average value of $8200 \mathrm{cal}$. It is this that accounts for the high food value of fat.

From the nitrogen-free extract and crude fibre of the food only those materials are digested which, inclusive of the pentosans, possess the same percentage composition and heat value as carbohydrates of the class of pure starch and pure cellulose. This fact has been proved by most thorough investigations and it makes the estimate of the feeding values of these substances considerably easier. Cane, fruit, grape and milk sugars have a somewhat different nature. They contain a smaller quantity of carbon and possess a lower heat value than the digestible portion of the other nitrogen-free extract substances and crude fibre. These two latter yield on combustion 4200 cal. for each gram burnt; milk and cane sugars yield $395^{\circ}$ cal., and grape sugar 3740 ca.1. ; similar differences being also shown in the feeding value of the substances.

The other nitrogen-free compounds, the organic 
acids, might also be mentioned here, but as they are only present in small quantities in the usual feeding-stuffs they may be left out of consideration.

It may be noted further that crude fibre and nitrogen-free extract are decomposed to a considerable extent by bacteria in the intestines, and thereby organic acids, carbon dioxide, and marsh gas are formed. The organic acids enter the circulation, but the marsh gas leaves the body, unused, in large quantities. This loss is considerable, and reckoned upon the digestible part of the nitrogen-free extract and crude fibre reaches on an average $4.3 \%$ marsh gas, equal to $13.7 \%$ of the total heat value of the digested substance. With very hard food-stuffs it is still more, and in wheat straw, for example, amounts to $20 \%$ of the heat value. The average amount of heat in I gram of digested nitrogen-free extract and crude fibre, after deducting the loss of marsh gas, is in round figures $3600 \mathrm{cal}$. The food metabolism, after feeding with nitrogen-free nutrients, may now be considered.

\section{(d) The action of nitrogen-free mutrients upon the protein and fat metabolism.}

The clearest insight into the effects is given from investigations which have been carried out upon carnivorous animals, a single example of which will suffice. Three dogs received a food 


\section{SCIENTIFIC FEEDING OF ANIMALS}

entirely free from nitrogen, and during the experiment gained $(+)$ or lost $(-)$ the following weights of body substance-

I.

Method of

Feeding.

Fasting . 200 gr. bacon

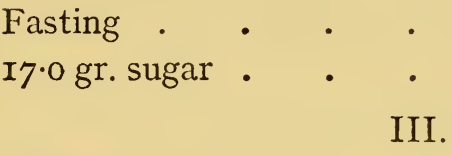

Fasting 94 gr. sugar +68 gr. starch +4.7 gr. fat

II.

Loss of

Flesh.

Fat.

- -IO.I gr. $-60.5 \mathrm{gr}$.

. - IO.I gr. +I28.2 gr.

- II.2 gr. $-42 \cdot 7$ gr.

- 8.5 gr. $\quad-35.8$ gr.

$$
-I_{5} \cdot 8 \text { gr. } \quad-25 \cdot 0 \text { gr. }
$$$$
-7 \cdot 4 \text { gr. } \quad+58 \cdot 2 \mathrm{gr} \text {. }
$$

Thus feeding with a ration composed only of nitrogen-free material decreases the metabolism of body protein and body fat. Such nitrogenfree nutrients preserve then the proteins and fats. If along with the nitrogen-free substances proteins are also fed, the protein metabolism regulates itself according to the supply of protein in the food, as was previously seen (p. 62). Under the influence of nitrogen-free substances a slightly smaller quantity of protein is metabolised than without. A dog of about 35 kilos ( 77 lbs.) weight was fed according to the following table, with the results recorded below- 
Daily ration. Decomposition Gain $(+)$ or Meat Starch. of protein loss (-) of

(protein). in the body. body protein.

500 gr. $\quad$ o gr. 564 gr. $\quad 64$ gr.

500 gr. I00-300 gr. 502 gr. - 2 gr.

800 gr. $\quad$ o gr. 826 gr. -26 gr.

800 gr. Ino-400 gr. 763 gr. +37 gr.

rooo gr. $\quad 0$ gr. I028 gr. $-28 \mathrm{gr}$.

I000 gr. IOO-400 gr. 902 gr. + 98 gr.

2000 gr. $\quad$ o gr. I99I gr. + 9 gr.

2000 gr. 200-300 gr. I792 gr. +208 gr.

With the addition of protein to the diet the nitrogen metabolism increased; when starch was added a decrease in the metabolism was noticed, and led to a storage of protein in the body.

Further investigations have shown that the quantity of protein which just suffices for an animal can be considerably reduced if nitrogen-free substances are fed with the protein. A dog weighing 30 kilos (66 lbs.) required I200-I500 gr. of lean meat in order not to lose body flesh; if, however, fat (250 gr.) was given along with the meat, then 500 gr. sufficed to prevent loss from the body. In this connection it has been shown that the minimum requirements in protein are astonishingly low, when at the same time large quantities of nitrogen-free substances are consumed. The full-grown ruminant does not require to draw 


\section{SCIENTIFIC FEEDING OF ANIMALS}

upon its reserve of protein when $0.4-0.6 \mathrm{lb}$. of digestible protein per Iooo lbs. body weight are given. Equally low figures would also be found in the case of men accustomed to a purely vegetable diet.

The protective action of the nitrogen-free nutrients extends, as has been seen, not only to the protein of the body, but also to that of the food. If an animal has the power of turning large quantities of protein into flesh, it is not necessary to feed with a lot of food rich in protein, for a small quantity suffices provided a sufficient supply of nitrogen-free substances is given. The latter, then, play a very important part in the formation of flesh.

(e) Formation of body fat from food fat.

The first investigations as to whether the fat of the food can be stored in the body were performed with a dog which, after fasting for thirty days, decreased in weight from 26.5 to $16 \cdot 0$ kilos. In this state it was computed from other experiments that the body did not contain more than 150 gr. fat. The animal was then given, for five days, a large quantity of fat, the average daily amount being 370.8 gr. and 49 gr. dry flesh. At the end of the experiment the animal was killed and the body was found to contain $1352.7 \mathrm{gr}$. fat, from which the 150 gr. present at the beginning must be de- 
ducted. A further deduction had to be made for the fat (26.I gr.) which might, according to Henneberg's figures (p. 65) be formed from the 49 gr. of flesh in the food. So a total deduction of $26 \cdot I \times 5=$ I $30.5 \mathrm{gr}$. had to be added to the I50 gr. present in the body at the beginning of the experiment. Subtracting these two amounts 280.5 from I352.7, the fat added to the body, there is left ro72.2 gr. which could only have come from the food fat. This divided by five gives the daily addition of 2 I 4.4 gr. of fat from the $370.8 \mathrm{gr}$. of fat (and the small quantity of flesh) in the food.

Numerous other experiments, in which the materials going into and leaving the body were carefully measured by means of a respiration apparatus (p. 46), confirm these results. An example is seen in experiment III of the table on page 72 .

The determination of the quantity of body fat which can arise from a known quantity of food fat has been carried out on fattening oxen, and it has been shown that I kilo emulsified earth-nut oil causes an increase of $598 \mathrm{gr}$. in the fat of the body. Thus $64.4 \%$ of the energy of the digested oil has been retained as newly-created body fat, and $35.6 \%$ has been lost. The fat from the different kinds of hay or straw possesses a considerably smaller energy value (p. 7o), and a kilogram of it would only produce 474 gr. body fat. The cereal grains and their by-products yield fats which take a medium posi- 


\section{SCIENTIFIC FEEDING OF ANIMALS}

tion, each kilogram giving on an average 526 gr. body fat.

The ability of the animal to store the fat of the food in the body extends to fats which are otherwise foreign to the organism. It has been noticed that lean dogs fed with large quantities of linseed oil developed fat which differed very considerably from the usual fat of the dog, and remained liquid even at $0^{\circ} \mathrm{C}$. $\left(32^{\circ} \mathrm{F}\right.$.). Further, a dog in a lean condition after being fed on mutton suet stored in its tissues a fat which did not melt at $50^{\circ} \mathrm{C}$. In another experiment two young pigs were fed on barley meal and then from each a small piece was cut from the layer of fat on the back, cocaine being used to prevent pain. In both cases the fat had exactly similar properties. One pig was then fed for ten weeks on barley meal and linseed oil and the other for the same length of time on barley meal and cocoa-nut oil. Afterwards small portions of fat were again taken from the backs, and it was found that where the linseed oil had been given the fat was soft and had the characteristic smell of linseed oil as well as containing some materials (sativinic acid) peculiar to that oil. The pig which had been given cocoa-nut oil yielded a fat which was much firmer and which could be distinguished chemically from that of the other pig. These examples and many more prove that not only can the fat of the food be stored in the body, but also that it is possible to make the 
bacon or suet harder or softer; to this point a return will be made later.

(f) Formation of body fat from carbohydrates.

Although it must long have been seen in practice, particularly in feeding pigs, that the carbohydrates play a very important part in the formation of fat, it was some time before definite proof was given on this point. The opinion held was that next to the fat of the food the splitting up of the protein was the important source of fat. This being the case, it was only necessary in an investigation to calculate the amount of fat which could come from these two sources, and if it were assumed that all the fat and $5 \mathrm{I} \cdot 4 \%$ (p. 65 ) of the decomposed protein passed into newly formed body fat, then the increase of the latter would be directly due to these two substances.

When, however, in I880-I experiments were made with a ration very poor in protein and fat, it was observed that the quantity of fat stored in the body was far greater than could have arisen from the fat of the food, or from the decomposition of the food protein.

The investigations were carried out on three pigs which were fed for 32I days before the experiment began on a rather low diet. The animals, which were very much alike as regards weight and condi- 


\section{SCIENTIFIE FEEDING OF ANIMALS}

tion, were found at the beginning of the experiment to weigh $99 \cdot 36,99 \cdot 60,96 \cdot 60$ kilograms respectively. The pig weighing $99 \cdot 36$ kilos was then killed and analysed. The other two pigs received husked rice as food for 75 and 82 days respectively, and gained during that time 39.07 and 38.76 kilos. At the end of the feeding period a chemical analysis of the animals was made, and the results compared with those obtained before the experiment began. In this way a direct determination of the increase of flesh and fat from the rice was made. The quantity of protein, fat, and carbohydrates in the food which had been digested was also determined.

The average amount of fat made by the animal from the rice was . . I6.I3 $\mathrm{kg}$. The amount of fat in the food was . $0.32 \mathrm{~kg}$.

Newly formed fat $15 \cdot 8 \mathrm{I} \mathrm{kg}$.

$5.32 \mathrm{~kg}$. of food protein were split up

which, according to Henneberg's calcu-

lation (p. 65), could yield in the most

favourable case . . . $2 \cdot 73 \mathrm{~kg}$.

The amount of fat which has come from

the carbohydrates is at least . . $13.08 \mathrm{~kg}$.

Thus it is seen that the pigs formed four times more fat than could be got from the fat of the food 
or the decomposition of the protein. This result was repeatedly supported by further investigations with sheep, fattening oxen, and geese, and also with carnivorous animals, so that it has been proved that domestic animals form large quantities of fat from carbohydrates. The question then arose whether by this transformation the carbohydrate portion of the food protein played a direct or indirect part. On the false assumption that it is necessary to give a large supply of protein in a feeding ration, many believed that the formation of fat from carbohydrates could not take place completely without the help of protein. A case is seen on page 72, Experiment III, where a considerable quantity of fat was formed when no protein at all was given. The small amount of protein matter came from the body tissue, the food consisting only of carbohydrates with a little fat.

In other investigations carried out with the help of the respiration chamber, it was shown that the formation of fat took place whether the relation of digestible protein in the food was I : $2 \cdot 4$ of nitrogenfree substance or I : I2-I4 of the latter. With oxen it was proved in the same way that from each kilogram of digestible nutrients above the maintenance ration, the following quantities of body fat, 202, 202, 2I7 grams, were obtained. In these three cases the relation of digestible protein to nitrogenfree extract was I : 4, I : IO-II, I : I6 respectively. 


\section{8o SCIENTIFIC FEEDING OF ANIMALS}

None of these experiments show that protein is necessary for the formation of fat from carbohydrates, and this has been repeatedly confirmed in other experiments. It must not, however, be concluded from this that the quantity of protein in a feeding ration is not of importance, for it has already been shown (p. 37) that the digestibility of a food is depressed where there is not a certain quantity of protein in it. It will also be seen later that growing, fattening animals require fairly large quantities of protein for the formation of body tissue.

In order to ascertain the quantity of fat which can be formed from the various carbohydrates, several investigations with oxen have been carried out. The method adopted was to add the material to be tested to a basal ration, the action of which was determined either before or after the addition. The results showed that body fat was stored in the following quantities-

From I kg. digestible starch .

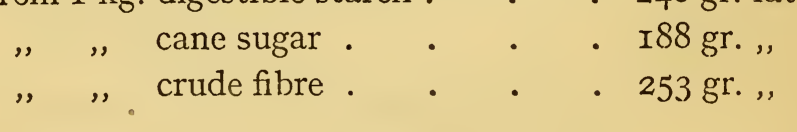

The crude fibre was given in pure finely divided form (straw pulp of paper works), and it is seen that in this condition it has about the same effect as pure starch. In round numbers $57 \%$ of the 
heat value of these two substances was stored up as body fat, whereas from the cane sugar only $45 \%$ was stored. The smaller return obtained from the sugar is doubtless to be explained by the fact that this material is very easily soluble and therefore more largely attacked by the bacteria in the intestines than are the starch or crude fibre.

It is well known that solutions of sugar readily become sour when mixed with fermenting substances, and it has been observed that shortly after ruminants have eaten sugar there is very little to be detected in the partially digested food, but, on the other hand, considerable quantities of lactic acid.

With pigs, in whose alimentary canal the bacterial activity is much less, and also with horses, most probably the sugar gives a much more favourable return than with ruminants. Lactic acid is not able, as has been shown from investigations on this point, to undergo conversion into body fat, so it can only serve as a source of heat to the animal.

If the results of all the investigations which have been made on the action of digestible components of the food were put together they could be expressed in the following sentences-

(a) Flesh is formed in the body principally from protein. Amongst the nitrogenous substances of non-protein nature there are some which can be changed in the intestines with the help of bacteria into protein, and so take part in the formation of 


\section{SCIENTIFIC FEEDING OF ANIMALS}

flesh. To these substances belong asparagine and ammonia. The behaviour of other members of this large group has not yet been determined.

This formation of protein only takes place to any extent in the alimentary canal of the ruminants ; with horses and pigs it is probably very slight, in fact with the latter there may be no such changes.

Although nitrogen-free extract substances and fat do not take a direct part in the formation of flesh, they have an important influence on the decomposition of the food protein, for they are able to decrease decomposition of this material, and so a larger proportion is free to form body protein (flesh and milk).

$(\beta)$ Fat can be formed in the body either from the fat of the food or from nitrogen-free extract substances and crude fibre.

\section{(g) The utilisation of complete foods.}

In accordance with the foregoing statements, ruminants are able to form the following quantities of fat from digested food materials (if they are added in pure, finely divided form to a maintenance ration).

From I kg. protein . . • . $235 \mathrm{gr}$ fat

", I kg. starch and crude fibre . 248 gr. ","

" I kg. cane sugar . . . I 88 gr. ,

, I kg. fat . . . 474-598 gr. , 
From the large number of investigations which have been carried out in the last few years, it is possible to learn whether the digestible nutrients of the ordinary feeding-stuffs act in the same way, or differently, to the representatives of the same groups when fed in pure form. Experiments were carried out with the aid of the respiration chamber in exactly the same way as was done with the pure nutrients. A known quantity of the feeding-stuff was added to a basal ration sufficient for maintenance, and the digestibility as well as the increase of flesh and fat were determined for the maintenance ration and for the increased ration. In this way it was found what amount of flesh and fat was obtained from the added food-stuff. In the case of various oil-cake meals it was shown that from each kilogram of dry substances consumed the animals digested the following quantities, in grams-

Cotton-seed Earth-nut Palm-nut Linseed cake meal. meal. cake meal. cake meal.

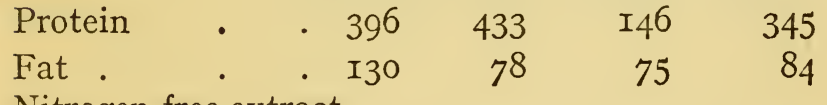
Nitrogen-free extract

or crude fibre . I2I I6I $403 \quad 26 I$

If these nutrients had behaved exactly as the pure digestible protein, fat, and carbohydrates,* then there would have been stored in the body of

* Carbohydrates $=$ nitrogen-free extract + crude fibre. 


\section{SCIENTIFIC FEEDING OF ANIMALS}

the animal the following quantities, in grams, of fat-

Cotton-seed Earth-nut Palm-nut Linseed cake meal. meal. cake meal. cake meai.

\begin{tabular}{|c|c|c|c|c|c|}
\hline From & the protein & 93 & I02 & 34 & $8 \mathrm{I}$ \\
\hline " & , fat . & 78 & 47 & 45 & 50 \\
\hline$"$ & $\begin{array}{c}\text { " carbo- } \\
\text { hydrates }\end{array}$ & * 30 & 40 & IOO & 6 \\
\hline & Altogether & $20 I$ & I89 & I79 & I96 \\
\hline
\end{tabular}

In the experiment $\dagger$

with the animal there was acually

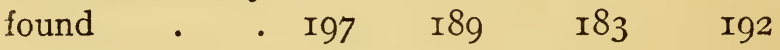

Thus there is an almost complete agreement between the calculated quantity of fat and that actually found in the animal. It is seen that the digested nutrients have in fact acted exactly as if the same quantities of pure digestible protein, fat, or carbohydrates had been given to the animal. From these facts it is shown further that the protein, fat, and carbohydrates have the same action, although coming from such different materials as the four oil-cake meals. Finally, these experiments teach that the figures obtained are a good standard by which the action of the different foodstuffs can be measured.

Investigations with a number of different hays

- Carbohydrates = nitrogen-free extract + crude fibre.

+ Inclusive of very small quantities of flesh which were calculated as fat, and this amount added to the other fat. 
and straws carried out in a similar manner showed that from I kilo dry substance the following additions of fat, in grams, were to be expected, if the digested materials had also behaved as do the pure nutrients-

a straw. straw. $a \quad b$ hay. hay. math. $\begin{array}{llllllllll}\text { Fat calculated } & 104 & 82 & 109 & 117 & 129 & 156 & 125 & 153 & 124\end{array}$ " actually

\begin{tabular}{cccccccccc} 
found . & 21 & 24 & 66 & 79 & 81 & 109 & 85 & 85 & 79 \\
\cline { 2 - 9 } Difference & 83 & 58 & 43 & 36 & 48 & 47 & 40 & 48 & 45
\end{tabular}

Percentage dif-

ference be-

tween calcu-

lated and

observed in-

$\begin{array}{llllllllll}\text { crease of fat } & 80 & 71 & 40 & 31 & 37 & 30 & 32 & 36 & 36\end{array}$

Here very different results are obtained to those with the oil cakes. The calculated increase of fat does not agree with that observed in the animal. In each case the fodder has yielded less fat than was expected, supposing the digested nutrients in the hay and straw to act as do the pure, isolated nutrients. The difference in the wheat straw is $70-80 \%$, in the oat and barley straws $30-40 \%$, and with the various varieties of hay also $30-40 \%$. If, then, in calculating rations the same value were given to the digestible materials of the coarse fodders as to those of the oil-cake meals, the food value of hay and straw would be estimated 30-80\% too high. The quantity of digestible nutrients without reference to their effect cannot therefore 


\section{SCIENTIFIC FEEDING OF ANIMALS}

be used as a basis upon which to calculate rations. The productive value of the nutrients has to be considered, and this can vary a great deal, as is shown from the comparison of the oil-cake meals and the coarse fodders.

Attention has already been called (p. 20) to the fact that the work of mastication and of digestion is not by any means small in the case of coarse foods. To obtain definite information on this point, straw was fed in one case as coarse chaff and in the other in a finely ground form. It was found that the finely ground straw which did not require to be chewed was considerably better utilised than the chaff. The decrease in productive value was, in fact, on an average $50 \%$ greater in the case of the chopped straw than in the case of the finely ground straw. The improvement due to grinding was greater with the wheat straw than with the barley or oat straw, and experiments with wheat chaff showed that the limit of improvement is reached when the particles of ground straw are about as large as in the chaff. As the grinding of the straw only partly reduced the bad results noticed in the case where it was chopped, there must be some other cause in addition to the difficulty of mastication. Experiments where sawdust was added to the ration have indeed shown that this slightly digestible material depresses the digestibility of the other food: 
As a third cause for the diminished utilisation of the more indigestible feeding-stuffs, regard must be paid to the processes of decomposition which go on in the intestines. There many components of the food are so far decomposed that they can serve for the production of heat, but not for the formation of flesh or fat. It is usual to regard the difference between food and dung as being digested, but in the case of difficultly digestible food, a portion is not really digested, but has undergone putrefaction. In certain cases food constituents, such as organic acids, which have no value for the formation of new tissue, may also partially account for the inferiority of the digested substances.

It is therefore quite clear that the amount of work required for mastication and digestion, as well as the extent of putrefaction in the partially digested food, must be closely connected with the hardness and digestibility of the food material. When it is considered what components of the food determine its hardness and digestibility, there can be no doubt that the quantity of crude fibre takes the first place. The digestible crude fibre is of itself equal in nutritive value to starch, but the work of mastication and of digestion, and also the putrefactive changes in the intestines, fall not upon this portion alone, but upon the whole of the crude fibre consumed. The richer the straw or hay is in crude fibre, the less must be the amount of the digested substances of 


\section{8}

SCIENTIFIC FEEDING OF ANIMALS

the food which is utilised. Proof of this is to be found in the details of the investigation carried out with the nine coarse fodders (p. 85). The dry matter of the four varieties of straw contained on the average $4 \mathrm{I} \cdot 7 \%$ crude fibre, whilst in the five varieties of hay it was $30.1 \%$. The digested materials of the straw gave an average of $55 \%$ less body fat than would have been formed if they had acted like pure, isolated materials. With the hay there was an average of $45.6 \%$ less body fat. The straw, which was richer in crude fibre, yielded according to this I7\% less body fat than the hay, which did not contain so much crude fibre.

From these investigations it is computed that Ioo gr. of crude fibre depressed the fat production I 4.3 gr.- such a deficit as could be balanced by the addition* of $58 \mathrm{gr}$. starch for each Ioo gr. of crude fibre consumed. With various chaffs of the nature of wheat chaff, the depression is only half of that given above.

As regards the green fodders, it is easy to see that it is much easier to masticate them in that condition than when dried. An experiment where meadow hay and green lucerne were fed to a horse confirmed this, for during the consumption of the green food $38 \%$ less energy was used in mastication than when the same quantity of dry matter was eaten in the form of meadow hay. Tender fodder

* $100 \mathrm{gr}$. starch $=24.8 \mathrm{gr}$. body fat. 
plants without much stem give a hay which is easily broken up, and it has been found by direct experiment that to masticate it no more work is required than is the case with the same food in a green condition. The more the plants advance in growth, the richer do they become in crude fibre, and when they are over-ripe differ very little in food value from hay which has been made from them without loss. If the energy required for mastication and digestion of the crude fibre were expressed as starch, it would be found that more energy is required in the case of woody green fodder than with young grass or clover. Green plants which contain $16 \%$ or more of crude fibre would have to receive an addition of $58 \mathrm{gr}$. of starch for each Ioo gr. consumed. If the amount of crude fibre were only $4 \%$, then half the above quantity of starch $(29 \mathrm{gr}$.) would be necessary, and in the same way $34 \mathrm{gr}$. of starch for $6 \%$ crude fibre, $38 \mathrm{gr}$. for $8 \%, 43 \mathrm{gr}$. for Io $\%, 48 \mathrm{gr}$. for $\mathrm{I} 2 \%$, and $53 \mathrm{gr}$. for $14 \%$.

It has been previously shown that there are food-stuffs whose digestible portion acts exactly as the corresponding nutrient in a pure form. If these pure nutrients were fed in finely divided condition, it is certain that they, would cause the greatest production of which the animal is capable, and the food-stuffs whose digestible components show this maximum value are said to possess "full 


\section{SCIENTIFIC FEEDING OF ANIMALS}

value." In order to express this in figures, the fullvalue feeding-stuffs can be called Ioo and the less valuable ones receive a number below Ioo depending upon their value. When in Table I of the Appendix it is seen, for example, that the value of barley straw is 46 , it means that Ioo gr. of the digested material of the straw when added to a maintenance ration only cause an increase of fat equal to that which $46 \mathrm{gr}$. of the same nutrients in pure, finely divided form would give. Substances which depress the action of the other foods are marked with a-sign, e.g. sawdust from pinewood has a value of -22 . This means that the $7.8 \mathrm{gr}$. of nitrogen-free extract and the 6.9 gr. of crude fibre, in all 14.7 gr. nitrogen-free extract, which are digested from roo gr. of pine sawdust, not only have no nutritive value, but reduce the action of the other food by $22 \%$ of the amount which would be obtained if the nutrients of the sawdust were of full value.

In the Ioo gr. sawdust I 4.7 gr. are digestible, and $22 \%$ of this is 3.2 gr., so the addition of the sawdust acts as though $3 \cdot 2$ gr. of starch had been taken from the food instead of sawdust being added.

By means of this "quantitative number" exact expression is given to the action of the digestible materials contained in each food-stuff. Further investigations have shown that the coarsely ground cereal grains without husks, and feeding-meals free from chaff or bran, are of full value. The 
husked grains (oats, barley) and the leguminous seeds have a less value on account of the husks and chaff. All those by-products from which the inner nutritious portion of the grain has been withdrawn by grinding or mashing, e.g. brans, barley refuse, brewers' grains, slumps, etc., have proved to be of low value.

Amongst potatoes, turnips, and similar foods, the former have proved to be of full value, whereas mangels and their by-products are not. The digestible nutrients in the different food-stuffs therefore differ considerably in value. If attention is not paid to this important fact and the rations are calculated as formerly on the amount of digestible material which they contain, very serious errors can be made. In view of what has just been said, it is absolutely necessary that the value of the nutrients should enter into the calculation. This is done most suitably and easily if the amount of full-value nutrients which the food-stuff contains is reckoned with the help of the "value" number. If, however, such a calculation were to be made for each group of nutrients, a clear estimate of the productive value of many feeding-stuffs would not be obtained, quite apart from the labour of such a procedure. The writer therefore considers it best to express the fat-forming value of the feeding-stuffs by a single number, and to use starch as a standard. An example will make this clear. Suppose an 


\section{SCIENTIFIC FEEDING OF ANIMALS}

experiment with ruminants has shown that Ioo $\mathrm{kg}$. fairly good meadow hay forms $8 \mathrm{~kg}$. body fat when added to the maintenance ration. In a similar experiment where starch was fed instead of meadow hay it was found that the weight of fat gained was exactly equal to quarter of the weight of starch given. If the $8 \mathrm{~kg}$. fat obtained from the hay be multiplied by 4 , the quantity of starch which would have the same effect as Ioo kg. of the hay is obtained, that is, 32 . This figure 32 is then the starch equivalent of the meadow hay. This does not in any way mean that the meadow hay contained $32 \%$ starch, but expresses the food value of the hay compared to the starch. When, therefore, it is seen in Table $I$ of the Appendix that winter cereal straw has a starch equivalent of II $\cdot 5$, summer cereal straw I8.8, potatoes I9, rye bran 46.9, barley 72 , and flax seed II9.2, the meaning will be clear. How far these figures are applicable in the production of energy or milk, or how they apply to horses and pigs, will be discussed later. The method of estimating the starch equivalents or values of different feeding-stuffs will also be treated later in the introduction to the Tables for the calculation of rations.

In digestion, in the formation of flesh, and, as will be subsequently seen, in the production of milk, the digestible protein plays a very important part, so the mere giving of the starch equivalent will not suffice to fully express the nutritive value of a food- 
stuff. In Tables I and III of the Appendix the amount of digestible protein in the food is also given. It must not be forgotten though that the starch value also includes the effect which the protein has in common with the starch. It would not be correct to include only nitrogen-free substances in the starch equivalent, for in very many cases the greater part of the food protein is not used for the formation of flesh, but utilised in the same way as the nitrogen-free nutrients.

(h) The effect of mineral substances.

When an animal is burnt, ash is left which contains, as does the ash of the plant, potash, soda, lime, magnesia, oxide of iron, phosphoric and su?phuric acids, chlorine, etc. These materials are not unimportant, but are an absolute necessity, as has been proved by experiments in which food lacking in them was given. It was found that under these conditions the animals constantly lost mineral substances, such as phosphoric acid and lime; in one case lambs were found to lose $0.5 \mathrm{gr}$. phosphoric acid and I.2 gr. of lime per head per day. If feeding with food poor in mineral substances is continued for some length of time, appearances of disease are to be seen in consequence of the loss of mineral substances from the body. The symptoms as a rule are great weakness in the legs, trembling 


\section{SCIENTIFIC FEEDING OF ANIMALS}

of the muscles, cramp, and excitability, whilst death follows sooner than if the animal had had no food at all. The mineral substances of the body undergo metabolism just as do the protein and fat, only to a less extent, for they are a necessary part of the organism, and must be given to growing animals, whose organs are increasing, in larger quantities than when growth has ceased. As to the exact part which the various mineral substances play there is not yet any very exact knowledge. The following are the most important facts known-

(a) Potash and soda.-Potassium is found principally in the cell walls, muscles, and blood corpuscles. Sodium, on the other hand, in the blood, lymph, saliva, gastric juice, etc. The value of potassium for the changes which take place in the body is not yet known, but sodium combined with chlorine is present as common salt, and there are indications that it prevents swelling up of the cells, assists the passage of many substances through the cells, dissolves some proteins, and forms hydrochloric acid and soda in the digestive juices. When salt is taken in moderate quantities it appears to favour the putting on of flesh, but in excess it increases the quantity of water drunk, and causes all those drawbacks which are associated with a too liberal consumption of water (p. Ior). The ordinary feeding-stuffs and drinking-water contain, as a rule, so much sodium and chlorine that if no salt is given the vital functions 
still proceed regularly. Animals which are giving milk are, however, exceptions to this, and they ought to be given some salt to replace the chlorine taken away in the milk. Milch cattle after being two or three weeks without salt begin to show great craving for it; they gnaw the manger and the walls, lick the hands and clothes of those attending them, and even eat refuse and dung. No change is to be noticed in their appearance or weight, nor does the yield of milk decrease. This condition can continue for some weeks or even for a year, depending upon the animal and the quantity of milk given, but finally the appetite decreases, the eyes become dull, the coat "stares," and the animal becomes very weak and thin. If salt is now given recovery quickly begins, but if not, weakness continues, and generally death follows, about time of calving. These phenomena are due to the lack of chlorine, not of sodium, for it has been found that improvement and recovery follow if potassium chloride is added to the food.

Common salt finally possesses, in a very high degree, the properties of a spice; it improves the appetite and makes many feeding-stuffs palatable which, without salt, would not be readily eaten. It further increases the flow of digestive juices (p. 40), promotes activity of the circulation, and prevents disturbances of the digestive apparatus, so a deficiency in the food should not occur. 


\section{SCIENTIFIC FEEDING OF ANIMALS}

( $\beta$ ) Lime, magnesia, and phosphoric acid.-These substances are found in the greatest quantities in the bones. They are also used up in the body, so that if the food does not contain sufficient to make up for the losses in dung or urine, the animal has to draw upon its own skeleton. Under some conditions the mineral substances of the bones may be drawn upon to such an extent that the latter become porous and brittle. Where the soil is deficient in lime and phosphoric acid and this deficiency is not made good by manures, the bones may become permanently brittle, for the fodder plants are not able to take up a sufficient quantity of mineral substances for the requirements of the animal. This diseased condition of the bones is particularly prevalent in dry years, because owing to the lack of moisture in the soil less lime and phosphoric acid enter the roots. Soft water poor in lime also favours this disease, whilst insufficient or acid food, digestive disturbances, etc., can hasten its course. In young, growing animals these diseased conditions, due to the lack of lime and phosphoric acid, develop more rapidly than with full-grown ones. Puppies, particularly those of the larger breeds, when fed on meat free from bone and potatoes or rice, show after a few weeks signs of pain when they move, later even when they lie. The ends of the bones and of the ribs are swollen, the legs and bones of the back bend, the teeth re- 
main small, and finally the animal is unable to move. On examining the bones of such miserably grown animals it is seen that the parts, notably on the ends of the joints, are composed of soft cartilage in which lime and phosphoric acid are only slightly deposited. Animals in this condition are said to be suffering from softening of the bones or osteomalacia, in children known as rickets. Amongst domestic animals, young pigs fed upon potatoes, whey, maize, and cereal grains, and so not obtaining enough lime in the food, are most liable to suffer. This softening of the bones is found less frequently in young cattle, horses, or sheep, for the hay and other fodder which they get generally contains sufficient phosphoric acid and lime. Amongst grown animals the females are more liable to brittleness of the bones, for they have to supply the fotus with mineral substances in addition to the phosphoric acid and lime that go into the milk. It is essential then in feeding to pay attention to these points, and to provide a sufficient supply of both these substances in the food.

Feeding-stuffs which are deficient in lime are the straw and chaff of cereals, cereals and their by-products, such as brans and meals, malt coombs, and also roots and molasses. On the other hand, foods which contain a good supply of lime are clovers, meadow hay, and many leguminous seeds. With regard to deficiency in phosphoric acid, the 


\section{SCIENTIFIC FEEDING OF ANIMALS}

following foods are to be noted-straw and chaff of cereals, pulped mangels and potatoes, distillery refuse, molasses; whilst cereal grains, bran, malt coombs, brewers' grains, oil cakes, flesh and fish by-products, are rich in this substance. Only onethird to one-half of the phosphoric acid and lime can be taken from vegetable foods by animals, so that two to three times as much material must be given as can be stored in the body. Further information on this subject will be given in Part III.

If the amount of lime and phosphoric acid in the food is not sufficient, it can be increased by the addition of phosphate of lime. In many cases there is only a lack of lime, so that chalk, which is cheaper, can be used, instead of the phosphate. Sometimes, especially when mangels are much used, the bones for some unknown reason become brittle, in spite of the addition of lime and phosphoric acid. Those food-stuffs, such as cereal grains and oil cakes, which are rich in lecithine (p. 8) are particularly beneficial for the growth of bone. It is not improbable that a deficiency of lecithine in the food has also something to do with diseases of the bones.

$(\gamma)$ Iron.-Lack of iron compounds in the food causes anæmia, a disease, however, very seldom met with in domestic animals. It has been noticed in sheep and in pregnant animals, but ordinary foods contain more iron than an animal requires. 


\section{(i) The effect of water.}

Water plays a very important part in the animal economy. Its first duty is to facilitate the chewing and swallowing of the food. In the processes of digestion and in the absorption of the soluble substances in the body water is again necessary, for solutions which are too concentrated do not penetrate the walls of the alimentary canal, but rather draw water from them. This causes increased movement of the intestine (peristalsis) and its premature evacuation. Water serves further as a transporter of the nutrients in the blood and lymph vessels and for the excretion of the final products of metabolism. It is connected also with the loss of heat from the body, for by its evaporation, either from the skin or lungs, there is a considerable lowering of the temperature. In this way an excess of heat, which is always the result of high feeding or hard, muscular work, is prevented, for this might otherwise lead to a fatal overheating of the body if a sufficient quantity of water were not there.

A lack of water, it will then be understood, would cause all sorts of disturbances both in the metabolism of the food and in the general condition of the animal. Observations on men and on different animals have shown that when too little water is taken the gastric digestion and the passage 


\section{IOO SCIENTIFIC FEEDING OF ANIMALS}

of the digested substances into the blood and lymph are hindered. The final nitrogenous products of metabolism are also not excreted sufficiently rapidly, and are retained in the body. Where there is a continued lack of water, the blood gradually thickens and the temperature of the body rises. In this condition, which is similar to that of fever, the protein and fat metabolism increases, and continues to exist until by ingestion of water the normal quantity found in the body is again reached. Young, growing animals can easily be injured in their development by even a moderate lack of water, or by irregular watering. If the supply of fluids continues to be insufficient for an animal, then with increasing thirst the desire for solid food decreases, and is usually followed by vomiting and violent purging, the latter symptom often being observed when water is given after long periods of thirst. Complete withdrawal of food is, for the reasons given above, better withstood than is complete withdrawal of water.

There is little fear of animals receiving too much water unless they are given excessive quantities of watery foods, or, through the consumption of salt, are forced to drink too much. In ordinary feeding practice, where animals are allowed to drink as much water as they wish, the quantity relative to the dry matter consumed is fairly constant. It has been found that for I kilo of dry matter in the food 
pigs take $7-8$, cows $4-6$, oxen $4-5$, and horses $2-3$ kilos of water. Naturally the surrounding temperature has a considerable influence on these quantities, for the heat of the body is lowered in hot weather by evaporation of water from the surface of the skin. In cold weather or in cold surroundings the evaporation of water is much reduced.

If the amount of water consumed is continually above that which is necessary, then the tissues become of a soft, flabby nature owing to the storage of fluid in them; animals in this condition are less resistant to injurious influences or disease. Further, when the body is over-supplied with water, the food is not so well utilised owing to the digestive juices being too dilute (see Chap. VI), and it is also found that the metabolism of the food is increased by an excessive supply of water. The water contained in green fodder, roots, tubers, etc., the socalled water of vegetation, is said curiously enough to exercise a favourable influence upon the consumption of protein. It has been observed that the protein of green foods causes more increase of tissue than does the protein of hay, which may have been prepared from the same plants without loss. These differences may perhaps, however, only be due to the fact that mastication of the green food involves less work than for the hay, which would leave more protein for the production of flesh. 


\section{I02 SCIENTIFIC FEEDING OF ANIMALS}

Another factor must also be considered, and it is that green plants lose a certain amount of nitrogenfree substance by respiration when dried in the air ; at the same time there is a change of protein into amides or similar substances whose nutritive value is not that of protein (p. 65). It is very doubtful then if the water of vegetation has any of the effect ascribed to it.

When drinking-water is taken into the body it has to be raised to the temperature of the blood, and that requires more or less heat according to the temperature of the water. Under some conditions food may have to be split up to supply the heat necessary to warm the water, and so there is less available for production. Well-fed animals, ruminants for instance, generally produce more heat than they require; and in this case the introduction of cold water, especially if given in small quantities, as is done where the animal can help itself, occasions no increased food metabolism. Where animals are getting only a maintenance ration, the consumption of cold water may cause an increased use of nutrients for the production of heat. Pigs, which quickly lose heat owing to their thin covering of hair, may have to utilise some of their food material for the production of heat, if they are given a lot of cold, wet food. The custom of giving pigs and cows a portion of the food in warm drinks is quite sound, and drinking-water 
may also be slightly warmed-a temperature of IO- $15^{\circ} \mathrm{C}$. $\left(50-60^{\circ} \mathrm{F}\right.$.) is about right. Cold water and food not only lower the production, but can also cause disturbance of health.

There ought to be little need to mention here that the drinking-water for animals should be almost as carefully chosen as for human beings. 


\section{CHAPTER V}

THE UTILISATION OF FOOD AND ENERGY IN MUSCULAR WORK-LAWS OF PRODUCTION OF ENERGY

(I) The sources of muscular energy.

(a) Protein as a source of muscular energy.

COME of the many investigations which have $S$ been carried out on dogs and men have shown that even during hard work the quantity of protein metabolised was not much in excess of that during rest. In other cases an increase, which was sometimes quite considerable, was observed during work. Sometimes, too, but this was exceptional, the performance of work resulted in an increased metabolism of nitrogen-free substances. In all these investigations the time during which they were carried out was only short, so that the energy which had been stored up whilst the animal was at rest was possibly sufficient to provide for the extra work. The matter was first placed in a clear light when the work was allowed to go on for a longer period, as was done in the following ex- 


\section{UTILISATION OF FOOD AND ENERGY I05}

periment on a horse. The animal received, during the whole time, a food which was very rich in protein ( 7.5 kilos meadow hay and 4 kilos beans), and during the first part of the experiment it had only light work to perform. The average amount of nitrogen found in the urine daily was $198.6 \mathrm{gr}$. for a period of fourteen days. The work was then trebled and represented a hard day's work. During the twenty-four days this part of the experiment lasted the daily excretion of nitrogen rose until it reached $243.3 \mathrm{gr}$., an increase of $44.7 \mathrm{gr}$., which is equal to $280 \mathrm{gr}$. protein or flesh. The live weight of the horse sank in this time from $496 \cdot 8$ to $458 \cdot 0$ kilos, which is a decrease of 38.8 kilos. When, at the conclusion of this period of increased work, a return was made to the original light work, the excretion of nitrogen sank to the original amount. The extra work had therefore caused an increase in the nitrogen excreted.' Where only light work was being performed the food sufficed, but when the former was trebled the food was no longer sufficient, and body tissue (fat and flesh) had to be consumed. As long as there was plenty of fat present this would be drawn upon and furnish energy, but the less the reserve of fat became, so much more would the body protein be called upon to supply energy for the purposes of muscular work. The protein was thus capable of furnishing part of the energy demanded by the animal. 


\section{Io6 SCIENTIFIC FEEDING OF ANIMALS}

(b) The nitrogen-free nutrients (fats and carbohydrates) as a source of muscular energy.

Whenever comparisons were made with animals, of whatever species, it was always found that the performance of work caused a considerable increase in the excretion of carbon dioxide, even where no more protein was split up than when the animal was at rest. This shows at once that the nitrogenfree substances must take part in the production of muscular energy, for the energy which an animal requires for the performance of work can only come from the decomposition of substances in the body. If it is found that during work an animal uses only small amounts of protein but more nitrogenfree substances than when at rest, it is safe to conclude that the energy comes, at least partially, from the extra nitrogen-free substances. Numerous investigations lead to the same conclusion, and a few examples of the results obtained with horses may be quoted here.

I. In the experiment just quoted, where the animal received a ration (hay and beans) rich in proteins, more and more of these were split up, until at the end 280 gr. more per day were decomposed than during light work. When the same animal was given a ration (hay and maize) poor in protein but richer to about three kilos in fats and carbohydrates, the excretion of nitrogen and the body weight remained unaltered whether the 
daily work was light or increased threefold. The food rich in carbohydrates had sufficed for the production of the energy required for the hard work.

II. The same animal was given a ration rather poor in protein and afterwards the same ration to which one kilo of starch was added. Whilst on these rations the animal had to perform hard work, which was gradually decreased until the excretion of nitrogen remained constant and did not decrease. In this way the maximum work which could be performed on the two rations without calling upon body protein was determined. The results showed that by the addition of starch the animal was able to perform considerably more work.

III. A similar experiment was carried out with the addition of linseed oil to the basal ration, and it was found that the food to which oil had been added yielded more energy than food without.

These investigations show that carbohydrates and fats are a source of muscular energy, and also under what conditions the animal draws upon its body protein to obtain energy. This happens only when the total quantity of nutrients in the food, together with the body fat, do not suffice to yield the necessary energy. In such a case the animal is not getting enough food and draws upon its own tissues. Under the usual conditions of feeding the nitrogenfree nutrients (carbohydrates and fats) of the food are the chief sources of energy, the protein only 


\section{I08 SCIENTIFIC FEEDING OF ANIMALS}

undergoing decomposition to the same extent as when the animal is completely at rest.

If the materials in the food do not yield enough energy for the work which the animal is performing, the body fat is drawn upon, and when this reaches a certain minimum the protein has to supply the rest of the energy required.

All those organic substances capable of yielding dynamic energy (p. 57), whether coming from the food or from the body fat or protein, are the source of muscular energy.

(c) Storage of protein in consequence of muscular work.

The food does not alone determine the quantity of work that an animal can perform. The muscular system, which is the apparatus for the performance of work, must also be properly grown. A man whose muscles are feebly developed cannot perform as much work as a robust man would do on the same diet. If, however, a man, still capable of development, is obliged to use his muscles regularly, they become stronger and increase in size with the daily exercise. In consequence of such conditions the performance of work can lead to an increase of flesh, as has been satisfactorily proved in numerous experiments.

Experience has taught that for the proper development of young cattle sufficient exercise, that is the use of the muscles, is necessary. 
(2) The relation between metabolism and muscular work.

It has been shown already (p. 48) that each nutrient brings to the animal a certain quantity of utilisable energy. As a measure of this energy the quantity of heat which remains after deducting that contained in the excreta is taken. It is usual to express this quantity of energy by a certain number of heat units or calories. The metrekilogram (foot-pound in British units) is taken as the standard by which to measure the work of an animal or a machine, and is the quantity of energy necessary to raise one kilo one metre high (or one pound one foot high).

From exact experiments it has been satisfactorily ascertained that the energy of one large calorie (Cal.) in its transformation into kinetic energy can perform 425 metre-kilograms work.

If an animal were able to convert all the available energy contained in the nutrients into muscular work, one kilo starch, which brings $3.76 \mathrm{Cal}$. into the body, would be able to yield energy for, in round figures, I60o mkg. work. From investigations carried out on this branch of the subject it has been found that only one-third of the available energy in the food is obtained in the form of utilisable work. In ten different experiments on a man who performed 


\section{IIO SCIENTIFIC FEEDING OF ANIMALS}

work by mounting stairs, the proportion was from $28 \cdot 1-36 \cdot 6 \%$-an average of $33 \cdot I \%$. In experiments with dogs doing draught work the percentage of energy utilised was 28.8 , and when the dog was ascending and so performing work, it rose to $30 \cdot 7 \%$. In eighteen experiments with a horse, it was found that when turning a capstan at a walk the percentage was $29-38 \%$. As it is known that from a steam engine of the best construction it is only possible to get $15 \%$ of the energy of the steam in the form of utilisable work, it is easy to see how perfectly the animal organism utilises the energy which is brought to it. It must not be forgotten that the work that any animal does in the ordinary sense of the word is not the total energy that is obtained from the nutrients. Another portion is utilised for the performance of the internal work of the body-increased activity of the muscles of the heart, organs of respiration, etc. When the amount of energy used in living muscle which has been cut from the body is determined, it is found that half goes to perform real work, whilst the other half takes the form of heat.

From one gram of pure isolated nutrient ruminants obtain after deduction of all losses the following amounts of energy-from carbohydrates $37 \cdot 6$, from fat 8.57 , and from protein $4.63 \mathrm{Cal}$. As only one-third of this energy is available for muscular work, one grm. of pure carbohydrate will yield 
$533 \mathrm{mkg}$. of work, I grm. of fat I2I $4 \mathrm{mkg}$., and from the same quantity of protein $656 \mathrm{mkg}$. The quantity of food nutrients used differs according to the kind of work and also to the rate at which the work is performed, as well as the gradient. It has been observed that the material, expressed in starch equivalent, consumed by a horse weighing 500 kilograms when going at the rate of 78 metres per minute was 43.3 grms. If the speed was increased to 90 metres per minute the quantity rose to $48 \cdot 2$ grms., whilst at 98 metres it was $52 \cdot 2$ grms. When a comparison was made between the work done at a trot (I95 metres per minute) and at a walk ( 90 metres per minute), it was found that $4 \mathrm{I} \%$ more energy was expended in the former case. If the horse carried a load of 125 kilograms, say a rider of average weight, about $8 \%$ more energy was used when the rate was that of walking, and about 10\% more when the pace was that of a trot (I86 metres per minute) than when no load was carried.

When drawing a load along an almost horizontal surface at a walk $3 \mathrm{I} \cdot 3 \%$ of the energy which the animal obtained from its food was used in the form of work. Similar work performed at the trot caused no appreciable difference. On an inclined surface $\left(8.5^{\circ}\right.$ grade) at a walk the utilisation of the energy fell to $22 \cdot 7 \%$.

If work is carried on to the point of fatigue, the energy necessary for the performance of the work 


\section{II2 SCIENTIFIC FEEDING OF ANIMALS}

increases very considerably. Experiments on men have shown as much as $14-20 \%$ increase. The fact of being accustomed to a certain kind of work has also considerable influence, for according to experiments on a man working a treadmill the metabolism after twenty-two days' practice decreased by $10 \%$, the work remaining the same; whilst after fifty-six days' practice it decreased $25 \%$. 


\section{PART II}

\section{THE FEEDING-STUFFS:}

TIIEIR PROPERTIES, CONSERVATION, PREPARATION, AND APPLICABILITY 



\section{CHAPTER I}

THE NUTRIENT CONTENTS, PALATABLENESS, AND DURABILITY OF THE FEEDING-STUFFS.

NLY those materials can be accounted foodstuffs that contain organic or mineral nutrients in a form which can be utilised and which, within the usual limits of practice, have no injurious action.

Indigestible materials, such as peat, ground leather, powdered coal, sand, earth, etc., or poisonous substances like castor-oil seed meal, poppy seeds, poisonous plants, etc., further such substances as contain injurious bacteria, are not food materials.

Amongst the properties which determine the value of a feeding-stuff the first place is taken by the variety, quality, and action of the digestible nutrients.

A glance at Table I, in the Appendix, will show that great differences exist. Thère is only one way in which information regarding these properties can be obtained, and that is by a chemical and micro- 


\section{II6 SCIENTIFIC FEEDING OF ANIMALS}

scopical examination. The first gives the quantities of crude nutrients, and the second shows in what form the products of the food are present. Both, either together or separately, give information as to the quality, purity, or falsification of the material.

Where it is a question of grain, roots, tubers, hay, or straw, the practical man can often distinguish various gradations in the quality of these, particularly if the conditions of growth and harvest are known. It is much more difficult to estimate the feeding value of foods in the form of meals or cakes, for much impurity may be invisible to the naked eye. Inadmissible impurities and direct falsification are often so frequent that an examination by a qualified person is absolutely necessary. Special care should be taken with foods which are sold under names which are not descriptive of the article, for often they are mixtures of cheap byproducts with very little feeding value. Although a guarantee as to the amount of protein and fat which they contain may be given, this is not sufficient, for there are plenty of materials rich in protein, but it is not digestible. Such substances, owing to their cheapness, are largely used in the manufacture of mixtures of this indefinite nature.

The composition of some waste products used for this purpose is seen from the following- 


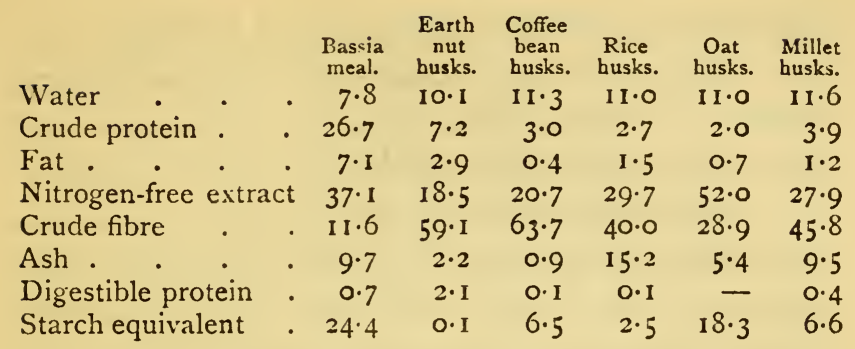

Earth-nut shells and rice husks are seen to be practically worthless, coffee and millet husks lower the feeding value of the other food, whilst the oat husk is no better than straw. Of the $26.7 \%$ crude protein in Bassia meal only $7 \%$ digestible proteins are present.

When the percentage composition of a food has been determined by analysis, then the quantity of digestible nutrients, and from that the amount of digestible protein and the starch equivalent, can be calculated according to the method given in the tables in the Appendix.

With regard to the palatableness of the various food-stuffs and the quantities that can be fed without injury, practice has furnished certain data which will be mentioned when the several foodstuffs are described. The descriptions-it must not be forgotten-apply only to good samples, not to those materials which have been injured by moulds or fungi, etc. Further, there may be admixture with injurious substances or the foods may have 


\section{II8 SCIENTIFIC FEEDING OF ANIMALS}

been harvested after being attacked by blight, rust, etc. Damage may also have occurred during storage. A few of the ways in which foods may have been reduced in value are-

I. Admixture of sand, earth, and ashes causes sometimes no injury, even with relatively large amounts, but cases have been met with where violent digestive disturbances, constipation, and death have been the consequence of feeding with food adulterated with the above substances.

2. The smoke from manufactories, iron works, etc., sometimes carries poisonous metallic substances (arsenic, lead, and zinc compounds) or acid fumes on to the plants. When fodder plants become damaged in this way they can cause slow poisoning and wasting of the animal. Fodder attacked by acid fumes may give rise to disease of the bones.

3. The rust and smut fungi sometimes cause inflammation and disease of the digestive organs, kidneys and bladder, as well as abortion; so feeding with materials attacked by these diseases should be avoided as far as possible. By first steaming the diseased fodder and then making it into a kind of silage, it is possible but not certain that the injurious properties are removed. The potato disease is held to be non-injurious to health, but it causes loss on account of the decomposition which the tubers undergo. 
4. Fodder which has been attacked by moulds or bacteria can also take on poisonous properties and is equally dangerous for all sorts of domestic animals. These moulds, it is well known, are able to make poisons from otherwise innocuous constituents of the food. Under what conditions of temperature and moisture and in which stage of growth this takes place has not yet been investigated. In any case diseases of the digestive organs and disturbances of the nervous system, as well as abortion and death, have been noticed to follow the feeding of damaged food. The instances are sufficiently numerous to warn those who have to feed damaged food to be very careful in the amount given.

Yeasts have a different action to moulds, they are sometimes found in the by-products from breweries and distilleries, and also in moist molasses feeds, and they cause the formation of alcohol. Food containing alcohol can give rise to very grave symptoms in domestic animals, sometimes resulting in injury to the heart. After thorough boiling or steaming such waste products can be fed without danger, whereas in the crude state they cause fermentation in the stomach, accompanied by distension and purging.

5. Frozen fodder is not of itself incapable of use, but when fed in large quantities, particularly if after fasting, a condition of catarrh of the digestive organs can result. The danger of frozen food- 


\section{I20 SCIENTIFIC FEEDING OF ANIMALS}

stuffs is greater after they begin to thaw, for they then readily undergo decomposition. By drying or making into silage or sour fodder (p. I26) it is possible to utilise frozen food.

6. To complete this subject mention may be made of the fact that many weeds have injurious effects. Amongst these are the field poppy, deadly nightshade, corn cockle, and charlock. In some of these plants it is the seeds that are poisonous, and in others the stems, leaves, and seeds.

All food-stuffs, the action of which is doubtful, are best not given to young or pregnant animals or horses.

The durability or keeping properties of the feeding-stuffs depends in a large measure upon the amount of water they contain. Usually the quantity should not exceed $14 \%$ in the ordinary foods of commerce, and even with this amount decomposition can set in if in the storage an insufficient amount of air is admitted to the bulk. Malt coombs, rape cake, also cotton and earth-nut cakes are particularly susceptible in this respect. In the next three chapters further particulars on this subject will be given. 


\section{CHAPTER II}

\section{CONSERVATION OF FEEDING-STUFFS}

\section{(I) The making of hay.}

I F green fodder plants of a not too succulent 1 nature are dried in the air and nothing lost by the breaking off of the stem, leaf, or seed, it is found that the digestibility of the green food and the hay made from it is practically the same. In the case of fresh lucerne $57.8 \%$ of the organic matter was digested, whilst the hay from it, care having been taken to prevent any loss, had a digestibility coefficient of $57 \cdot 2 \%$. Nevertheless, when green plants are dried in the air, even when on a smooth surface and every particle carefully collected, a not unimportant loss takes place. This arises chiefly from the fact that as long as the plants are living they carry on the process of respiration by which proteins are decomposed and the nitrogen-free substances suffer loss. Young grass which had been left to lie for ten days at $10^{\circ} \mathrm{C}$ in the air lost I2\% of dry matter by respiration and mangel leaves lying for six days lost $8 \%$. It is clear that these losses can be considerable when owing to a low temperature or a moist atmosphere, the process of drying is slow. 


\section{I22 SCIENTIFIC FEEDING OF ANIMALS}

Under the practical conditions of hay-making further unavoidable loss occurs in the one instance from the breaking off of parts of the plant and in the other from the washing out of soluble nutrients from the grass by rain. In the most favourable harvest weather 10-20\% of the dry matter is lost during the making of the hay. As the fragments which are broken off are the tenderest and contain the least crude fibre, it is clear that the losses can easily exceed those mentioned. To prevent the very considerable losses which fodder plants undergo in good weather, and still more so when rain falls, there are various methods of making the withered grass loosely into cocks. In some countries the partially dried hay is heaped round a framework, and so a larger surface is exposed to the air and wind, whilst in case of rain the greater part runs off. The drying of hay in such ways is preferable in the case of clovers, lupines, and similar plants whose tender leaves dry more rapidly than do the stems, and on turning are more easily lost than is the case with meadow plants. Experiments with red clover have shown that in bad weather $25.2 \%$ of the dry substance was lost, and in good weather $16.4 \%$ where the ordinary methods of hay-making were used, whereas by drying in pyramid form on a framework the loss was only $9 \cdot I \%$.

From Ioo parts of the crude protein present in the fresh clover the loss was I8.I\% where frames 
were used, whereas the ordinary drying caused a loss of $23.3 \%$ in fairly good weather and $49.7 \%$ in bad weather. New hay usually contains a fairly large quantity of water and sweats for six to eight weeks after being made into the stack. During this time fermentation, the details of which have not yet been worked out, takes place. Before the end of the fermentation newly made hay easily causes disturbances in the health of animals. If it is necessary to feed new hay it should be mixed at first with old hay or straw, and the quantity of new hay gradually increased.

When hay is stored in dry, airy buildings it does not change in composition and digestibility for some considerable length of time. Gradually, however, the hay loses its fresh smell, becomes attacked by hay mites and is then soon brittle and dusty. In such a condition hay is not readily eaten, so it is then advisable to mix it with other coarse fodder. Often, to obviate the necessity of too much drying and so incurring loss by crumbling, $\mathrm{I}-2 \%$ of cattle salt is added to the hay when it is being made. This should be distributed as evenly as possible over the layers of hay, and it may also be used to improve the taste of hay that has been badly harvested and so lost its flavour. The addition of salt also limits the heating of wet hay (p. I24) and so is useful for meadow and clover hay.

In some districts another method of making hay 


\section{SCIENTIFIC FEEDING OF ANIMALS}

is practised, in which the plants are allowed to wither after cutting, and are then made into stacks, or stored in barns. The various modifications which are adopted differ considerably as regards the drying of the grasses, etc. It is preferable to continue the drying until the plants begin to rustle when they are handled, but the leaves should remain tough and not brittle, and the stems green but containing little sap. The hay is then carted to the stack, or left for a day or two in the field in cocks. In making the stack, the hay is put on in layers and trampled down so that no cavities remain, for in them moulds would form. The stacks are afterwards usually covered with a thatch of straw. After some little time, in some cases even twelve hours, fermentation, accompanied by a rise of temperature, sets in. In the interior of the stack, the temperature rises to $100-140^{\circ} \mathrm{F}$, even $202^{\circ} \mathrm{F}$., but it should not be allowed to go above $175^{\circ} \mathrm{F}$. Sometimes the heating of a stack goes so far that there is danger even of it taking fire, but in any case the temperature should not be allowed to rise too high, for otherwise the quality of the hay suffers. The cutting of holes into the stack, or the taking off of some of the hay, are the methods usually adopted to cool down the mass.

The heating of the hay is due to several causes, such as the respiration of the still living parts of the plants, the combination of oxygen enclosed 
in the stack with the organic matter, and above all the activity of different varieties of bacteria, which very soon develop prodigiously. In small stacks, the water is quickly got rid of owing to the high temperature, but in larger stacks it cannot escape so quickly, and so fermentation continues for a longer period. This means a greater loss of material than in a small stack. Experiments have shown that whilst in a small stack the loss of dry matter was $14.2 \%$, in a stack double the size the loss was $30 \%$.

The losses fall principally upon the nitrogen-free extract substances, but the proteins also suffer. The former are completely decomposed, whilst the latter pass partly into non-protein matter and partly into an indigestible form. The higher the temperature rises during the making of the hay, and the darker the colour of it is, the less digestible are the proteins found to be. By means of artificial digestion experiments it was found that of the crude protein in the meadow grass $86.5 \%$ was digestible when the hay made from the grass was light brown in colour, when it was dark brown $75 . \mathrm{I} \%$, when black $2 \cdot 6 \%$ only.

(2) Sour fodder and silage.

For the preparation of sour fodder the leaves and tops of root crops, green maize, potatoes, mangels, 


\section{I26 SCIENTIFIC FEEDING OF ANIMALS}

slices of sugar beet, and less frequently, ordinary grasses and clovers are used. These materials are brought into pits or silos, which are either simply dug out of the earth or made with bricks, cement, etc. In filling the silo, the fodder is put in in layers and well stamped down so as to get rid of air. At the top of the pit or pile, a layer of chaff or chopped straw is put, or else thick roofing paper, and above that a layer of earth two feet thick. The pit is finished off by placing boards closely together on the top and weighting them with large stones. As it is important to prevent the ground water from mixing with the contents of the silo, it is advisable where sour fodder is made regularly to provide pits with impermeable walls rather than simple pits dug out of the earth. To prevent rain water entering the pits it is best to fill them above the surface level, so that when the contents settle down there is no depression. When the pits are walled the walls ought to be continued above the ground. Any cracks or chinks in the roofing must always be carefully closed, to prevent as far as possible the entrance of air. The size of the pits is naturally regulated by the amount of fodder to be made - a width of 6-I4 feet with a depth of 6-Io feet and length according to circumstances.

In countries where maize is the chief fodder the silos are generally above ground, often of considerable height, and are protected against changes of 
temperature by double walls, the space between being left empty.

When green maize is being made into silage it is usual to cut it into pieces an inch or two in length and then fill them into the silo. Potatoes, mangels, beet, etc., are best sliced, and sometimes some chaff or chopped hay is mixed with them to prevent loss of the juice. It is not necessary to add any salt. When filling the silo or pits, the fodder should be given time in which to settle down both in order to fully utilise the space and to allow succulent materials to heat slightly-so that the temperature rises to $104^{\circ}$ or $I I O^{\circ} \mathrm{F}$. In the case of green maize it has been found advisable only to add a layer of $2 \frac{1}{2}-3$ feet daily. Where long intervals elapse during filling, it is necessary to cover up the fodder.

The plants stored in the silo are living, and until they die they respire and this means the loss of nitrogen-free substances and the splitting up of protein. In the silo the various bacteria and yeasts soon become active and acetic, butyric, and lactic acids, as well as marsh gas and alcohol, etc., are formed; at the same time the contents of the silo begin to rise in temperature. Generally, the lactic acid bacteria gain the upper hand and prevent the activity of the other micro-organisms. This is particularly the case where the temperature rises above $120^{\circ} \mathrm{F}$. Acetic and butyric acid bacteria cannot withstand this temperature, whereas the lactic 


\section{I28 SCIENTIFIC FEEDING OF ANIMALS}

acid bacteria can. The object in making silage is to obtain conditions which are favourable to the lactic acid bacteria. The chief fermentation is usually over in six to eight weeks and the silage is then ready for use. When prepared in this way it has a sour smell and taste and resembles in its physical properties cooked food. Care should be taken when feeding silage to take only a day's supply from the silo, for when it is exposed to the air it easily decomposes and becomes dangerous as a food. A special warning may also be given against feeding silage that has undergone decomposition in the silo (p. II9).

Well-made silage is excellent for feeding grown cattle; fattening bullocks may be given up to 50 lbs. per rooo lbs. live weight per day, whilst for milking cows 30-40 lbs. is enough, and for sheep 25-30 lbs. Pigs also readily eat such food, and do well on potatoes, mangels or beet, which have been made into fodder in this way. On the other hand, young or pregnant animals and also horses had better not be given silage. The free acids in the silage have a loosening tendency, and it is advisable to add to each Ioo lbs. of silage about $\frac{1}{4} \mathrm{lb}$. of precipitated chalk.

Unfortunately the losses which food-stuffs undergo on being made into silage are very considerable. Green maize which had been left in the silo twenty weeks when taken out was found to have lost $I 7.5 \%$ 
of the organic matter, $22 \cdot 3 \%$ of crude protein, $4 \mathrm{I} \cdot 7 \%$ of pure protein, $2 \mathrm{I} \cdot \mathrm{I} \%$ of crude fibre, and $I 7.5 \%$ of nitrogen-free extract. Beet tops and leaves which had lain $4 \frac{1}{2}$ months in a pit silo lost $49 \%$ of dry matter, $63 \%$ crude protein, $74 \%$ pure protein, $33 \%$ crude fibre, $43 \%$ nitrogen-free extract, and $67 \%$ mineral substances. In a water-tight silo, where the juices could not drain away, the losses were considerably less, being only I $8 \%$ of dry matter, I6\% of nitrogen-free extract, and $32 \%$ crude fibre. Even here, though, the changes which the protein had undergone were considerable, $66 \%$ of the proteins being changed into non-protein substances. According to other observations, sliced beetroots, after being seven months in a walled silo, lost $22 \%$ of organic matter, in an unwalled silo $35 \%$. Potatoes lost, in six months, I9-36\%, mangels, 32\%, and beet leaves $3 \mathrm{I} \%$. The losses increase with the time of storage; the loss of organic matter from steamed potatoes made into sour fodder, after fifty days, was $13.4 \%$, after seventy-six days I8.3\%, and after one hundred and forty days $22.4 \%$. It must be noted too that the losses fall principally upon the easily digestible portion of the food. An example is given in the case of sainfoin made in one case into hay, and in the other into silage; the digestibility coefficient of the organic matter in the hay was 62 , whilst in the silage it was only 45 . In view of the heavy losses which are associated 


\section{I30 SCIENTIFIC FEEDING OF ANIMALS}

with the making of silage, the practice can only be regarded as a makeshift to be resorted to when no other method is practicable. Where the making of hay is possible it should have the preference over ensilage, and the latter practice be limited to the conservation of beet leaves, beet slices, frozen mangels and potatoes, etc. Most careful consideration is required before using fodders rich in protein, such as clovers, for the preparation of silage, and it would be quite useless to mix bran or other byproducts with the fermenting material.

\section{(3) The storage of cereal grains.}

Cereal grains, if in a well-ripened condition and not attacked by mould, are usually stored without further treatment in dry cool buildings. The grains are either spread out on the floor and the layer turned over from time to time with a shovel, or else they are stored in tall metal holders (elevators). The grains undergo a process of respiration, as do all living substances, taking up oxygen and giving out carbon dioxide, and so using up organic substances. Experiments which have been made with oats have shown that when they were kept in the air they lost in the course of a year, through respiration, $6.5 \%$ of the original carbon present. In closed vessels this loss is smaller, because the oxygen which is in the vessel is soon used up. The 
extent of the losses which grain undergoes when stored depends chiefly upon the moisture it contains and upon the temperature of the place in which it is stored; the moister the grain the greater the loss. On being kept three weeks 50 grams each of oats containing $2 \cdot 52, \mathrm{II} \cdot \mathrm{I} 8, \mathrm{I} 6 \cdot 98, \mathrm{I} 7 \cdot 82 \%$ of water gave out $0.2,3 \cdot I, 24.7,35 \cdot I$ c.c. of carbon dioxide respectively. When stored in elevators moist grain is subject to a further disadvantage, for, in consequence of the rise of temperature, part of the water passes off as steam and condenses on the cooler parts of the elevator, causing moulds to form. It is therefore advisable not to store grain in such holders if the quantity of water it contains exceeds $13-14 \%$. Should the grain contain more than this amount it ought to be dried at a low temperature before being stored.

The temperature also favours the processes of respiration in grains, as is seen from the following experiments with oats. When the temperatures were $12^{\circ}, 24^{\circ}, 27^{\circ}, 37^{\circ}, 46^{\circ} \mathrm{C}$. it was found that in eighteen days the oats produced $7.5,36 \cdot \mathrm{I}, 54.7$, $66.3,92.4$ c.c. of carbon dioxide respectively. Another circumstance is also of importance, and that is the purity of the grains which are to be stored; if they are mixed with dust, earth, broken grains, all of which easily absorb moisture and so become damp and liable to be attacked by moulds, the sound grains are infected. On this account it is 


\section{I32 SCIENTIFIC FEEDING OF ANIMALS}

essential to sift, winnow, and in other ways clean the grain that is to be stored for any length of time. It is not recommended to store for long crushed or ground grains, meals, etc., for materials in that condition undergo a still more rapid formation of carbon dioxide and so lose more weight. They are also very liable to attack by mites, which in a short time increase enormously and finally leave behind very little but their dung and the hard husks of the grain.

(4) The keeping of roots and tubers.

Roots and tubers also undergo the process of respiration, which depends in extent principally upon the temperature of the place in which they are stored. From experiments carried out with potatoes it was found that the formation of carbon dioxide per hour was $10.5 \mathrm{mgms}$. at $20^{\circ} \mathrm{C}$., $4.5 \mathrm{mgms}$. at $10^{\circ} \mathrm{C}$., and $2.5 \mathrm{mgms}$. at $0^{\circ} \mathrm{C}$., whilst again at $20^{\circ} \mathrm{C}$. the quantity of carbon dioxide rose to Io mgms. If these figures are applied on the basis of roo $\mathrm{kg}$. of fresh roots stored for a month the losses of starch would be as follows: at $20^{\circ} 0.43 \mathrm{~kg}$., at $10^{\circ}$ $0.19 \mathrm{~kg}$., and at $0^{\circ} 0.10 \mathrm{~kg}$. In these experiments it was also shown that roo lbs. of sugar beets respire in one month as much organic substance as would equal $0 . \mathrm{II}, 0.29,0.88 \mathrm{kgs}$. cane sugar when the temperatures were $0^{\circ}, 5^{\circ}$, and $10^{\circ} \mathrm{C}$. respectively. 
The losses due to respiration fall chiefly upon the starch, which must previously be converted into sugar. Such a formation of sugar takes place uninterruptedly in the living tubers, but this is not so easy to prove at higher temperature as it is immediately used up in the process of respiration. If, however, respiration is diminished by keeping the potatoes at a low temperature, the sugar is not completely destroyed, a portion remains over. As the change of starch into sugar is not prevented by low temperature, the potatoes under these conditions become sweet owing to the storage of the sugar. The extent of this increase is shown in an experiment where potatoes were kept for a long time at $0^{\circ} \mathrm{C}$., and it was observed that after-

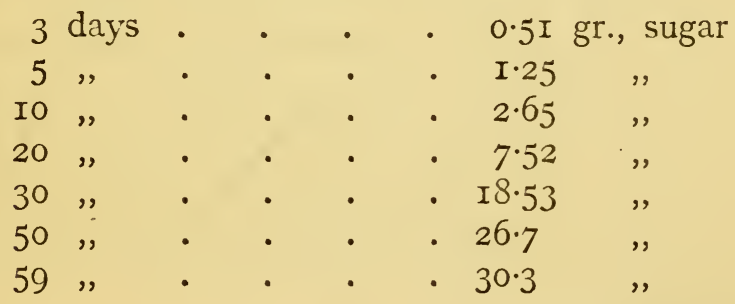

At $3^{\circ} \mathrm{C}$. the increase in sugar was much more gradual, so that after 50 days only $5.79 \mathrm{gr}$. were found. At $8-10^{\circ}$ there was no storage of sugar at all.

If potatoes which have become sweet at a low temperature are brought into a warm place the 


\section{I34 SCIENTIFIC FEEDING OF ANIMALS}

sugar vanishes in a short time-part of it is respired, part of it reconverted into starch and in consequence the tubers lose their sweetness.

Where thirty different varieties of potatoes were tested, $300 \mathrm{~kg}$. of each being stored in a uniform way, it was found that after nearly five months' storage there was an average loss in weight of $8 \%$, which is equivalent to $2.04 \mathrm{~kg}$. on Ioo $\mathrm{kg}$. potatoes.

Similar results were obtained in another experiment where forty-six varieties were kept in a dry cellar and protected from frost, the losses varying from $3 \cdot 8-20.4 \%$, and on an average were $8.1 \%$, to which must be added the loss, $4 \cdot 2 \%$, due to rotten and diseased potatoes.

In general it may be said that potatoes carefully stored lose $\mathrm{I} \cdot 3 \%$ of their weight per month. When the tubers germinate in spring, the losses increase very considerably. If the potatoes are kept until June, then $15-20 \%$ of their weight, it may be assumed, will have vanished. Turnips, on the other hand, have been known to increase in weight in the damp, which must be ascribed to the water which they take up.

In twenty-seven experiments, in which mangels were kept from the middle of October to the middle of March, there was a loss in the dry matter of $8 \%$, which was due principally to the respiration of the carbohydrates. Mangels which contained a lot of water lost $9.5 \%$ of the dry matter and $9.1 \%$ of the 
nitrogen-free extract, whilst mangels which contained less water lost only $5.8 \%$ dry matter and $5.7 \%$ nitrogen-free extract. A very considerable part of the cane sugar in mangels is converted, on storage of the roots, into grape and fruit sugars. All these circumstances are strongly influenced by the temperature of the storage place, and in the same sense as was the case with the potatoes mentioned above. Protection from frost, from temperature above $50-54^{\circ} \mathrm{F}$., from moisture, sufficient mechanical ventilation under certain circumstances, removal of diseased tubers, as well as the excess of earth before clamping, are points to be remembered in storing roots, either in clamps or in cellars.

(5) The artificial drying of feeding-stuffs.

Beet slices, brewers' grains, distillery waste, etc., which are difficult to preserve in their original state are often dried artificially. For this purpose many different forms of apparatus have been designed to effect a rapid desiccation, and the success which they have achieved has led to other materials - potatoes, turnip tops, and even skim milk-being so treated. In many cases, as with sliced beets, sometimes also with brewers' grains and distillery waste, the greater part of the water is first got rid of by pressure or centrifugal force. After this steam or furnace gases are used to thoroughly dry the material. 


\section{I36 SCIENTIFIC FEEDING OF ANIMALS}

The artificial drying of food-stuffs at fairly high temperatures diminishes, as a rule, the digestibility of the protein. Sometimes other constituents of the food are also rendered less digestible, particularly when by use of the furnace gases a partial charring of the substance takes place. It has been shown by comparative experiments, however, that with turnip slices and potatoes the dry material obtained by the use of furnace gases is quite as good as that dried by steam if the temperature is carefully regulated.

Turnip or mangel tops are most difficult to dry successfully, for the tender leaves are very apt to char whilst the fleshy part of the top is still undried. As a result it often happens that the leaves are quite black and the digestibility of them greatly diminished. The average coefficient of digestibility for the crude protein in dried turnip leaves was found to be $40-50 \%$, whilst the digestibility of the fresh material was $74 \%$.

When a high temperature acts upen succulent food-stuffs the proteins are converted into other forms, which resist the digestive juices. The nitrogen-free extract substances are not injured by drying unless the material is actually charred. 


\section{CHAPTER III}

\section{PREPARATION OF THE FEEDING-STUFFS}

I. REEN or coarse fodder from long-stemmed plants is usually chopped to prevent loss by scattering about, to make chewing easier, and by admixture with other foods to secure a thorough mastication. The pieces of chopped material should be of such a length that they have to be chewed before being swallowed. Cattle, as a rule, ought to get chopped straw in pieces of $\mathrm{I}-\mathrm{I} \frac{1}{2}$ inches, horses and sheep $\frac{3}{4}-\mathrm{I}$ inch; green fodder and hay are best cut longer than this. There is no advantage in chopping the materials any shorter than this; on the contrary there is danger of colic if the pieces are too small. Short chaff is not digested any better than long, for in comparative experiments with wheat and barley straw, it was found that even in the form of powder they were not more completely digested by oxen.

Mangels, turnips, and potatoes, which even uncut are readily eaten, are usually sliced in order to mix them more thoroughly with other 


\section{I38 SCIENTIFIC FEEDING OF ANIMALS}

foods and to prevent large pieces sticking in the gullet.

Hard grains of corn easily escape the action of the teeth and so pass unchanged into the dung. Certain species of animals and those with defective teeth should get their corn either crushed or ground. It is often a matter of discussion whether oats should be crushed for horses. Trials in which chopped hay was mixed with the oats showed that when the whole grains were fed $64.6 \%$ of the dry matter of the oat was digested, when crushed oats were given $68.6 \%$, and coarsely ground oats $72.7 \%$. It was found in another series of experiments that by crushing the oats 5-I6 lbs., according to the animal, could be saved on each Iooo lbs. of grain. Sometimes, of course, the cost of crushing will not be repaid by the gain in digestibility. Amongst owners of horses there seems to be a fairly prevalent idea that crushed oats are not so good as whole ones for maintaining the vivacity and staying powers of the animal.

Maize, barley, rye, buckwheat, and leguminous seeds should be coarsely ground for all animals, as these hard grains are difficult to chew, and when eaten whole they swell considerably in the stomach. Horses were found to digest only $82.5 \%$ of the dry matter of whole maize, whereas when the maize was ground they digested $89.5 \%$. In the case of pigs the difference was greater, $74.4 \%$ as against 
$88.4 \%$; these animals, as is well known, swallow their food without chewing it much, and so they usually get corn in the form of meal. The advantages gained by this have been clearly shown by tests in the United States, where one lot of pigs were fed on whole maize and bran gruel, whilst the others got both maize and bran ground up and made into gruel. The animals in each case were allowed as much as they could eat.

The experiments lasted for ten years, during which time eighteen series of experiments with, in all, 280 pigs were carried out. The total food consumed and the total increase of live weight during this time were as follows-

Whole maize . ${ }_{46,736}^{\text {lbs. }} \ldots$ Bran . 22,590 ... Increase . 13,828 Ground $" \quad .50,647 \ldots \quad \ldots \quad .24,189 \ldots \quad \ldots \quad \ldots \quad .15,891$

From these figures it is found that in the whole maize and bran series 50I lbs. of food were necessary to make Ioo lbs. increase of body weight, whilst with the meal only $47 \mathrm{I}$ lbs. were essential, so that $6 \%$ more maize would be needed if the whole grains were fed. Whether it would be profitable to grind the maize would depend upon the price of it and of the pigs, as well as upon the cost of grinding. Pigs that have not been accustomed to feed on whole grain from a young state are easily upset, and may suffer serious digestive troubles if the corn is given unground. 


\section{I40 SCIENTIFIC FEEDING OF ANIMALS}

2. The moistening of food with cold water just before feeding helps to ensure consumption of hard unpalatable materials and allows of the different materials being well mixed. It also prevents the fine particles of meal being blown about, as well as the injury which the dust might cause to the respiratory organs. It has been shown experimentally that simply moistening the food has not the least influence upon its digestibility, but where it is left to soak for some time in cold water the effect is somewhat different. If the amount of water soaked up is so much that the drinkingwater is reduced $25 \%$ of what it would be if the food were taken dry, then a slight depression of protein digestion results. An excessive consumption of water is also for other reasons (p. IOI) to be avoided.

3. The cooking, scalding, or steaming of food has for its object the softening of hard material, and the rendering of the whole more palatable and more easily masticated. When hot water or steam are used injurious moulds or animal parasites are killed, but there is naturally no guarantee that injurious products of decomposition or poisonous substances will be rendered harmless.

Cooked, scalded, or steamed food is usually given warm and so brings a certain amount of heat into the animal body, which, where a meagre ration is being fed, or where the stable is cold, may serve 
a useful purpose. Food treated in this way is not more digestible; rather the opposite, for in experiments with steamed meadow hay and scalded wheat bran the crude protein was less digestible. It was found in fact that whilst $46 \%$ of the crude protein of the hay and $77 \%$ of that in the bran were digestible the amount sank in the steamed hay to $30 \%$, and in the scalded bran to $70-74 \%$. These differences are still more pronounced where superheated steam is allowed to act upon the food. According then to these observations the above methods should never be employed where sound, palatable, and easily digestible food is given. Treatment with hot water or steam may be of service with chaff containing rust spores, diseased plants, mouldy fodder, etc. etc., and may render some parts of the food available. It should not be forgotten either that in this way weed seeds and spores of fungi are killed and so prevented from again finding their way to the field in the dung.

Some food-stuffs like potatoes are more valuable when cooked or steamed, as will be mentioned later, but such treatment yields a tasteless, relaxing diet, which is most suitable for pigs. Fattening cattle and dairy stock may also get cooked food, but young or working animals should only be given small quantities. In any case care must be taken that such food does not cause more water to be brought into the body than is necessary, for exces- 


\section{I42 SCIENTIFIC FEEDING OF ANIMALS}

sive quantities of thin gruel-like foods cause weakness of the digestive organs (p. IOI). Horses and sheep thrive best when the ration is in dry form, but in some cases, e.g. when feeding potatoes, fiozen and damaged roots, diseased straw, musty corn, etc., cooking or steaming may fitly be employed. With cattle it is somewhat different, for they do well on steamed coarse fodder, or on other foods which have been prepared in this way. For pigs, cooked or steamed food is the principal article of diet, and it has been shown that the increase of live weight is then greater than when the same food is given in crushed or ground form. As a rule such preparation of the food is carried somewhat too far, for it should be reserved for those materials which are difficult of digestion in the crude state, or which show unpleasant after-effects. In all cases particular care should be taken that the mangers are scrupulously clean.

4. The roasting of food-stuffs is very seldom done owing to the losses in digestible nutrients, but occasionally where a food has become musty or mouldy, or otherwise attacked by fungi, it may be usefully employed. Roasting also serves to destroy the unpleasant-tasting substances in horse chestnuts and lupine seeds.

5. Feeding-stuffs are sometimes steeped in water in order to get rid of some soluble constituents which are objectionable. Potatoes, for example, are cut 
into thin slices and put into a cask with a double bottom and tap, then covered with cold water which after standing 6-I2 hours is drawn off. In this way the greater part of the acrid substances are got rid of without loss of nutrients. Potatoes contain about $3 \%$ of material soluble in cold water.

Good results are obtained by steeping lupine seeds, which contain a bitter principle with poisonous properties, in cold water, for otherwise only small quantities are eaten by stock. Lupine seeds are very liable to cause distension and affect the milk, either reducing the quantity or giving it a bitter taste, etc.

To get rid of these bitter substances the lupines are soaked for $24-36$ hours in cold or lukewarm water, then boiled for an hour, and finally washed well with cold water, the water being changed every 6-I2 hours. Where convenient the final washing can be done in a stream, the seeds being placed in baskets or sacks. As lupine seeds after treatment are very slippery and difficult to chew, it is advisable to crush them before feeding. This method of preparing lupine seeds would probably prevent lupine sickness, which from time to time is prevalent (see under "Grains").

In the process of steeping the ripe seeds lose I $2-20 \%$ of dry matter, mostly nitrogen-free extract substance, whilst unripe seeds lose up to $30 \%$. 


\section{I44 SCIENTIFIC FEEDING OF ANIMALS}

6. The heating of straw with soda lye under pressure.

This process has for its object the solution of part of the incrusting material, which decreases the digestibility (p. I4). For the treatment of $200 \mathrm{lbs}$. of straw it is advised to take 40 gals. of water and 4-8 lbs. of caustic soda, and heat the whole in a boiler under a pressure of $60-80$ lbs. to square inch for six hours. On cooling, the material can be fed without further treatment to cattle or sheep, both of which eat it readily. When the mixture has been heated for a sufficiently long time under pressure it loses its alkaline properties, for so much acid is formed from the straw that the soda lye is neutralised.

Ammonia has also been tried in place of the soda lye, for it would have the advantage of being recoverable by distillation. The organic matter of oat straw which had been treated by this process with soda lye showed a digestibility coefficient of $56-60 \cdot 5$, whereas in the original straw it was only $42 \%$.

The above process, which is patented, is still only in the experimental stage, so it remains to be seen if it will be possible to use it in actual practice.

7. The heating of fodder with dilute hydrochloric acid and neutralisation of the acid with soda diminishes the digestibility, particularly the protein, and as the process is costly it has no advantages. 


\section{PREPARATION OF FEEDING-STUFFS I45}

8. The malting of grains and the preparation of sweet mashes.

The preparation of green malt for feeding purposes is not to be recommended, for the germination of the grain causes considerable loss of easily digestible nutrients. It has been observed that from roo kilos of barley $2 \cdot 5-3$ kilos of starch were lost during four days' germination, whilst after nine days the loss reached 5-6 kilos. The proteins were also decomposed, and in the first period of germination $20-30 \%$ were changed into non-protein substance. Seeds such as those of the lupine, which have an unpleasant taste, are not improved by germination, so that in cases of this kind no benefit results from "malting." Sometimes a sweet mash is prepared from potatoes with the help of small quantities of malt (0.3-0.5 lb. per Ioo lbs. potatoes), and this when freshly prepared is readily eaten, and with good results. It is very apt, though, to cause scouring when it has stood for some time and become sour.

Such sweet mashes should always be used quickly, for otherwise the spores of yeasts in the air can cause them to undergo alcoholic fermentation and to have an objectionable effect upon the animal (p. II9). Very good results are obtained with calves and young pigs from a swèet mash prepared in the following way according to Liebig's directions. For each calf take $3 \frac{1}{2}$ quarts of milk, $3 \frac{1}{2}$ quarts of 


\section{I46 SCIENTIFIC FEEDING OF ANIMALS}

water, Io oz. of wheat flour, Io oz. of ground malt, and $\frac{1}{4} \mathrm{oz}$. potassium bicarbonate. The method of preparation is as follows. The flour is boiled with the water and half of the milk to form a porridge, and when this is cold the other half of the milk, in which the potassium bicarbonate is dissolved, is added, and the ground malt stirred in. The mixture is then allowed to stand for half an hour in a warm place, then once more boiled and sieved through muslin. Lately saccharified starch has been recommended as an addition to skim milk in the rearing of calves ; further particulars regarding this will be found in the third part of this volume.

9. The predigestion of food by gastric or pancreatic juice has been tried on waste meat and fish products, blood from slaughter houses, milk and waste dairy products. This is an entirely useless process, for the above products require no predigestion, being easily digested by a normal animal, and the process takes place better in the body than outside of it. It is certainly no accident that the proteins as a rule enter the digestive apparatus in an insoluble form. Even where they are in a fluid state, as in milk, they are curdled in the stomach in order to be gradually digested (p. 23). Healthy animals do far better without artificial digestion of their food, and sick ones require professional treatment, not the undiscerning use of any artificial nutrient. 
Io. The preparation of food by fermentation.

Ground cereals, feeding meals, bran, etc. are sometimes made into a dough, then raised by means of a little sour dough, and after twenty-four hours or so are fed. The object of this is to improve the flavour, but there is not, as a matter of fact, any advantage, rather a disadvantage, for the digestibility of the food-stuff is thereby diminished.

An experiment with wheat bran showed that before fermentation $75.5 \%$ of the organic matter was digestible, whilst afterwards only $67 \cdot 3 \%$. Similarly with the crude protein, of which $82.2 \%$ was digestible in the original bran, but afterwards only $79 \cdot$ I $\%$.

Scalding, boiling, or steaming are less troublesome processes and are better suited for the purpose than is the fermentation method.

II. In the preparation of sour food by fermentation, chopped straw or hay, chaff, green fodder, roots, and sometimes distillery waste are used. All these substances are well mixed, the mangels and potatoes having been previously sliced, a little salt added and then enough water or distillers' wash to make a mixture from which the liquid does not drain away when it is squeezed in the hand. The whole is then made into heaps about three feet wide and two feet high, well beaten down and covered with straw, upon which boards and stones are laid. Fermentation soon begins, depending 


\section{I48 SCIENTIFIC FEEDING OF ANIMALS}

upon the temperature of the place in which the heap is made, and after about forty-eight hours the material is ready to be used. The object of such a process is to improve the flavour of food substances, which otherwise would not readily be eaten. As fermentation is always accompanied by loss of nutrients such concentrated foods as oil cakes, ground corn, bran, etc. should not be used. In years when it is necessary to feed a lot of straw, the above-mentioned fermentation process provides a welcome change. The fermented fodder has a pleasant fruit-like smell, and is best suited to grown cattle ; if given to cows it is apt to impart an unpleasant taste to the milk, particularly if it has lain for some time or has not been cleanly prepared.

I2. The manufacture of feeding loaves.

For this purpose the various feeding flours, ground corn, and leguminous seeds, bran, flesh, and fish meals, and blood meal are used. Sometimes also old bread, milk, whey, molasses, potatoes, chaff, chopped hay, etc. The dough made from some such suitable material generally gets an addition of salt, sometimes also a little flavouring, such as aniseed, and after being raised by sour dough, or yeast, is baked. If the materials chosen give a sufficiently light loaf the fermentation may be dispensed with.

As such loaves are apt to become mouldy, it is preferable, if they have to be kept for some time, 


\section{PREPARATION OF FEEDING-STUFFS I49}

to make them into a kind of biscuit. Such preparations are practically never used except in the case of fodder for army horses during a campaign. The loaves are said to be an excellent substitute for oats, but if they are bought and not home-made care must be taken that the materials of which they are made are not merely rubbish. 


\section{CHAPTER IV}

DESCRIPTION OF THE FEEDING-STUFFS

(I) Green fodder and hay.

THESE consist of the parts of plants growing

1 above ground which have not yet completed their growth, and so contain considerable quantities of chlorophyll. Their value depends upon-

(a) The age of the plant, as is seen from the following examples, which give the composition of various plants at different stages of growth.

I. Meadow grass harvested from plots which corresponded to one another on the same meadow on I4 May, 9 and 26 June. The first crop was about equal in food value to green fodder, the second crop, cut at the usual time of hay harvest, corresponded to a meadow hay harvested under favourable conditions. The third crop was overgrown, the stems of the plants being very coarse. The composition of the three varieties of hay reckoned upon the same percentage of water-I $5 \%$ -was as follows- 
$\underset{\%}{\text { I Crop. }} \quad \underset{\%}{\text { Crop. }} \quad 3$ Crop.

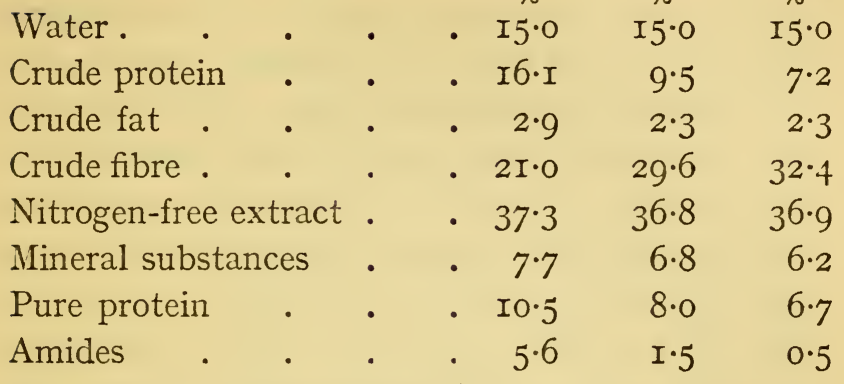

The latter in percentage of

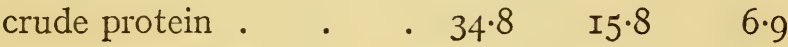

2. Red clover in second year of growth, harvested on 9, I7, and 23 May, Ig and 26 July, and 23 August.

$$
\begin{array}{cccccc}
\begin{array}{c}
\text { T. } \\
\text { nowers }
\end{array} & \begin{array}{c}
\text { Flowers } \\
\text { hardly }
\end{array} & \begin{array}{c}
\text { Flowers } \\
\text { notice- }
\end{array} & \begin{array}{c}
\text { 4. } \\
\text { In }
\end{array} & \text { In full } &
\end{array}
$$

In the fresh plants-

$\begin{array}{llllllll}\text { Water . } & 88.0 & 88.2 & 87 \cdot 1 & 77 \cdot 5 & 77 \cdot 3 & 65.2 \\ \text { Dry matter . } & \text {. } & 12.0 & 11.8 & 12.9 & 22.5 & 22.7 & 34.8\end{array}$

In the dry matter-

\begin{tabular}{|c|c|c|c|c|c|c|c|}
\hline & • & 5 & $5 \cdot 6$ & $5 \cdot 2$ & 5.5 & 4.4 & $5 \cdot 1$ \\
\hline fibre & & 20.9 & $24 \cdot 6$ & $22 \cdot 2$ & $25 \cdot 6$ & $37 \cdot 1$ & $39 \cdot 5$ \\
\hline gen-free & extract & $3 j \cdot 6$ & $33 \cdot 2$ & $3^{8} \cdot 3$ & 38.4 & $32 \cdot 9$ & $3 \mathrm{I} \cdot \mathrm{I}$ \\
\hline ash & . & I I 3 & I $2 \cdot$ I & I I $\cdot 2$ & 9. I & $8 \cdot 3$ & $7 \cdot 3$ \\
\hline ot & . & $17 \cdot 5$ & I $7 \cdot 2$ & 15.5 & 16.0 & 13.6 & \\
\hline & . & I I $\cdot 7$ & $7 \cdot 3$ & $7 \cdot 6$ & $5 \cdot 4$ & $3 \cdot 7$ & \\
\hline
\end{tabular}

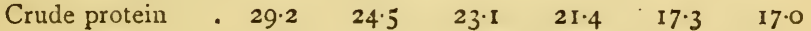

The latter in percen-

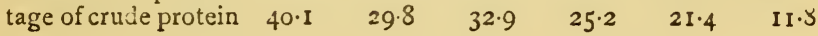

These tables show very well some of the similarities which are found in most fodder plants. The figures for red clover show that the amount of 


\section{I52 SCIENTIFIC FEEDING OF ANIMALS}

water in fresh plants decreases with growth, whilst the dry matter increases, also that the components of the latter alter in certain directions. During the development the amounts of crude protein, proteins and non-proteins, and also the mineral substances regularly decrease, whilst the crude fibre increases. In the early stages of growth the plant takes up a lot of nitrogenous food and converts it gradually into protein, whilst at a later period the production of nitrogen-free substances predominates. The higher the plant grows so much greater are the demands made upon the supporting powers of the stem, and it becomes richer in crude fibre. For this purpose a part of the nitrogen-free extract is converted into crude fibre, and in it from the time of flowering chemical changes take place which result in the formation of incrusting materials, which make the fibre woody. After flowering there is also a movement of nitrogenous and nitrogen-free substances from the green organs of the plants to the seeds and fruits, whereby the percentage composition of the stem and leaves in crude fibre is increased. In the case of root crops the materials formed during the first year in the green parts of the plant pass into the roots, or tubers.

As the degree of lignification stands in a certain relation to the digestibility of fodder plants it is clear that the older plants must contain a smaller quantity of digestible material than do the younger. 
This has been repeatedly shown, and a good example is furnished by the three crops of meadow grass whose composition was given on page I5I. The digestibility trials were with sheep, and the following figures were obtained-

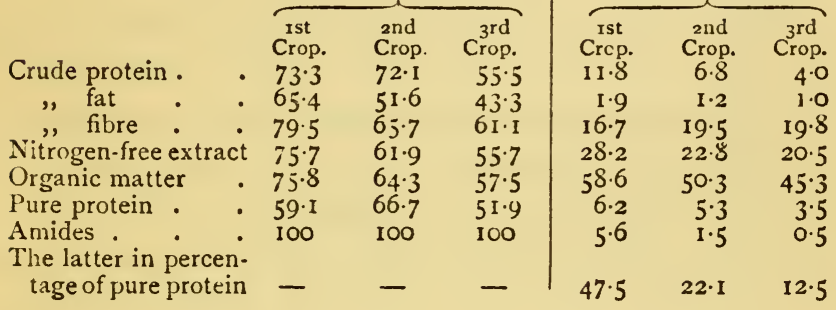

Similar experiments to those with meadow grass have been carried out with red clover. Three portions of a well-grown field of clover were chosen, the first plot cut on 20 May, when the green inflorescences were just visible, the second on 7 June was in full flower, and the third on 20 June when two-thirds of the flower heads had lost their colour. All were well harvested in spite of some rain, and a digestibility trial gave the following figures, which are reckoned on the assumption that the hay in each case contained I6\% water.*

* In these experiments the non-protein nitrogenous substances in the food were not determined, for at that time this group of substances was not thought to be so generally distributed as it is now known to be. 


\section{I54 SCIENTIFIC FEEDING OF ANIMALS}

\begin{tabular}{|c|c|c|c|c|c|c|c|c|c|}
\hline \multirow[b]{2}{*}{ Water. } & \multicolumn{3}{|c|}{ Composition. } & \multicolumn{3}{|c|}{$\begin{array}{l}\text { Digestibility } \\
\text { coefficients. }\end{array}$} & \multicolumn{3}{|c|}{$\begin{array}{l}\text { Percentage quanti- } \\
\text { ties of digestible } \\
\text { nutrients. }\end{array}$} \\
\hline & I6.0 & $\begin{array}{l}\text { Lots. } \\
2 . \\
16 \cdot 0\end{array}$ & 16.0 & I. & $\begin{array}{c}\text { Lots. } \\
2 . \\
\end{array}$ & 3. & I. & $\begin{array}{l}\text { Lots. } \\
2 . \\
\end{array}$ & 3. \\
\hline Crude protein & 16.4 & $13 \cdot 7$ & I I $\cdot$ I & $70 \cdot 9$ & 65.0 & $58 \cdot 8$ & I I 6 & 89 & 6.5 \\
\hline ," fat . & I. 9 & $2 \cdot 4$ & $2 \cdot 4$ & 58.0 & $64 \cdot 4$ & $60 \cdot 2$ & $\mathbf{I} \cdot \mathbf{I}$ & $I \cdot 5$ & I. 4 \\
\hline Nitrogen-free & $2 I \cdot 3$ & $23 \cdot 6$ & $24 \cdot 2$ & $50 \cdot 6$ & $46 \cdot 6$ & $39 \cdot 8$ & $10 \cdot 8$ & II. O & $9 \cdot 6$ \\
\hline extract & $35 \cdot 9$ & $37 \cdot 8$ & $40 \cdot 6$ & $70 \cdot 2$ & $68 \cdot 4$ & $66 \cdot 3$ & $25 \cdot 3$ & 25.9 & $27 \cdot 0$ \\
\hline $\begin{array}{l}\text { Pure ash } \\
\text { Organic }\end{array}$ & $8 \cdot 5$ & $6 \cdot 5$ & $5 \cdot 7$ & - & - & - & - & - & - \\
\hline matter & $75 \cdot 5$ & $77 \cdot 5$ & $78 \cdot 3$ & $64 \cdot 6$ & $6 I \cdot 0$ & $5^{6 \cdot 8}$ & 48.8 & $47 \cdot 3$ & 44.5 \\
\hline
\end{tabular}

With those plants which are cultivated for hay, and where it is desirable to preserve as much of the digestible nutrients as possible, it is seen from these investigations that the best time for harvest is usually during the first half of the flowering period. If the grass is cut earlier, although the percentage amount of digestible material may be higher, the total quantity is still small. A food richer in nutrients but of less value is obtained when the harvest is taken some time after flowering. The balance of profit seems to lie with the early harvest, for then the quality is superior although the quantity suffers.

(b) The nutritive value of the fodder plants depends also to a certain measure upon the variety. Between the various cultivated forms of one and the same species of plant great variations are observed. These manifest themselves in many ways, the chief being the difference in time of growth, the weight of produce and the formation of stem 
and leaves. As the leaves are considerably more nutritious than the stem, those fodder plants which have the most leaf in the same weight of produce are to be preferred.

(c) The distance apart at which the plants are placed is also important, for usually there are stronger stems and fewer leaves where plants grow wide apart. Thin sowing gives then coarser fodder than thick sowing, and the latter is to be preferred, both on that account and because of the greater yield.

(d) Soil and manuring have very great influence on the nutritive value of fodder. This is particularly noticeable in meadows and permanent pastures, where in the struggle for existence only those plants survive which are under conditions where they can obtain their nutrition. The differences in moisture and temperature of the soil, the presence in it of lime or acids, all tend to favour the growth of one or more varieties of the natural flora. The result is that on the one hand clovers, vetches, and sweet grasses may flourish, whilst other conditions bring forward rushes, horse-tails, or plants that grow well on a sour soil. Only radical methods of cultivation, such as draining, irrigation, liming, plentiful manuring with potash or phosphoric acid can effect any alteration ; the sowing of other seeds is quite useless unless the conditions are altered in some of the above ways. As regards the influence of manure 


\section{I56 SCIENTIFIC FEEDING OF ANIMALS}

upon the composition of the fodder plants, it is well known that a plentiful addition of nitrogenous fertilisers, where the supply of nitrogen is otherwise sufficient, tends to improve the growth and to raise the percentage of protein and nitrogenous substances of a non-protein nature in the plant. This is particularly the case with the grasses and with many other plants which do not belong to the order of the Leguminosæ.

Plants of a richer nature, such as oats, barley, rye, and wheat, contain, for example, $16 \cdot 4 \%$ crude protein in the dry matter at the beginning of flowering, as against $10.4 \%$ found in the ordinary grasses. As a rule the crude fibre also increases after plentiful nitrogenous manuring, whereby the nutritive value of the fodder is somewhat reduced; very luxuriant plants are usually more fibrous and less palatable. Practical experience has also shown that the feeding value of such fodder is not particularly high, a good example being afforded in the hay made from irrigation meadows. One very noticeable effect of manuring is seen where manures of a similar nature are repeatedly put upon meadows possessing otherwise good soil conditions. Some particular varieties of plants are in this way stimulated, whilst others disappear. Repeated annual applications of sulphate of ammonia particularly favour the growth of some grasses at the expense of clover, vetches, etc. On the other hand, a 
potash-phosphate manure, without nitrogen, tends very largely to induce the valuable leguminous plants. The causes of this are to be found in the special requirement of the two classes of plants; grasses need nitrogen, whilst the Leguminosæ can get their supply of this element from the atmosphere provided they have sufficient potash and phosphates.

If more mineral substances are at the disposal of the plant than it requires for growth, it nevertheless takes up some of the excess, a circumstance which is of great importance as regards the supply of lime and phosphoric acid to domestic animals.

(e) The weather conditions during growth influence not only the quantity, but also the composition of the fodder plants. In wet years the plants usually contain more water and grow to a greater height. The stem, which is rich in crude fibre, thereby increases at the expense of the more valuable leaves, and a coarse food less palatable and nutritious is the result. A period of drought, on the other hand, causes the plants to be shorter and more compact, with small leaves and stems, which quickly lignify. If the drought is longcontinued the entrance of mineral substances into the roots is prevented, and so the fodder is poor in lime and phosphoric acid, and may give rise to diseases of the bones.

( $f$ ) The fodder plants have a different effect in 


\section{I58 SCIENTIFIC FEEDING OF ANIMALS}

production, according to whether they are fed green or as hay. In the latter case a considerable portion of the nutrients is always lost by respiration, crumbling, fermentation, etc., and there is extra energy required for the work of mastication and digestion (p. 88). It therefore follows that the green fodder has more feeding value than the hay prepared from it; this quite apart from the expense of hay-making. When it is possible to use the food in a green state, it is preferable to do this and not to limit the green feeding unless there are special reasons. Fodder plants can be fed to all domestic animals, but there are limitations depending upon the kind of fodder and the species of the animal. First of all a sudden change to green food should be avoided. Further, owing to the large quantity of water in the green plant, relatively large quantities have to be consumed which is often burdensome to the animal and apt to lead to an ugly distension of the belly. Draught oxen and high-class horses require to be limited in the amount of green food which they get. Caution is also necessary on account of the large quantities of gas which are formed in the stomach when such fodder is being fed, and this is particularly the case when the grass, clover, etc. has been wet by dew or rain, or left so long in a heap that it has begun to heat. In this respect clover is the most dangerous of these green foods and is very apt to cause dis- 
tension. Following upon these general statements a short description of the various green foods and hay may be briefly mentioned here.*

I. Fodder from pastures and meadows.

The value of the food obtained from natural grass lands depends in the first place upon the plants which have become established in any particular soil. Viewed from the practical standpoint these plants may be divided into (a) grasses, (b) clovers, (c) plants belonging to other families.

Amongst the grasses, such examples as rye grass, meadow grass, meadow oat-grass, timothy, meadow foxtail, brome grass, etc. are noted for their palatableness and other valuable properties. In opposition to these are sedge grasses, rushes, sedges, etc., which diminish the feeding value considerably. The clovers and vetches are almost all reckoned amongst the best fodder plants, whilst amongst the herbs are a lot-burnet, thyme, scabiosa, etc.which give a valuable fodder.

A fodder which contains a large quantity of sweet grasses and clovers is more valuable than one composed largely of those grasses which flourish on poor or acid soils. The reason of this is not so much to be sought in the actual differences in chemical

* In the description of the several food-stuffs the author has refrained from giving particulars as to their composition and digestibility. Tables I and II in the Appendix show the differences in composition more clearly than could be done in words. The reader is particularly recommended to look through these from time to time. 


\section{I60 SCIENTIFIC FEEDING OF ANIMALS}

composition, for both types of grass contain about the same amount of nutrient substances. It is rather that in the one case the fodder is palatable, although digestibility trials would perhaps show that the coarser grasses are not so well digested on account of the higher percentage of silica which they contain and which doubtless acts as do the incrusting materials in the crude fibre of hay or straw. Further, it must be noted that the sharp particles of the coarse grasses have an irritant effect, often indeed cause injury to the mucous membrane, and thereby diminish the food metabolism in the animal.

In order to maintain a compact growth of plants in permanent pastures care has to be taken that the development of the stem shall not take place. As animals grazing on the pasture also bite off certain plants very completely, the flora has an entirely different character to that of meadows in the same position. English and Italian rye grasses, timothy, cock's foot, dog's tail, and the different fescues have proved themselves good lasting varieties for permanent pastures, whilst amongst the clovers, the red, and, on dry soil, the yellow varieties are also very successful. As the leaf surface upon which the formation of fresh organic matter depends never reaches the extent in pasture plants that it does in meadow plants, the weight of the harvest from the former is often $30-60 \%$ less than from the 
latter. Pastures, however, yield a very nutritious fodder; it has been found in roo kilos dry matter, from the grass of good pastures, that I0.6 kilos of digestible protein were present, and the starch value of the fodder was equivalent to 60 kilos. These are figures which approach those got from many grains.

Meadow grass at the time when it is usually fed in a green state is generally somewhat more developed, and therefore is poorer in protein and richer in crude fibre and nitrogen-free extract substances than pasture grass.

Meadow hay shows the greatest differences in composition of any natural fodder. On the one hand, where the grass is cut late and the weather is unfavourable, a hay may be got which in nutritive value is below that of good straw. On the other hand, a fertile, low-lying meadow may yield a hay, particularly if the grass is cut early, which equals pasture grass in feeding value.

The best hay is got from sunny, moderately moist mountain and alpine meadows, for there the plants are short and close together and mingled with aromatic herbs. Such hay is distinguished not so much by the large amount of protein it contains, as by its tenderness, aroma, and exceptional palatableness, etc. The hay from damp forest meadows or sour soils has the opposite properties, for it is composed, for the most part, of coarse, tasteless grasses. Irrigation meadows yield a hay 


\section{I62 SCIENTIFIC FEEDING OF ANIMALS}

which, although rich in protein, is coarse stemmed and lacks aroma, so that it usually requires to be mixed with some good hay before animals will take any quantity of it.

Good hay ought to be made from tender, leafy plants, chiefly the sweet grasses and clovers cut at the commencement of flowering, and should possess a pleasant smell and be free from mud and dust.

The hay from the aftermath is also to be reckoned amongst the good varieties, if harvested in favourable weather, but it is usually below good meadow hay as regards palatableness and aroma. Often at the time of harvesting the aftermath cool, rainy weather is prevalent, so that it suffers more than the first crop on account of the large quantities of soluble substances it contains, and which are washed out.

2. Seed grasses, such as rye grass, timothy, cock's foot, along with clover, give according to their age a fodder which is usually less palatable, but as nourishing as meadow hay of the same age. The same applies to cereals such as rye, wheat, oats, or barley, which are sometimes used as fodder.

3. Green maize in comparison with other fodder plants is fairly rich in water and poor in protein, but owing to the large amount of sugar (4-6\%) which it contains, it is readily consumed. As young green maize contains up to $90 \%$ of water and in addition grows quickly, it is advisable not to cut it 


\section{DESCRIPTION OF FEEDING-STUFFS I63}

too soon; the best time is from the beginning to the end of the flowering period.

Sorghum (Kaffir corn), which is allied to maize, has a less coarse straw, and may be cut several times in the season. It is richer in sugar than maize and when quite young it contains, like young linseed, a substance which gives rise to the poisonous prussic acid in the stomach, whereas later the sorghum is non-injurious.

4. The clovers, like all Leguminosæ, are characterised by a high percentage of crude protein, which before flowering can be as much as $30-34 \%$ of the dry matter. Considerably more non-protein nitrogenous material is found in the crude protein than in the grasses (p. I5I). The digestibility of the crude protein and of the nitrogen-free extract substances is in general slightly higher in the clovers than in the grasses, whilst the reverse is the case with the crude fibre.

Red clover, up to the time of flowering, is usually used as a green food. At a later stage when used for the same purpose, it is not nourishing enough to be the sole food of animals and is then generally made into hay. The second crop of red clover is usually richer in crude protein and crude fibre, but somewhat poorer in nitrogen-free extract.

On account of its heating properties red clover should only be fed in limited quantities to horses and sheep, but it is very suitable for grown cattle. 


\section{I64 SCIENTIFIC FEEDING OF ANIMALS}

Pregnant animals and young stock should not get more than half their coarse fodder in the form of clover, which is further credited with causing a yellowish, badly coloured meat, with an inferior flavour when given as green food to pigs.

Lucerne stands in many ways very close to the clovers, both as regards palatableness and the quantities to be used, only it is on an average richer in crude protein. As it tends to get woody even before flowering it is best to cut it at the beginning of that period, which may be done without fear of loss, as several crops can be taken. The after-growth following the first and second crops is, like the red clover, richer in crude protein and crude fibre, but poorer in nitrogen-free extract substances.

Sainfoin is another leguminous crop which in its different periods of growth somewhat resembles red clover; it should be cut early on account of its strong after-growth.

Incarnate clover, an annual variety, gives when cut early a fodder similar to red clover, but it lignifies very quickly from the time of flowering.

Bastard clover, also called Swedish clover, and still more white clover, retain their tender properties for a longer period and can, therefore, be left standing until the end of the flowering period. The same applies to serradella.

5. The kidney vetch contains the lowest amount 
of protein amongst those fodder plants that will be mentioned here. It lignifies slowly, and like serradella is remarkable for growing well on sandy soil. Owing to its astringent taste, it is not readily eaten in the green state by horses. The different varieties of vetches when cut young yield a fodder very rich in protein, but which, however, quickly become woody. The above-mentioned plants can be placed alongside red clover as regards their palatableness and suitability for animals, but they all, with the exception of incarnate clover, sainfoin, and serradella, have a heating action, the vetches particularly.

Lupines are often not cut until their side branches are in flower and the main stem has formed seeds, but sometimes they are cut before flowering in order to get two crops. Fodder from lupines has always a heating effect, and in some years all parts of the plant-seeds, straw, chaff-contain a deadly poison. This is a protein-like substance probably due to the action of some fungus which, favoured by the conditions of weather, emigrates to the plant. As the poisoning is generally fatal, it is very advisable to make a feeding test for a few weeks on some valueless animal (a rabbit), in order to judge if the material is safe to use as food. If the lupine fodder is shown to be poisonous, there is nothing to be done but to steam it for 4-5 hours, at a pressure of $60-80 \mathrm{lbs}$. to the square inch, in order to destroy its poisonous properties. Simple scalding, or the 


\section{I66 SCIENTIFIC FEEDING OF ANIMALS}

conversion into brown or sour hay, is not sufficient to render it harmless. Lupine fodder serves principally for feeding sheep, which take it readily, whilst horses and cattle, to which in any case only small quantities should be given, do not accustom themselves to it very quickly. Where large quantities of lupines are fed the quality of the milk is very apt to suffer.

White mustard after flowering quickly becomes woody, and must on that account not be left later than the flowering period before being fed. Another reason for feeding the plants at that time is that the seeds when eaten form mustard oil in the stomach, which is injurious. In order that this crop may be fed at the right stage of growth it is best to sow portions at different times. It is principally fed in moderate quantities to dairy stock, sheep, and young cattle.

Buckwheat, which is generally cut at the height of the flowering period, should be fed preferably to cattle. In some years the use of it tends to cause sickness, particularly in sheep and pigs.

6. The leaves and tops of the sugar beet and the mangel wurzel give a very watery food, the dry matter of which, however, is rich in protein, low in crude fibre, and contains a large percentage of soluble mineral substances, amongst which oxalic acid ( $3-4 \%$ of the dry matter) is found. This acid may be consumed in small quantities without any 
ill effects, but increased amounts cause symptoms of poisoning and may lead to death. Generally oxalic acid undergoes partial fermentation in the first stomach of the ruminants, but in pigs and horses this preventative arrangement fails. It is, therefore, advisable to give some carbonate of lime (precipitated chalk) along with the beet tops to render the oxalic acid insoluble; a similar addition should also be made when sour fodder or silage are fed. On an average a quarter-pound of chalk may be given to $250 \mathrm{lbs}$. of leaves.

Mangel or beet leaves have, in any form, a loosening effect on the bowels, and should, therefore, be given along with straw or hay. A third of the total ration of a dairy cow might be composed of these leaves, whilst a fattening bullock could be given more. The earth which often adheres in large amounts to the leaves and heads should always be washed off. Generally, the greater part of the mangel leaves are made into sour fodder, but lately machinery has been erected for the purpose of drying this valuable food (p. I35). Up to the present, however, the adhering soil has generally not been sufficiently removed before drying, and that has led in some instances to a partial charring of the material. The dried leaves, when properly prepared, have a feeding value equal to moderately good meadow hay.

The leaves of carrots, kohl-rabi, and turnips do 


\section{I68 SCIENTIFIC FEEDING OF ANIMALS}

'not possess any properties injurious to health, nor does cabbage, which is highly prized for feeding milch cows. The haulms of potatoes should not be used as fodder; they are very indigestible and contain a powerful poison-solanine. In case of necessity they may be made into sour fodder, but they are best not used.

7. Fodder from leaves and twigs. The leaves of the ordinary foliage trees dried in July or August give an inferior fodder about equal to poor meadow hay, but which, in cases of necessity, is worth feeding.

Some leaves, e.g. beech, oak, alder, hazel, contain a lot of tannin, which causes them to have a constipatory effect if eaten in large quantities. The leaves of the poplar, willow, and maple make the best fodder, whilst the needles of the pine and fir act injuriously upon the digestive and urinary organs. The leaves and twigs of the yew contain a deadly poison. Brushwood, cut in winter, has very little value indeed as fodder, the woody fibre being hardly digested at all; the twigs of the acacia and the poplar are usually the best. Sawdust is only very slightly acted upon by the digestive juices, and diminishes the value of the rest of the food (p. 90). 


\section{(2) Chaff and straw.}

During the maturation of a plant the nitrogenous and non-nitrogenous substances are transferred from the green portions of the plant to the seeds, as has already been noticed (p. I52). At this time the stems, haulms, etc. undergo lignification, and after the ripening of the fruit there remains but little protein, fat, and nitrogen-free extract in the straw or chaff, the quantity varying with the completeness of ripening. A good example of this is seen in the following analyses of oat straw at three different periods of ripening-

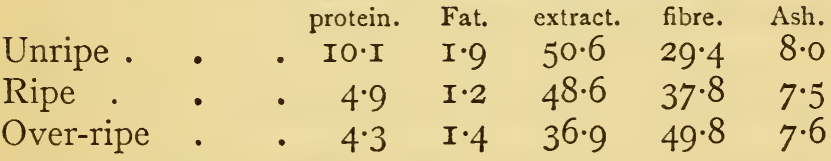

If the passage of substances from the stem and leaves is entirely or partially prevented in any way, as when the plant is laid by hail, rain, wind, or other causes, or by drought, then a more nutritious straw is obtained, as the above figures show. In consequence of such conditions, the protein content of cereal straw, which as a rule is only $2-3 \%$, can rise to $6 \%$ and more. Continued wet weather, on the other hand, causes the formation of a straw poor in protein and rich in crude fibre.

Manuring has also a distinct, although usually 


\section{I70 SCIENTIFIC FEEDING OF ANIMALS}

small, influence upon the composition of the straw, particularly that of the cereals. The nitrogenous manures are the most important, and raise the percentage of protein in the straw. In experiments carried on for six years on barley straw, the average amount of crude protein, when only mineral manures were used, was $2 \cdot 88 \%$, but a manure containing a large quantity of nitrogen with a medium amount of minerals raised it to $3.94 \%$.

In the straw itself the nutrients are unevenly divided, the lower parts of the stem containing more woody tissue and less protein than the upper. Similar differences are also seen between the lower and upper leaves, whilst the ears are richest in protein and poorest in crude fibre.

Those portions of the straw which are nearest to the seeds are the most valuable for feeding, so it is sound practice to allow sheep to pick over the straw intended for litter, for they will eat the nutritious portions, which are almost equal to good meadow hay.

I. The straw of the cereals belongs to those fodders which are very poor in protein and rich in crude fibre. The lignification often goes so far that $80 \%$ of the digestible nutrients in winter wheat straw is required to furnish energy for the work of mastication, digestion, etc. (p. 87), whilst with rye straw there is probably even less available for the animal. The shorter the period of growth, 
the better the straw is, so that spring sown cereals give a more valuable feeding straw than do the autumn sown. Oat, barley, and spring wheat straws are of about equal value, and barley straw is often preferred for feeding milch cattle without any special reason being given. Autumn sown straw, on account of its smaller nutritive value, is generally used for litter, either before or after sheep have picked it over. Straw that has grown and been cut along with other plants-weeds, clover, etc.-has a higher feeding value than straw from well-cleaned fields. After lying for a long time straw, like other coarse fodders, loses its aroma and brightness, becomes crumbly, dusty, and flavourless, and is then best given as chaff mixed with soft food.

2. Straw from leguminous plants is considerably more nutritious than cereal straw, and can equal good meadow hay, or fairly good clover hay, in feeding value. As a rule leguminous. straw is coarse stemmed, less palatable, often attacked by moulds and liable to cause constipation. This is especially the case with the straw from vetches, beans, and peas, which sometimes causes sickness similar to that noticed after feeding with lupines (p. I65). A tenderer and more palatable straw is got from lentils and serradella. Leguminous straw can only be fed as subsidiary food to cattle and sheep; horses do not eat it readily. 


\section{I72 SCIENTIFIC FEEDING OF ANIMALS}

3. Rape, flax, buckwheat and similar plants give a straw that in outward properties resembles coarse leguminous straw, and which is used in the same way. Buckwheat straw can cause the buckwheat sickness (p. I66).

4. Chaff is principally the straw-like husks of the seeds, which often contain a lot of silica along with broken leaves, twigs, imperfect grains, etc. It is usually richer in nutrients than the straw of the same plant, but may contain a lot of rubbish, such as sand, earth, dust, weed seeds, spores of fungi, etc., all of which should be removed as far as possible before feeding. Amongst the varieties of cereal chaff that of oats and non-awned barley is the most valuable, then comes wheat chaff, whilst that of rye is only slightly digestible. Rice and millet chaff are the least valuable and contain a lot of woody fibre, and silica. Chaff from awned cereals is best not fed at all, for the sharp awns bore into the mucous membrane of the digestive apparatus, and may give rise to inflammation. Sometimes, too, a fungus (Actinomyces bovis), which is found on cereal straw, causes the formation of abscesses in the throat and stomach. Scalding and steaming, which kill the fungus, prevent this, for if the awns enter the mucous membrane they do not then introduce the living fungus, which is the cause of the disease.

The chaff of leguminous seeds-peas, vetches, beans, lupines-is about equal in feeding value to 
ordinary red clover hay; the chaff from lentils and clover is more valuable, whilst the husks of peas, beans, and vetches approach ordinary meadow hay in value. Rape, mustard, buckwheat, and linseed give a chaff which is richer in fibre and more indigestible than cereal chaff. The husks of many foreign fruits-earth nuts, coffee beans, etc.-are of no value as food, as is seen on p. II7. Caution must always be exercised in feeding chaff, for there is hardly another feeding-stuff in which so much that is dangerous can collect. The rubbish in the chaff ought to be sifted out, and if weed seeds, spores, etc. are there the chaff ought to be scalded, or steamed.

\section{(3) Roots and tubers.}

Roots and tubers are all characterised by the amount of easily digestible carbohydrates-starch, sugar, pectin substances-which they contain. A considerable portion of the crude protein (30-70\%) is not in the form of proteins, but is present as amides.

The crude fibre is, without exception, very low, as is also the fat. Amongst the mineral substances potash and soda predominate, whilst lime and phosphoric acid are only present in small quantities. On account of the high percentage of water which roots and tubers contain they are liable to cause a weakening of the digestive organs unless some 


\section{I74 SCIENTIFIC FEEDING OF ANIMALS}

other dry matter is given along with them. It is well to restrict the amount of roots or tubers to $\frac{1}{4}-\frac{1}{3}$ of the total dry matter in the ration, and up to this point they have a very beneficial effect on fattening and milch cattle, and in smaller quantities on young stock also. Roots are less suitable for horses which have to work at a rapid pace, for they tend to cause softness and liability to sweat, but slow-working animals may be given moderate quantities. Foals ought only, from time to time, to get a few mangels. Sheep which are fed continuously on such watery food are rather liable to sickness and disease, but pigs do very well on large quantities of roots and tubers.

On account of their cooling and slightly purgative action, mangels, etc., are useful in preventing torpidity of the digestive organs and constipation. As a good deal of soil adheres to roots and tubers, it is advisable to wash them before they are given to the animals.

I. Plants similar to the beet all contain considerable quantities of sugar, the dry matter of the mangel as much as $60 \%$, the carrot and kohlrabi $50 \%$, and turnips 50-60\%. The members of the beet family are also distinguished by containing a large amount of pectin substances which are very digestible, but starch is absent except in the case of the carrot. They also agree in having a high percentage of non-protein nitrogenous sub- 
stance in the crude protein: in the mangel $60 \%$ in round numbers, and in the carrot and kohl-rabi $40 \%$.

It may be noted that under the same conditions all the varieties of the beet agree in that with increase in size of the individual roots the water increases and the dry matter decreases. Variety has also an influence upon the weight of individual roots, as have also the soil, the weather, the distance of plants apart, and the manuring. The further the plants are from one another, the heavier the soil, and the richer the manuring with nitrogenous manures, so much larger do the single roots become, and so much less the percentage of dry matter. With an increase in the proportion of water comes an increase in the quantity of crude protein, particularly of non-proteins, in the dry matter, whilst the percentage of sugar decreases. The stripping off of the leaves of beets or mangels increases the percentage of water and also diminishes the crop.

Mangels are a particularly good food for dairy stock, and can be given to cows in quantities of 40-6o lbs. per head per day. Fattening cattle may have as much as Ioo lbs. per day, whilst young, or working, animals should only get moderate quantities. Pigs, according to their age and weight, may have 4-20 lbs.

If sugar beets are used, then a less quantity should be given on account of the larger amount of 


\section{I76 SCIENTIFIC FEEDING OF ANIMALS}

dry matter which they contain; the daily rations given above may be reduced by about one-half. Carrots are valued for the effect which they have on the general health, and they are said to be a preventative of glanders, intestinal worms, inflammation of the digestive organs, as well as being useful against the heating action of the food when a change is made to winter feeding. Horses should not be given more than $20 \mathrm{lbs}$. of sliced carrots per head per day, dairy cattle up to 60 lbs., fattening bullocks up to $80 \mathrm{lbs}$., and young animals a less proportion. They may form one of the chief articles of diet for pigs, and should be given either cooked or steamed. Kohl-rabi is fed much in the same quantities as carrots, but it is best to restrict the daily ration of the dairy cow to 20-30 lbs., for otherwise the milk and butter acquire the taste of the kohl-rabi. This is not due to the passage of the flavouring material of the food into the milk in the body, but to the action of bacteria which are present on the kohlrabi, and get into the milk during milking.

If the milking is done in a clean place where the animals have not been fed, and if the cows are kept clean, this objection to the otherwise excellent food is removed, and larger quantities may be fed.

Turnips contain the most water of all roots, and should only be used as a subsidiary food for cows, fattening cattle, and pigs. In the case of dairy cows not more than 20-25 lbs. should be given, for 
this food tends to flavour the milk and butter in an objectionable way.

2. Potatoes. Starch is the chief constituent of the dry matter of potatoes, and it is this which forms the bulk of the digested material. Crude protein and fat are only present in small quantities, and $40 \%$ or so of the former is in the form of non-protein nitrogenous substances. A poisonous material "solanine" is a regular constituent of all parts of the potato plant, the tubers containing about - I gram in I kilogram. Although this poison does not increase when the potatoes are stored, or when they decompose, it passes in considerable quantities into the young shoots when the tubers germinate, so that the sprouts may contain as much as 50 grams per kilogram. This means that the young sprouts should not on any account be used in feeding. Increase of the solanine to three times the original amount was also noticed when the potatoes were placed in the light and allowed to go green on one side. Scabby potatoes do not, however, contain more solanine than sound ones, but it has been found that heavy dressings of nitrogenous manures cause the amount of this poison to increase.

The composition of potatoes depends upon the same conditions as it does in the case of mangels, etc. After wet weather, liberal nitrogenous manuring, early harvest, etc. the tubers are watery and poor 


\section{I78 SCIENTIFIC FEEDING OF ANIMALS}

in starch. Large quantities of kainit produce the same effect, whilst $40 \%$ potash salts reduce the dry matter very little or not at all.

There is on all sides a certain dislike to feeding raw potatoes, due to the fact that they possess a peculiar acrid taste and increase the flow of digestive juices in the stomach and intestines. They are also thought by some to cause colic, purging, distension, lameness in young cattle, and abortion in pregnant ones. There is no doubt that when raw potatoes have been fed either for a long time or in large quantities, some of the above-mentioned disturbances have been observed, but if the daily supply is not too large, and some other suitable food is also given, attention being paid to observe any injurious effects, then they may be used. Cattle are the least sensitive to raw potatoes, and a fattening ox may be given 50 lbs. per Iooo lbs. live weight, cows in milk $25 \mathrm{lbs}$. per Iooo lbs. live weight, and dry cows in the last stages up to $40 \mathrm{lbs}$.

The potatoes must be sliced and added gradually to the daily ration, also when they have to be discontinued this should be done by degrees. Along with them some soothing food, such as oil cake (linseed, sesame, cocoa-nut), and a good supply of coarse fodder is necessary. Feeding stuffs which have an irritant effect on the digestive organsrape cake, malt coombs, molasses, silage-should not be fed at the same time. 
Sheep can take raw potatoes almost as well as cattle, and should be given up to $25 \mathrm{lbs}$. per Iooo lbs. live weight; when fattening they may get up to $40 \mathrm{lbs}$.

Horses are more easily affected by raw potatoes, but small quantities, 3-5 lbs. per head per day, have a beneficial effect on the general condition. Slow-working horses can, when under careful supervision, be given up to I2 lbs. per day for each Iooo lbs. live weight.

It is always important to feed only sound, ripe tubers, not those that have sprouted, and to give them and withdraw them gradually. Pregnant animals and young stock generally had better not be given raw potatoes. For pigs, cooked or steamed potatoes are one of the most common foods, but raw potatoes are not suitable for these animals.

Potatoes when boiled or steamed are a tasteless, non-irritant food, but even in this form they can easily upset the digestive organs. The water which drains away from the potatoes after boiling should not be used, and salt should be added to the potatoes to make them more palatable ; cattle can take more of the boiled, or steamed tubers, than the raw ones.

Of the other methods of preparing potatoes for food mention may be made of soaking (p. I43), making into sweet mash (p. I45), or into sour fodder.

Recently various ways of drying potatoes have 


\section{I80 SCIENTIFIC FEEDING OF ANIMALS}

been tried, and a material which keeps well and promises to have a great future has been prepared. The digestibility (see Table II of Appendix) and the effect of the dried potatoes is excellent, whatever the method of drying. Where the potatoes are dried directly by the fire gases, they are first cut into slices, whereas when they are dried by steam they are steamed and then passed between rollers heated by steam, and pressed into thin flakes. When moistened and mixed with chopped hay, or straw, the dried potatoes are readily eaten by horses and cattle. Sheep take them dry, whilst for pigs it is best either to scald them or soak them in water, skim milk, or whey.

3. The tubers of artichokes are closely allied to potatoes in composition, but instead of starch they contain other carbohydrates-lævulin and inulin-and slightly more water. Owing to the restricted quantities in which they are grown they are usually only a supplementary food. Large quantities cause purging and make the milk watery.

\section{(4) Grains and seeds.}

The composition of grains and seeds is influenced chiefly by the condition of ripeness at the time of harvesting. In the stream of materials which flows to the growing seed, it is found that at the beginning there is more nitrogenous and mineral 


\section{DESCRIPTION OF FEEDING-STUFFS I8I}

matter and less nitrogen-free extract than at a later stage. Unripe grains contain, therefore, more crude protein and mineral substances, and less carbohydrate than ripe ones.

Thus it was found that the dry matter in maize varied in composition according to the state of ripeness.

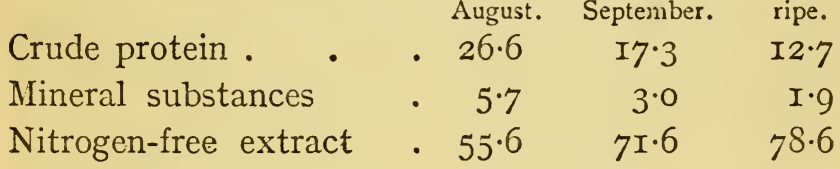

$\begin{array}{ccr}\begin{array}{ccr}20 t h \\ \text { August. }\end{array} & \begin{array}{c}\text { 3rd } \\ \text { September. }\end{array} & \begin{array}{c}\text { When } \\ \text { ripe. }\end{array} \\ 26 \cdot 6 & \text { I7.3 } & \text { I2.7 } \\ 5 \cdot 7 & 3 \cdot 0 & I \cdot 9 \\ 55.6 & 7 \mathrm{I} \cdot 6 & 78 \cdot 6\end{array}$

The amount of protein substance in the crude protein was also subject to variation according to the ripeness of the grain, for in the $26.6 \%$ crude protein on 20 August there were II. $2 \%$ proteins and I $5.4 \%$ non-proteins, whilst the $12.7 \%$ crude protein in the ripe grain contained $10.9 \%$ proteins and only I. $8 \%$ non-proteins.

The nitrogen-free extract is also subject to variation during the formation of the seed. In the dry matter of maize, the grains being still milky, there were found $8 \cdot 6 \%$ cane sugar, $6 \cdot 1 \%$ glucose and lævulose, and only $48.9 \%$ starch. In the ripe grain the sugar had almost disappeared, whilst the starch had risen to $64.3 \%$. Thus it is seen that alongside the movement of substances to the ripening seed there are also chemical changes taking place, both in the nitrogenous and non-nitrogenous ingredients. 


\section{SCIENTIFIC FEEDING OF ANIMALS}

When the normal ripening of the seeds is hindered, or prevented, then they are not only small, but have also the properties of more or less unripe grains. This is clearly seen where the crop is laid by wind, rain, or hail, or where it is attacked by disease. Drought also has the same effect, for it causes too early ripening.

In the dry matter of oat grains grown on the same field it was found that the following differences in composition were obtained-

$\begin{array}{lllllll}\begin{array}{c}\text { Crude } \\ \text { protein. }\end{array} & \text { Protein. } & \text { Amides. } & \text { Fat. } & \begin{array}{c}\text { Nitrogen- } \\ \text { exree }\end{array} & \text { Crude } & \\ \text { frbre. } & \text { Ash. } \\ \text { I3.2 } & \text { I0.7 } & 2.5 & 2.8 & 66.0 & \text { I } 2.5 & 5.5 \\ \text { I0.8 } & \text { I0.0 } & 0.8 & 4.6 & 68.8 & \text { II.8 } & 4.0\end{array}$

Even when no apparent obstacle has hindered the formation of the seeds, it is still found that some are small and others large. When during bad weather the grain sprouts in the fields, the opposite effects to those observed during ripening are found to result. First the materials in the grain are changed-protein into amides, starch and fat into sugar-and these pass into the young shoot and root. At the same time, a portion of the nitrogenfree substance is destroyed by the respiration of the young plant which has sprung from the grain. A loss of $15 \%$ or more of valuable food material can be lost according to the extent to which germination has taken place. As germinated seeds such as malt contain a powerful sugar-forming ferment 


\section{DESCRIPTION OF FEEDING-STUFFS I83}

they can be used for the conversion of starchy material into sugar.

In addition to the changes in composition of the grain due to the time of harvesting, there is the influence of the soil, manuring, etc. Where the crop has been thinly sown the plants are generally stronger, but the lateral shoots do not develop so well, and only small flat grains are obtained. Thin sowing, as a rule, gives grain richer in protein and carbohydrates, and poorer in fat than that from thick sowing. Strong soil and plentiful manuring, with nitrogenous manures, give grains of higher protein content. In the case of barley it was found from tests extending over six years that on unmanured plots the protein was $9.8 \%$, whilst after heavy manuring with nitrate of soda it rose to $12 \cdot 5 \%$.

In another experiment on oats on the unmanured soil, they contained $7 \cdot 7 \%$ crude protein and $3.8 \%$ fat, whilst where nitrate of soda was used, the protein rose to $I 0.5 \%$ and the fat fell to $2.9 \%$. If there is a lack of water, as often happens on a light soil, then the grains are somewhat richer in protein than those grown on heavy soils, which retain water better. The richer the grains are in nitrogen the more do they tend to become " hard," or glutinous.

It has already been seen (p. I30) that when cereal grains are stored changes are found in the amount of nutrients in the grains.

When buying ground cereals care must be taken 


\section{I84 SCIENTIFIC FEEDING OF ANIMALS}

to see that they contain all the parts of the grain, and that there has been no withdrawal of flour, or the addition of foreign material, both of which must be regarded as falsification. Often under the name of ground corn, by-products from the manufacture of flour, groats, barley are sold, and they contain a large amount of the husks or seed coats. Coarsely ground barley, oat and pea meals are often little more than bran. Sometimes waste products from other grains-husks and chaff of all sorts, stone nut meal, precipitated chalk, clay, earth, sand, marble dust, etc.-are added to the meal. Against such adulterations the analysis of samples from each consignment is the only remedy.

With regard to the preparation of grains for feeding, they are usually either coarsely or finely ground, or crushed, or soaked in water, as has been previously described (p. I38 et seq.).

\section{(a) Cereal grains.}

Of these oats are the most used for feeding, particularly to horses, young stock or male breeding animals. As regards palatableness and effect oats are the best of the cereals, and on this account they are used as concentrated food for that most sensitive animal the horse, and they are seldom replaced by any other cereal, at any rate only partially. Oats, on an average, contain I4.I\% 


\section{DESCRIPTION OF FEEDING-STUFFS I85}

crude protein, $7 \cdot 6 \%$ crude fat, $74 \%$ nitrogen-free extract, with only $2 \cdot 2 \%$ crude fibre and $2 \cdot I \%$ ash. The husks of the oat, on the other hand, have only the value of straw (p. II 7 ). The percentage quantity of husk, which varies between 20-35\% and averages $26 \%$ of the whole grain, is therefore an important characteristic in judging the value of the grain.

All the attempts which have been made to discover to what special substance, if any, the excellent properties which oats possess are due, have up to the present been unsuccessful. Horses fed on freshly harvested oats have frequently been found to suffer from colic, purging, etc. and to be very liable to tire and sweat. It should be a rule to let this grain lie for 2-3 months before giving it to horses.

Barley comes next to oats in its properties as an animal food, and in southern countries it is the only concentrated grain food used. In Central and Northern Europe it has not succeeded in displacing oats, for it has been noticed that its effect on the energy and stamina is less valuable than the latter. It is not advisable to replace more than one-third, at most one-half, of the oat ration by barley, and it should be given either crushed or steeped. Barley is more suitable for dairy or fattening cattle, to which it is given, as are other cereals, in a ground state either moistened or not. 


\section{I86 SCIENTIFIC FEEDING OF ANIMALS}

The principal use though is in the feeding of pigs; the pork and bacon from barley-fed swine are of unexcelled quality. Where the pigs are under three months old, oats are, however, preferable. There does not appear to be any marked differences between the various awned barleys and the amount of chaff, which is between 7-I $\%$, average II $\%$, determines in the first place the feeding value.

Rye and wheat, on account of the price, are only used to a slight extent for feeding animals. Sometimes the small misshapen, or sprouted, grains are given. Rye is considered to serve rather for the production of energy than for fattening, but is liable to upset the digestive organs. In a fresh condition it is the most dangerous of all the cereals. It may be given whole, after being cooked, to horses, but not to the extent of more than half their corn ration. Draught oxen get 4-6 lbs. and sheep, at most, $\frac{1}{2} \mathrm{lb}$. per day. Fattening pigs should have the rye ground and then given either dry or scalded, as a supplementary food with potatoes, mangels, etc. Fresh wheat is also dangerous, and on that account is best used for fattening cattle and pigs, to which it is given either ground or crushed.

Maize is a very good food and seldom causes disturbances of health. Horses may have half their corn ration in split, or coarsely ground, maize, without diminishing their efficiency, or causing any other drawbacks. Maize is also admirably suited 
for draught oxen, fattening bullocks and pigs, and can also be given in considerable quantities to dairy stock, if the making of butter is not the main object ; otherwise only smaller amounts must be given, or the butter will be too soft. Pigs which are being fattened may have half the ration composed of maize, particularly in the first half of the fattening period. Where large quantities are given, the bacon tends to become oily and the flesh soft, points which will be considered at a later stage. For foals maize can only be considered a supplementary food, and as it is very hard it ought to be coarsely ground or soaked in water before being fed.

Millet is rather costlier, its nutritive value about that of oats, and on account of the small size of the grains must only be given in a ground form.

Buckwheat (p. I66) is slightly less nutritious than oats, and is most suitable for fattening cattle and pigs, or for draught oxen ; it is less useful for horses, and not at all good for young stock. Owing to the hardness of the grain it must be ground or soaked.

\section{(b) Leguminous seeds.}

These take the first place amongst the grains, because of the amount of protein they contain. Generally the percentage of fat is not more than in cereal grains, but some-soja beans-and lupineshave a considerable quantity. Some of the seeds of 
leguminous plants, such as the gorse and the Java bean(Phaseolus lunatus), are poisonous, and the latter has been the subject of numerous investigations. It has been found that when the crushed seeds are stirred in water, or come in contact with the digestive juices, the very poisonous prussic acid is formed, under the action of an enzyme. This acid can be got in small quantities from some of the vetches; the ordinary fodder vetch also contains a little. The climate and weather seem to have a great influence upon the formation of those substances which yield prussic acid.

All the leguminous seeds, when insufficiently ground or improperly prepared, tend to cause distension and constipation. When given in large quantities they cause thickening of the blood, and in this respect vetches are the worst, then come peas, whilst field beans least of all. On this account caution should be exercised in the use of leguminous seeds, particularly with horses, and they should be reserved principally for hard-working animals of coarse breeds. For them $\frac{1}{5}-\frac{1}{3}$, at most $\frac{1}{2}$, of the corn may be given in this form, but much depends upon the amount of work done. Draught oxen and fattening stock of all species, particularly pigs, are well suited for a diet of leguminous seeds, the meat from the latter animals being then excellent. Vetches are said to react unfavourably upon the taste and quality of the milk, but recent 
investigations have not upheld this view. In the rearing of rapidly growing foals, weak calves, lambs, and young pigs good results are often seen when peas or beans are added to the food.

The leguminous seeds are given, either ground, crushed, or soaked; the seeds of serradella, which are used in the same way, are reported to be a very satisfactory food.

Lupine seeds, of whatever variety, contain substances with a very bitter taste, and these diminish the appetite of animals and also enter into the milk and butter. Sheep eat the seeds in the natural state the most readily of any animals. After the removal of the bitter principle (p. I43), which should always be done, they yield a food which is suitable for all kinds of animals. Horses may be given up to Io lbs., fattening oxen up to I 8 lbs., cows up to $8 \mathrm{lbs}$. of the wet, non-bitter seeds, which are best fed in crushed form, mixed with chopped hay or straw.

\section{(c) Oily seeds.}

These are seldom used as food on account of their high price. An exception is made in the case of linseed, which, when crushed and stirred with hot water, gives a mucilaginous mass with a particularly salutary and soothing effect.

Linseed, or flaxseed, is used principally for feeding calves, or for its sedative action when the digestive 


\section{I90 SCIENTIFIC FEEDING OF ANIMALS}

organs are inflamed. It can also be used for feeding sickly animals, but is often successfully replaced by the cheaper linseed cake. Of the other oily seeds use is sometimes made of those of rape, colza, hemp, sunflower, etc., and the properties of them and of the cake prepared from them will be discussed later. All oily seeds should be crushed before being fed.

Beech mast, which is also fairly rich in oil, contains a poison that is injurious to some animals (horses), and should, therefore, only be given in moderate quantities to grown pigs and fattening cattle.

Acorns and horse chestnuts are most valuable for the fattening of pigs and oxen, but owing to their astringent taste they are not always readily eaten. When given fresh they should be crushed, when dry they may be ground.

(5) By-products from flour mills.

In the manufacture of human food from the seeds of the cereal and leguminous plants, a large number of by-products are obtained, both in the preliminary preparation and in the process of grinding. In the refuse from the cleaning machines there are, in addition to casual impurities, non-fertile and broken grains, small stones, earth, sand, mouse droppings, as well as various weed seeds, rust spores, particles 
of straw and wood, in fact rubbish of all sorts, the greater part of which is quite unfit for food. Although the broken and worthless grains of the sort which is being cleaned and many of the weed seeds can be quite well used as fodder, there are other seeds which cannot. Some of these, such as ergot, corn cockle, charlock, darnel, yellow rattle, cow wheat and rust spores often cause serious injury by poisoning, and in some cases death has been known to result. Such weed seeds are further to be avoided because they pass into the dung, and are brought again to the field, where they later cause more weeds to grow, or else breed fungi to attack the plants again.

After the corn has been cleaned, it is heated, the husks and seed coats removed and the grain ground. Only the bran and feeding meals should come into use as feeding-stuffs, but some millers seem to consider that they have the right to add the ground rubbish obtained in the preliminary cleaning, and in extreme cases even buy rubbish for the purpose of adulteration. A list of the materials which have been ground up with bran or feeding meals with the object of deceiving the buyer would be almost interminable, and it is only necessary to mention such substances as sand, clay, lime-dust, chalk, gypsum, marble, mill sweepings, stone-nut, olive and date kernels, dried potato pulp, maize stems, millet seed husks, 


\section{I92 SCIENTIFIC FEEDING OF ANIMALS}

earth-nut shells, chaff from rice and oats. All the above-mentioned have at times been used, and when carefully ground and mixed with the bran, or meal, deceive the eye of the customer, and give a big profit to the seller. Whoever wishes to escape such fraud and not injure his cattle and fields should always demand pure, unadulterated bran, or feeding meal, and not use anything that has not been tested for purity and absence of adulterants.

It may be noted here that the less perfectly the corn is ground the richer the bran is in flour, and so of higher food value. The brans from wheat and rye are known to the trade under various names, according to the fineness and the way in which the process of milling is carried on.

The feeding meals, which are also sold under various names, are the last portions of flour obtained during milling. Usually from cleaned rye $20-25 \%$ bran and 5-10\% feeding meal are got, whilst from cleaned wheat the total amount of bran is $20 \%$ and $5 \%$ of feeding meal.

The by-products, or refuse, from the grinding of barley or oats are more numerous than those from wheat or rye, owing to the husks, which cause the refuse to differ very considerably, according to the method of husking and grinding. Barley, which is principally made into pearl barley, groats, etc., yields, as by-products, a bran which contains 
only a little flour, and also barley meal, which contains varying amounts of husks. The refuse from barley is one of the most adulterated foodstuffs; more than $50 \%$ of all consignments contain foreign substances, indeed it has happened that barley meal has been made up of $70 \%$ ground oat husks, and $30 \%$ of powdered chalk, and not a trace of barley.

In the preparation of groats and other foods from oats, the husks are separated from the grain and then sold as oat bran, which of course they are not. The further treatment of the oat grain gives oat feeding meal, which consists of the ends of the grain, particles of flour, and the plant hairs. Sometimes, as is preferable, the hairs are separated and they, along with the husks and some meal, are sold as " oat cleanings," or " oat-dust feed." Owing to the varying quantities of husks the valuation of the refuse from barley and oats is very difficult without an exact analysis being made. Amongst the refuse materials from other grains may be noted millet feeding meal, or " millet polish," which is that portion of the grain left after polishing the skinned grain. This material is often sold falsely under the name of ground millet, and it may or may not contain the husks.

Rice meal, or rice polish, obtained from the preparation of cooking rice, ought not to contain large quantities of ground husks, although they are often 


\section{I94 SCIENTIFIC FEEDING OF ANIMALS}

mixed with the meal. The so-called rice bran, like oat bran, is not rightly named, for it consists chiefly of ground husks and some damaged rice. Maize also gives a bran and a feeding meal; the former is sold under the name of Homco or hominy feeding meal.

In the preparation of leguminous seeds for human consumption, various by-products are obtained, according to whether the seed coats are retained or not. As a rule these products are very digestible, and they are sold under various names.

Bran and feeding meals belong to that class of substances which, when fed in quantity for a length of time, have a weakening effect on the digestive organs. They are more suitable for fattening purposes than as food for working animals. On account of the loosening effect of wheat bran, it is used for milch cows, but it tends, as do rice meal and millet meal, to cause the butter to be soft. Rye bran causes the butter to have a coarse, dry flavour, whilst the leguminous seeds and their by-products tend to make the butter hard. For horses bran and feeding meal are only suitable as a supplementary food. In the fattening of swine, feeding meals are largely used, but in some cases the bran from rye, buckwheat, peas, and in a less measure wheat, is also fed.

Rice meal, otherwise very suitable for feeding pigs, tends to give a soft bacon, as do also the waste 
DESCRIPTION OF FEEDING-STUFFS I95

products from millet. For young stock feeding meals are particularly suitable, and are given in the form of warm mashes, gruel, etc.

\section{(6) Residues from oil mills.}

The materials used in the manufacture of oils are, as a rule, first freed from foreign substances by means of sieves or winnowing machines. If the seeds are large they are then husked or shelled and broken up in a crushing or grinding machine. The material so prepared is subjected to great pressure between cloths, whereby the greater part of the oil flows away. Another method of obtaining the oil from the seeds is by extraction with carbon bisulphide, petroleum ether, or benzine, in a suitable apparatus. The residual material, whether pressed or extracted, is ground up again and the pressure or extraction repeated, sometimes also for a third time. When the oil is extracted by pressure, the residues are considerably richer in oil than in the extraction process, where often only $2-3 \%$ is left. The best oil cakes are prepared by the old or pressure method, and these when ground are sold as oil cake meals. The material left after extraction" new process"-is sometimes made into cake, but more generally sold as meal. Linseed-cake meal is therefore different to linseed meal, and generally contains more oil.

The residues from the oil mills, like all feeding- 


\section{I96 SCIENTIFIC FEEDING OF ANIMALS}

stuffs in the form of cakes or meals, are liable to be adulterated, and not only is the rubbish left after cleaning added, but use is also made of those adulterants mentioned under milling refuse. Valuable oil cakes and meals are not infrequently mixed with the cheaper poppy and rape cakes, and even poisonous substances, such as castor bean meal and charlock seeds, are sometimes added. Cakes that have become mouldy or otherwise damaged are occasionally reground, heated, and pressed again into cakes.

Many residues from oil mills, particularly those from palm- and cocoa-nuts, easily become rancid and in this condition cause inflammation of the digestive organs or damage the quality of the milk and butter. Mouldy and rotten oil cakes are a most dangerous food, because, being rich in protein, they undergo decomposition, with the formation of very poisonous substances similar to those found in putrefying flesh. Oil cakes are broken into small pieces before being fed, and they, like oil meals, are given dry, mixed with other food-stuffs, to horses, cattle, sheep, or else slightly moistened and given a short time before the usual feeding time. Undamaged oil cakes and meals do not need to be cooked or scalded for feeding pigs.

Cotton-seed meal is found in many different qualities in commerce, the chief differences being between that made from seeds, the hulls of which 
have been removed (decorticated) and that where the hulls and seeds are all ground together (undecorticated). The seed from which the decorticated cotton cake or meal is made comes principally from the United States and is often freed from impurities, such as stones, pieces of iron, cotton fibre, etc., in the ports where it is imported and then is sold as a purified product. The meal made from unhulled seeds comes from Egypt and India, and possesses a smaller nutritive value on account of the larger amount of hulls (about 50\%).

Good fresh cotton-seed meal ought to have a bright yellow colour, a nutty flavour and a pleasant smell. Milch cattle ought not to get more than 2 lbs. per head per day, horses the same quantity, draught oxen up to $4 \mathrm{lbs}$., fattening cattle $5 \mathrm{lbs}$., whilst fattening sheep may be given $\frac{1}{4}-\frac{1}{2} \mathrm{lb}$. Caution should be exercised in using this feeding-stuff, for it has been known to affect the animals injuriously in some cases. As a rule cotton-seed meal causes severe and sometimes fatal sickness amongst pigs, so they and also young and pregnant animals ought not to get any. It is not the hulls and cotton fibre that cause the injury, as was previously thought, for in the countries where cotton is grown, the hulls are fed in large quantities without any ill results.

Earth-nut cake and earth-nut meal are also sold in various forms. The best product is made from 


\section{IgS SCIENTIFIC FEEDING OF ANIMLAL}

the Rufisque nuts, which have a bright flesh, and on account of the high quality of the oil, the nuts are carefully shelled and the brown skin removed. Then comes the "German" meal made from wellcleaned and skinned nuts, and finally the "Marseilles" variety, which is a less carefully prepared product, and usually contains $2-3 \%$ of sand.

Good earth-nut cake and meal should have a sweet, bean-like taste and a sweet smell ; the colour varies between greyish-white and reddish-brown. In general this is a palatable and satisfactory food, but lately repeated cases of disturbance of the digestive organs, violent colic, and even death by poisoning have been noticed, where inferior material was certainly not the cause. In some cases, but not by any means in all, the cause was proved to be castor-oil meal (p. 204).

Milch and fattening cattle may be given up to 4 lbs. per head per day, horses up to 3 lbs., fattening sheep and pigs from I-I $\frac{1}{2}$ lbs. and young stock smaller quantities in proportion.

Sesane cake is made from various coloured, unhulled seeds of several varieties of the sesame plant. The cakes are an excellent feed, and in digestibility and palatableness they closely resemble linseed cake; like them they have also a sedative action on the digestive organs. Although they tend to cause softness of the butter they are a highly prized food for dairy cattle, and they have 
also been very successful for fattening stock, draught oxen, and horses. Sesame cake is given in quantities similar to earth-nut meal, and owing to the fact that it soon becomes mouldy and rancid, it should be carefully stored.

Cocoa-nut cake and meal are both made from the fleshy portion of the cocoa-nut after the oil has been extracted and have a colour that varies betw:een bright red and brown. They have a nut-like smell and taste, and are readily eaten by all classes of animals. It is preferred to feed them to dairy stock, for they are said to increase the quantity of fat in the milk, and about 4 lbs. per head per day may be given. The butter and the bacon from animals fed on cocoa-nut cake or meal tend to be harder, and in this respect resemble those from palm-nut cake, as will be mentioned directly. In spite of the very farourable effect on other animals cocoa-nut cake, or meal, is generally limited to milch cows on account of the high price.

Palm-nut cake, made from the husked fruit of a species of palm by pressure, is a greyish-white substance interspersed with dark particles which are the remains of the husk. This cake has not a rery pronounced flavour, and is usually fed in the dry state, for if moistened with water stock do not eat it readily. The same applies to palm-nut meal, which contains less fat, as it has been subjected to extraction. These by-products from the palm-nut 
are used in the first place for feeding dairy cattle, and, like the cocoa-nut cake, they are said to innprove the fat contents of the milk, but to cause the butter to be hard. The corresponding effect is seen in the bacon of pigs fed on this material.

Cows are given up to $5 \mathrm{lbs}$. palm-nut cake per head per day, but other animals only get it when the price is low. Both the cake and the meal easily become rancid on keeping.

Linseed cake. The residues from linseed, in the form of cake or meal, have a favourable action on the digestive organs. When treated with hot water they ought to form a mildly acting mucilaginous food. Before the oil is extracted, the crushed seeds are sometimes heated with steam, which causes the mucilaginous part of the seeds to swell, and then dried again. This gives a material that does not swell up again when heated with warm water. The linseed by-products are used in the same way as linseed itself, particularly as dietetic substances for animals reduced in flesh, and for young stock at the time of weaning. They are further used to counteract the irritating properties which some foods have upon the alimentary canal, and for this purpose they are often given in the form of warm gruel. Pigs fattened largely upon linseed preparations yield an oily bacon and soft, tasteless flesh; linseed cakes cause this more than do the extracted meals. 
Rape and colza cakes and the meals made from them have the peculiarity of yielding a pungent, volatile oil-mustard oil-when moistened with water. This may cause many unpleasant symptoms and diseases of the digestive and urinary organs, abortion in cows, loss of flesh, are said to be the results when much of this food is given. The milk from cows fed on rape cake is also said to have an unpleasant taste, and to have an effect on the health of infants, or calves, to which it is given. European rape and colza seeds and their by-products are thought to be preferable to some foreign varieties, cakes made from Indian seed having frequently been proved to be injurious to the health of animals. Although these properties of the different kinds of rape seed require further investigation, it is only right that the origin of the seeds in "rape cake" should be given in each case, particularly as the Indian seed is cheaper than the European.

On account of the smell of mustard, which rape cake gives when moistened, it should always be fed dry, otherwise it may not be eaten. Milch cows should not get more than 2 lbs., fattening and draught oxen up to $4 \mathrm{lbs}$., and sheep less than $\frac{1}{2} \mathrm{lb}$. Rape cake is not suitable for young stock on account of the obstinate scouring which, it sometimes causes. Pigs ought only to get $\frac{1}{2} \mathrm{lb}$. per day, otherwise the bacon is apt to be oily. A material called "rape 


\section{SCIENTIFIC FEEDING OF ANIMALS}

cake meal," consisting of ground weed seeds (charlock, polygonum, corn cockle, etc.), is sometimes offered for sale.

Sunflower-seed cake and the meal made from it are usually prepared from seeds that have been imperfectly skinned and cleaned, and so seed coats and earth are common. Sunflower-seed cake is very useful for cows, and is said to influence the amount of fat in the milk favourably; it is also of considerable value in fattening bullocks and sheep, and it is said to improve the "tallowy" flavour of fat meat. The bacon of pigs is not affected by it, at least not favourably.

Sunflower-seed cake possesses an extraordinary hardness, and is difficult to break into suitable pieces. It has the advantage though of keeping for a long time without going mouldy.

Poppy-seed cake. After the feeding of animals with this by-product they have been observed to be remarkably slow and sleepy, and this has been attributed to a small quantity of opium. Good ripe poppy seeds do not contain any of this poison, or at least only traces, but in the unripe seeds and the capsules small quantities are found. For this reason it is not advisable to feed this otherwise palatable cake to young stock, neither to pregnant or suckling animals. Horses also are better without it, and its use should be restricted to fattening stock-bullocks or sheep. This food is also said 


\section{DESCRIPTION OF FEEDING-STUFFS 203}

to diminish the amount of fat in the milk, and also to affect, adversely, the taste, colour, and ease with which the cream is separated. In any case $2 \mathrm{lbs}$. per head per day is quite enough for cows. Poppyseed cake is not very durable.

Hemp cake. The waste products from the hemp which come into commerce as cake or meals are often badly adulterated with leaves, stems, sand, and earth. The extraction of the oil has also to take place at a high temperature, so the cakes are often burnt, and on account of the moisture which they take up tend to become mouldy. Hemp cake, like poppy cake, is credited with containing poisonous substances, so that it is advisable to restrict the use of it to grown male animals. Good undamaged hemp cake is a suitable food for working horses, which may be given 3 lbs. per day, fattening cattle can stand $5 \mathrm{lbs}$, and fattening sheep up to I lb.; cows also ought not to get more than I lb. per head per day.

The following residues from oil works occasionally come into the market, but generally only in small quantities.

Beech-nut cake, the properties of which closely resemble those of the unpressed beech mast (p. I90).

The seeds of False flax (Camelina sativa) ar: sometimes made into cake, which has an acrid, unpalatable taste, resembling onions and mustard. It flavours the milk, butter, and even the flesh unpleasantly, and is said to cause abortion. 
Castor-oil seed cake, which can only be used after being heated, for otherwise a poisonous albuminoid material which it contains can cause death; it is always dangerous.

Almond cake, a very prized and palatable food for dairy stock and for other animals. Amongst the rarer foods are the residues of the caraway, aniseed, coriander, and fennel seeds, which are left after the oils have been separated by distillation. As in the manufacture the seeds are not pressed, or extracted with any fat solvent, the oil originally present in the seeds finds its way almost entirely into the residues, which are very good for feeding to cows and fattening animals.

(7) Residues from the manufacture of starch.

The waste products from starch factories which can be used for food vary according to the crude material employed. The chief substances from which starch is got are potatoes, wheat, rice, and maize.

When the starch has been washed out of the macerated potatoes there remains the pulp or fibre, which is a very watery material liable to acid fermentation and putrefaction, and can be utilised either in the moist or dry state. The fresh pulp is a watery tasteless food which may be given to fattening bullocks or pigs, also to dairy stock, but is not suitable for horses or sheep. 
Fattening animals may be given up to 65 , cows up to 50 , and pigs up to $20 \mathrm{lbs}$., whilst less of the dry pressed pulp, which often contains slaked lime, is naturally required. This food is given in a boiled state to pigs, other animals get it raw, but slightly warmed. The dry ground pulp, which contains lime, is given in quantities of $6-8 \mathrm{lbs}$. to horses and fattening stock, and 5 lbs. to cows without any drawback; young animals ought only to have it as accessory food. The juice from the potatoes, which only contains $0 \cdot 2-0.6 \%$ of dry matter, quickly goes bad, and is not worth feeding.

In the old-fashioned fermentation process for the manufacture of starch from wheat, the starch was freed from the husks, germs, and gluten, and afterwards was purified by means of centrifuges or settling. According to the newer methods the flour alone is used, not the whole grain, and the starch is separated by means of sieves, leaving as by-product a very pure, sweet gluten. The waste products mentioned contain a lot of water, and soon undergo decomposition. In the fresh state they are fed to oxen, cows, and pigs, but the gluten is the only material to be dried as a rule, and it is too dear for cattle food, just as maize and rice gluten are.

Rice which is to be used for making starch is soaked in dilute caustic soda, which dissolves to a 


\section{SCIENTIFIC FEEDING OF ANIMALS}

large extent the protein substances. The undissolved portion, after being washed almost free from starch, consists principally of husks, germs, and starch, and is called rice slump, which can be fed either fresh, pressed, or dried, like the wheat slump. The dissolved protein is precipitated by hydrochloric acid, or by a stream of carbon-dioxide gas, and is then sometimes dried and ground; it is the rice gluten.

Various by-products from the manufacture of starch from maize are used as cattle foods. The grains of maize are usually soaked in water containing a little sulphur dioxide, and then, by means of machinery, the outer horny parts and germs are separated from the flour, and all is then stirred up with water. The germs which collect on the surface are used for the preparation of oil, and after pressing give maize-germ cake. From the sediment the starch is separated by means of sieves, and the husks, mixed with the gluten from the further purification of the starch, are dried and give gluten feed, as it is generally called. All these by-products are used in the same way as maize itself, only in smaller quantities, and they have given good results. The germ cake or meal is a very palatable food, and only affects the bacon or flesh of pigs if large quantities are given. 


\section{DESCRIPTION OF FEEDING-STUFFS 207}

(8) By-products from the manufacture of sugar.

In the preparation of sugar from beets two important foods, beet slices and molasses, are obtained.

The beet slices, or diffusion slices, as they are sometimes called, are the material which is left after the extraction of the sugar by soaking the sliced beets in water. They contain only a small amount of sugar, and can be fed either pressed or unpressed in the fresh state, or else made into sour fodder or dried. According to the recent method of Steffen, the limited extraction of the beets yields a product called sugar slices, which in the wet state still contains $9 \%$ of sugar, and is generally dried before being used as food. In the drying of both sorts of slices furnace gases are chiefly used, although during the past few years steam has been introduced for the purpose. There is no difference in the feeding value of the products dried by either method, but the slices dried by steam have a better appearance, and are in smaller pieces. Further, they are never charred, and they swell considerably in water.

Beet slices, either fresh or made into sour fodder, have given very good results with fattening bullocks and dairy stock; the quantities fed are 6o-8o lbs. per 1000 lbs. live weight for the former class of 
stock, and for the latter not more than half these quantities. There is a danger in feeding large amounts of this material to cows, unless concentrated food rich in protein and fat is given, that a hard white butter of bad flavour will result. Horses which are either not working, or only to a slight extent, may occasionally be given small quantities of the slices. Pregnant animals and young stock ought only to receive moderate quantities of the fresh slices.

Serious cases of illness have been noticed where animals have been fed with the beet slices that have undergone decomposition, but dried slices very seldom cause any disturbance. Fattening stock may be given I0-I5 lbs. of the latter, cows 6-Io lbs., draught oxen IO-I4 lbs., calves according to their age $\mathrm{I}-5 \mathrm{lbs}$., pigs $\mathrm{I} \frac{1}{2}-4 \mathrm{lbs}$. It is advisable to soak the beet slices either in hot water, dilute molasses, skim milk or whey, before giving them to pigs.

The sugar slices (see above) may be fed in the following amounts to stock: cows $6-8$ lbs., bullocks 5. O-I2 lbs., draught oxen 8-Io lbs., horses 4-6 lbs., and fattening pigs $3-4 \mathrm{lbs}$. It is to be remembered that the material is poor in bone-forming mineral substances.

Molasses. This is the residual product left from the manufacture of sugar from beet juice. The chief component is cane sugar or saccharose, which 
forms $63-71 \%$ of the dry matter, and in liquid molasses is about $48 \%$. There is only about $0.5 \%$ of protein in the nitrogenous substances of molasses, the rest being amides, which, according to investigations, have no feeding value. The ash of molasses is very rich in potash, almost entirely free from phosphoric acid, and contains only a little lime.

In general the method of manufacture and purification of ordinary molasses has very little influence on its composition. Where the molasses is specially treated to obtain as much sugar as possible, it is found that the final product has dry matter to the extent of $72-80 \%$, of which $\mathrm{I} 2-\mathrm{I} 7 \%$ is the rather rare sugar raffinose, which is found to the extent of only $2-4 \%$ in ordinary molasses. The value of molasses is almost entirely in proportion to the amount of carbohydrates it contains. Beet molasses is a thick dark brown liquid, with a characteristic smell, and contains a varying quantity of water $\left(\mathrm{I}_{5} \cdot 5-32 \%\right)$. The percentage of water determines largely the keeping properties of the molasses, for dilute molasses somewhat readily becomes sour, and is then worthless. Before using molasses it should be mixed with warm water, and then poured over the dry food, and well mixed with it. Scouring sometimes follows the use of molasses, and this is generally ascribed to the salts which it contains, but it is more likely due to the sugar being given in a dissolved form 


\section{IO SCIENTIFIC FEEDING OF ANIMALS}

(p. I45). By gradually introducing molasses into a ration it is possible to avoid this, and as molasses is such a very valuable material in preventing colic in horses, or diminishing the severity of an attack, it should never be forgotten by those who keep these animals. Moderate quantities only of molasses should be fed; per Iooo lbs. live weight horses may get 3 lbs., cows $2 \frac{1}{2}$ lbs., draught oxen 3-4 lbs., fattening bullocks and sheep 4 lbs., and fattening pigs $5 \mathrm{lbs}$. Animals in an advanced stage of pregnancy are said to show a tendency to abortion when molasses is fed.

The difficulty of handling such a material as molasses has led to the commercial making of mixtures with it and some dry food. At the commencement the manufacture was limited to beet pulp, and this gave with the molasses an excellent and durable food, but now other materials have been employed. The feeding value of these mixtures is most easily determined where there is only one other food besides the molasses, e.g. dried grains, palm-nut meal, cocoa-nut meal, wheat bran, etc. In such mixtures as these the amount of molasses varies from $50-70 \%$. The palm-nut and cocoa-nut meals which are used in this process have been usually extracted with some solvent, and are not simply ground cake meal, for the latter do not soak up the molasses so well, on account of the oil which they contain. A molasses feed made with 
straw has given good results, and can be prepared by the feeder himself, whilst molasses bread made with bran, coarse flour, or feeding meal and molasses, and then baked, has also been successful. The cheapest and most desirable way of using molasses still remains to dilute it with hot water, and mix it with the food before feeding.

Unfortunately, the manufacture of molasses feeds did not stop with those substances named, but a whole host of the most varied waste products, digestible and indigestible, mouldy or unsaleable, have been employed as a basis. Thus there reappear in these foods all those adulterants which have been mentioned under brans and oil cakes, and in addition such rubbish as leather, which, although it raises the percentage of protein,.. is quite indigestible.

Peat is also a worthless substance which no animal will touch unless it is sweetened with molasses, but when made into peat molasses it is eaten just as other mixtures of rubbish and molasses are. The buyer of molasses feeds should reject those preparations which are sold under a proprietary name, or are known to contain worthless materials, and buy only those which have some good food material as the basis. Indefinite names ought to be a sufficient warning that if the true description were given there would probably be little chance of a sale being effected. 


\section{I2 SCIENTIFIC FEEDING OF ANIMALS}

Even when two known materials are used for soaking up the molasses it is a disadvantage, for it is then very difficult to determine the proportion of these two, and it is almost certain that the cheaper will predominate. It is only possible to guard the buyer of molasses feeds from fraud when the relation between the molasses and the other substance can be determined by a chemical analysis. Molasses feeds should be bought with a guarantee for the amount of molasses, water, protein, and fat which they contain, as well as information as to the dry material used. The amount of water is of great importance; more than $20 \%$ in ordinary mixtures, and $25 \%$ in peat molasses is excessive, for on storing such mixtures they are very liable to ferment, whereby the greater part of the sugar can be destroyed. It is often claimed in advertisements that the mixture of molasses with some other material produces results when used as a food quite superior to the two substances when separate, but this is not true, for the components have exactly the same effect, whether they are fed singly or mixed.

The residues from sugar factories, which consist of impure sugar, have been repeatedly tested experimentally for feeding purposes. This feeding sugar is generally mixed with coal dust, bran, oil-cake meal, or some other material (to prevent it being stolen for human consumption), and may 
be given to horses, if gradually introduced into the ration, in quantities of $5^{-6} \mathrm{lbs}$. per $1000 \mathrm{lbs}$. live weight per day, without impairing the efficiency of the animal. Feeding sugar is not suitable for ruminants, owing to its less powerful effect as a food, and it is still doubtful, in spite of many investigations, whether it is useful for pigs. Whether the preparation of sugar for feeding purposes is profitable, or whether it would not be better to leave the sugar in the beets and use these, has not yet been satisfactorily decided.

\section{(9) Residues from fermentation processes.}

Amongst the residues from the breweries and distilleries are found several substances, such as malt culms, brewers' grains, and various distillers' and brewers' wastes, which are sometimes called slumps. Malt culms or coombs ought to have a bright colour, for if they have been dried too much they are less digestible. Damp, mouldy material is often dried a second time, and then becomes dusty, and has a darker colour, and this is sometimes bleached with sulphur dioxide, which serves also to get rid of the musty smell.

Malt coombs are particularly rich in non-protein nitrogenous substances $(6-8 \%)$, and also contain a fair amount of sugar (12-13\%). They are particularly prized as food for milking cows, which 


\section{I4 SCIENTIFIC FEEDING OF ANIMALS}

may be given up to $6 \mathrm{lbs}$. per head per day, either moistened or scalded.

In the same manner and quantities they are given to draught oxen and fattening bullocks, whilst working horses may be given 6 lbs., and sheep up to $\frac{1}{2} \mathrm{lb}$., of the dried coombs. Fattening pigs can take up to $2 \mathrm{lbs}$., foals according to their age $\frac{1}{2}-2 \mathrm{lbs}$. dry, and calves up to $4 \mathrm{lbs}$. scalded. Animals that are pregnant or suckling should only have small amounts, for the malt coombs are said to cause abortion and, in the case of the calves, scouring; young pigs have also been upset by this food. It is possible that a slightly poisonous substance, "Hordenin," which has been recently discovered in the coombs, may cause these disturbances of health.

Brewers' grains are the waste products left after the mashing of barley or some similar starchy material, such as maize, rice, potatoes, etc. They can be fed either fresh or dried, and amongst the latter the lighter, less strongly heated, and therefore more digestible samples are to be preferred. Good dried brewers' grains ought to be free from particles of carbon, and they shoild have a pleasant smell, resembling fresh bread. When they are stirred with warm water they ought not to have a sour or musty smell. When fresh, even when still warm, brewers' grains are a very palatable and useful food, but they easily become sour and 
mouldy, and are then injurious. Milking cows may be given $20-40 \mathrm{lbs}$. per head per day. Fattening bullocks and pigs can take up to 25 lbs. per rooo lbs. live weight; but for horses and sheep they are only to be regarded as a supplementary food, because of the large amount of water they hold.

When the grains are dried horses may be given half of their corn ration in this form, the quantity to be fed to cows and fattening bullocks is not more than 6 lbs., fattening sheep up to I lb. per day; pigs are not able to satisfactorily digest dried grains. The grains from distilleries are very similar in method of preparation and use.

Distillery waste, sometimes called distillery slump, is quite different from brewery or distillery grains. When the mashed grain has fermented, and the liquid not been drawn off, there is left, after the distillation of the alcohol, a material which contains everything but the fermented carbohydrate. During the fermentation the yeast, which is rich in nitrogenous matter, increases, and at the same time certain amides are formed into protein, so that distillery waste contains more of this than did the crude material. In unfermented mash made from potatoes there was found in one case only $55 \%$ crude protein, whilst the material left after distillation of the alcohol contained $72 \%$.

As the protein of the yeast is digestible the slump becomes more valuable by its presence, but as the 


\section{6 SCIENTIFIC FEEDING OF ANIMALS}

raw material used in the distilleries differs so much it is only to be expected that the nutritive value of the by-products will also vary considerably. The best distillery waste is got where cereal grains are used in the manufacture of the alcohol, then comes that from potatoes, and lastly that from molasses, which, owing to the large amount of salts which it contains, is hardly fit for food. Of whatever origin the distillery waste may be, it is very advisable to feed it in a fresh warm condition, and to keep the vessels and troughs in which it is put in a clean state; otherwise the material rapidly becomes sour, and causes injury to the health of the animal. Fattening cattle may be given up to 60 litres ( $\mathrm{I}$ litre $=\mathrm{I} \frac{3}{4}$ pints), cows 40 litres, fattening sheep and pigs 2-3 litres per head per day. Horses which are doing moderate work may have IO-I5 litres. Hard-working horses, breeding and suckling animals, as well as young stock, had better not receive any of this material. Potato slump acts like raw potatoes, and may cause colic, diarrhœa, abortion, as well as giving rise sometimes to a peculiar cough and sores on the legs. When grain slumps are used for feeding the above-mentioned diseases are observed to a much less extent, and, therefore, these by-products can be given in larger quantities than those from the manufacture of potato spirit.

Amongst the dricd slumps the feilowing may be 
mentioned : (I) Hungarian or French maize slump, of a dark colour, and containing a lot of husk; it is generally mixed with chalk before being dried. (2) American maize slump, of a lighter colour, and got from more or less perfectly husked grain; it often contains oat husks, and, having been dried in partially exhausted chambers, does not possess the pleasant aromatic smell of the dark Hungarian slumps. (3) Grain slump of American origin, made from maize and rye. And (4) Rye slump made from rye, sometimes with and sometimes without barley malt.

What has been said as regards the buying and use of dried grains, as well as the quantities to be used, applies equally well to dried slumps, which resemble them closely.

\section{(10) Feeding-stufs of animal origin.}

In this class of substances come cow's milk and the by-products from the manufacture of cream, butter, and cheese, as well as some materials made from the flesh, blood, bones, and even the whole bodies of animals.

Milk, the chief food material of young animals during the first periods of life, is composed of water, protein substances (casein and albumin), fat, milk sugar, and mineral matter. Along with these are also found small and usually unimportant 


\section{I8 SCIENTIFIC FEEDING OF ANIMALS}

quantities of urea, lecithine, cholesterine, citric acid, etc.

When milk is placed under the microscope it is seen to be composed of a clear liquid, in which a great number of tiny drops of fat are present. The fluid form of the nutrients and the finely divided condition (emulsion) of the fat ensure the complete accessibility of the digestive juices to all the constituents of the milk. It is true that the proteins of the milk are acted upon shortly after ingestion by an enzyme in the gastric juice, and curdled, but the curd is in such a form that it offers no resistance to the process of digestion (p. I46). Investigations with sucking calves have also shown that only $2 \cdot 3 \%$ of the ingested dry matter of the milk passes into the frces (see Part III, Chapter VI).

When a comparison is made of the composition of the milk of various animals, considerable differences are seen to exist between the quantities of the organic and also the mineral constituents. In cow's milk, for instance, the average composition is $2.9 \%$ casein, $0.5 \%$ albumin, $3.4 \%$ fat, $4.6 \%$ milk sugar, $0.7 \%$ ash, which contains $26 \%$ phosphoric acid. The milk of the mare has $I \cdot 3 \%$ casein, $0.7 \%$ albumin, I. I $\%$ fat, $5.9 \%$ milk sugar, $0.4 \%$ ash, which contains $32 \%$ phosphoric acid. From such differences it is easy to see that cow's milk when used as food for the young of other species cannot be as beneficial as the milk of the animal's own mother. 
Colostrum (first milk, beastings) is a fluid which is yielded by the corv at the birth of a calf, and for several days afterwards. It is a yellow, or yellowish brown, liquid of a viscid nature, with a salty taste and a peculiar smell. Compared with ordinary milk, colostrum is richer in dry matter, particularly in protein substances, which coagulate on heating; it contains also more mineral substances, but is poorer in milk sugar. The action of the colostrum is slightly purgative, and this property is very valuable in the case of young animals, from which it should not be withheld. Some 5-IO days after the birth of the calf the milk of the mother gradually returns to its normal condition.

It has been already noticed in describing the feeding-stuffs of vegetable origin that sometimes after using some of them the milk acquires properties which, although they may be quite non-injurious, nevertheless make it unsuitable for rearing young animals. Many poisons and medicinal substances, such as copper, lead, iodine, salicylic acid, etc., it has been repeatedly proved can in some measure pass into the milk. Such milk, as well as that which comes from animals that have been forced to eat suspicious or poisonous plants, ought not to be given to calves, and the same applies to the milk from cows which have partaken of foddcr that has been damaged by mud or fumes, bran mixed with sweepings, or other unsuitable food. 


\section{SCIENTIFIC FEEDING OF ANIMALS}

Sour milk often causes severe and even fatal scouring in young stock, but faulty (blue, yellow, salty, bitter) milk, if boiled, can often be used without any bad results; it is best, though, to give it to older animals.

Milk from animals suffering from contagious or infectious diseases (tuberculosis, foot and mouth disease, etc.) is the best carrier of infection to other animals, but if the milk is heated to about $190^{\circ} \mathrm{F}$, or, better still, boiled for a few minutes, the danger is removed.

Separated milk from efficient separators does not usually contain more than $\cdot 05^{-\cdot 2} \%$ of fat, whilst the skim milk from the old process of skimming still retains $\cdot 75^{-1} \%$ of fat. What has been said previously regarding whole milk applies equally to separated or skim milk, save that the smaller quantity of fat means a less nutritive value. The use of separated milk, and also of whole milk, is discussed in Part III of this book.

Butter-milk, according to the method of buttermaking, has the properties of either sweet or more or less sour separated milk, and contains on an average $\cdot 4-\cdot 5 \%$ fat. Sour butter-milk, like sour separated milk, is best used for fattening pigs; calves and young swine are not able to make much use of it during the first few weeks of life, and even later only moderate quantities, always boiled, should be given.

Whey which is left after the coagulation of the 
casein of milk by rennet is, as its composition shows, a very watery food, which it is advisable to feed in a boiled condition to fattening pigs; for delicate animals sour whey is not suitable.

Meat meal is a by-product obtained in the manufacture of extract of meat, by Liebig's method, in South America. In this process fresh, healthy meat, freed as far as possible from bones, sinews, and fat, is chopped up, and then put to soak in warm water. The residue which remains after extraction is mixed with mineral salts (potassium chloride, sodium phosphate, and calcium salts), then dried thoroughly and ground, and becomes the Liebig's meat meal. In some places the flesh of sheep or horses is used.

Adulteration of the meat meal is seldom practised, but occasionally dried glue, cartilage, also leather and bone meal, are found. Meat meal is an excellent means of raising the protein in a ration, and it is principally used in feeding swine. Young pigs may be given $\frac{1}{4} \mathrm{lb}$. to $\mathrm{I} \mathrm{lb}$. per head per day, beginning with the lowest amount and gradually increasing the supply. Calves also do well on this food, and grown cattle may be given up to $2 \mathrm{lbs}$. per day; neither the milk nor butter is damaged by the meat meal. Sheep obstinately refuse to take this preparation.

Recently there has arisen a competing material in the shape of a meal made from the carcasses of 


\section{SCIENTIFIC FEEDING OF ANIMALS}

dead or poisoned animals, refuse from slaughterhouses, spoiled, preserved, or pickled meat, rotten fish, and waste flesh of all kinds. The carcasses, etc., are heated with superheated steam in large drums containing revolving knives, and the heating and mincing continued until a dry powder is left. Glue and fat which are drawn from the drums are obtained as by-products. It cannot be denied that in this process all is done that it is possible to do to destroy the germs of infection and to prevent a subsequent contamination with such germs. This "carcass" meal has already been in use a few years, and no injurious effects have so far been reported; unfortunately it is not infrequently sold as Liebig's meat meal, and at the price of the latter. Compared to this the carcass meal leaves much to be desired, for, in consequence of the bones, and remains of food and dung, it is poorer in protein. In consequence also of the heating which the carcass meal has undergone, it is less digestible and richer in nonprotein nitrogenous substances than the meat meal. Horses, oxen, and sheep either refuse to eat it or else do so reluctantly, but swine consume it readily.

Fish meal is a food manufactured from fish, or fish refuse, by heating the material with superheated steam to free it as far as possible from fat, and then drying, grinding and sifting the resulting powder. A fish meal richer in fat is also made from unsound fish by a process similar to that used in the preparation of 
the carcass meal. The composition of the material varies considerably, owing to the varying proportions of bones and heads that it contains, and there is always present, as in carcass meal, a large quantity of phosphate of lime. Fish meal is used in the same way as meat meal, particularly for feeding pigs and poultry. It is said to have no effect upon the milk, but a meal which contained a lot of oil would certainly not be as suitable as one free from oil. The flesh and bacon of pigs tend to become oily where such a meal is used.

Blood meal. By drying and grinding blood from the slaughter-houses, a good food material which is readily eaten by all animals is obtained, and it can be used in a similar manner to meat meal. It is also used as an addition to feeding loaves and biscuits, also for mixing with the poorer molasses feeds.

Phosphate of lime for feeding purposes is a material which is known under several names, and is a by-product in the manufacture of glue from bones. In order to separate the glue-yielding substances from the mineral material the bones after cleaning are broken up and treated with hydrochloric acid, which brings the phosphate of lime into solution along with lime and phosphoric acid. By the addition of milk of lime to the solution, a white powder which when dry contains on an 


\section{SCIENTIFIC FEEDING OF ANIMALS}

average $37-38 \%$ of phosphoric acid is obtained. This powder is the phosphate of lime used for feeding purposes, in which $90 \%$ of the phosphoric acid ought to be soluble in ammonium citrate. The phosphate of lime is valued according to its content of citrate-soluble phosphoric acid. Often the product is very damp, and therefore less valuable; sometimes in it are found dangerous quantities of arsenic, soluble calcium salts, or sulphurous acid, which latter is now used in some places instead of hydrochloric acid for dissolving out the mineral matter from the bones. It is necessary to be cautious in buying phosphate of lime for feeding purposes, for not seldom less valuable materials, such as bone meal or bone ash, are sold, instead of the precipitated phosphate of lime. The phosphoric acid in the last product can be utilised to the extent of $50-60 \%$, whereas the animal is not able to assimilate more than $\mathrm{I}_{3}-\mathrm{I}_{4} \%$ of the phosphoric acid in the two former products.

\section{(II) Cattle powders.}

In spite of the many scientific investigations which have been carried out on the nutrition of animals, no means have yet been discovered whereby the digestive power of a healthy animal can be increased or its ability to produce flesh augmented. The failure of competent men to 
succeed in this direction has not prevented dozens of manufacturers of cattle powders and similar preparations from claiming, without any investigation, that they have been successful. The greater the ignorance of these people the more persistently do they push forward their so-called discoveries, which serve only to obtain other people's money. For of what are these powders largely composed? Only quite ordinary substances as a rule, such as common salt, Glauber's salt, bicarbonate of soda, charcoal, powdered sulphur, bone-ash, etc.

In order that these powders may smell or taste like a chemist's shop they are mixed with all sorts of rubbish from the manufacture of drugs with a little fennel, aniseed, gentian root, locust bean, etc., according to whatever is most convenient. Testimonials as to the favourable effect of the powders are naturally not forgotten, but the value of such testimony is well known, for often a packet of the powders is bought simply to get rid of a persistent seller, and the next time when the man appears with a ready-prepared testimonial the former buyer is glad to sign it so as to be left in peace. Even so-called experts who have never conducted an investigation on the question of animal nutrition can be suborned by high remuneration for this, as for any other fraud.

It is therefore the urgent duty of all those who enjoy the confidence of their fellow-workers to 


\section{SCIENTIFIC FEEDING OF ANIMALS}

warn those who are less acquainted with these matters of their true nature. A healthy animal is much too complete to require any artificial assistance, and sick animals are not to be cured by any quack remedies. 
PART III

THE FEEDING OF DOMESTIC ANIMAI.S UNDER THE CONDITIONS USUALLY FOUND IN PRACTICE 



\section{CHAPTER I}

GENERAL CONSIDERATIONS-EXPERIMENTAL TRIALS IN PRACTICE

T NVESTIGATIONS on the metabolism of material 1 and energy in animals have shown that animal heat, muscular energy, and body fat can arise from proteins as well as from fats and carbohydrates, and that a liberal supply of nitrogen-free nutrients allows of the food protein being reduced to a certain quantity without detriment to the utility of the animal. This many-sidedness which the animal possesses in dealing with its nutrients and the margin which is thereby allowed in the composition of the ration is of great importance in practice. If the cost of raising and procuring digestible protein was about the same as it is for digestible carbohydrates, it would be of little importance whether slightly more proteins were given than necessary, for these substances are without exception able to perform the functions of carbohydrates and fats. But as at the present time protein matter is very considerably dearer than carbohydrates, it is 


\section{SCIENTIFIC FEEDING OF ANIMALS}

essential to be as economical as possible in the use of the former, and to limit the quantity as far as is practicable. It thus becomes necessary to find what this limit is for the different species of animals, and the purposes for which they are kept.

Fats and carbohydrates can replace one another both in the production of energy and of heat, and I part of fat in a mixed ration can perform the functions of 2.2 parts carbohydrate. A limit, however, is placed upon the amount of fat in the food of domestic animals, for more than I lb. of fat per I000 lbs. live weight often diminishes the appetite, and upsets the digestion in full-grown herbivora, although young animals can generally take larger quantities. In addition to this the fat of the food often has a prejudicial effect upon the body, or milkfat, as has already been noticed, and attention will also be drawn to this point later. For these reasons the amount and kind of fat in the food require particular attention.

Amongst the other constituents of the food to be considered are, in addition to the mineral matter, the nitrogenous substances of a non-protein nature, whose effect in the production of fat and energy is included in the "starch equivalent" of the feeding-stuffs. In view of what has already been said (p. 65), it is not correct to reckon these substances as proteins. It would, in many cases, be a matter of indifference whether, in the calcu- 
lation of a ration, the crude protein (proteins+ non-protein nitrogenous substances) or proteins alone were reckoned, but if the food were rich in amides, it is possible that the animal would not get sufficient proteins if the crude protein only were used in the calculation.

In order to quickly and conveniently see the relation between crude protein and the various nitrogen-free substances, it has been for some time the custom to employ the " nutritive ratio" which gives the amount of digestible nitrogen-free materials of the nature of carbohydrates which falls to I part of digestible crude protein. The digestible portions of the nitrogen-free extract and of the crude fibre are similar in their percentage composition and heat value to the carbohydrates (p. 69); the fat, however, is a more concentrated nutrient, and on combustion uses $2 \cdot 44$ times as much oxygen as do the carbohydrates. Formerly the amount of oxygen consumed in the combustion of a material was taken as a standard of its value in the production of heat and as a nutrient, so that to calculate the digestible fat as carbohydrate it was multiplied by 2.44 , and the amount added to the nitrogen-free extract substances. To calculate, for example, the nutritive ratio of oats, which contain $8.0 \%$ crude protein, $4.0 \%$ fat, $44.8 \%$ nitrogen-free extract, and $2.6 \%$ crude fibre, all of which are in a digestible form, the sum of the carbohydrates would be 


\section{SCIENTIFIC FEEDING OF ANIMALS}

$44 \cdot 8+2 \cdot 6+4 \cdot 0 \times 2 \cdot 44=57 \cdot 2 \%$. To this $57 \cdot 2 \%$ carbohydrates fall $8.0 \%$ crude protein, from which the nutritive ratio $(8 \cdot 0: 57 \cdot 2)=\mathrm{I}: 7 \cdot \mathrm{I} 5$ is calculated.

A nutritive ratio of $I: 5-6$ is termed a medium one, I : 2-4 a narrow one, and I : 8-I2 a wide one.

According to recent investigations the factor 2.44 for the conversion of fat into carbohydrates is not correct, and is better replaced by the number $2 \cdot 2$.

If the calculations are made with proteins instead of crude protein, the following difference would be found in the case of oats: $44 \cdot 8+2 \cdot 6+4 \times 2 \cdot 2=$ $56.2 \%$, and as the oats contain $7 \cdot 2 \%$ proteins, there would be $56.2 \%$ carbohydrates to $7 \cdot 2 \%$ proteins, which gives an "albuminoid ratio" (as it is called) of $I: 7 \cdot 8$.

In the construction of feeding rations attention has to be paid to other points besides the digestible protein and the starch equivalent, and one of these is the suitability of the food for the animal. As has been seen in Part II, there are some species which are only able to take small quantities of some particular feeding-stuff, or perhaps none at all. The palatableness of a food must also be studied, especially in a fattening ration where large quantities are given. It should be a rule in constructing such a ration to unite in it as many different foods as possible, particularly concentrated foods. The advantages of this method are numerous; if, for ex- 
ample, one of the foods is not above suspicion, then the amount which finds its way into the daily ration is so small as to have no bad effect, whereas a larger quantity might cause injury.

It is further important not only to draw the foods which contain chiefly starch or sugar from various sources, but also to give the nitrogenous portion of the ration in as many different forms as possible. Some foods are digested principally in the stomach, others in the small intestine, whilst others again undergo the chief digestion in the large intestine. A mixture of several food-stuffs therefore spreads the work of digestion over various parts of the digestive tract, and for this reason such a ration is more suitable than one made from large quantities of a single material.

A satisfactory ration must further be adjusted to the size of the stomach and intestines, for if it occupies too little space the animal will not be satiated, even though it gets sufficient nutrient material, and so it will be in a restless and unsatisfactory condition. On the other hand, a ration should not be too voluminous, for the danger then is that all is not eaten, and so fattening does not proceed. An idea of the amount of food to be given can be gathered from the feeding standards in Table III of the Appendix, where the daily supply of dry matter is calculated per rooo lbs. body weight. These figures, like others of the same 


\section{SCIENTIFIC FEEDING OF ANIMALS}

nature, are not, of course, to be strictly followed, but they are meant to indicate whether larger or smaller amounts of coarse fodder are necessary. Variations of $10 \%$ and more in these data are not of great importance, provided the animals are gradually accustomed to the changed food. The supply of home-produced food-stuffs will determine, in the first place, whether a more or less voluminous food is chosen. When fodder is scarce it is often difficult to find substitutes, and recourse to such little-used materials as potato-tops, gorse, heather, even sawdust, has to be had in order to provide the animals with the necessary bulky stuff. A mixture of ground peat moss free from sand with diluted molasses has proved to be a suitable substance in such cases. Compared with the large losses which a reduction in the stock of cattle brings at the time of a scarcity of food the drawbacks associated with the use of indigestible materials pass into the background.

Whenever a change of food is made it should be gradual, even an increase in the volume can cause disturbances if suddenly made, for the natural expansion of the digestive tract is limited. When the increase is gradual, the digestive organs expand by the growth of their walls, but for this time is necessary.

In the use of new concentrated foods caution is also necessary, for every food has its peculiarities, particularly in its action upon the nervous 
system. Against disturbing effects of this nature, and even against the most powerful poisons, the body produces substances of an antitoxic nature, and can even withstand deadly doses of arsenic, morphia, ricinine, etc., if by their very gradual introduction time is allowed for the preparation of the corresponding antidote. If the body, however, is suddenly given large quantities of these injurious materials, it suffers from the action of the poisons. For this reason a new feeding-stuff should not at once be fed in full quantities, but the daily supply increased so that 4-7 days are taken to reach the full amount. A gradual change is also necessary in passing from stall- to meadow-feeding and vice versâ, so also when green fodder, roots, silage are introduced into the ration, or when a change is made in the concentrated food. When new hay or oats are substituted for old, when feeding with molasses begins, or even when the food is altered the change must be gradual. The greater the difference between the new food and the old the longer should the transition period be. The custom of dividing the daily ration into several meals is entirely sound from the point of view of the food metabolism in the body, for the heat which is produced during and after feeding is divided more regularly over the day and night, and so is better utilised. The production value of the nutrients is also greater when the food is spread over 


\section{SCIENTIFIC FEEDING OF ANIMALS}

a certain space of time; this has been proved in fattening experiments, when the same quantity of food was given at once and where it was divided into several meals. The capacity of the digestive organs, and the behaviour of animals free to eat when they wish, point to the division of the ration into three, or at most four meals for full-grown animals, and four to six for young ones, as being the most natural. When large quantities of fodder are given at one time portions are very liable to be thrown about and to be trodden under foot. Regularity in the times of feeding plays a not unimportant part in the comfort and well-being of the animal. By a suitable admixture of tasty foods with those that are not so readily eaten the appetite of the animal is maintained to the end of the meal, and so the ration is fully consumed. With ruminants and horses it is usual to first give coarse or green fodder, and then the mixture of chopped hay or straw or roots and concentrated food. This ensures the consumption of each portion of the ration before the next is begun. Finally some long hay or straw for the animal to eat at leisure should be given. The order in which the food is fed can be altered according to taste, so long as the chief end-a complete consumption-is attained.

Mention has already been made (p. 94) of the necessity of an addition of salt to the food, and the daily need of a cow of average weight is $\frac{3}{4}-\mathrm{I} \frac{1}{2} \mathrm{oz}$., 
for a horse $\frac{1}{2}-\mathrm{I}$ oz., sheep or pig $\frac{1}{8}-\frac{1}{4} \mathrm{oz}$. ; and this is best sprinkled over the food, as animals are apt to take too much when a lump of rock salt is given them to lick. If materials which are difficult of digestion have to be given in large quantities, then the supply of salt may be increased to $2 \frac{1}{2} \mathrm{oz}$. for cattle, and $\frac{1}{2} \mathrm{oz}$. for pigs and sheep; more than these quantities should not under any circumstances be given. As regards the watering of animals, it is preferable to let cattle have as much water as they will take after the first portion of the dry fodder has been eaten; horses should be watered before being fed, otherwise portions of the concentrated food (oats, barley, etc.) may be washed from the stomach into the intestine, and so not properly digested. When horses are overheated or have been without water for a long time care should be exercised, and they should only be allowed to drink when they have cooled down, and the respiration and pulse are again normal. Such heated animals may be given some hay moistened with water, and then each quarter of an hour more water can be poured on to the hay. Sheep, pigs, and young animals do best when they have an unlimited supply of water at their disposal. A suitable ration, care being exercised in the choice of the individual foods and in the total bulk, punctuality in feeding and watering, cleanliness of the manger and drinking vessels, adequate grooming, a well-ventilated stable 
or stall of medium temperature with clean bedding, are the chief points essential for success in feeding domestic animals.

A great deal of the work of investigation which has been done in agricultural practice, it is safe to say, has entirely failed in its object, because the methods of research have been faulty. It is therefore not out of place to mention here the chief rules to be followed in experiments which are being carried out in practice. The conditions under which a feeding experiment is performed must be so arranged that every chance of accident is excluded. In the first place care must be taken that the individual characters of the animals used in the investigation do not disturb the observations-one of the most important conditions. If only a few animals are used this influence cannot be rightly judged nor can allowance be made for it. In scientific investigations the conditions are in many ways more favourable, for there, owing to the examination of all parts of the metabolism, a much more complete control is possible. A conscientious investigator does not, however, remain satisfied with a single animal when he believes he has made any discovery, and refrains from publishing the result until it has stood the test of repetition. (People who have not had a regular training, and are not thoroughly versed in one or the other methods of investigation, attempt 
difficult problems, and do not hesitate to give to the world their unripe results clothed in a scientific dressing. In time the valuelessness of their conclusions is recognised, but the distrust that they have sown is not so easily uprooted.

The practical man, no less than the scientist, whose aim is directed to the laws of nutrition, has to work on a broad basis if he wishes to make clear some of the points which interest him in the feeding of his cattle. He must first of all use a number of animals, in order to get rid of individual peculiarities, and ought to choose ten, even better fifteen or twenty, animals for each section. It is only the continued repetition of an experiment with other animals which will yield a satisfactory answer to the question under examination.

He who begins a great deal finishes little, and this holds true also with the investigations under consideration. If it were wished, for example, to test ten feeding-stuffs one after another in a continuous experiment it is certain that the results would be of doubtful value, for the condition of the animals would vary according to the kind and quantity of the food used in the experiment. Nobody will suggest that a lean animal behaves as does a fat one when each gets the same food, nor an old animal as a young one.

Continuous investigations on the same animals in which the food is changed periodically are, 


\section{SCIENTIFIC FEEDING OF ANIMALS}

therefore, not free from objections, and the results are more reliable when the trials are carried out upon groups of animals at the same time. Here also the chief condition is that the groups which are to be compared with one another should be equivalent at the beginning of the investigation as regards race, age, sex, live weight, etc., of the animals, in fact, one group must be the counterpart of the other. When such groups have been arranged, a preliminary trial must be made to see if they behave similarly on the same food. Should differences be observed changes must be made in the groups until a close agreement is found, afterwards the food to be investigated may be given.

Investigations, then, are of two kinds, those conducted in periods and those in groups; the former have only a limited use, for the animals change in condition, especially young and fattening cattle, and so the conclusions are not reliable. With milking cows, though, this method can be used, and mention will be made of it later.

With regard to the kind and quantity of the food used in the trial it is impossible to give any general rules, for each investigation has different objects. Where a feeding-stuff is being tested the total quantity of food must not be too large, because with excess the nutrients in different rations would not show any difference at all. If the object is to see how varying quantities of protein in the food 
act, the starch equivalent of the rations under comparison must be kept the same, as must all other conditions, except on the one point which is being tested. Further, a chemical and microscopical examination is also essential, for it is only by these means that the nutritive value of the food-stuff can be judged. In very many cases, whether the investigations are concerned with fattening, working, or breeding stock, the live weight is the most important, and often the only means of judging of the action of the food. Owing to the considerable differences in weight, due to irregular excretion of dung and urine and to the unequal consumption of drinking water, it is not enough to weigh the animals every fourteen days or so, but the weighing must always be done on three consecutive days at exactly the same time, and preferably before the first meal. The length of the experiment ought also not to be too short with fattening and working animals; the minimum should be two months, and it is even better to take a longer period, particularly in feeding groups of animals, which ought to be carried on until ready for the butcher. Important manifestations, such as loss of appetite, cessation of growth in young animals, diminished staying power in working animals, often only appear after the investigation has been in progress for a length of time.

All other conditions, such as temperature of the 


\section{SCIENTIFIC FEEDING OF ANIMALS}

stall, supply of salt, bedding, grooming, number of meals, etc., must be kept the same in each group or each period.

The care which according to the above is essential in the carrying out of an investigation may seem to some to be exaggerated. It is only those who know from experience how changeful an animal is, and have critically studied the reports of investigations in practice, who cannot doubt that the most strict care is essential in conducting such investigations. He who does not or will not consider these demands to be necessary had far better not undertake investigations, for he will only succeed in increasing the huge number of valueless results. 


\section{CHAPTER II}

MAINTENANCE RATION FOR OXEN AT REST

THE feeding of working oxen at rest in the

1 stall is the simplest of the tasks which the owner of cattle has to undertake. The animals to be dealt with are practically sexless, little subject to nervous influences, and except for the slight growth of hair, hoofs and horns, do not increase in size, nor do they perform any utilisable work. The chief aim, then, is to feed such resting animals so that the body does not need to supply any of its substance for the production of energy, and that, on the other hand, there shall be no excess of food to be made into body fat.

According to some of the older observations which were confined to the digestible nutrients of the food and the protein metabolism, it was possible to keep oxen at rest in the stall on the following daily rations, calculated per Iooo lbs. live weight, without loss of weight.

I. 12.6 lbs. oat straw

2. 14.2 , ,

3. 13.0,

4. $13 \cdot 3$, rye straw
25.6 lbs. mangels $2 \cdot 6$," clover hay $\begin{array}{ll}3.7, & , \\ 3.8, & \text {," }\end{array}$ 


\section{SCIENTIFIC FEEDING OF ANIMALS}

The temperature of the stall, which, as has previously been seen (p. 52), also has an influence upon the consumption of nutrients in an animal on a low diet, because of the heat given off from the body, was kept fairly high in these investigations $\left(54-68^{\circ} \mathrm{F}\right.$.). It must also be remembered that at the time of these experiments-some forty years ago-the varieties of cereals which were grown gave a more digestible straw than those cultivated at the present time.

On the above rations a slight increase of tissue took place, which sufficed for the growth of hoofs and horns and for the renewal of the hairy covering. Whether an increase in body fat also took place was not proved, but in any case the body weight of the experimental animals underwent no change for a long time.

More exact investigations which were later carried out with the help of the respiration chamber gave the following results per day and per $1000 \mathrm{~kg}$. (I kg. $=2 \cdot 2$ lbs.) live weight.

\section{INSUFFICIENT FOOD.}

\begin{tabular}{|c|c|c|c|c|c|c|}
\hline \multirow[b]{2}{*}{$\begin{array}{l}\text { Ox } \\
\text { No. }\end{array}$} & \multicolumn{4}{|c|}{ Digestible nutrients. } & \multicolumn{2}{|c|}{$\begin{array}{l}\text { Addition }(+) \\
\text { or loss }(-) \text { of }\end{array}$} \\
\hline & $\begin{array}{l}\text { Protein. } \\
\text { kg. }\end{array}$ & $\begin{array}{l}\text { Fat. } \\
\text { kg. }\end{array}$ & $\begin{array}{c}\text { Nitrogen-free } \\
\text { extract and } \\
\text { crude fibre. } \\
\text { kg. }\end{array}$ & $\begin{array}{l}\text { Starch } \\
\text { equiva- } \\
\text { lent. } \\
\text { kg. }\end{array}$ & $\begin{array}{c}\text { Flesh. } \\
\text { g. }\end{array}$ & $\begin{array}{c}\text { Body } \\
\text { fat. } \\
\text { g. }\end{array}$ \\
\hline III. & 0.35 & 0.10 & 6.17 & $4 \cdot 00$ & -51 & +139 \\
\hline IV. & 0.34 & 0.10 & 6.08 & $3 \cdot 96$ & -57 & +45 \\
\hline B & 0.28 & 0.12 & 6.63 & $4 \cdot 52$ & -144 & -172 \\
\hline $\bar{C}^{1}$ & 0.42 & 0.21 & $6 \cdot 58$ & $4 \cdot 60$ & -6 & +1 \\
\hline Average & 0.35 & 0.13 & $6 \cdot 37$ & $4 \cdot 28$ & -65 & +3 \\
\hline
\end{tabular}




\section{SUFFICIENT FOOD.}

\begin{tabular}{|c|c|c|c|c|c|c|}
\hline \multirow[b]{2}{*}{$\begin{array}{l}\text { Ox } \\
\text { No. }\end{array}$} & \multicolumn{4}{|c|}{ Digestible nutrients. } & \multicolumn{2}{|c|}{$\begin{array}{l}\text { Addition (+) } \\
\text { or loss }(-) \text { of }\end{array}$} \\
\hline & $\begin{array}{l}\text { Protein. } \\
\text { kg. }\end{array}$ & $\begin{array}{l}\text { Fat. } \\
\text { kg. }\end{array}$ & $\begin{array}{l}\text { Nitrogen-free } \\
\text { extract and } \\
\text { crude fibre. } \\
\text { kg. }\end{array}$ & $\begin{array}{l}\text { Starch } \\
\text { equiva. } \\
\text { lent. } \\
\text { kg. }\end{array}$ & Flesh. & $\begin{array}{l}\text { Body } \\
\text { fat. } \\
\text { g. }\end{array}$ \\
\hline V. & 0.60 & 0.07 & $6 \cdot 45$ & $5 \cdot 04$ & +48 & +235 \\
\hline VI. & 0.57 & 0.07 & & & +26 & +263 \\
\hline 20 & $0.6 j$ & 0.20 & 6.78 & $5 \cdot 76$ & & +158 \\
\hline A & 0.56 & 0.18 & $6 \cdot 62$ & 5. & +66 & +227 \\
\hline $\mathrm{C}^{2}$ & 0.54 & 0.28 & $7 \cdot 26$ & & +161 & +37 \\
\hline verag & 0.59 & 0.20 & $6 \cdot 68$ & $5 \cdot 20$ & +59 & +184 \\
\hline
\end{tabular}

When the figures for the animals which were insufficiently fed are compared with those obtained when the food was sufficient, it is seen that the sum of the digestible nutrients had less influence upon the equilibrium of the animal than had the starch equivalents or values of the whole rations. Thus in a maintenance diet attention has also to be paid to the value of the nutrients. If, for example, the ration given to ox $\mathrm{A}$, which consisted of $8.5 \mathrm{~kg}$. meadow hay, were replaced to the extent of one-half by potatoes and rape cake, then, instead of $7 \mathrm{~kg}$. digestible nitrogen-free nutrients (including fat), there would only have been $6 \mathrm{~kg}$., but this would have sufficed.

For full-grown oxen which have not to perform work and are kept at a temperature of $54-60^{\circ} \mathrm{F}$., it suffices for maintenance to give $0.5 \mathrm{~kg}$. digestible protein, and $5.2 \mathrm{~kg}$. starch equivalent. As, however, in practice it is not advisable, owing to the individuality of the animals, to restrict the feeding to the absolute minimum, it is preferable to reckon 


\section{SCIENTIFIC FEEDING OF ANIMALS}

per day $0.6-0.8 \mathrm{lb}$. digestible protein, and 8-9.5 lbs. digestible nitrogen-free nutrients (including fat) with a starch equivalent of $6 \cdot 0 \mathrm{lbs}$. per I000 lbs. live weight. With these figures the dry matter of the ration can oscillate between $I_{5}$ and $2 \mathrm{I}$ lbs. This standard ration assumes that primarily coarse fodder will be used, and that any deficit in protein will be made good by small additions of oil cakes, distillers' waste, brewers' grains, etc., and a lack of carbohydrates by roots or tubers or their byproducts. Such rations contain a sufficient quantity of mineral substances, for investigations on this point have shown that the daily consumption of $50 \mathrm{~g}$. phosphoric acid and Ioo g. lime per $1000 \mathrm{~kg}$. live weight sufficiently meet all requirements. As the larger animals of $1000 \mathrm{~kg}$. (2200 lbs.) give off less heat than do the smaller ones (p. 53), it is necessary on a maintenance diet to pay attention to this, for there is not then the excess of heat as when on a production ration. Calculated per body surface, the following weights of food are to be given per $1000 \mathrm{~kg}$. when the single animals weigh:

$300,400,500,600,700,800 \mathrm{~kg}$., starch equivalent:

$7 \cdot 70,7 \cdot 00,6 \cdot 50,6 \cdot 10,5 \cdot 80,5 \cdot 55 \mathrm{~kg}$.

The maintenance ration for animals which only weigh $300 \mathrm{~kg}$. is, therefore, $28 \%$ greater per $1000 \mathrm{~kg}$. than for animals of $800 \mathrm{~kg}$. As regards the requirements of animals for protein, their size has no noticeable influence. 


\section{CHAPTER III}

THE MAINTENANCE RATION FOR SHEEP-THE PRODUCTION OF IVOOL

$\mathrm{I}$ addition to the material and energy which 1 every animal requires for maintaining life, there is in the sheep a further demand for material for the production of wool, and this being of a protein nature, requires protein for its formation. It is, therefore, clear that sheep require more food protein than do full-grown oxen at rest in the stall. The greater sensitiveness of sheep and the liveliness of their movements, as well as the greater extent of body surface, all point to the increased needs of this species for nitrogenous nutrients, as compared with resting oxen, even though the wool of the former protects them from loss of heat.

Amongst the first investigations carried out on the maintenance food for sheep was one series with two $4 \frac{1}{2}$-year-old wethers of a coarse-woolled Hanover breed. The animals had an average weight of $47.9 \mathrm{~kg}$., including $2.4 \mathrm{~kg}$. wool, and they were given daily per $1000 \mathrm{~kg}$. live weight (without wool) $25.96 \mathrm{~kg}$. meadow hay, which contained in digestible 


\section{SCIENTIFIC FEEDING OF ANIMALS}

material $\mathrm{I} \cdot 04 \mathrm{~kg}$. protein, $0.32 \mathrm{~kg}$. fat, $6 \cdot 28 \mathrm{~kg}$. nitrogen-free extract substance, and $3.93 \mathrm{~kg}$. crude fibre, the total starch equivalent being $9.66 \mathrm{~kg}$. On this ration there was a daily gain of $\mathrm{I} 44 \mathrm{~g}$. flesh, $325 \mathrm{~g}$. body fat, and $209 \mathrm{~g}$. wool, which is altogether equal to a starch value of $I .88 \mathrm{~kg}$. If there had been no gain of wool, flesh, or fat, the animals would have found enough food in $7 \cdot 78 \mathrm{~kg}$. starch equivalent per Iooo kg. naked body weight.

In another experiment with a half-fat English cross-bred sheep which weighed $64.9 \mathrm{~kg}$. with its wool, and without $62.4 \mathrm{~kg}$., the daily ration was $550 \mathrm{~g}$. meadow hay, and $440 \mathrm{~g}$. coarsely ground maize. Calculating the ration upon $1000 \mathrm{~kg}$. naked body weight, it would contain $0.8 \mathrm{I} \mathrm{kg}$. protein, $0.40 \mathrm{~kg}$. fat, $7.05 \mathrm{~kg}$. nitrogen-free extract substance, and $\mathrm{I} \cdot 37 \mathrm{~kg}$. crude fibre, together with a starch value of II.24 $\mathrm{kg}$. The production, which was ascertained by means of the respiration apparatus, yielded by this ration was $7 \mathrm{I} \mathrm{g}$. each, flesh and wool and $785 \mathrm{~g}$. body fat, which means a starch value of $3.28 \mathrm{~kg}$. If this portion of food which has served for the purposes of production is subtracted from the total quantity given, there remains $7 \cdot 96 \mathrm{~kg}$. starch value for the simple maintenance of the animal.

Mention might perhaps be made here of the relation between the nutrients given and the production which was observed in the above two 
experiments. The amounts digested per rooo kg. naked body weight were :-

With meadow hay $\mathrm{I}^{\circ} 04 \mathrm{~kg}$. protein and I0.94 $\mathrm{kg}$. carbohydrates.

With meadow hay and maize $0.8 \mathrm{I} \mathrm{kg}$. protein and $9 \cdot 30 \mathrm{~kg}$. carbohydrates.

That is, less nutrients when hay and maize were given than when hay alone. In spite of this, the production on the hay ration was considerably less (325 g. body fat) than when maize was also given (785 g. body fat). This is again a good proof of the differences in the feeding value of the digested materials and of the correctness of reckoning according to starch values. In both cases for maintenance alone there was required practically the same starch value- $7 \cdot 78 \mathrm{~kg}$. or $7.96 \mathrm{~kg}$. - as compared with $5 \cdot 2 \mathrm{~kg}$. for the ox.

From the results of all the investigations which have been recorded up to the present it may be said that maintenance of life and the production of wool are assured if sheep of the larger breeds are given per Iooo lbs. body weight a daily ration containing I lb. digestible protein together with $8.3 \mathrm{lbs}$. starch equivalent, but the smaller breeds must have slightly more, viz. I.2 lbs. protein, and 9.0 lbs. starch equivalent.

There is further the question of the influence of food on the growth of the wool. It is known that in human beings who have to subsist for a con- 


\section{SCIENTIFIC FEEDING OF ANIMALS}

siderable time on insufficient food, or who may even be starving, the growth of the hair and the beard does not entirely cease. The formation of hair or wool does, however, most certainly diminish when through improper nutrition the body weight sinks below a certain amount. This may be seen from an investigation where two groups of twelve sheep were taken and one group fed on meadow hay and ground beans for four months, the weights at the beginning being $46.50 \mathrm{~kg}$. and at the end $46.55 \mathrm{~kg}$. The second group were fed on oat straw and mangels, and their weight, which was $46 \cdot \mathrm{I} \mathrm{kg}$. at the beginning, sank to $44^{.} \mathrm{I} \mathrm{kg}$. during the four months the experiment lasted. The first group during the experiment made $9 \cdot 12 \mathrm{~kg}$. of roughly washed wool, which contained $5.99 \mathrm{~kg}$. pure wool, and the second group, which were underfed, yielded only $7 \cdot 02 \mathrm{~kg}$. of roughly washed wool, of which $4.58 \mathrm{~kg}$. was pure. Similar results were shown in another experiment, where the following figures per day and per $1000 \mathrm{~kg}$. live weight were obtained :-

$$
\text { III. I. IV. II. }
$$

Increase in body weight $0.79 \mathrm{~kg} .0 .42 \mathrm{~kg}$. $0.17 \mathrm{~kg} . \quad 1.05 \mathrm{~kg}$. Growth of wool . 0.16" 0.15" 0.15" 0.13" Growth of wool expressed in percentage of weight $\begin{array}{lllll}\text { of fleece } & 0.0 .306 \% & 0.292 \% & 0.293 \% & 0.237 \%\end{array}$

As is seen in sections III, I, and IV, the growth of wool does not always suffer when the body weight diminishes; but when, as in section II. 


\section{MAINTENANCE RATION FOR SHEEP $25 \mathrm{I}$}

the decrease of weight passes a certain limit, then the yield of wool is less. As wool can only be formed from protein, it is most probable that of those rations which do not suffice for the maintenance of the animal, those which contain sufficient protein will have the least unfavourable influence upon the wool, and this has been confirmed in numerous investigations.

If, on the other hand, more food is given than is necessary, the production of wool is not thereby increased to any extent. The mean figures obtained in seven experiments with a bare maintenance diet and in fourteen experiments with a feeding ration, were, in the first case, I4I g. of wool $=0.273 \%$ of the weight of the fleece, at the end of the investigation, and, in the second case, I4I g. wool= $0.286 \%$ of the weight of the fleece.

In another experiment with lambs five months old, one group were given meadow hay and oats, and weighed in the beginning $25.4 \mathrm{~kg}$. per head, and at the end of nine months $46.25 \mathrm{~kg}$., the animals being then fat. The other group were given meadow hay only, and the average weight of each lamb was $25^{\circ} 0 \mathrm{~kg}$. at the beginning, and $36.15 \mathrm{~kg}$. at the end; the uncleaned wool weighed $2 \cdot 69 \mathrm{~kg}$. as compared with $2 \cdot 18 \mathrm{~kg}$. uncleaned wool from the animals which had received hay and oats.

To sum up, then, the growth of wool only suffers 


\section{SCIENTIFIC FEEDING OF ANIMALS}

when, in consequence of insufficient food, the live weight of the animal steadily decreases. Very rich feeding, though, does not, on the other hand, cause a greater growth of wool than when a sufficient maintenance ration is given.

With regard to the feeding-stuffs which may be used, care should be taken not to give an excess of watery foods, for these are not good for sheep. Roots and tubers, on this account, are only used as subsidiary foods, and the main diet is composed of the different varieties of hay and straw, and the lack of protein made good with small quantities of oil cakes, lupines, dried grains, dried distillers' waste, etc. Full-grown sheep only require very small amounts of bone-forming mineral substances, for it has been found that two-year-old wethers which had ceased to grow and weighed $55 \mathrm{~kg}$. only required $0.57 \mathrm{~g}$. lime and $0.05 \mathrm{~g}$. phosphoric acid, which quantities are to be obtained from the usual rations. 


\section{CHAPTER IV}

THE FATTENING OF FULL-GROWN ANIMALS

THE changes which the composition of the

1 bodies of domestic animals undergoes have been ascertained directly by the analysis of whole animals and single parts of them. For this purpose the following were used :-

Two oxen of 4 years of age, one of which weighed

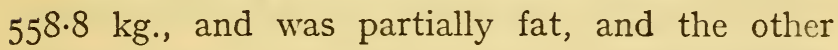
weighed $643.7 \mathrm{~kg}$., and may be regarded as being fat.

Four sheep of the Hampshire Down breed:

(a) Lean, I year old, and $44.3 \mathrm{~kg}$. weight.

(b) Half fat, $3 \frac{1}{4} \quad$ ", , $47 \cdot 7$, , ,

(c) Fat, I $\frac{1}{4} \quad, \quad, \quad 57 \cdot 7$, , ,

(d) Very fat, I $\frac{3}{4}$, , I08.6 , ,

Two pigs of the same breed, one of which was lean, and weighed $42.6 \mathrm{~kg}$, and the other had been fattened for ten weeks, and weighed $83.9 \mathrm{~kg}$.

One fat Durham calf, 8-9 weeks old, and weighing II $7 \cdot 4 \mathrm{~kg}$.

One lamb, 6 months old, and $38.3 \mathrm{~kg}$. in weight. 


\section{SCIENTIFIC FEEDING OF ANIMALS}

These ten animals were analysed I8-24 hours after the last food was given, and the percentage composition is shown below :-

\begin{tabular}{|c|c|c|c|c|c|c|}
\hline a $=18 \mathrm{C}$ & $\begin{array}{l}\text { Nitrogenous } \\
\text { matter. }\end{array}$ & Fat. & $\begin{array}{c}\text { Mineral } \\
\text { substances. }\end{array}$ & $\underset{\text { Dry }}{\text { Drter. }}$ & Water. & $\begin{array}{l}\text { Contents } \\
\text { of stomach } \\
\text { and intes. } \\
\text { tine, moist. }\end{array}$ \\
\hline $\begin{array}{l}\text { Ox, half fat } \\
" \text { fat }\end{array}$ & $\begin{array}{r}16.6 \\
. \quad 14.5\end{array}$ & $\begin{array}{l}19 \cdot I \\
30 \cdot I\end{array}$ & $\begin{array}{l}4 \cdot 7 \\
3 \cdot 9\end{array}$ & $\begin{array}{l}40 \cdot 3 \\
48 \cdot 5\end{array}$ & $\begin{array}{l}51 \cdot 4 \\
45 \cdot 5\end{array}$ & $\begin{array}{l}8 \cdot 2 \\
6.0\end{array}$ \\
\hline $\begin{array}{l}\text { Sheep, lean } \\
\quad " \quad \text { half fat } \\
" \text { fat } \\
" \quad \text { very fa }\end{array}$ & $\begin{array}{l}14 \cdot 8 \\
14 \cdot 0 \\
12 \cdot 2 \\
10 \cdot 8\end{array}$ & $\begin{array}{l}18 \cdot 7 \\
23 \cdot 5 \\
35 \cdot 6 \\
45 \cdot 8\end{array}$ & $\begin{array}{l}3 \cdot 2 \\
3 \cdot 2 \\
2 \cdot 8 \\
2 \cdot 9\end{array}$ & $\begin{array}{l}36 \cdot 7 \\
40 \cdot 7 \\
50 \cdot 6 \\
59 \cdot 6\end{array}$ & $\begin{array}{l}57 \cdot 3 \\
50 \cdot 2 \\
43 \cdot 5 \\
35 \cdot 2\end{array}$ & $\begin{array}{l}6 \cdot 0 \\
9 \cdot 1 \\
6 \cdot 0 \\
5 \cdot 2\end{array}$ \\
\hline $\begin{array}{l}\text { Pig, lean } \\
\quad " \text { fat . }\end{array}$ & $\begin{array}{r}13.7 \\
\text {. } 10.9\end{array}$ & $\begin{array}{l}23 \cdot 3 \\
42 \cdot 2\end{array}$ & $\begin{array}{l}2 \cdot 7 \\
1 \cdot 7\end{array}$ & $\begin{array}{l}39 \cdot 7 \\
54 \cdot 7\end{array}$ & $\begin{array}{l}55 \cdot 1 \\
4 I \cdot 3\end{array}$ & $\begin{array}{l}5 \cdot 2 \\
4 \cdot 0\end{array}$ \\
\hline $\begin{array}{l}\text { Calf, fat } \\
\text { Lamb, fat }\end{array}$ & $\begin{array}{r}15.2 \\
. \quad 12.5\end{array}$ & $\begin{array}{l}14.8 \\
28.5\end{array}$ & $\begin{array}{l}3 \cdot 8 \\
2 \cdot 9\end{array}$ & $\begin{array}{l}33 \cdot 8 \\
43 \cdot 7\end{array}$ & $\begin{array}{l}63 \cdot 0 \\
47 \cdot 8\end{array}$ & $\begin{array}{l}3 \cdot 2 \\
8 \cdot 5\end{array}$ \\
\hline
\end{tabular}

According to these figures the increase of body substance during fattening had the following composition :-

\begin{tabular}{lccccr} 
& $\begin{array}{c}\text { Nitrogenous } \\
\text { matter. }\end{array}$ & Fat. & $\begin{array}{c}\text { Mineral } \\
\text { substances. }\end{array}$ & $\begin{array}{c}\text { Dry } \\
\text { matter. }\end{array}$ & Water. \\
Ox & $7 \cdot 7$ & $66 \cdot 2$ & $1 \cdot 5$ & $75 \cdot 4$ & 24.6 \\
Sheep : & $7 \cdot 1$ & $70 \cdot 4$ & $2 \cdot 3$ & $79 \cdot 9$ & $20 \cdot 1$ \\
Pig & $7 \cdot 8$ & $63 \cdot 1$ & 0.5 & $71 \cdot 4$ & 28.6 \\
\cline { 2 - 6 } Average & $7 \cdot 5$ & 66.6 & $\mathbf{1} \cdot 4$ & $75 \cdot 6$ & $24 \cdot 4$
\end{tabular}

In considering the above figures it must not be forgotten that they deal for the most part with either young animals or those which have scarcely completed their growth. Still, it is clearly shown here that the increase of body substance on fattening is composed at least of two-thirds of fat, a quarter of water, and only to a very small extent of nitro- 
genous substance. The greater part of this last goes to increase the amount of blood, and only the residue is used for the formation of flesh. With animals of an advanced age which are not in a very low condition, but moderately well nourished, there is very little gain in flesh to be reckoned upon after fattening. The microscopic examination of the muscle fibres of young and old animals has shown this (p. 62), and the chemical analysis carried out on grown animals at different periods of fattening has confirmed it. In order that the differences in the condition of flesh and fat can be recognised during fattening, a number of sheep $2 \frac{3}{4}$ years old were taken and divided into groups, one being killed and examined at once, another after $2 \frac{1}{2}$, and the third after $6 \frac{1}{2}$ months' feeding. The results showed that the animals contained the following amounts of flesh per head :-

Group I.

Group II.

Group III.

II.89I kg. .. II.740 kg. .. I2.I23 kg.

which is in the proportion of :-

$$
\text { I00 : } 99: \text { I02 }
$$

There was thus no increase in flesh to be noted as the result of fattening. On the other hand, the quantity of fat per animal was:-

$5.406 \mathrm{~kg}$. .. I5.077 kg. .. I9.0I9 kg. which may be expressed thus :-

$$
\text { I00 : } 279: 352
$$

From which it is seen that when grown animals in 


\section{SCIENTIFIC FEEDING OF ANIMALS}

tolerable condition are fattened, there is no noticeable increase in the amount of flesh, but principally large quantities of body fat are formed. As the proteins in the food do not take part in the conversion of the nitrogen-free food constituents (fat+ carbohydrates) into body fat (p. 79), there is no reason why animals during fattening should be given much protein matter. It might be concluded from this that in a fattening ration no more protein was necessary than in a maintenance ration, a view which, however, is not correct. The large rations which are given during fattening cause a heavy drain upon the glands which secrete the protein-containing digestive juices. If only $0.6 \mathrm{lb}$. digestible protein per rooo lbs. live weight were given to animals which were being fattened, a large portion of the non-nitrogenous nutrients in the ration would not be digested. For the proper utilisation of the food, not more than 8-Io parts of digestible nitrogen-free material ought to be given with each part of digestible protein, as was mentioned on page 39. If it is possible to obtain a supply of cheap food rich in protein, the nutritive ratio (p. 23I) may with advantage be narrowed down to as low as $I \cdot 4$. To give more nitrogenous material than this would, for the reasons already given (p. 62), be a mistake, and in practice ought never to be done.

In fattening grown animals there is thus a con- 
siderable margin left in the quantity of digestible protein which may be fed. If the animals at the beginning of the fattening period are in moderate condition, a commencement may be made with the wide " nutritive" or " albuminoid ratio."

It is different though when lean, worn-out animals are put aside to be fattened, and it is then advisable to give a ration richer in protein, so that the fibres of the flesh develop and are able to store up large quantities of fat. For 2-4 weeks the ration should be moderately rich in protein $(1: 6)$, but not too large, whilst afterwards the quantity of food may be increased until the full fattening ration is being given, the amount of protein being slowly diminished. A large number of investigations have proved that with the very moderate quantity of protein given above excellent results can be obtained.

With regard to the supply of fat in the food, it must first of all be remembered that this is the most concentrated form of nitrogen-free nutrients, and that with cattle it yields $2 \cdot 2$ times as much in body fat as do the carbohydrates. It is, then, advisable where intensive fattening is being carried out to increase the fat as much as possible. When oils in quantities of about $I \mathrm{lb}$. are given per I000 lbs. body weight, the appetite and digestion of ruminants suffer as a rule. Also when foods rich in fat are fed, the same disturbances are some- 


\section{SCIENTIFIC FEEDING OF ANIMALS}

times noticed when the ration contains more than $I \frac{1}{2}-I \frac{3}{4}$ lbs. digestible fat. The latter quantity may therefore be regarded as the limit, and only exceptionally should as much as I lb. fat per Iooo Jbs. live weight be given to ruminants. Pigs are able to take more than this, and young animals when fed on milk also have the ability to consume large quantities of fat-more than 2 lbs.-without disturbance to health.

By means of various investigations (p. 76) the proof has been given that some oils and tats can be partially stored up as body fat, and so alter the properties of the latter, a fact which possesses practical importance. The body fat of ruminants, which arises chiefly from the carbohydrates, possesses a hard, tallowy consistency which may be much improved by feeding certain oily foods if the animal is intended for the butcher. An experiment with four groups of fattening lambs which received a basal ration of hay, straw, and beet slices showed that when $6 \cdot 16 \mathrm{~kg}$. maize and $6 \cdot 63 \mathrm{~kg}$. of sunflower-seed cake were added to the basal ration an excellent quality of meat, with soft fat, was obtained, whereas the addition of $10.58 \mathrm{~kg}$. of crushed peas and I.I9 $\mathrm{kg}$. of wheat husks gave a very poor product, the fat being hard and crumbly. Where the addition was II.75 $\mathrm{kg}$. of wheat husks and $4.69 \mathrm{~kg}$. rape cake the fat was moderately soft, and the same result was got from $3.73 \mathrm{~kg}$. 


\section{FATTENING OF GROWN ANIMALS 259}

earth-nut cake and $10.57 \mathrm{~kg}$. of coarsely ground barley.

The nature of the bacon is also influenced by many other foods. In the following Table the quality of the product obtained when the foods in question were given alone or mixed is expressed with the help of figures; I and 2 denote a good bacon, 3 somewhat soft, 4 and 5 a bad sample, too soft. Fractions of the whole numbers are also used to give more exact expression.

I.

\begin{tabular}{|c|c|c|}
\hline & & \\
\hline els & & \\
\hline & & \\
\hline (rye a & and & \\
\hline heat bran & & \\
\hline arley . & & \\
\hline aize . & & \\
\hline
\end{tabular}

II.

Cereals only . $\quad$. $\mathbf{I} \cdot \mathbf{2}$ $\frac{1}{2}-\frac{1}{3}$ cereals and $\frac{1}{2}-\frac{2}{3}$ sunflower seeds $\quad . \quad 2 \cdot 2$ $0-\frac{1}{2}$ cereals and $I-\frac{2}{3}$ sunflower-seed cake $\quad 3.4$ $\frac{2}{3}$ cereals $\frac{1}{3}$ palm-nut cake $\quad \mathbf{I} \cdot 0$ $\frac{1}{3}, \quad \frac{3}{3} \quad, \quad$, $1 \cdot 2$

III.

Cereals only $\cdot{ }_{1} \cdot$ I $_{4}$

Maize up to $60 \mathrm{~kg}$. body weight, afterwards barley : $\quad 1 \cdot 6$

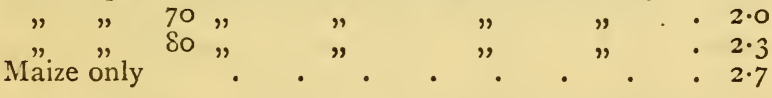

According to these experiments, and also to practical experience, it is known that both pigs and ruminants have harder bacon, or fat, when grains rich in carbohydrates and poor in oil (rye, barley, peas, beans, lentils) are given. Also, too, with potatoes and mangels and amongst the oil cakes, palm-nut and cocoa-nut. A soft, in some cases oily, fat is obtained from sunflower-seed cake, 


\section{SCIENTIFIC FEEDING OF ANIMALS}

linseed cake, rape cake, rice, peas, maize, wheat bran, oats, and from fish or meat feeding meals rich in fat. For cattle, an improvement in quality of the meat is obtained by giving those foods which tend to soften the fat, whilst for pigs the opposite is necessary.

The temperature of the surroundings has also a powerful influence upon the nature of the body fat. Wild animals exposed to much cold have a fat which is more oily than that of tame animals, whose fat does not melt at such a low temperature. This was well shown in the case of three young pigs of the same breed, one of which was put in a place the temperature of which was $30-35^{\circ} \mathrm{C}$., the second and third were kept at a temperature of about freezing point, the third pig being, however, sewn up in a sheepskin-wool inside. The three animals were fed in an exactly similar manner, and after two months it was found that the second animal had a much softer fat than had the other two pigs. A warm sty, therefore, assists in producing a firmer bacon.

The quantity of non-nitrogenous nutrients (exclusive of fat) which are to be given will depend principally upon whether the fattening is to be slow or rapid. It should not be forgotten though that very large supplies of food are not utilised so well as more moderate rations.

In a series of experiments with sheep, it was 


\section{FATTENING OF GROWN ANIMALS 26r}

found that when the rations contained I6.5, I8.9, and $2 \mathrm{I} \cdot 3 \mathrm{~kg}$. digestible nitrogen-free substances, with in each case $3.5 \mathrm{~kg}$. of digestible protein, the daily increase in weight was $3.557,3.763$, and $2.789 \mathrm{~kg}$. respectively. In another series of experiments, also with sheep, in which $5.2 \mathrm{~kg}$. digestible crude protein was combined with I8.I, 20.7 or $23.3 \mathrm{~kg}$. of nitrogen-free extract substances, the gains in weight were $4.062,3 \cdot 873$, and $3.695 \mathrm{~kg}$.all being calculated per I000 $\mathrm{kg}$. live weight per day. Even when, along with large quantities of nitrogen-free extract, the amount of crude protein was increased, the gain in weight was less than with moderate rations.

With fattening oxen a very satisfactory daily gain of $2.35 \mathrm{~kg}$. was obtained when only $\mathrm{I} \cdot 7 \mathrm{~kg}$. protein and $10.6 \mathrm{~kg}$. digestible non-nitrogenous material, which altogether had the starch equivalent of ro kg., were fed. Overfeeding should therefore be avoided.

(I) The fattening of grown ruminants.

In the fattening of full-grown cattle it may be taken that, exclusive of the concentrated food and of roots, about IO-I5 lbs. of coarse fodder per Iooo lbs. live weight should be given. Such a ration would contain 25-30 lbs. of dry matter, of which the digestible constituents would be at most $\mathrm{I} \cdot 6 \mathrm{lbs}$. protein, $0.7 \mathrm{lb}$. fat, and $\mathrm{I} 6.0 \mathrm{lbs}$. 


\section{SCIENTIFIC FEEDING OF ANIMALS}

nitrogen-free extract substances and crude fibre, together with a starch equivalent of $\mathrm{I} 4.5 \mathrm{lbs}$. When less coarse fodder is given, the ration may be decreased to a starch equivalent of I2 lbs. for cattle, and still produce a daily increase of $2 \mathrm{lbs}$. per Iooo lbs. of the weight at the commencement of the fattening.

There is a very large choice of feeding-stuffs suitable for fattening ruminants, and in cases where foods are equally palatable and suitable, the digestibility and percentage of water which they contain ought to be considered. Everybody knows that with cereal straw, chaff and similar fodder, no increase of weight worth mentioning can be obtained. If these substances are included in large quantities in the fattening ration there is not room enough in the limited capacity of the animal for the more easily digestible and profitable foods. Where intensive fattening is being carried on these less valuable food-stuffs must be limited, and under some circumstances not more than 5-Io lbs. of the coarse fodder per Iooo lbs. live weight need be given to maintain the appetite of the animal. Good meadow or clover hays, which otherwise give an excellent product when the animal comes into the butcher's hands, are seldom used as the chief fodder, for their value in fattening is not sufficiently high where large quantities are given.

It is otherwise with the young plants from good 


\section{FATTENING OF GROWN ANIMALS 263}

pastures, the nutritive value of which, it has been seen, approaches that of the best feeding-stuffs, and in particularly favoured districts they serve as the only material used in fattening. Even on the best pastures it is advisable to give the animals some hay before they go to the pasture, particularly when they first begin to go out, for otherwise the hasty eating of the palatable green food to which they are not accustomed easily causes disturbances of the digestive functions. The amount of fodder to be got from the pastures and its nutritive value will determine what additions, if any, of subsidiary food are necessary. As a rule, it is not possible to finish the fattening of cattle on the pastures, so a period of stall feeding usually has to follow. Sheep, too, are generally only partially fattened on the pasture, and then finished under cover on a full ration. Pasture feeding, as a rule, is cheaper than stall feeding, even when special care is taken to watch the animals and to systematically eat off the grass, for the labour is so much less. It must not be thought though that the food got from the pasture is more profitably utilised than that given in the stall. The increased movements of the animals, the conditions of weather, etc. all result in a larger quantity of nutrients being required for maintenance than when the feeding is indoors and the animals are practically at rest. On the other hand, in the open the appe- 


\section{SCIENTIFIC FEEDING OF ANIMALS}

tite is usually greater, and larger quantities of food are eaten.

Where green fodder is given in the stall, the same degree of fattening can be reached as with dry food, only the rations must, of course, be supplemented by other foods according to the nutritive value of the green food. Where the green plants (clover, lucerne, vetches, serradella, etc.) are rich in protein the addition should be in the form of cereal grains or maize, rice meal, dried beet slices, or other carbohydrate or fatty foods, whereas in the opposite case the protein-content can be raised to the necessary degree by means of oil cakes, dried brewers' grains, ground leguminous seeds, etc.

In most cases the process of fattening is carried out by first using whatever hay or straw is to be obtained from the farm, as well as the cheaper roots (mangels, carrots, turnips, kohl-rabi). Where the price of potatoes, beet slices, molasses, lupines, brewers' grains, potato pulp, etc. is low these should also be chosen, and any deficiency made up with suitable concentrated foods. Information with regard to the preparation and use of these feedingstuffs, as well as the most suitable quantities to give, has already been given in Part II.

When choosing a food, the amount of water which it contains must also be taken into account. The consequences of a too abundant supply of water have already been noticed (p. IOI). Where it is 
necessary to feed watery foods, such as beet slices, distillery waste, brewers' grains, potato pulp, mangel tops, etc., a suitable quantity of dry food should be given at the same time. Attention must also be paid to the palatableness of the food, and molasses diluted with water and poured over food that has not a very good taste assists the appetite considerably. Common salt can also be used for the same purpose, particularly when large quantities of beet slices, potatoes, potato pulp, or other tasteless foods have to be fed.

Rapid fattening is cheap fattening. The correctness of this is at once seen when it is remembered that that part of the ration which serves for maintenance has no influence upon production. The longer, therefore, the fattening lasts, so much more will the amount of food be that has to be used for maintenance. Where there is no reason for using a lot of food of little value, a better ration of higher starch equivalent would be more profitable than a more restricted one.

Plentiful bedding, so that the animal can lie down in comfort, is also important, for exact experiments have shown that metabolism is almost a third greater when an ox is standing than when he is lying down. The temperature of the stall should rather be lower when fattening is being carried on than when feeding for other purposes. Stock receiving large fattening rations generate 


\section{SCIENTIFIC FEEDING OF ANIMALS}

almost twice as much heat as they do on a maintenance diet, and therefore if the temperature of the stall is high they have difficulty in getting rid of this excess of heat; they then generally eat badly and drink too much water. It is for reasons of this nature that fattening is more difficult in summer than in winter, but even in the latter period the stall should not be allowed to sink below IO-I $5^{\circ}$ C. $\left(50-60^{\circ} \mathrm{F}\right.$.), except, perhaps, when a lot of poor food of low starch equivalent has to be fed, as, for example, in the United States, where often ripe maize plants (straw and cobs) are used.

The shearing of fattening animals is also sometimes of advantage, and for the same reasons as those mentioned under the temperature of the stall. As many investigations have shown, shearing does not cause a direct increase of flesh or of fat, but by facilitating the loss of heat from the body causes the appetite to be maintained. It thus acts as a preventative of overheating of the body, which easily arises through rich feeding and a warm stall, and which would lead to the intake of an insufficient amount of food. In the colder periods of the year shearing is only of advantage when very intensive fattening is being carried on in a place where the temperature is fairly high. When, on the contrary, the ration is only a medium one and the stall temperature low, there is no advantage gained by this operation. 
The action of the fattening ration makes itself manifest by an increase in live weight, which, however, is not maintained at the same level from the beginning to the end of the fattening period, but, as a rule, diminishes in the course of the process. This is because the animals need a larger amount of food the heavier they become. Each extra pound of weight raises the quantity of food re quired for the maintenance of the animal in its improved condition, and this amount is the greater the nearer the animal approaches the finished condition. Exact experiments carried out with the help of a respiration apparatus have shown that fat animals require almost twice as much food to maintain Ioo lbs. weight gained during fattening, as to maintain Ioo lbs. of a lean animal.

For this reason the costs of production are raised very considerably towards the end of the fattening period, and where this is continued for a long time it may happen that, for an increase in live weight of I lb., more than twice as much food must be given as at the beginning of the period. As many consumers also object to meat which is overladen with fat, it is advisable not to carry the fattening of ruminants too far.

From what has been said above, it follows that the maintenance requirements per Iooo lbs. live weight of fattened animals are greater than for thin animals. Investigations on this point were 


\section{SCIENTIFIC FEEDING OF ANIMALS}

carried out first of all with twenty fat sheep which weighed together $1160.5 \mathrm{~kg}$. at the end of the fattening time. They each received for $2 \frac{1}{2}$ months a daily ration of $I \cdot 25-I \cdot 50 \mathrm{~kg}$. aftermath hay, and later $1.5 \mathrm{~kg}$. meadow hay. During this time they lost no weight, and after the $2 \frac{1}{2}$ months' feeding with hay they weighed II66.5 kg.; nor when they were killed did they seem to have lost any of their fat. Similar results were got when two fat oxen were fed for 47 days on hay alone. More exact investigations with the respiration chamber have shown that fat oxen can be maintained in their fat condition when for each rooo lbs. live weight only $I-I \cdot 5$ lbs. digestible protein and a starch equivalent of $7-9$ lbs. are given.

If fat animals have to be kept for some time before they can be sold, the fattening ration should be very gradually broken off and the above maintenance ration substituted. Here, as also during the fattening period, it is of great advantage to weigh the animals regularly.

\section{(2) The fattening of grown pigs.}

At the age of $I-I \frac{1}{2}$ years, pigs of the more quickly growing breeds which are then practically fullgrown and have ceased to put on flesh, require, as do full-grown ruminants, only a moderate supply of protein. This fact, which has often been observed in practice, received full confirmation from 
experiments in which the respiration chamber was used. Pigs of I4-I8 months when fed on rice, which is very deficient in protein (albuminoid ratio I : I3.7), gained daily $48 \cdot 0 \mathrm{~g}$. flesh per head, and when they were given meat meal and whey, which tcgether had an albuminoid ratio of $I: 2 \cdot 4$, they only gained $45 \cdot \mathrm{I} \mathrm{g}$. The supply of protein in the food can also here be limited to that sufficient to ensure digestion of the food and to furnish the small increase of flesh which takes place during fattening. Diminution in the way in which the food is utilised by pigs is not observed even when the albuminoid ratio is as wide as I : I2 (p. 39), so that if animals in moderate condition are to be fattened it is sufficient if they get ten parts of carbohydrates (including fat) to one part of protein. When the pigs are in poor condition it is wise to increase the amount of protein by $25-30 \%$ for a few weeks at the beginning of the fattening period. The quantities of food constituents which it is best to give will be mentioned later. The amount of fat in the food ought to be kept fairly low on account of the undesirable effect which foods rich in fat have upon the quality of the bacon. On the other hand, the non-nitrogenous portion of the ration can be considerably greater than is the case with cattle or sheep, as the pig has greater power of digestibility in this respect. As the fattening advances, and in 3-4 months it can be completed, it is good practice 


\section{SCIENTIFIC FEEDING OF ANIMALS}

to gradually diminish the rations, but only so far that the animals are always completely satisfied.

In Table III of the Appendix information relative to the rations can be found. 


\section{CHAPTER V}

THE FEEDING OF WORKING ANIMALS

T $F$ a comparison is made between the kind of 1 nutrients and the production of fat or energy in the domestic animals no fundamental difference is to be found. Just as the body fat (p. 77) is derived principally from the carbohydrates of the food, so it is with the muscular energy (p. I07). Fat also plays a considerable part, but the proteins have only a very limited share in the process; in fact, neither in the production of fat nor of energy from nitrogen-free substances are they of great importance. From this it follows that it is not necessary under ordinary circumstances to give working animals very large quantities of protein. It is sufficient, as it also is with fattening animals, to let the supply of protein be such that the complete digestion of the food is assured (p. 39), and for this an albuminoid ratio of $I: 8-I O$ is enough. Exceptions to this are such animals as have not yet completed their growth and those which have to perform a lot of work in a short space of time. 


\section{SCIENTIFIC FEEDING OF ANIMALS}

Racing and driving horses which have to work at a very rapid pace require large quantities of oxygen, and as the carrier of this is in the blood it is essential to maintain the latter at a certain level, and for this purpose a plentiful amount of protein in the ration is needed.

For the ordinary work of draught horses, the albuminoid ratio above is ample; in fact, investigations with cab horses have shown that the animals can be preserved in excellent condition when the ratio is as low as $\mathrm{I}: 2 \mathrm{I}-28$.

Fat can be given in the food of working animals (oxen and horses) in larger quantities than is the case with fattening cattle, for the muscular exertion helps to maintain the appetite, which otherwise tends to diminish. Further, too, the fat does not throw as much work on the digestive organs as does an equivalent quantity of carbohydrate material. A draught ox can be given up to $\mathrm{I} \mathrm{lb}$. digestible fat for each rooo lbs. live weight without any inconvenience.

The quantity of carbohydrates in the ration depends generally upon the work which the animals have to perform and upon the food value of the constituents of the ration. As the heat generated in the body cannot be transformed into work, the digestible nutrients of those foods from which much heat arises directly, do not yield as much energy as the "full-value" nutrients (pp. 57 and 9I). 


\section{(I) The feeding of draught oxen.}

It has already been seen (p. Iog) that men, dogs, and horses are able to convert, in round numbers, a third of the utilisable energy of their food into work. There is not much likelihood of error if the same proportion is assumed to take place with the ox. If the daily work of a draught ox is known, it is not difficult to calculate how much digestible protein matter and starch equivalent are required for this amount of work. From previous considerations (p. IIo) it may be taken that I g. starch value is able to perform $533 \mathrm{mkg}$. work, so that if $2,400,000$ mkg., which is considered an average amount of work for $1000 \mathrm{~kg}$. live weight, be taken the starch equivalent would have to be $4.50 \mathrm{~kg}$. To this must be added $5 \cdot 20 \mathrm{~kg}$. starch equivalent for the maintenance of the animal (p. 245).

The ration of oxen performing medium work must therefore contain a starch equivalent per rooo lbs. live weight of $9.7 \mathrm{lbs}$. and $\mathrm{I} \cdot 4 \mathrm{lbs}$. digestible protein, the latter under ordinary circumstances sufficing for the complete digestion of the food. If food-stuffs rich in protein have to be used, then double the quantity of protein can be given without any danger. In Table III of the Appendix will be found further details relative to the rations for different kinds of work. With regard to the sort of food to be given, it must first of all be remembered 


\section{SCIENTIFIC FEEDING OF ANIMALS}

that the mass of food inside the animal is a weight which must be carried about and tends to diminish the amount of work which can be done. For this reason it is advisable to restrict the quantity of coarse fodder, which on account of its indigestibility is a considerable burden to the animal. A lot of coarse fodder also requires a longer time for its consumption and rumination, and so shortens the working period. .

It must further be remembered that very watery food has a lowering tendency and causes sweating, so that in general dry feeding is preferable to wet feeding, and when there is a shortage of green fodder, mangels, turnips, etc. these should preferably be given to the milking stock.

Draught oxen, even if they are only performing light work, cannot be kept on coarse fodder alone, although it may be of the best quality, and this in spite of the large capacity which these animals have for bulky food. Some addition of protein food must be given in order to obtain a ration corresponding to the standard. Suitable mixtures can be got from coarse fodder with moderate additions of roots; potatoes, if the price is low, are to be preferred to mangels. Instead of such roots, fresh or dried beet slices can be used, and the deficiency in protein made up by the addition of oil cakes, refuse from distilleries or breweries, ground cereal grains or leguminous seeds, molasses, etc. 
The previous descriptions of the food-stuffs, together with the feeding standards given in the Appendix, supply all the details necessary for making up the rations.

During work the animals ought to have short periods of rest in order to prevent the excessive fatigue which would raise the metabolism considerably (p. III). The length of time which an ox should be allowed to rest at midday has already been mentioned (p. 34), and it should be a rule to give a longer rest in the hot periods of the year. This is then particularly necessary, both to give time to overcome fatigue and also to admit the rise of body heat, which follows a meal, to be dissipated. The best plan is to begin work earlier in the morning in summer and to cease somewhat later in the evening than during the cooler part of the year.

(2) The feeding of horses.

In order to know what nourishment to give to a horse which is performing a certain amount of work, it is necessary to find out what is required for maintenance. Investigations on this point have been carried out in three different ways. In one series of experiments omnibus horses were used, and one-third of the working ration was given to animals at rest in the stable.

On this diet the animals lost weight; they 


\section{SCIENTIFIC FEEDING OF ANIMALS}

weighed on an average $545 \mathrm{~kg}$. each at the beginning, and after $30-48$ days the weight had fallen to 5 I $8 \mathrm{~kg}$. After this, half the working ration was given, and the average weight after 25-33 days rose to $553 \mathrm{~kg}$. A third of the working ration was, therefore, too little, whilst a half was too much. Then another lot of horses were taken, and on $\frac{5}{12}$ of the working ration an almost perfect equilibrium was established, there being after 30-48 days only an average gain of $8 \mathrm{~kg}$. The $\frac{5}{12}$ of the working ration which was fed consisted per head per day of I250 g. hay, $2500 \mathrm{~g}$. wheat straw, I250 g. oats, I875 g. maize, $625 \mathrm{~g}$. field beans, and $\mathrm{I} 66 \mathrm{~g}$. wheat bran, all together having a starch equivalent of 3254 g. per $500 \mathrm{~kg}$. live weight.

In a second experiment, with cab horses, the weight remained stationary (433 $\mathrm{kg}$. per horse) when the animals were kept for about two months at rest in the stall on a ration composed of $940 \mathrm{~g}$. hay, $508 \mathrm{~g}$. straw, I772 g. oats, $380 \mathrm{~g}$. beans, I308 g. maize, and $260 \mathrm{~g}$. maize cake, together with a starch equivalent of $3364 \mathrm{~g}$. per $500 \mathrm{~kg}$. live weight.

In a third series of experiments with meadow hay, to which in some cases straw and corn were added, the maintenance requirements were on an average $33 \mathrm{I} 2 \mathrm{~g}$. starch equivalent.

The mean of these various experiments, then, shows that for $500 \mathrm{~kg}$. live weight horses need $3 \cdot 3 \mathrm{~kg}$. starch equivalent for maintenance, so that an 
animal of that weight performing daily two million metrekilograms of work would need to get $7 \cdot 05 \mathrm{~kg}$. starch equivalent. As I kg. starch equivalent equals $533 \mathrm{mkg}$. work, two millions mkg. would use $3.75 \mathrm{~kg}$. starch equivalent, to which must be added $3.3 \mathrm{~kg}$. for maintenance (see above), making the total $7.05 \mathrm{~kg}$. The following figures show what is the daily work of a horse working eight hours a day and at a rate of $4 \mathrm{~km}$. per hour.

Live weight, kg. . $\quad \begin{array}{llllll}300 & 400 & 500 & 600 & 700\end{array}$

$\begin{array}{lllllll}\text { Draught energy, kg. } & 45 & 56 & 67 & 78 & 89\end{array}$

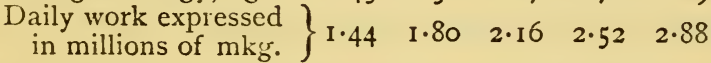

For the above work the following starch equivalents in $\mathrm{kg}$. are necessary :-

For the work .

For the maintenance of the animal

$\left\{\begin{array}{lllll}2.70 & 3.38 & 4.05 & 4.73 & 5.40 \\ 2.35 & 2.84 & 3.30 & 3.73 & 4.13 \\ \hline 5.05 & 6.22 & 7.35 & 8.46 & 9.53\end{array}\right.$

Light horses perform slightly more work in proportion to their weight than do heavy ones, for a $300 \mathrm{~kg}$. animal will do for an average day's work 4.80 million mkg. per $1000 \mathrm{~kg}$. live weight, whilst a $700 \mathrm{~kg}$. horse will only do $4 \cdot \mathrm{II}$ million $\mathrm{mkg}$. With the food it is the opposite, for each one million mkg. requires a starch equivalent of $3.5 \mathrm{I}$ in the case of the horse weighing $300 \mathrm{~kg}$., whilst for the $700 \mathrm{~kg}$. horse only $3.3 \mathrm{I} \mathrm{kg}$. are necessary. It is on the above facts that the feeding standards for 


\section{SCIENTIFIC FEEDING OF ANIMALS}

light, medium, and heavy work, given in Table III of the Appendix, are based, and these standards, it has been proved, are covered by the food given in many establishments where large numbers of horses are kept. Naturally, what in actual practice is termed medium or heavy work differs very considerably. As a rule, those rations which have been found to give good results are continued, and it is only, for example, when the price of oats is very high, or when other reasons make it imperative to introduce some other feeding-stuff into the ration, that a recalculation is made. In such cases Table I of the Appendix gives all the necessary data for the calculation. In this table the estimations of the starch equivalents are calculated for ruminants, but it has been shown that they can serve equally well for horses. It has been found by means of eighteen separate experiments with different foods how much work the starch equivalent of the various rations was able to perform, and the results have agreed very closely with the theory. The horses in these tests had to turn a braked capstan, and the work was gradually increased until the animal began to lose weight. If Ioo be taken as the observed maximum of work, it was found that the figures obtained by calculation from the starch equivalents in the several cases varied between 96.5 and I03.I, the average of which is $99 \cdot 8$. It is thus possible to use, until 
something better is discovered, the starch equivalent as a measure of the work in calculating rations for horses.

With regard to the form which the food shall take that is to be fed to working horses, it must first be remembered that the coarse fodder must be decreased the greater the call upon the animal is. The smaller capacity of the digestive organs of a horse compared with that of a ruminant indicates at once that the more voluminous foods-hay, straw, green fodder-must be cut down in the case of the horse. The burden of these badly digested materials, the disturbance of respiration through too large a volume of food, and the relatively small amount of nutritive matter which they contain, is the reason why usually less than 20 lbs. coarse fodder are given per Iooo lbs. live weight-generally, in fact, less than ${ }_{5} 5 \mathrm{lbs}$. and sometimes even less than Io lbs. The supply of coarse fodder can only be totally suppressed for a very short time, for otherwise, even if a good supply of oats be given, the appetite diminishes and the digestive organs become upset. The coarse fodders most useful to give to horses are meadow and grass hay, lucerne, sainfoin and clover hay, also the straw of summer and winter cereals, above all oat, barley, and wheat straws. In some large stables where fodder has to be bought, the practice of feeding oat or wheat straw instead of hay has been followed 


\section{SCIENTIFIC FEEDING OF ANIMALS}

for some time, for the number of cases of colic was observed to be greater the more hay was given.

The difficulty of knowing whether the whole of the hay is sound, when large quantities are bought, may just as well have been the cause of the sickness.

In Middle and Northern Europe and in North America oats are the chief food given to horses, whilst in more southerly countries barley and maize take the first place. Oats, without doubt, are the most suitable of the grains, then barley and finally maize. The latter has come much more into use during the last ten years amongst those who keep large numbers of horses. Maize is said to somewhat diminish the vivacity of the animals and to cause them to sweat, but recent investigations have shown that the substitution of it for oats did not impair the efficiency of military horses. Cavalry and artillery horses which were given maize as the only corn food were able to perform the same work as those on oats without the least falling off. Similarly with omnibus horses, where the experiment was continued for a long period and the greater part of the oats replaced by maize, there was nothing found to the disadvantage of the maize. For large horse-owners and in farm practice it would almost certainly be more profitable to substitute maize for some, if not all, of the oats, when the price of maize is not too high. As is 


\section{FEEDING OF WORKING ANIMALS 28I}

seen from the tables in the Appendix, maize has a higher starch equivalent than oats.

Barley can also take the place of oats, but it must be remembered that this grain varies a good deal in composition, and so care should be taken to choose good samples. Small, hard grains of barley easily pass undigested through the animal, and cannot completely replace an equal weight of oats.

Rye is sometimes also used as food for horses; it is preferable to cook it and to give I part to 2-3 parts of oats.

Wheat seems to be less suitable for horses; it is sometimes given to breeding stallions, but, like buckwheat, it causes irritation of the skin, and this can greatly inconvenience the animal.

Amongst the Leguminosæ field beans in quantities of $\mathrm{I}-2 \mathrm{lbs}$. fitly find a place in the ration, and particularly so if an extra effort has to be made, or if continuous hard work is being done. Oil cakeslinseed, palm-nut, cocoa-nut, sesame, maize germ -and meals made from these are given in quantities of I, at most 2 lbs. per day per horse. Molasses and its mixtures with brewers' grains, maize germ cake, palm-nut meal, chopped straw, etc. are all excellent for horses, and may be given in quantities up to 3 lbs. per day to horses, which are thereby kept in better condition for work as well as in improved health. Most of the other ordinary foods are only used in a supplementary manner 


\section{SCIENTIFIC FEEDING OF ANIMALS}

for the horse; particulars as to these have already been given in Part II of this book.

With working animals, and particularly with the highly-strung horse, all that tends to load the digestive organs ought to be shut out from the diet, and also those food-stuffs which make the animal take more water than it would under normal feeding conditions. Care should be taken that the food is of the best, and anything that is musty or has been attacked by moulds or fungi should not be given. Any food either that contains injurious substances even in a small degree ought not to be fed.

Horses ought to have a rest of $2-2 \frac{1}{2}$ hours in which to eat and digest their food in peace, and this gives them a chance of resting before the work is begun again. What it is essential to know about watering has already been mentioned (p. 237). 


\section{CHAPTER VI}

THE FEEDING OF GROWING ANIMALS FOR BREEDING OR FATTENING

A FULY grown animal is practically in a state - 1 of permanence, and gives out exactly as much as it takes in. During fattening, in spite of the most liberal feeding, there is only very little, if any, protein or mineral matter added to the body substance, the increase being almost entirely fat. With a growing animal, on the contrary, when it receives sufficient food there is a regular gain in its nitrogenous and mineral components. There is no cessation in the development of the organs of growing animals, not even when as much is taken in as is given out, for in such a case some of the organs would grow at the expense of the others, a condition which naturally could only be maintained for a certain time.

When the rate at which young animals lay on flesh and mineral substances is considered, it is easy to understand how some have thought that the maintenance requirements are less during growth than later, and that with young cattle the 


\section{SCIENTIFIC FEEDING OF ANIMALS}

food has greater productive value. Investigations carried on from several standpoints have, however, taught that the metabolism in the young body is at least as much and perhaps more than when growth has ceased, but that the protein and mineral substances in excess of maintenance requirements can be utilised to a much greater extent for the development of the growing organs. The complete investigations of the daily income and output of a 2-3 weeks old sucking-calf weighing $50 \mathrm{~kg}$. gave the following :-

\begin{tabular}{|c|c|c|c|c|c|c|c|c|c|c|}
\hline & 㟧 & 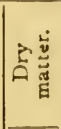 & 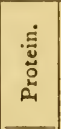 & 萑 & 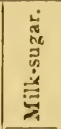 & 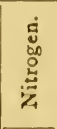 & ठًં & 焉离 & 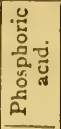 & $\stackrel{\Xi}{\Xi}$ \\
\hline In the food $8093 \mathrm{~g} \cdot$ milk & $\underset{7 \cdot 28}{g .}$ & 96.5 & $\begin{array}{c}\mathrm{g} . \\
24 \cdot 5\end{array}$ & g. & $\begin{array}{c}\text { g. } \\
42 \cdot 2\end{array}$ & $\begin{array}{c}\text { g. } \\
39^{\circ} 2\end{array}$ & $\begin{array}{l}\text { g. } \\
4^{8} \cdot 8\end{array}$ & $\begin{array}{l}\text { g. } \\
6 \cdot 2\end{array}$ & $\begin{array}{l}g . \\
109\end{array}$ & $\begin{array}{l}\text { g. } \\
1 \cdot 5\end{array}$ \\
\hline In the ding $=91 \mathrm{~g}$. . & - & $2 \cdot 2$ & $13 \%$ & 0.5 & . & $2 \cdot 2$ & 9 & $1 \cdot 6$ & 0.2 & $0 . \frac{5}{5}$ \\
\hline " , urine $=5370 \mathrm{~g}$. & - & - & - & - & - & $10 \cdot 2$ & $11 \cdot 6$ & $27 \cdot 4$ & $5^{\circ} \mathrm{O}$ & $\circ$ \\
\hline ärbonic acid $=945 \mathrm{~g}\}$. & 一 & - & - & - & - & 一 & $257^{\circ} 6$ & - & - & 一 \\
\hline Decomposed & - & 一 & $63 \cdot 5$ & $78 \cdot 5$ & $42 \cdot 2$ & - & - & - & - & 一 \\
\hline Stored in the body & 一 & - & $16 \cdot 8$ & 15.8 & - & $26 \cdot 8$ & $209^{\circ} 8$ & $33^{\circ} \mathrm{O}$ & 138 & 14.5 \\
\hline
\end{tabular}

The daily increase was thus $925 \mathrm{~g}$., of which $379 \mathrm{~g}$. were dry matter and $566 \mathrm{~g}$. water. Only very small quantities of the ingested milk passed into the freces, and of the digested proteins $72 \cdot 6 \%$ were stored in the body, and only $27.4 \%$ were decomposed. Thus it is seen that the growing animal possesses an extraordinary power of incorporating the proteins which are offered to it, 
and this it only loses gradually. As with the protein, so also with the mineral substances which are necessary for the formation of the important vital organs. In the above case the sucking-calf retained $53 \%$ of the total ash of the milk which it consumed.

Of the phosphoric acid $72.5 \%$ was kept in the body, of the lime as much as $97 \%$, and of the other mineral substances (potash, soda, oxide of iron, magnesia) $20-40 \%$, of which chlorine was the least, only $4 \%$. Lime and phosphoric acid were, therefore, retained to a much larger extent than the other substances, in the case of the lime only $3 \%$ passing into the excreta According to this it almost seems as though the milk of highly bred cattle was too poor in this material, which is so important for the making of bone. The eagerness with which calves eat mortar, chalk, or other limecontaining substances, points to the milk being deficient in this respect and the advisability of giving some precipitated chalk to animals of this kind.

With regard to the food metabolism after weaning, investigations with lambs (SouthdownMerino cross) from the 5-24 months have given results noted below. The ration which was given kept the animals in good condition and they developed satisfactorily, digesting the following quantities per head per day :- 
286 SCIENTIFIC FEEDING OF ANIMALS

$\begin{array}{ccccc}\text { Age. } & \begin{array}{c}\text { Live } \\ \text { weight. } \\ \text { g. }\end{array} & \begin{array}{c}\text { Protein. } \\ \text { g. }\end{array} & \begin{array}{c}\text { Carbo- } \\ \text { hydrates. } \\ \text { g. }\end{array} & \begin{array}{c}\text { Fat. } \\ \text { g. }\end{array} \\ 5-6 & 23 & 79 & 376 & \text { I6 } \\ 7-9 & 30 & 86 & 427 & \text { I7 } \\ \text { I0-I2 } & 35 & 82 & 429 & \text { I9 } \\ \text { I3-I5 } & 39 & 8 \text { I } & 445 & \text { 2I } \\ \text { I6-24 } & 47 & 73 & 492 & 24\end{array}$

The storage of mineral matter per day and per head was :-

\begin{tabular}{|c|c|c|c|c|c|c|}
\hline $\begin{array}{c}\text { Age, } \\
\text { m jnth. }\end{array}$ & $\begin{array}{c}\text { Live } \\
\text { weight. } \\
\text { kg. }\end{array}$ & $\begin{array}{l}\text { Potash. } \\
\text { g. }\end{array}$ & $\begin{array}{c}\text { Soda. } \\
\text { g. }\end{array}$ & $\begin{array}{l}\text { Lime. } \\
\text { g. }\end{array}$ & $\begin{array}{l}\text { Magnesia } \\
\mathrm{g} .\end{array}$ & $\begin{array}{c}\text { Phosphoric } \\
\text { acid. } \\
\text { g. }\end{array}$ \\
\hline $5-6$ & 23 & $2 \cdot 04$ & 0.84 & $I \cdot 56$ & O.I2 & $I \cdot 09$ \\
\hline $7-9$ & 30 & $2 \cdot 89$ & I.05 & $2 \cdot 00$ & 0.32 & $I \cdot 65$ \\
\hline $\mathrm{IO}-\mathrm{I} 2$ & 35 & $3 \cdot 05$ & $0.8 I$ & $I \cdot 8 I$ & 0.38 & $2 \cdot 50$ \\
\hline I3 - I 5 & 47 & $2 \cdot 65$ & 0.72 & $2 \cdot 07$ & $0 \cdot 35$ & $3 \cdot I_{4}$ \\
\hline
\end{tabular}

Potash, soda, lime, and magnesia, according to the above, are retained in about the same quantities at the various ages, whereas the phosphoric acid is held back in the body in increasing quantities.

Owing to the demand of growing animals for mineral matter this point should have special attention in feeding, for a lack of these substances, particularly of lime and phosphoric acid, brings serious results (p. 96). It must further be remembered that the animals are not in a position to make use of all the mineral matter in the food. From 
two investigations with calves of 5-6 months of age, it was found in one case that only $42 \%$ of the lime of the food was utilised, and of the phosphoric only $46 \%$; in the second case, $5 I-54 \%$ of the lime and $56-65 \%$ of the phosphoric acid. The two last mentioned numbers may be taken as the maximum, for in a further series of experiments in which precipitated phosphate of lime was added to the food the animals did retain a little lime and phosphoric acid in their bodies, but it should be remarked that the food itself was deficient in these two substances.

From what has been said, it may be taken that animals should have in their ordinary food about 2-3 times as much lime and phosphoric acid as they store in their bodies. Milk, however, is utilised in a higher degree, as has already been noticed.

In the rearing of young stock the direction which the animals will take later ought not to be overlooked. If they are to be fattened, then, even before their birth they are helped by giving the mother a liberal diet, and afterwards they should also be treated well in the matter of food.

Male animals intended for breeding should also get a more liberal diet, without being allowed to grow too fat, than those animals intended for the production of wool or meat or for draught purposes. The first principle should be not to hinder the development of the animals by a lack of food, for 


\section{SCIENTIFIC FEEDING OF ANIMALS}

what is lost in the beginning can never be regained.

Owing to the sensitiveness of young domestic animals, every care should be taken to prevent any injurious influences. The food given whilst the animal is getting set, and also afterwards, ought to be of the best quality. Untried feeding-stuffs, or artificial ones which are certain to be offered, ought not to be tried. Even in the preparation of the food for young stock it is best to remain by the usual practice and to divide the ration into several meals (p. 235). It is far better to give 2-3 more meals than to force the animal to overeat itself through getting food too seldom. All that has been said regarding the care and treatment of the animals applies even more to young stock.

The stall should be well ventilated, dry, light, and clean, and in winter the temperature ought to be kept about $I 5-18^{\circ} \mathrm{C}$. $\left(60-65^{\circ} \mathrm{F}\right.$.), and in summer there should be some provision for moderating the heat. Draughts, cold, and damp are often the only causes of failure.

A regulated amount of exercise in the open air is of the greatest benefit during development, for it is only when the limbs are used that the muscles and bones mature satisfactorily. Movement in the open air, best of all a long sojourn at grass, prevents - the too early formation of fat and ensures a tough, strong constitution. The resistance to disease is 
FEEDING OF GROWING ANIMALS 289

also strengthened in this way, and other properties which make the animal valuable for the purposes for which it is being reared are fostered. If a suitable pasture is not to be had, then shift must be made with any place that will serve as a sort of play-ground.

(I) The feeding of calves.

At first it will be enough to let the calves have the colostrum (p. 2I9) from the mother, which causes the removal of the pitch-like contents of the intestines. After this whole milk is the chief food, and if the calves are allowed to suck, the udder is seldom completely emptied; there remains a portion of the milk which many cows obstinately hold back, and as they are not then milked dry the yield diminishes. If the calves as soon as possible after birth are fed by hand the above disadvantage is avoided, and there is also the advantage of being able to measure as much milk as is needed to each calf, and also avoid the troubles of weaning. Scrupulous cleanliness of the drinking vessels, careful measurement of the quantity of milk, and punctual feeding are absolute necessities if success is to follow.

The quantity of milk to be fed depends upon the body weight and the purpose for which the calves are intended. If they are later to be used for milk production or for draught purposes they should 


\section{SCIENTIFIC FEEDING OF ANIMALS}

get daily $\frac{1}{7}-\frac{1}{8}$ of their live weight in whole milk, and the purely-milk period should be limited to four or at the least three weeks. Calves which will later be fattened or are being kept for breeding should be given rather more milk $-\frac{1}{5}-\frac{1}{6}$ their live weight, and should not be weaned for six weeks.

Warm fresh milk should always be used, for when cold it is apt to cause scouring. In order to escape tuberculosis boiled milk has often been used, but it is said that the animals reared with this do not do as well as those on raw milk. Experiments on this point have, however, shown that hardly any difference exists, for the quantities found to give I $\mathrm{kg}$. live weight increase were 10.82 litres of boiled milk, I0.45 litres boiled milk and salt ( 2 g. per litre), and II.II litres of raw milk. With properly measured milk supply and good attention to the calves ro litres ( $2 \frac{1}{4}$ gals.) of milk give on an average I $\mathrm{kg}$. (2.2 lbs.) increase of live weight.

The weaning of calves from a milk diet must be done very gradually, the whole milk being replaced by equal quantities of separated or skimmed milk, which is best boiled and given in a lukewarm state. Not more than $\frac{1}{2}$ litre of whole milk should be replaced daily. As in this way a considerable quantity of fat is withdrawn from the animals, it must be replaced, and this is best done by the addition of linseed, 25-30 g. (I oz.) to $\frac{1}{2}$ litre (I pint) skim milk. Oatmeal and later linseed cake, as well 
as cocoa-nut, earth-nut, and palm-nut cakes, may be given, also barley and pea meals, malt coombs, and small quantities of bran, whey, etc. The lack of fat can also be made good by some suitable oil (20 g. earth-nut oil per litre) which should be beaten with the hot separated milk by means of a whisk until no drops of oil are to be seen.

An excellent substitute for whole milk is found in Liebig's recipe (p. I45), which is also suitable for those calves that cannot digest the mother's milk. Good results have been got from the addition of saccharified starch to the skim milk. If commercial extract of malt is used for the saccharification the following quantities have been found to give a suitable preparation: $500 \mathrm{~g}$. ( $\mathrm{r} \delta \mathrm{oz}$.) potato starch stirred with $\frac{1}{2}$ litre (I pint) cold water, and then $3 \frac{1}{2}$ litres ( 6 pints) almost boiling water gradually added. This gives a stiff paste, which should be allowed to cool to $50-60^{\circ} \mathrm{C}$. ( $\left(25-140^{\circ} \mathrm{F}\right.$.), and then $50 \mathrm{~g}$. $(2 \mathrm{oz}$.) malt extract stirred in ; after standing half hour the drink is ready. Finely ground malt (about 2 oz.) can naturally be used instead of the extract, only then the liquid ought to be drawn off through a sieve before being fed to young calves. Instead of starch or flour it is possible to use wheat or rye feeding meals with good results. The use of such saccharified foods with skim milk in place of whole milk can be begun when the calves are four weeks old, and the I4-I6 pints whole milk replaced 


\section{SCIENTIFIC FEEDING OF ANIMALS}

by Io pints whole milk and 5 pints of the liquid just mentioned. In the fifth week the whole milk should be reduced to 5 pints, and to it should be added Io pints skim milk and 5 pints of the saccharified solution. From the sixth week on the ration per head and per day would consist of 16 pints of skim milk and 5 pints of solution. According to observations made on twenty-two calves aged 4-36 days for a period of half a year, the daily increase of weight per head was on an average $\mathrm{I} \cdot 05 \mathrm{~kg}$. when potato starch and extract of malt were given. The favourable effect of the saccharified solution depends partly upon the change of the starch into dextrine and maltose, whereby digestion and resorption is facilitated, and partly upon the mucilaginous nature of the dextrine which acts like linseed or linseed cake upon the digestive organs.

Newly born calves have only a simple stomach, and so in early life they have to be provided with easily digestible nourishment. The formation of the fore stomachs only begins later, and the process is considerably helped if, as early as a week after birth, a small but gradually increasing quantity of tender, palatable meadow hay is given.

If the time for weaning has come the milk should be withdrawn a pint at a time and some other warm drink substituted; at the same time, more meadow hay should be given up to 3 or 4 lbs. Along with this, about the end of the third month, finely 
pulped or crushed mangels or carrots may be given, and with them finely chopped straw, crushed oats, ground barley or peas, oil-cake meal, malt coombs. At the proper time the hay may be replaced by grass, the best form being a pasture with plenty of sweet grasses; clover should be avoided for a time.

In the period after weaning the young stock must always be better fed, for the withdrawal of the milk easily puts the animals back, their growth at the time being very rapid. From the 4-6 months onward the calves can take more coarse fodder and mangels, and after the end of the first year they do best on the same kind of food as grown cattle. As the skeleton of a year-old calf contains on an average $7700 \mathrm{~g}$. lime (I $7 \mathrm{lbs}$.) and $7000 \mathrm{~g}$. (I $5 \frac{1}{2} \mathrm{lbs}$.) phosphoric acid, the daily addition would be $2 \mathrm{I} g$. lime and $I_{9}$ g. phosphoric acid. The daily ration must, therefore, contain 40-60 g. ( $\left(\frac{1}{2}-2 \mathrm{oz}\right.$.) of each of these materials to fully meet the demands.

When calves are being fattened only sweet milk is used as a rule, for if other foods (hay and corn) are given the meat loses its taste and also its bright colour. The best quality of meat is got when milk alone is used, and sometimes eggs are beaten up in it. As a partial substitute for whole milk it is usual to give separated milk, or a mixture of this with whey, and other substances, such as earth-nut oil, saccharified starch, etc., to make up the deficiency 


\section{SCIENTIFIC FEEDING OF ANIMALS}

in fat. Good results have also been obtained with mixtures of $\mathrm{I}$ oz. rice meal and $\mathrm{I}-\mathrm{I} \frac{1}{2} \mathrm{oz}$. crushed linseed, or with about $2 \mathrm{oz}$. maize meal to each quart skim milk. Buckwheat flour is said to have the best effect on the quality of the flesh. All these added materials are best borne if they are boiled, steamed, or saccharified before being fed.

\section{(2) The feeding of lambs.}

The weaning of lambs begins, as a rule, 3-4 weeks after birth, and only those intended for breeding purposes are allowed to stay longer with the mother. In order to accustom the lambs to take solid food they are separated after the time given above for some 6-8 weeks, but only in the daytime. Then by gradually reducing the opportunity which the animals have of sucking the mother they are completely weaned. During the time of separation good tender meadow hay should be given, and later also crushed oats as well as a supply of good water. In this way it is possible to accomplish the weaning in about three months, from which time on good meadow hay, together with crushed oats, coarsely ground peas, mild oil-cake meals, etc., are the chief food. Lambs, like other young stock, do best when they are gradually accustomed to being on the pasture.

The daily requirement per Ioo head of lambs 
up to completion of weaning is about $20 \mathrm{~kg}$. (44 lbs.) hay and $6 \mathrm{~kg}$. (I3 lbs.) corn for the lighter breeds, and about $30 \mathrm{~kg}$. (66 lbs.) hay and 7.5-10 kg. (I620 lbs.) corn for the heavier breeds. After the withdrawal of the mother's milk the amount required up to the end of the first year is about $50 \mathrm{~kg}$. ( $\mathrm{I}-\mathrm{I} \frac{1}{2} \mathrm{cwt}$.) hay and Io-20 kg. (22-44 lbs.) corn.

In the second year each Ioo sheep will need daily I-I $\frac{1}{2}$ cwt. hay and 22-33 lbs. corn, together with some mangels and also some straw to pull. Where the animals are on the pasture a small amount of hay and corn should also be given.

Watery food, of whatever kind, which contains more liquid than the sheep naturally take (p. Ior) is not readily eaten by them, and if constantly given is not as well borne as with other species. Roots and watery by-products, as also gruels and drinks, can only be used as subsidiary food in the rearing of these animals.

On account of their rapid growth lambs need a more concentrated food than do calves, and the feeding should be according to the purpose for which the animals are intended. Where the lambs are to be fattened and killed the food should be richer than where the production of wool is the main object. Information relative to the size of rations, etc. can be gathered from the standards given in Table III of the Appendix.

Lambs about 4-5 months old are found to take 


\section{SCIENTIFIC FEEDING OF ANIMALS}

up daily $2 \cdot 5-3 \cdot 8 \mathrm{~g}$. lime and $2 \cdot 0-4 \cdot \mathrm{I} \mathrm{g}$. phosphoric acid per $50 \mathrm{~kg}$. live weight. To cover this need the food per 200 lbs. live weight should contain I oz. lime and I oz. phosphoric acid; these quantities are, as a rule, contained in the ordinary ration for lambs.

\section{(3) The feeding of growing pigs.}

With regard to the feeding of young pigs there is not, unfortunately, any investigation which throws light upon their requirements, and so the experience of practice has to be relied upon. Experienced breeders allow those pigs which are intended for breeding purposes to suck for 6-8 weeks, whereas those which are to be fattened may be limited to 4 weeks. Weaklings may be allowed to go on for as long as ten weeks.

When only 2-3 weeks old the young pigs begin to gnaw and eat other food, which is an indication that some whole barley, wheat, or crushed oats should be given. They should also have from this time onward some charcoal, coal, earth, or sand given to them daily.

In consequence of the rapid growth of the young pigs the mother is soon unable to feed them sufficiently, so from the third week on whole cow's milk, after being boiled and diluted with an equal quantity of water, is given in a lukewarm state. As the composition of sow's and cow's milk differs, 
and the latter tends to cause scouring in young pigs, it should be slowly introduced into the diet. The quantity at first should not exceed $\frac{1}{8}$ litre ( $\frac{1}{5}$ pint), and it may be gradually raised to about I litre ( $\mathrm{I}_{4}^{\frac{3}{4}}$ pints), but not more. If separated milk is used, then the addition of some saccharified starch food, as described previously (pp. I45 and 29I), is advisable. The milk and the corn, which is given in increasing quantities, supply, as a rule, all the phosphoric acid required, but there is often a deficiency of lime which must be made good by the addition of precipitated chalk to the food; by degrees, $\frac{1}{4}-\frac{1}{2}$ oz. may be given.

When the young pigs are capable of taking a sufficient amount of food they should be accustomed as quickly as possible to the use of those foods which they will have after weaning, and the mother's milk gradually withdrawn. After weaning, the whole milk is replaced by degrees by skim milk, which should be boiled and fed in a lukewarm state, but not necessarily diluted. If the pigs are intended for breeding purposes they may be given skim milk and crushed corn (barley, oats, or wheat) up to three months old, or ground peas and beans instead of the corn. From the third month onward pulped mangels, boiled or steamed potatoes, finely ground maize, tender green fodder and, above all, young clover may be introduced into the ration, and the skim milk withdrawn if the 


\section{SCIENTIFIC FEEDING OF ANIMALS}

development need not be particularly rapid and perfect.

The young boars should always be rather better fed than the young breeding sows, and from the commencement of sexual maturity, which usually begins at eight months, up to the end of the growing period they ought to have a food richer in protein. This can be made up of green fodder or mangels, and oats or coarsely ground beans. When the growing period is over the boars should be kept in good condition, but not allowed to grow fat, and a daily addition of $\mathrm{I} \mathrm{lb}$. coarsely ground rye is sufficient concentrated food.

The young females intended for breeding purposes should be fed less intensively from their 5-6 month, so from that time they get more green food and roots with larger quantities of chaff and less ground corn. These animals do the best if allowed to run out to grass, and as that is one of the cheapest ways of keeping them it may be begun at the fifth month. The most valuable pastures are those with red clover, and $2 \frac{1}{2}$ acres of this ought to keep 25-40 pigs for about I20 days. Fallow or stubble land, harvested potato or mangel fields, and waste land can also be used if the pigs get some suitable food before leaving the sty and on their return. Such an exercise ground though, which merely allows the animals to move about in the fresh air, is a poor substitute for pasture. This sparer diet 
prevents the deposition of fat and should be continued until the animals are sexually mature. When they are pregnant they should get increasing quantities of coarsely ground oats and barley. When pregnancy is far advanced the sows may be given some wheat bran and linseed cake, and as these have a loosening tendency upon the bowels they are of benefit. At this stage a richer diet is necessary not only to secure proper development of the young, but because at the time of the first farrow the sows are not fully grown. Similarly, during the suckling period extra food is needed to furnish milk.

Young pigs which from the age of 4-6 months are being prepared for the butcher are fed similarly to those intended for breeding purposes, and the aim should be to get well-developed flesh not overburdened with fat. Animals destined for this purpose may be given a ration with more protein than is given to those kept for breeding. The feeding of pigs on which fattening only commences when they are fully grown, say $I \frac{1}{2}$ years old, is different, for there a coarse, solid meat with a firm layer of bacon is wanted. In the rearing of these animals they should be given from the time of weaning a ration richer in protein, and this can be done by feeding along with separated milk such foods as roots, rye bran, ground maize. After the fifth month they may be given in addition other 


\section{SCIENTIFIC FEEDING OF ANIMALS}

materials, such as whey, wheat bran, beet slices. Later, potato pulp and corn, or potato slumps, feeding meals, green maize or other green food and chaff may be given. At suitable periods of the year these animals also find the best and cheapest nourishment on the pastures.

Most of the food-stuffs which are used for rearing swine-milk, cereal grains and, above all, potatoes and mangels-contain only a small quantity of lime. By the use of green food, leguminous seeds, etc. and by pasturing this scarcity is lessened to some extent, but still it is often noticeable in the malformation and disease of the bones. It is, therefore, advisable to let the pigs have some carbonate of lime in the form of precipitated chalk from the first week they are born. The quantity must be regulated according to age and size, and will vary from $5^{-\mathrm{I} 2} \mathrm{~g}$. ( $\frac{1}{4}-\frac{1}{2} \mathrm{oz}$.) per head per day. Phosphate of lime or its surrogate (p. 224) will then only be needed when the ration is composed chiefly of those foods which are poor in phosphoric acid (p. 97). As the body of a full-grown pig contains in all $\mathrm{I} \cdot \mathrm{I} 5 \%$ lime and I.IO \% phosphoric acid, and as after a year's fattening an average specimen will have gained about $120 \mathrm{~kg}$., the total increase in this time will have been $I \cdot 35 \mathrm{~kg}$. lime and $\mathrm{I} \cdot 32 \mathrm{~kg}$. phosphoric acid, which is a daily addition of 3.8 and $3.7 \mathrm{~g}$. respectively. If it be assumed, as is probable, for I $\mathrm{g}$. of these materials to be stored in 
the body about $3 \mathrm{~g}$. must be present in the food, then the daily amount required is in round numbers I2 g. ( $\frac{1}{2}$ oz.) each of lime and phosphoric acid, but on a milk diet less than half this quantity. It is thus possible to estimate whether a ration contains sufficient of these nutrients, and what addition of phosphate of lime is necessary if there is a deficiency of phosphoric acid.

As regards the fattening of young pigs, a large number of investigations have taught that the protein in the ration must be kept at a fairly high figure. In one series of experiments with pigs of the Yorkshire breed, which weighed $57-60 \mathrm{~kg}$. (I25-I30 lbs.) each, the daily increase of weight over a period of 90-95 days was: with maize, $0.465 \mathrm{~kg}$. (I lb.); with barley, $0.665 \mathrm{~kg}$. (I.5 lbs.); with maize and separated milk, $0.735 \mathrm{~kg}$. ( $\mathrm{r} \cdot 6 \mathrm{lbs}$.); and with barley and separated milk $0.745 \mathrm{~kg}$. ( $\mathrm{I} \cdot 64 \mathrm{lbs}$.$) . The total increase of weight with$ maize alone was $45^{\circ} 0 \mathrm{~kg}$. (99 lbs.), and with barley and separated milk 70.5 kg. (I55 lbs.) - a remarkable increase which must be ascribed to the extra quantity of protein. The pigs, it is true, would become fat on the maize, which is poor in protein, but they would never reach the perfect development which is assured by a more nitrogenous diet, and-what is very important from the financial side of the question-they require considerably more food for an increase of Ioo lbs. than when 


\section{SCIENTIFIC FEEDING OF ANIMALS}

sufficient protein is given. This holds particularly for quick-growing breeds which begin to be fattened at an average weight of 8o-roo lbs. The carbohydrates must also be kept at a reasonably high amount for young fattening pigs.

At the beginning of the fattening period the pigs can eat very large quantities of food daily, up to $44 \mathrm{lbs}$. dry matter per Iooo lbs. live weight, but later the appetite diminishes, and towards the end the daily amount is generally not more than 25-30 lbs. All these circumstances are taken into account in the feeding standards in the Appendix (Table III), which are designed for rapid fattening of the large, rapidly growing breeds, and assure a daily increase of $0.6-0.7 \mathrm{lb}$. during the whole course of the fattening.

The most intensive fattening is achieved when the animals are given very digestible food mixtures. The higher the digestibility of the whole diet the greater is the amount of active nutrients that can be given to the animals, and the better the increase of weight proceeds. Indigestible feeding-stuffs, such as dried grains, old green fodder, refuse from cereals containing a lot of chaff, not only bring less flesh- and fat-forming material into the body, but also, owing to the room taken up by the undigested matter, prevent larger quantities of digestible nutrients from being fed. On the other hand, sround cereal and leguminous seeds, maize, buck- 
FEEDING OF GROWING ANIMALS 303

wheat, feeding meals, potatoes, meat- and fishmeal, waste products from the dairy are amongst the most suitable feeding-stuffs. Dried beet slices and bran are digested by pigs to the same extent as by cattle, but they do not have the same value in production as do the full-value (p. 90) nutrients. If the ration is composed of very digestible foods, then some bran, chaff, or husky barley refuse should be given at the same time so as to assist the expulsion of the frces. Very large quantities of protein, much in excess of the feeding standards, favour foot-halt.

Experience has taught that many feeding-stuffs have an influence upon the quality of the meat and particularly so upon the bacon. This influence is much more marked in the colder periods of the year, as has already been mentioned (p. 26o). The feeding-stuffs which have the greatest effect in this direction are above all maize, most oily seeds and rich oil-cake meals, rice meal, oily fish meal, distillery waste, brewers' grains. If these materials, however, are given in moderate quantities, at the most one-third of the total concentrated food, or if they are replaced during the last third of the fattening period by other foods, the effect is greatly or entirely diminished. The same advice applies to very watery roots, fresh beet slices, waste products from the manufacture of alcohol or starch, or refuse from the dairy. None of these should be 


\section{SCIENTIFIC FEEDING OF ANIMALS}

given in large quantities during the last four or five weeks of fattening, or even earlier than that, for the tissues ought to have time to get rid of the excess of water before the animal is killed. With those foods which tend to give a soft oily bacon, it is advisable to feed at the same time some palm-nut or cocoa-nut cake meal, either of which tends to correct the softness. When feeding with maize satisfactory results have been got from a mixture of 80 parts maize meal and 20 parts palm-nut cake meal.

Cotton-seed meal has frequently been the cause of fatal illness to pigs, and must therefore be used with the greatest possible caution. Roughly ground lupines also act poisonously and lead to cramp and death, but when they have been freed from the bitter principle, which must be thoroughly done, they are a good fattening food. Meat meal, which is very suitable as an addition to a diet deficient in protein, allows of the consumption of large quantities of steamed or boiled potatoes, but it has the disadvantage of easily causing diarrhœa, and therefore should only be given to young animals in quantities of 50-Ioo g. (2-4 Oz.), or by very gradual increase up to $250 \mathrm{~g}$. (9 oz.).

A more detailed description of the other feedingstuffs is to be found in the second part of this volume.

The preparation of food for pigs is often carried 
too far, for it is not essential that everything should be converted into a thin gruel. The boiling or steaming should be restricted to potatoes, hard grains, and chaff, or to those foods which contain injurious spores of fungi, etc. Where by-products from the distillery, brewery, or starch manufactory are being used, and they are not quite fresh, they may also be cooked in some way, and the same applies to milk and all waste material from the dairy. Grain should be given either coarsely ground or crushed, whilst feeding meals may be mixed with the coarser parts of the ration. When food is made into a gruel it should not be too thin; the best consistency is that of a thick porridge, and it should be cooled to below the body temperature. Special care must be taken to keep the feedingtroughs and vessels clean.

The daily ration should be divided into three meals for young pigs, and they should be given regularly and punctually. The sty should be moderately warm, dry, clean, and well ventilated; an excess of heat destroys the appetite and can prove as dangerous as a cold sty. 


\section{CHAPTER VII}

\section{THE FEEDING OF MILCH CATTLE}

(I) The formation of milk.

\HEN the constituents of milk are considered, it is seen that amongst them are some-as, for instance, casein and milk-sugar-which are not found in any other of the tissues or fluids of the body. This fact proves that the milk is not already formed in the juices that flow to the udder, but that it must be separated in the milk glands and pass from them to the cavities of the udder. Milk, therefore, is not a simple excretory product like urine, which is simply filtered from the blood in the kidneys, but it is a substance formed from the fluids of the body by chemical changes in the milk glands. The material which is brought to the mammary gland is utilised first of all to build up certain cells which on completion are wholly or partly destroyed. These products of decomposition are milk, which in this way may be regarded as a fluid organ. It follows that milk is not directly formed from the blood because of the 
richness of the ash in potash and its poorness in soda, for the ash of blood, on the contrary, contains much soda and only a little potash.

In the cow the mammary gland, which is covered with fatty tissue and folds of skin, consists of two portions which are separated from one another by a wall of muscular tissue which runs parallel to the long axis of the body. Each of these halves possesses a grape-like shape and is composed of a great number of smaller or larger flaps, which are traversed by small branching ducts. These snfâl ducts unite to form wider ones, which finally open into a broad passage which empties into the milk cistern - a large hollow space lying above the teats. If the small ducts above mentioned are followed into their finest capillaries they are found to end in tiny sacs or alveoli, which compose the small flaps. The alveoli are furnished with a delicate homogeneous membrane on which a single layer of so-called epithelial cells lies. A dense network of the finest blood and lymph vessels surrounds the outer walls and supplies the epithelial cells, from or in which the milk arises, with the necessary material. Numerous nerve fibres imbedded alongside the blood capillaries regulate the activity of the alveoli. The alveoli, therefore, are that portion of the mammary gland in which the materials forming the milk undergo conversion. Whether the alveoli are partly or entirely destroyed and then 


\section{SCIENTIFIC FEEDING OF ANIMALS}

grow again, or whether they remain intact, has not been proved.

Milk is therefore a product of the mammary gland, and it is upon the development and productiveness of this organ that the extent to which the quantity and composition of the milk can be influenced by other factors-particularly the food-depends.

(2) The influence of the constitution of the animal upon the formation of milk.

(a) Breed and individuality.

The development of the mammary gland, like any other organ, cannot be increased separately by any kind of feeding, but is to a certain extent hereditarily fixed. Therefore it arises that between the several breeds and individuals considerable differences in the quantity and composition of the milk are to be found. The natural breeds of cattle not bred for the production of milk only give some 400-500 litres (88-IIo gals.) of milk per annum, in which, though, the percentage of solid substances is high. The cultivated breeds have, however, been gradually raised to an extraordinarily high pitch as milk producers. Cows which annually give more than 5000 litres (IIo0 gals.) milk with more than $3 \%$ of fat are nowadays not rare. Definite information regarding the milk yields of the various breeds is not easy to give, on account of the variety of con- 


\section{THE FEEDING OF MILCH CATTLE 309}

ditions. It may be said, though, that in general the Dutch, Oldenburg, East Friesland, etc. cattle give a greater quantity of milk poorer in fat and solids than such breeds as the Simmental, Shorthorn, Jersey, Guernsey, Alderney, etc.

The individual animals of the various breeds also behave very differently: for example, eighteen Dutch cows which had been bred in East Prussia were kept under observation during the whole period of lactation, and between the best and worst yields the following differences were noticed :-

Total milk yield . . 2230-4702 kg. . Proportion, 100 : 202 " amount of fat . $74.4-149 \cdot 3$, . " 100 : 201 Percentage of solids $10.56-12.86 \%$. $\quad, \quad 100$ : 122 " "fat . 2.63-3.81" " " $100: 145$

In addition to the differences which are observed between cows, there are also the variations in the daily yield which are often observed with the same cow, and which in some cases may be as much as 3-4 kg. milk, as well as differences in the percentage of fat. The same cow may one day give milk with $2.8 \%$ of fat, and the next day $3.9 \%$ without any explanation, except the peculiarity of the animal, being possible.

The individual relations also show themselves in the alterations which a change of food makes in the quantity and contents of the milk. In one series of experiments with fifteen cows, where some of the carbohydrate portion of the ration was replaced by 


\section{IO SCIENTIFIC FEEDING OF ANIMALS}

fat (rye feeding meal by rice feeding meal) without any change being made in the more active portions of the food, it was found that-

One cow gave $\mathrm{I} \cdot 85 \mathrm{~kg}$. more milk and $29 \mathrm{~g}$. more fat Another " "2.24" less " "66" less"

" " "

Observations of this kind, which anybody can make in practice, show how extraordinarily changeable is the influence of individuality upon the production of milk. They teach also how deceptive are the results of experiments carried out upon a small number of animals.

\section{(b) The period of lactation.}

The formation of milk, which begins at the time of calving, does not always remain at the same level, but in time decreases until, usually some time before the next calving, no more milk is formed and the cow is dry. Here also the individuality of the animal gives very variable results. With many cows the yield of milk increases for several months after calving, remains for some considerable time at the highest yield, then falls quickly or slowly and remains for a period at that level; but here again no universally applicable rule exists. Generally in the course of lactation the percentage quantity of dry matter and fat increases, but to this also there are plenty of exceptions. 
(c) The age of the cow.

The general capacity of the more highly developed animals increases during the first period of life, then remains for some time at the same level and afterwards begins to diminish. It is the same with the milking capacity of cows, and observations have shown that the yield of milk increases up to about the time of the fifth or sixth calf, whereas the average percentage of fat in the milk remains constant up to that time and for several years longer. Great differences are shown though in the behaviour of individual cows.

(3) The infuence of other factors on the formation of milk.

(a) The frequency and manner of milking.

There can be no doubt that the passage of the milk from the alveoli to the milk cistern is easiest and most rapid when the udder is empty. When the udder is more or less filled there is a damming of the small ducts leading from the alveoli, and the pressure acting upon the alveoli hinders the separation of milk. From this it would be thought that more frequent milking would increase the yield of milk, but there are other factors to be considered. Many circumstances point to a considerable portion of the milk only being formed in the alveoli under the stimulus of milking. It has been computed 


\section{I2 SCIENTIFIC FEEDING OF ANIMALS}

by measurement of the ducts that the whole of these, together with the cavities of the udder, have a capacity not greater than six pints of milk, whereas at a milking often more than twice this quantity is got. According to this a portion of the milk must certainly only leave the cells of the alveoli during milking.

Be that, however, as it may, the fact remains that the time between successive milkings has a considerable influence upon the milk formation. In an experiment where the cows were milked after different lengths of time, it was found that the milk obtained per minute was as follows :-

With intervals of 12 hours 5.29 g. milk per min.

\begin{tabular}{|c|c|c|c|c|}
\hline & ", &,$\quad 6$ & , 6.83, & " \\
\hline ", & " & " 4 & $8 \cdot 58$, & , \\
\hline & ", & , 2 & 9.25, & ", \\
\hline & ", & „, 65 mins & 1S. IO.I5, & ", \\
\hline & , & $" 50 \quad$, & I. $\mathrm{I} \cdot \mathrm{n}$ & ", \\
\hline
\end{tabular}

The shorter, then, the interval between the times of milking, so much greater, up to a certain point, was the quantity of milk obtained. Where milking was performed each hour the yield fell suddenly, from which it may be assumed that the otherwise favourable stimulus gave rise to pain if repeated too frequently. In general the extra amount of milk which can be got by frequent milkings is very much overestimated, for although considerable 


\section{THE FEEDING OF MILCH CATTLE 3 I 3}

differences are often observed with shorter intervals between the milkings, they are often not applicable to practice. As has been proved, the holding capacity of the milk cistern accommodates itself in time to the amount of milk which the animal can give, and so there ceases to be any considerable damming of the milk. From practical experience it has been shown that milking three times a day only gives $6-7 \%$ more milk than milking twice. Whether this increase in the amount of milk will repay the cost of the extra milking, carriage, etc. must be answered for each case separately. With freely milking cows which give good yields and where the milk can be sold to advantage, it may be possible to milk four times a day with profit, but under ordinary circumstances twice, or at most three times, is usually enough.

Frequent milking has an influence also upon the composition of the milk in that the milk is richer the shorter the time that has elapsed since the previous milking. The very numerous investigations which have been carried out on morning, midday, and evening milk leave no doubt on this point. When, for example, a large herd were milked at 4 in the morning, then at 12.30 p.m., and in the evening at 7 p.m., the following results were obtained :-

The morning milk . . $11.51 \%$ dry matter, and $2.79 \%$ fat

" midday " . . $11.79 " \quad$. $12.44 " \quad " 3.05 ", "$,




\section{I4 SCIENTIFIC FEEDING OF ANIMALS}

If the milk is collected in different lots, it is found that each successive portion is richer in solid matter than the one before. In one experiment, where six portions were collected separately successive, they contained the following quantities of fat: $\mathrm{I} \cdot 7 \mathrm{O}, \mathrm{I} \cdot 76,2 \cdot 10,2 \cdot 54,3 \cdot \mathrm{I} 4$, and $4 \cdot 08 \%$, whilst in the mixed milk $2.55 \%$ fat was found. Similar results were also got for the percentage amount of dry matter. As cause of this phenomenon, it is assumed that, owing to friction, the globules of fat in the milk move more slowly along the very narrow ducts leading from the alveoli than do the constituents which are dissolved in the fluid of the milk. The manner of milking has a very considerable influence upon the yield of milk, as is well known, so that a clever and experienced hand is of much value in milking.

\section{(b) Performance of work by cows.}

As every kind of work done by an animal is associated with a corresponding utilisation of material, the influence of work on the milk yield of a cow will depend largely upon the amount of food it has at its disposal. If the ration does not suffice for the full supply of milk as well as for the work, then under all circumstances it is the milk yield that will suffer, and this has been repeatedly proved. When, for example, a cow was made to 


\section{THE FEEDING OF MILCH CATTLE 315}

turn a capstan for four hours in the morning and again for the same time in the afternoon, the milk decreased in quantity by $4.5 \mathrm{~kg}$. as a result of the exertion. The milk constituents also suffered, for there were $60 \mathrm{I} \mathrm{g}$. less dry matter given, I73 $\mathrm{g}$. less protein, I84 g. less fat, $25 \mathrm{I}$ g. less milk-sugar, and $30 \mathrm{~g}$. less ash or mineral matter. Where the same cow did lighter work of the same kind-less than two hours - the effect was the opposite, for the yield of milk was favourably influenced, there being the following increases in the constituents: I28 g. dry matter, 29 g. protein, 44 g. fat, I6.2 g. milk-sugar, and $8 \mathrm{~g}$. ash, whilst the quantity of the milk was greater by $40 \mathrm{~g}$. Moderate exercise in the open, with the avoidance of unfavourable influences of weather, is, as has often been shown, of considerable benefit to the secretion of milk, and therefore ought not to be neglected. A daily stay of two hours in the fresh air has a very beneficial effect on the health of the cows. The feeling of comfort and well-being has a greater influence upon the production of milk than in almost any other direction.

A moderate amount of work on a suitable diet does not, therefore, need to entail any diminution of production. It is true that the quantity of milk may be reduced, but it is then of better quality, so that generally as much dry matter and fat are obtained as when the animal is at rest in the stall. 


\section{I6 SCIENTIFIC FEEDING OF ANIMALS}

Where the work is fatiguing the milk is also poorer in water and richer in dry matter, particularly in fat. Often under these conditions the quantity of milk sinks so low that, despite the increased concentration, there is a considerable loss of each constituent of the dry matter, as the figures previously noticed will show. Hard work and a large milk yield cannot be combined, but the use of the cow for light work, provided the ration is correspondingly improved, can be carried out without lessening the quantity of milk or fat.

\section{(c) Other influences: treatment and care.}

The great extent to which the secretion of the milk depends upon the well-being of the animals is seen from an experiment in which ten cows were not groomed for fourteen days. When daily grooming with brush and currycomb was in operation the total milk yield was $2087 \mathrm{~kg}$, but when this was in abeyance only $2007 \mathrm{~kg}$. were obtained. In the first case the milk contained II. $77 \%$ dry matter and $2.99 \%$ fat and in the second II.44\% dry matter and $3 \cdot 14 \%$ fat. Everything that upsets the cow-rough handling, insufficient litter, a cold stall, and similar disturbing factors, all act unfavourably upon the production of milk. 
(4) Methods for ascertaining the effect of food on the secretion of milk.

On account of the powerful influence which the individuality of the animal exercises upon the production of the milk in general (p. 308), and the effect which change of food also has (p. 309), special care has to be taken in feeding experiments to eliminate individual influences by the use of a large number of animals. Further, the frequent and irregular jumps which the yield of milk makes in course of the period of lactation (p.3Io) must also be taken into account and be guarded against in the same way, viz. by taking a number of experimental animals.

If the quantity and composition of the milk remain constant for some time when the food is unchanged, it would not be difficult to estimate the effect of different kinds and quantities of food upon the milk production. The natural changes, though, which take place during the period of lactation require that in each investigation these must be separately ascertained. To do this there are two ways, which may here be shortly described:

\section{(a) The period system.}

The use of this method of investigation assumes that the natural changes in the milk of a large number of cows proceed regularly, and that if 


\section{I8 SCIENTIFIC FEEDING OF ANIMALS}

three periods of equal length are taken, and the results in the first and third periods, where the same food is given, are recorded, the second period during which the added food is given can be calculated.

An example will best serve to make this clear Let it be assumed that it is to be proved whether the addition of $0.5 \mathrm{~kg}$. of a certain feeding-stuff to a ration causes the yield of milk to increase. For the investigation twenty healthy cows are chosen, and these are fed in the first and third periods with the original ration, and in each case for a month. If, now, the daily weighing and examination of the milk during the last twenty days of each period show that in the first period $15 \cdot 38 \mathrm{~kg}$. of milk with $3 \cdot 05 \%=469 \mathrm{~g}$. fat were given daily by each cow, and that in the third period only $I_{4} .65 \mathrm{~kg}$. milk with $3 \cdot 12 \%=457 \mathrm{~g}$. fat were got from each cow, the natural decrease in this time is $0.73 \mathrm{~kg}$. milk and $\mathrm{I} 2 \mathrm{~g}$. fat. As between the middle of the first and the middle of the third period forty days elapsed, the daily decrease is $18.25 \mathrm{~g}$. millk and $0.30 \mathrm{~g}$. fat. The middle of the second period in which the added food is given is seen to be separated from the middle of the first and third periods by twenty days, and $I_{5} \cdot 0{ }^{\circ} \mathrm{kg}$. milk with $463 \mathrm{~g}$. fat would, therefore, have been obtained if no addition had been made. As, however, the milk was $15.35 \mathrm{~kg}$. and the fat $480 \mathrm{~g}$., the daily increase of production due to the addition was $0.335 \mathrm{~kg}$. milk 


\section{THE FEEDING OF MILCH CATTLE 3I9}

with $17 \mathrm{~g}$. fat. Between the preliminary and final periods there are sometimes two, three, or more periods with different food-stuffs interpolated, and the calculation of the results is carried out in exactly the same manner as in the above example. It is best before and after each period with a different food to again have a period with the original ration (basal ration), e.g. in periods $I, 3,5,7$ to use the same food, and in periods $2,4,6$ to feed the ration which is to be compared with the basal ration.

A factor which can influence the result, and is not always to be avoided in this kind of investigation, is the change in the condition of the animals under the influence of the various kinds of food. If, in the above example, the average weight of the animals underwent much alteration in the second period, this change would make itself apparent in the yield of milk in the third period, and the calculation of the natural decrease in the flow of milk would be incorrect. This source of error is avoided by the adoption of the next method-

\section{(b) The group system.}

In its main features this kind of investigation has already been mentioned (p. 240). In each of the comparative groups ten cows are placed, and all the groups are then given the same food in order 


\section{SCIENTIFIC FEEDING OF ANIMALS}

to find out whether the several groups give the same quantities of milk of equal fat content. If this is not the case the animals must be rearranged or fresh ones introduced until perfect agreement between the several groups is attained.

If, for example, maize and coarsely ground corn are to be compared regarding their influence upon milk production, then both these feeding-stuffs must be given in the basal ration, and three groups of cows are necessary. If the agreement of these groups is settled the real experiment begins, and for a month all three groups are given the basal ration. Then follows another period of thirty days, during which the three groups are fed differently, group A receiving only the ground corn in place of the maize, group $\mathrm{C}$ maize instead of the corn ration, and group B the maize-corn ration unchanged. In the third period, which again lasts thirty days, a return is made to the same rations which were given in period I. In an investigation of this kind, where equal quantities of maize and corn were compared with one another, there was given, along with constant quantities of other feedingstuffs, the following quantities per head per day :-
rst Period.
and Period.
3rd Period.
$A, B$, and $C$. A. B. C. $\triangle, B$, and $C$.
Corn . . I.09 kg. 2.I2 I.06 - I.03
Maize . . $0.89 \mathrm{~kg} . \quad \mathrm{C}^{-} \mathrm{I} .062 . \mathrm{I} 2 \quad \mathrm{I} \cdot 09$ 
THE FEEDING OF MILCH CATTLE 32I

The daily average of milk per head in the last twenty days of each period was (in kilograms) :-

\begin{tabular}{|c|c|c|}
\hline & $\begin{array}{c}\text { A. } \\
\text { I } 3 \cdot 80\end{array}$ & $\begin{array}{c}\text { Groups. } \\
\text { p. } \\
\text { I } 3.80\end{array}$ \\
\hline ize period & II 75 & II $\cdot 85$ \\
\hline periva & 10.65 & 10.65 \\
\hline
\end{tabular}

The analysis of the milk for its percentage composition showed there was no difference at any time between the three groups. Naturally in these investigations, whether they be carried out according to one or the other method, the other properties of the milk (smell, taste, churning properties, nature of butter) must be noticed, and the live weight of the animal regularly recorded.

(5) The effect of food on the milk production.

(a) General considerations.

As milk is practically only changed mammary gland substance, it depends largely upon the development and activity of this gland what proportion of the nutrients flowing to it are converted into milk. There is, however, a limit to the development of the mammary gland as there is to all other organs, and adaptation and heredity determine this: The individuality and breed of the animal and the condition of the mammary gland, as influenced by the 


\section{SCIENTIFIC FEEDING OF ANIMALS}

period of lactation, have the greatest effect upon the milk yield. The food, along with other factors, plays a less important part, and only exerts an influence within the limits of the capacity of the mammary gland. It is upon the food, though, that the efficiency of the gland very largely depends.

In the above sentences a large number of the relations between food and milk production find an explanation. The mammary gland is most active shortly after the birth of the calf, and it is here that the greatest latitude is left for the action of the food. Later, when the gland from natural causes loses more and more of its activity, the most liberal feeding cannot maintain the milk yield at its former high level. Too much food in the second half of the lactation period, therefore, causes the deposition of fat, and when the mammary gland is fat its capacity is reduced.

From the part played by the mammary gland in the process of milk secretion, it is easily explained why the food, as will be seen later, has such a slight influence upon the composition of the milk. The animal organs one and all have a very constant composition; the lime of the bones cannot be replaced by the other similar alkaline earths (barium or strontium oxides and magnesia), nor the potash in the organism by the very analogous soda. Further, the protein substances in the blood cannot be replaced by others of a similar kind, nor can the 


\section{THE FEEDING OF MILCH CATTLE 323}

components of the mammary gland alter. An organ like the mammary gland which is always of the same composition, can, therefore, when it liquefies, only yield products which are characterised by great similarity. So an explanation is afforded of why the proportion which the constituents of milk bear to one another cannot be appreciably altered by the food.

(b) The effect of the quantity of food on the milk secretion.

When a change is made from a liberal to a scanty diet the lacteal gland, as a rule, does not immediately accommodate itself to the quantity of food, but remains for a shorter or longer time at the old level. In this case a greater or less portion of the milk is formed from body substance (flesh and fat), and the cow may lose weight to the extent of I cwt. or more without the yield of milk undergoing any noticeable diminution. As a rule, though, there is a rapid fall in the quantity. It was noticed, for example, that a cow on a heavy ration ( $23 \mathrm{lbs}$. clover hay, $38 \frac{1}{2}$ lbs. mangels, and $8 \mathrm{lbs}$. coarsely ground barley, per IIOo lbs. live weight) gave $30 \frac{1}{2} \mathrm{lbs}$. of milk with $3.46 \%$ fat; whereas after being fed for a month on a poor ration ( $9 \mathrm{lbs}$. clover hay, $44 \mathrm{lbs}$. mangels, II lbs. barley straw) the animal only gave 20 lbs. of milk with $3.50 \%$ fat. A second cow which 


\section{SCIENTIFIC FEEDING OF ANIMALS}

was fed in the same way gave $26 \mathrm{lbs}$. of milk with $3.92 \%$ of fat on the first ration, but on the poor one only I $8 \frac{1}{4} \mathrm{lbs}$. of milk with $3.80 \%$ fat. Calculated upon the basis of milk with I2\% dry matter and neglecting the natural decrease in yield, there were Io $\frac{1}{4}$ and $7 \frac{1}{2}$ lbs. less milk respectively on the poorer ration.

If, on the other hand, the change is made from poor food to richer by several large additions, the yield of milk increases where the ration is rich in protein and the cows are good milkers, in proportion to the extra nutriment.

In an experiment with crushed beans it was found that the addition of 3 lbs. gave a daily increase of $2 \mathrm{lbs}$. of milk, and when $6 \frac{1}{2} \mathrm{lbs}$. of beans were given there were $5 \frac{1}{4} \mathrm{lbs}$. more milk; with another cow the increase was $I \frac{1}{8}$ and $2 \frac{1}{4}$ lbs. respectively for the above amounts of beans. In a further experiment with malt coombs, where 2 and 4 lbs. were added, the increase in milk was $I_{\frac{3}{4}} \mathrm{lbs}$. and $2 \frac{3}{4} \mathrm{lbs}$. respectively, and in another case .66 and $.80 \mathrm{lb}$. respectively. In both experiments the cows which gave the highest increase were those which without the added food gave the most milk ( $26 \mathrm{lbs}$. and $26 \frac{1}{4} \mathrm{lbs}$. daily), the cows with the smaller increase for the extra food only giving $I 6 \frac{1}{4} \mathrm{lbs}$. and $\mathrm{I} 2 \mathrm{lbs}$. The more freely milking a cow then is, the greater, as a rule, is the increase of milk which will follow an extra supply of food. This increase has, of course, a 


\section{THE FEEDING OF MILCH CATTLE 325}

limit, and it is shown that from a certain stage the quantity of food required to produce a given increase of milk must be more and more, until finally a point is reached where, in spite of large additions to the ration, no extra milk is obtained. If the milk yield be raised by the use of more food, it is the last quart that requires the most nutriment for its production. How far the yield of milk can be raised cannot be stated beforehand, it can only be found by direct observation.

(c) The effect of food-protein on the production of milk.

As milk contains a lot of protein substances, milch cattle must always have a sufficient quantity of this material in the ration if the tissues of the body are not to be used for the formation of milk. All the investigations in which foods rich in protein have been compared with those poor in this material have shown the powerful influence which the former exercise upon the yield of milk. If the allowance of protein in a ration is diminished, then, although there may be a sufficiency of non-nitrogenous material, the quantity of milk decreases rapidly, as, for instance, in one observed case from $9.7 \mathrm{~kg}$. to $7.65 \mathrm{~kg}$., or in another from $13.4 \mathrm{~kg}$. to as little as $8.45 \mathrm{~kg}$., the condition of the cows falling off at the same time. As a rule, no influence of the food- 


\section{SCIENTIFIC FEEDING OF ANIMALS}

protein upon the percentage amounts of protein or fat in the milk has been observed. It is only when the body is much reduced in protein that the milk becomes poorer in fat and more watery. The amount of digestible protein which is essential for the production of a given quantity of milk depends to a certain degree upon the non-nitrogenous nutrients in the food. Just as fat and the carbohydrates can diminish protein metabolism in the formation of flesh (p. 72), so can they also act in the production of milk. It is possible, in fact, by a plentiful use of carbohydrates, to so reduce the metabolism of the food-protein in cows that no more is decomposed than the animals require for the maintenance of life. This saving can go so far that all the digestible protein substance above that needed for maintenance $(0.5 \mathrm{lb}$. per I000 lbs. live weight, p. 245) can be utilised for the formation of milk without any call being made upon the protein of the body. Such a result is possible, not only when moderate yields of milk are got, but when the amount is as high as $32 \mathrm{lbs}$. per head per day.

This fact, which has been proved from many sides, does not justify the protein content of the milk being taken as a measure of the protein to be given in the food. As far as is known, it does not conduce to a vigorous activity of the mammary gland to supply it with only as much protein matter as is 


\section{THE FEEDING OF MILCH CATTLE 327}

secreted in the milk; a certain excess is necessary in order to counteract the weakening which the gland experiences as the period of lactation advances. If the supply of protein in the food were limited to that which appears in the milk the natural decrease in the milk yield would most certainly be more rapid than if a food richer in protein were fed. It is advisable, then, to reckon for each Io lbs. of milk $\cdot 55^{-\cdot 65} \mathrm{lb}$. digestible protein in addition to that which the maintenance of the animal demands.

\section{(d) The effect of non-protein nitrogenous} substances.

Many substances of this nature, such as asparagine and ammonia, can, as investigations have shown (p. 66), raise the increase of flesh in ruminants. This is very probably due to the influence of bacteria in the partly digested food which convert the non-protein substances into proteins, and these are digested in another part of the intestine. In the same way these substances can naturally be utilised for the production of milk. Experiments on this question were first made with asparagine, and afterwards also with the nitrogenous substances extracted from young grass. The results showed that no definite effect upon the formation of milk can be ascribed to the non-protein sub- 


\section{SCIENTIFIC FEEDING OF ANIMALS}

stances, and that they do not by a long way attain the influence of the protein, even when a sufficient quantity of nitrogen-free material is present in the ration. If the food, as in some investigations was the case, contained more protein than the animals needed, it would be immaterial whether the excess were replaced by non-protein nitrogenous substances or not, for the replacement of proteins by compounds of this nature can only have an influence on the formation of milk when, before the substitution, no excess of protein is present. Investigations on this point have only so far been tried with ammonia, which, combined with acetic acid, was fed to the animals. It was found that ammonia could be as completely utilised for milk formation as are the proteins, provided a sufficiency of nitrogen-free substances was present. It was noticed, though, that thereby more carbohydrates were used, which may be explained by assuming that in the formation of proteins from this material other food constituents must be utilised at the same time. In this way the replacement of $168 \mathrm{~g}$. of digestible protein by an amount of ammonia which had the same quantity of nitrogen as the protein was possible, and without, as it proved, any change being made in the percentage composition of the milk.

There are then nitrogenous substances of a nonprotein nature which can, where there is plenty of 


\section{THE FEEDING OF MILCH CATTLE 329}

carbohydrate material, maintain the milk yield at the same level as do digestible proteins. Probably these substances are converted by the help of bacteria in the partly digested food into protein. Before it is possible to satisfactorily answer the questions which arise out of the above-mentioned observation, it will be necessary to test the effect of a large number of substances rich in amides in the same way as has been done with ammonia.

(e) The effect of non-nitrogenous mutrients.

It has been previously stated that with a food rich in nitrogen-free substances and poor in protein all the proteins that are not required for the maintenance of the animal can be transformed into milk proteins. As milk contains in addition to the protein large quantities of fat and milk sugar, these constituents must be formed from the digested fat and carbohydrates. Milk fat, like body fat, can be made from the carbohydrates of the food, as many experiments with cows to which a ration artificially freed from fat was given, have proved. In one case, for example, during an experimental period of fourteen days, the quantity of digested fat was $2 \cdot 18 \mathrm{~kg}$., and that portion of fat which could arise from the decomposed protein (p. 65) was at most $I 7.78 \mathrm{~kg}$., so that in all a maximum of $19.96 \mathrm{~kg}$. fat was available for the milk. As $37.65 \mathrm{~kg}$. fat 


\section{SCIENTIFIC FEEDING OF ANIMALS}

were extracted from the milk, there must have been at least $I 7.69 \mathrm{~kg}$. of milk fat, and all the milk sugar formed from the carbohydrates.

The nitrogen-free extract substances, then, supply the mammary gland with material for the production of milk fat and milk sugar. These two components of the milk can, it is true, probably be formed from the protein of the food, but as the amount of this is not as a rule excessive, there is not likely to be much available surplus after the proteins of the milk have taken what they require. Should there be a lack of non-nitrogenous material in the ration there must, in the course of time, be a decrease in the formation of milk. In the beginning, it is true, the body fat would be a substitute for the lack of carbohydrates, and would have to supply material for the formation of milk fat and milk sugar. After the gradual using up of the body fat a falling off in the milk yield is to be inevitably expected.

The nitrogen-free nutrients have, further, another indirect influence upon the secretion of milk in that they greatly diminish the consumption of protein (p. 72). This fact is of great practical importance, for by feeding large amounts of carbohydrates (mangels, molasses, beet slices) the quantity of concentrated food can be profitably reduced.

The effect which is exercised by the fat of the food upon the amount and properties of the 
THE FEEDING OF MILCH CATTLE 33I

milk fat requires special notice here. The older investigations on this subject led to very varying results; at one time there was found to be an increase in the milk fat and at another a decrease, whilst in many cases no effect at all was noticed. Ten series of experiments carried out on the same lines in different parts and with cattle of various breeds-there being almost 200 cows under observation-have given a trustworthy reply to this important question. The plan of these experiments was to feed a constant basal ration in each series, and then add to this at one time a rice meal rich in fat, and at another time rye meal and enough potato starch to make the starch equivalent of each food mixture the same. In one ration there was I $\mathrm{kg}$. digestible fat per rooo $\mathrm{kg}$. live weight, and in the other an equivalent quantity of digestible carbohydrates and very little fat. The average results of the ten experiments showed that with the food rich in fat there were $0.3 \mathrm{I} \mathrm{kg.}=2.7 \%$ less milk and I3 $g .=3.7 \%$ less fat obtained than with the food poor in fat-differences which are so small that they hardly come into consideration.

In separate cases the individual peculiarities of the cows were very striking, as has been seen in an experiment previously quoted (p. 3Io). There were also considerable differencès in the several groups, and if the results are arranged according to the changes in the milk yield and several groups 


\section{SCIENTIFIC FEEDING OF ANIMALS}

put together, the following figures are obtained. The plus sign denotes an increase and the minus sign a decrease as compared to the effect of the food poor in fat.

\begin{tabular}{|c|c|c|c|c|}
\hline & & $\begin{array}{l}\text { Quantity } \\
\text { of milk. } \\
\text { Per cent. }\end{array}$ & $\begin{array}{l}\text { Percentage } \\
\text { of fat. }\end{array}$ & $\begin{array}{l}\text { Weight } \\
\text { of fat. } \\
\text { Per cent }\end{array}$ \\
\hline 3 groups & . & $-7 \cdot 2$ & +0.28 & $+I \cdot O$ \\
\hline $3 \quad$, & - & $-2 \cdot 6$ & -0.02 & $-3 \cdot 2$ \\
\hline ", & $\bullet^{\circ}$ & +0.6 & -0.26 & $-7 \cdot 6$ \\
\hline \multicolumn{2}{|c|}{ Average } & $-2 \cdot 7$ & 0 & $-3 \cdot 7$ \\
\hline
\end{tabular}

Therefore the percentage fat composition of the milk has not changed under the influence of the ration richer in fat. Where, however, the yield of milk diminished the most $(7 \cdot 2 \%)$ the percentage amount of fat in the milk rose by almost $\cdot 3 \%$, and conversely where the quantity of milk was small the percentage of fat fell by $\cdot 26 \%$. In the intermediate series there was a slight decrease in quantity $(2.6 \%)$, but no change in the percentage fat composition of the milk was observed.

The above investigations, therefore, bring a very satisfactory explanation of the anomalies found in the older experiments, and the conclusion may be drawn that more than $\frac{1}{2} \mathrm{lb}$. food fat per Iooo lbs. live weight brings no advantage, and it is sufficient if the daily ration of a cow contain $\cdot 5-6 \mathrm{lb}$. of fat per $1000 \mathrm{lbs}$. live weight. For sheep and goats the 
food may contain more fat (up to I lb.). Without exception it has been shown in these experiments, as in the older ones, that the food fat has a powerful influence upon the properties of the milk fat. It has, indeed, been long known that certain fatty foods render the butter soft, whilst others tend to harden it, and advantage has been taken of this to improve the milk fat by feeding certain oil cakes.

The more a certain fat predominates in the ration, so much more do the properties of the butter fat approach those of the food fat. In the feeding of sesame, cocoa-nut and almond oils, it has been noticed that the butter fat which was obtained behaved on chemical analysis like a mixture of butter with the various oils. Similarly, in the experiments just recorded with rice meal the fat of the milk was found to be soft and greasy and to possess properties quite different to those of the fat got from the rye meal feeding. These peculiarities are only observed to take place gradually; the complete change may require as much as $2-3$ weeks. Thorough investigations have shown that those components of the food fat which otherwise are not found in the body, e.g. linoleic acid or phytosterin, do not pass into the milk. The only change in the milk fat is that of the prcportion between those liquid and solid fats which under normal conditions take part in the formation of milk.

However much of any fat may be given in the 


\section{SCIENTIFIC FEEDING OF ANIMALS}

food, it is not possible to produce a butter which will in all respects resemble the food fat. The mammary gland is apparently unable to work up those fats which are foreign to the body.

The carbohydrates also are not without influence upon the composition of the butter. It has been observed that towards autumn the butter from cows on pasture has behaved like a mixture of margarine and butter when chemically examined, and that feeding with mangel tops has the power to remove this drawback. Following upon this observation, it was discovered that the improvement must be ascribed to the sugar in the mangel tops, and that sugar-containing foods, as well as sugar itself, have the power of increasing the amount of compounds of volatile fatty acids (glycerides) in the butter.

\section{(f) The so-called specific effects of the food-stuffs.}

Alongside the effect which ordinary foods of good quality exercise through the nutrients which they contain there are, according to very prevalent views, other powers which affect the production of flesh or milk for good or ill. It certainly cannot be denied that when a feeding-stuff agrees with an animal it can increase the nutritive value, and also that the palatableness not only influences the consumption, but also the food value, particulariy 


\section{THE FEEDING OF MILCH CATTLE 335}

with animals like milch cows, which are easily affected by nervous impulses.

It has, in fact, been proved that under certain conditions substances which are particularly agreeable to animals-as, for instance, fennel, aniseed, the scent of aromatic hay, etc. - have a favourable influence upon the milk yield. In experiments with goats and milch sheep the effects of two rations with exactly the same nutritive value have been compared. In one case the ration was partly composed of very good meadow hay, whilst the other was an artificial mixture of straw, starch, gluten, oil, ash of hay, etc., and was a very tasteless food. The result of the experiments showed that in no case was it possible to obtain the same yield of milk from the second ration as was got from the ration containing the meadow hay.

When a small part of the mixed food was replaced by fennel, aniseed, or malt coombs, or when an extract from hay, or the volatile essential oils distilled from hay, were added to the unpalatable ration a distinct rise in milk production was achieved; sometimes even the milk yield was equal to that from normal food. Amongst those substances tried the only one which failed to show any advantage was fenugreek. When, however, the above-mentioned substances were added to the ration containing meadow hay no benefit at all was noticed, for the aromatic components of the hay were sufficient. 


\section{SCIENTIFIC FEEDING OF ANIMALS}

Under ordinary conditions, where the food-stuffs are not tasteless, insipid, and without smell, then the addition of 4 or $5 \mathrm{lbs}$. of good meadow hay makes the effect of the above-mentioned spices nil.

A very large number of experiments with these different substances, either alone or mixed, have proved this as well as with other materials, such as caraway, coriander, fenugreek, sweet calamus, and gentian roots, goat's rue, jaborandi leaves, and other drugs, flowers of sulphur, antimony sulphide, preparations of iron, phosphate of lime, sodium bicarbonate, common salt. Many of the above alter the properties of the milk, imparting to it a foreign smell or taste, or make it unsuitable for cheesemaking, whilst some few, if given without care, cause digestive disturbances. Fennel is of assistance in case of obstinate retention of milk, but under normal conditions the above-mentioned substances have no beneficial influence. A good meadow hay is and remains the best spice.

Many feeding-stuffs are said to raise the percentage of fat in the milk, and on this point very numerous experiments have been made, the results of which have, however, been most varied. For example, with palm-nut meal it was found in five of eleven cases that the effect was beneficial, in one case it was unfavourable, and in the remaining five neither favourable nor unfavourable. In seven experiments with cocoa-nut cake four were favourable, 


\section{THE FEEDING OF MILCH CATTLE 337}

one unfavourable, and the other two had no effect one way or the other. With cotton-seed meal one trial was favourable, another unfavourable, and the third showed no effect upon the milk yield or the percentage of fat. These contradictions can hardly be explained in any other way but by the extraordinarily different behaviour of the animals towards the various foods (p. 3Io). Without exception, in these investigations, too small a number of cows were used, and so the influence of individuality was not equalised. In contrast to the abovementioned observations, there have been other experiments in which not less than 200 cows have been used in each case, and still no specific action of the food-stuffs that have so far been tested has been detected. Here a mixture, half oats and half barley, both coarsely ground, was fed, and the effect of this vas compared with (I) ground maize, (2) a mixture of oil cakes ( $\frac{1}{3}$ rape, $\frac{1}{3}$ palm-nut, $\frac{1}{3}$ sunflower-seed), (3) wheat bran, (4) crushed wheat, (5) a mixture of wheat bran and palm-nut cake with molasses, (6) mangels. In none of these extensive series of experiments was the replacement of the ground cereals by the other foods attended by a change in the percentage amount of fat in the milk. The yield of milk certainly did rise when the mixture of oil cakes took the place of an equal weight of the ground cereals, but this must be ascribed to the greater quantity of protein in the former (p. 325). 


\section{SCIENTIFIC FEEDING OF ANIMALS}

Whilst it may be conceded that there are perhaps certain feeding-stuffs which favourably influence the production of milk fat, no conclusive proof has as yet been furnished in a single case.

(g) The effect of food-stuffs injurious to health.

All injurious foods, even when the quantity which is consumed does not lead to any apparent injury to health, are liable to reduce the quantity and fat contents of the milk. An earth-nut meal, for example, which contained small quantities of castor-oil meal, reduced the milk yield in a herd of cows by $I \%$, although only in a few cases was the health appreciably affected. A similar effect has been observed in the case of poppy-seed cake, which probably contained traces of opium. The unfavourable influence which many damaged foodstuffs have upon the milk yield may probably be due to the presence of substances injurious to health (p. II8). The prejudicial effects of injurious foods are much more pronounced with milking stock than with fattening or working cattle.

\section{(6) Food for Mitch Cattle.}

From the statements already made and from the results obtained from well-conducted associations dealing with the testing of milk, it may be said 
that for the production of $10 \mathrm{~kg}$. (22 lbs.) of milk $0.55-0.65 \mathrm{~kg}$. ( $\mathrm{I}_{4}^{\frac{1}{4}-\mathrm{I}} \frac{1}{2} \mathrm{lbs}$.) protein and a starch equivalent of $2 \cdot 0-2 \cdot 7 \mathrm{~kg}$. ( $4 \frac{1}{2}-6 \mathrm{lbs}$.) are necessary in addition to the nutrients required for the maintenance of life (p. 246). In the daily ration $0.5-0.6$ lb. of digestible fat may be given per Iooo lbs. live weight without any unfavourable effect (p. 332).

The amount of food must naturally be regulated according to the yield of milk, for a cow giving 40 lbs. of milk a day will, of course, require more nutrient than one giving $16 \mathrm{lbs}$. If all the cows are fed alike, as is so often done, and the quantity of food arranged for the average yield of the herd, there will be some cows getting too little and others too much food. Both cases act against the production of milk, for if the animal is starved the mammary gland is weakened and the natural decrease of milk is accelerated, which is injurious to the milking capacity of the calves which follow ; whilst if the mammary gland becomes fat its productive power is also diminished. Therefore it cannot be too strongly insisted that the feeding should be individual-that is, the cows in a herd should be divided into, say, five groups, according to the yield of milk, and fodd proportionate to the amount of milk should be given. It is not at all necessary to place the animals of the same group near to one another; all the cows may be given the same basal ration, but the mixture of concen- 


\section{SCIENTIFIC FEEDING OF ANIMALS}

trated foods should be measured according to the production of each group.* Regular test milkings to ascertain the yield of each cow must, of course, be undertaken. The quantity of food should be so measured that the cows neither get thin nor fat, but remain in good condition. In Table III in the Appendix are given food standards which are most useful in this respect. The yield of milk from a certain point onward does not keep pace with the extra supply of nutrients, but for the production of the last quart of milk a greater amount of food is necessary than below this point. For this reason two numbers are given in the feeding standards, the smaller one applicable when the profit on the milk is low, and the larger one when it is high.

Nothing stands in the way of an increase of protein above the standards; only seldom, though, will it be necessary to use more of this, the dearest of nutrients, than is prescribed in the standards.

In those cases where the cows are not to be used further for breeding, but to be milked dry and fattened, the food must be regulated according to the milk when the yield has reached 7-Io pints; only in the last 3 or 4 months need the food be made up to a fattening ration by the addition of

* R. Geissler, who first described this method, advises, for example, that cows giving 8-9 pints of milk should have I measure of concentrated food, whilst those giving II-I4 pints would get 2 measures. The number of measures can be marked on the boards which stand near each cow, giving particulars of breed, age, etc. 


\section{THE FEEDING OF MILCH CATTLE 34I}

carbohydrate material. If the fattening were begun earlier, then not only would the milk yield suffer, but the quantity of food used would also be more.

Pregnant cows require a slight addition of digestible protein matter for the development of the calf, and the quantity may be approximately calculated from the weight of the newly born calf. A calf weighing $40 \mathrm{~kg}$. contains about $8 \mathrm{~kg}$. protein, and for the formation of this the mother must be given about II $\mathrm{kg}$. protein in the food during the last 5 or 6 months of pregnancy-that is, $60 \mathrm{~g}$. per day, although with the bigger breeds roo $\mathrm{g}$. are necessary in any case, though the daily addition to the ration is very small. The nitrogen-free nutrients do not require to be increased, for calves at birth contain less than I\% fat. With cows heavy in calf a reduction of the coarse fodder during the last 2 or 3 months is advisable, because the weight of such food when partially digested presses on the internal organs, and can in some cases cause a miscarriage. Straw should only be given in very small amounts during this time, and the best coarse fodder is hay (Io lbs. per Iooo lbs. body weight). Foods with a heating or constipating effect should also be avoided. When a cow is dry a ration which contains $\frac{3}{4} \mathrm{lb}$. of digestible protein and a starch equivalent of $6 \mathrm{lbs}$. per Iooo lbs. live weight is sufficient. 


\section{SCIENTIFIC FEEDING OF ANIMALS}

If in drawing up feeding standards for milch cattle the "value" or "quantivalence" (p. 90) of the food-stuffs is taken into account, the following considerations must be noted. First of all it is clear that the energy required for the work of mastication and digestion, and also losses due to fermentation and putrefaction, must be the same in male and female animals of the same species. Many observations made by those whose work is the control of milk supplies, and also experiments carried out on food-stuffs of different "values," have shown that calculations based on the starch equivalents are also correct for milking stock. In an experiment with 24 cows, for example, there was the same amount of digestible nutrients always given, but in the first and last periods of the experiment one part of the nutrients was replaced by mangels, in the second period by dried beet slices, and in the third by beet slices made into silage. The starch equivalent of the mangels was $2 \cdot 00 \mathrm{~kg}$., of the dried beet slices $2.35 \mathrm{~kg}$., and of the silage $2.65 \mathrm{~kg}$., and it was found that the milk yields stood in the same relation, namely, the dry slices gave per day per head $0.95 \mathrm{~kg}$. more milk than the mangels, and the silage slices $I \cdot 72 \mathrm{~kg}$. more, the fat contents of the milk remaining unchanged.

In another experiment, a leguminous straw which was rich in crude fibre was compared with clover hay, and there was also here an increase of $\cdot 5 \mathrm{I} \mathrm{kg}$. 
milk in the case of the fodder with the higher starch equivalent-the clover hay-although both rations contained the same amount of nutrients.

Other investigations with milch sheep and goats confirm the statement that calculations with starch equivalents are sound and correct.

As cow's milk contains on an average $7 \cdot 4 \mathrm{~g}$. mineral substances, amongst which are $\mathrm{I} \cdot 8 \mathrm{~g}$. lime and $I .5 \mathrm{~g}$. phosphoric acid, it is necessary that the food should supply these amounts if the body is not to be depleted of them. Further, as only $\frac{1}{3}$ to $\frac{1}{2}$ of the lime and phosphoric acid in the ration can be utilised (p. 287), there would be in the case of $20 \mathrm{~kg}$. milk per I000 kg. live weight no less than 70-IIo g. lime, and $60-90 \mathrm{~g}$. of phosphoric acid required in the food. If to these numbers there be added the maintenance requirements (p. 246) of Ioo g. lime and $50 \mathrm{~g}$. phosphoric acid, the total require ments for the above quantity of milk will be $200 \mathrm{~g}$. lime and $140 \mathrm{~g}$. phosphoric acids, or $3 \frac{1}{2} \mathrm{oz}$. and $2 \frac{1}{2} \mathrm{Oz}$. for $20 \mathrm{lbs}$. of milk per I0oo lbs. live weight. Higher yields of milk require proportionately larger quantities of mineral matter.

Generally the requirements of the body and the milk are amply met by the supply of mineral substances in the food, particularly when good meadow hay, clovers, or good green fodder are given. With those food-stuffs poor in lime and phosphoric acid (p. 97) the addition of phosphate of lime must be 


\section{SCIENTIFIC FEEDING OF ANIMALS}

resorted to, or if there is only deficiency of lime precipitated chalk will do.

If there is a continued lack of lime and phosphoric acid, diseases of the bones (p. 96) arise, and at the same time the quantity of these substances in the milk diminishes. In the case of a goat which was kept for 42 days on a ration very poor in phosphoric acid, the ash of the dry matter sank from 9.96 to $9.57 \%$, the lime from 0.215 to $0.197 \%$, the phosphoric acid from 0.306 to $0.223 \%$. In general the mineral contents of the milk are extraordinarily invariable with ordinary food, and attempts to increase the amount of phosphoric acid, lime, magnesia, potash, soda or chlorine in the milk by feeding these substances in a suitable form were quite unsuccessful.

During the warmer portions of the year the cows are on the pasture, and this has, according to very general opinion, a favourable influence upon the quantity and quality of the milk. The moderate amount of exercise in the fresh air which is obtained on the pastures only decreases the yield of milk, as has been shown (p. 3I5), to a very slight extent, sometimes not at all, and leads to the secretion of a milk richer in dry matter and fat. As the animals have the opportunity of consuming a relatively large quantity of grass, which on a good pasture may equal many cereals in nutritive value, the yield of milk may not only not be diminished, but more and richer milk obtained than when stall 


\section{THE FEEDING OF MILCH CATTLE 345}

feeding was being followed. The good result of being at grass is not in consequence of a better utilisation of the food, but due to more and richer nourishment. Unfortunately, under the usual conditions of pasturing there is a waste of food material, in that much more protein substance is consumed than is necessary. Even when the green fodder is fed in the stall there is often more used than is needed-as, for instance, when stock are given as much young clover as they can eat. When, therefore, cows are on good pastures, or when they are getting young clover, they should also be given some straw; on the contrary, when the grass is poor some concentrated food is necessary. The quantity of straw which is to be given with the clover will vary according to the age of the latter, for the older the clover plant becomes the less straw will be required, until at the time of flowering no such addition is required, owing to the changes in the nutrients of the plant (p. I5I). Similarly with the leaves of roots such as mangels, sugar beet, or carrots, the vegetable portion of which possesses a fairly narrow albuminoid ratio, there is generally some dry food given to prevent scouring, which otherwise easily takes place owing to the salts of organic acids in the leaves. Liberal feeding with the leaves of the sugar beet, which is often done during and after the harvesting of the beets, has the same effect as with good pasture or clover 


\section{SCIENTIFIC FEEDING OF ANIMALS}

feeding, and gives a milk richer in dry matter and fat because of the quantity of protein in the food. On account of the beneficial effect of green fodder, and also from economic reasons, it is usual to take care that green feeding is not interrupted during the summer, and that it is carried on as late as possible into the autumn. Green maize, sorghum, spurry, different grass mixtures, white mustard, buckwheat, and in the spring grass, cereals, rape, etc. play an important part along with clover in summer feeding in the stall.

When winter feeding begins the place of the green fodder is taken by mangels, beets, beet slices silage, sometimes, also by small quantities of potatoes, which, along with sound hay and straw, ground corn, and by-products such as bran and oil cakes, go to make up suitable rations. When a milk rich in fat is wanted, the use of palm-nut cake, cocoa-nut cake, and the meals made from these is recommended, for by their use an increase of $\frac{1}{2} \%$ milk fat has been observed.

As in the production of milk not only the quantity but also the quality of the article has to be considered, some attention must be paid when choosing the food-stuffs to see that nothing is used which will harmfully affect the taste and properties of the milk and butter. It is well known that all musty and mouldy foods spoil the taste of the milk, and more particularly that of the butter, 
and that this bad effect can continue for some time after the damaged food has been stopped. The same is the case when spoiled silage or green fodder which has lain too long in thick rows or heaps is fed, and also with wet, decomposed foods such as brewers' grains, distillery waste, beet slices, etc. Lack of care in keeping the mangers or other feeding vessels clean is also a cause. In all these cases bacteria undoubtedly play a part; either they cause some decomposition in the food with the formation of substances which, after passing into the body, affect the taste of the milk or butter, or, as is more probable, the bacteria themselves get into the milk and there impart to it the unpleasant flavour. The taste of milk and butter is also affected disadvantageously if too much poor straw is fed, or if the coarse fodder contains any of the varieties of garlic. Large amounts of roots of all kinds, fresh or sour beet slices, potatoes, distillery waste, bran that contains corn-cockle, rape cake in quantities more than 2 lbs. per head per day, have all an unfavourable effect upon the milk. The residues from the manufacture of linseed oil if used too freely cause the milk and butter to taste of the oil, and if the drinking water is bad it can also destroy the flavour of the butter.

Foods which improve the taste of milk are good meadow grass, carrots, oats, and rice meal. In practice it is found that some food-stuffs make the 


\section{SCIENTIFIC FEEDING OF ANIMALS}

butter hard and tallowy, and such are pasture grass in autumn, grasses from sour soils, either green or in hay, over-ripe green fodder, hay that has been harvested too late, straw of various kinds, mangels, kohl-rabi, leaves of sugar beets and mangels, beet slices, potatoes, ground peas and vetches, palmnut and cocoa-nut meals, linseed and cotton-seed cakes.

Butter is often too soft when the following have been fed: crushed oats and maize, wheat bran, rice meal, rape, sesame and sunflower-seed cakes.

The effect of these feeding-stuffs depends naturally upon the quantities which are used and is not always apparent, particularly when the influence of the other foods in the ration acts in the opposite direction. In any case, a butter which is too hard may be improved by feeding with some rape cake, rice meal, or ground maize, whilst one that is too soft may be hardened by means of palm-nut or cocoanut cakes.

When a large quantity of very watery food has been used for some time a poor, thin milk may be obtained. Thus it was noticed in the case of a ration which, as regards the nutritive value, left nothing to be desired, but which was composed of 50 litres (II gals.) potato slump, 2I kg. (46 lbs.) wet brewers' grains, and $40 \mathrm{~kg}$. (88 lbs.) mangels, that the milk of the whole herd only averaged $2 \cdot$ IO and $2.45 \%$ fat, whereas the animals had previously 


\section{THE FEEDING OF MILCH CATTLE 349}

given milk of normal composition. As has been shown by numerous investigations, the percentage amount of water remains very constant in milk in spite of great differences in the quantity given in the food. Only under special circumstances, details of which are not understood, is a very watery milk secreted, but it is probably due to the weakening of the organ by continued use of foods containing a large percentage of water (p. IOI). 

APPENDIX 



\section{APPENDIX}

\section{TABLES FOR THE CALCULATION OF RATIONS}

\section{Mcthod of using the Tables}

$\mathrm{N}$ making up rations care must first of all be I taken that the foods which are to compose the ration are such as are suitable for the animals for which they are intended, and that they have already been successfully used in practice. Each food which it is proposed to use in the ration should then have its nutritive value ascertained, for which purpose the contents of $(a)$ crude nutrients, $(b)$ digestible nutrients, $(c)$ starch equivalent should be determined. If the food-stuff after analysis possesses a different composition to that given in Table I, then, with the help of Table II, the amount of digestible nutrients must be calculated. For this purpose the digestibility coefficients of materials of a similar kind are used. It would be quite wrong if the coefficients for grass were applied to clovers, even though the analyses of both were similar. 


\section{SCIENTIFIC FEEDING OF ANIMALS}

In Table II no digestibility coefficients are given for pure protein, but nevertheless numbers can be calculated; it is only necessary to subtract the amount of amides from the digestible crude protein. To find what quantity of amides are present the digestible protein shown in column I2 of Table I is subtracted from the digestible crude protein given in the same Table (column 7 ). The digestible nutrients in the food-stuff are then the basis for the calculation of the starch equivalent. It is :-

I part digestible protein $. \quad . \quad=0 * 94$ parts starch equivalent

1 part digestible fat in the coarse

fodders, chaff, roots, and

their by-products .

$=I \cdot 9 I \quad " \quad$,

In grains and their by-products,

exclusive of oily seeds $.=2^{\prime} \mathrm{I} 2, "$,

In oil seeds and oil cakes . $=2 \cdot 4 \mathrm{I}, \quad, \quad$,

I part digestible nitrogen-free

extract substances and

crude fibre together . = I',$\quad$,

If the nutrients of the particular food-stuff can be regarded as of " full value," which can be seen by reference to the data in Table I regarding similar or allied foods, then all that is necessary is to add together the equivalents, as shown above, of the three groups of nutrients, and obtain the total starch equivalent. If the value of the food is shown by Table I to be less than Ioo, a deduction depending upon the different feeding-stuffs has to 
be made. In the case of roots and tubers, grains and industrial by-products, use is made of the number expressing the "value." If, for example, the starch equivalent of rape cake is wanted, and the analysis is $36.5 \%$ crude protein, $8 \%$ fat, $25.8 \%$ nitrogen-free extract, and II.5\% crude fibre, and the digestibility coefficients for the digestible substances being, according to Table II, $29.6 \%$ crude protein, $6.3 \%$ fat, I9.6 \% nitrogenfree extract, and $0.9 \%$ crude fibre. As, according to Table I, there are 4.4 parts of amides in $33 . \mathrm{I}$ parts crude protein, there will be $4.8 \%$ amides in the $36.5 \%$ crude protein in the rape cake. The $4.8 \%$ amides are to be regarded as perfectly digestible, and if they are deducted from the $29.6 \%$ digestible crude protein which the cake contains, there is left $24.8 \%$ digestible proteins.

$24.8 \%$ digestible proteins $\times 0^{\circ} 94=23.3 \%$ starch equivalent

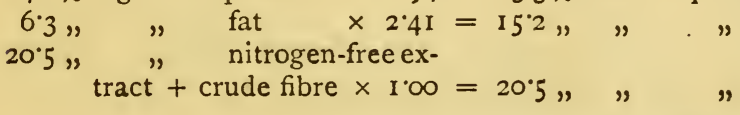

Total . . 59\% \% starch equivalent

If the nutrients in the rape cake were of full value, the sum obtained above would represent the starch equivalent; but the value of rape cake, according to Table I, is only $95 \%$, so $5 \%$ has to be deducted, which leaves the starch equivalent of rape cake at $56.0 \%$. When dealing with the 


\section{SCIENTIFIC FEEDING OF ANIMALS}

coarse fodders (hay and straw), it is advisable not to make use of the value number, but to deduct 0.58 from the starch equivalent, as calculated above for each per cent of crude fibre (not the digestible, be it noted) in the food.

Chaff is treated in the same way, a deduction of 0.29 being made for each I \% crude fibre. With green fodders the starch equivalent depends also upon the amount of crude fibre ; where the amount in the green fodder is $16 \%$ and more, a deduction of 0.58 starch equivalent; whereas, if the amount of crude fibre is $4 \%$ or less, the deduction is only 0.29 starch equivalent. For intermediate quantities of crude fibre a proportionate deduction has to be made: e.g. 0.34 for each per cent crude fibre in green fodder where the total is $6 \% ; 0.38$ where the total is $8 \% ; 0.43$ where it is $10 \%$; 0.48 where it is $12 \%$; and 0.53 where it is I $4 \%$.

Two typical cases are shown below. Spring cereal straw contains, according to Table $I$, the following digestible nutrients :-

I $\circ \%$ protein $\times 0.94 . \quad . \quad . \quad .=0.94 \%$ starch equivalent

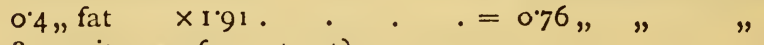
$\left.\begin{array}{l}18.5, \text { nitrogen-free extract } \\ 21^{\prime} \cdot \text {, crude fibre . . }\end{array}\right\} 39^{\circ} 6 \times 1 \mathrm{I}^{\circ} \mathrm{0}=39^{\circ} 60, ", \quad "$

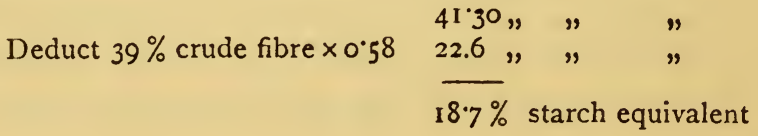




\section{APPENDIX}

For green cock's-foot grass in flower there are, according to $\backslash$ Table $\mathrm{I}$, the following amounts of digestible nutrients :-

I. $0 \%$ protein $\times 0.94$. . . . $=0.94 \%$ starch equivalent 0.4 " fat $\times$ I.9r. . . . = $=076$ " " " $\left.\begin{array}{l}9.5, \text { nitrogen-free extract } \\ 4.3 \% \text {, crude fibre . . }\end{array}\right\} 13.8 \times 1 \cdot 0=13.8, "$,
Deduct $7.3 \%$ crude fibre $\times 0.36$

$\begin{array}{lll}15.50, & \\ 2.6, " n & ,\end{array}$

$12.9 \%$ starch equivalent

Without any serious error the calculations can be simplified by reckoning $2 \cdot 2$ starch equivalent for I part digestible fat in all food-stuffs.

After finding the amount of digestible protein in the foods which are to compose the ration and the starch equivalents, Table III must then be turned to in order to find in what proportions the foods must be used. As some of the feeding-stuffs have almost certainly been grown on the farm, it must first of all be decided what quantities of hay, straw, mangels, etc. can be spared for each branch of stock per head per day, so that the supply is enough for the time during which this particular ration is to be fed.

Suppose that for cows weighing rooo lbs. and giving 20 lbs. milk, there are, after deducting straw for litter, 30 lbs. mangels, 8 lbs. meadow hay, Io lbs. straw available; also that brewers' grains are cheap, and $25 \mathrm{lbs}$. may be given. From 


\section{$35^{8}$ SCIENTIFIC FEEDING OF ANIMALS}

Table I it is seen that the four feeding-stuffs contain :-

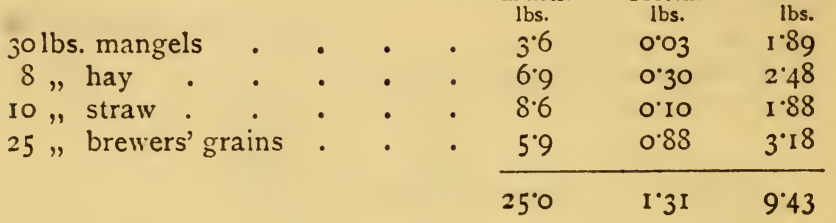

According to the feeding standards,

Table III, there should be given

\begin{tabular}{ccc}
$25^{\circ} 0$ & 175 & 10.5 \\
\hline 0 & 0.44 & 1.07
\end{tabular}

A feeding-stuff which will serve to make the ration up to the standard is then sought, and it is calculated what quantity is necessary for the purpose. In this way a large number of suitable foods or mixtures are found, as, for example, those given below :-

Ibs. extracted rape meat.

(a) extracted rape meal . $\quad 0_{48}$

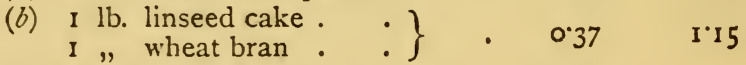

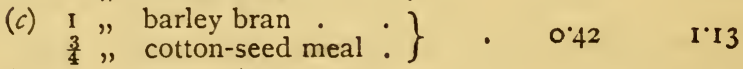

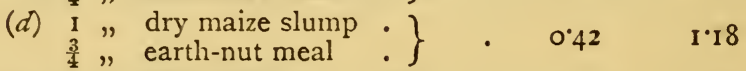

$\begin{array}{llll}\text { (e) I " field beans : } & \text {. } \\ \text { I " rape cake } & . & 0.42 & \text { I } 28\end{array}$

The small differences from the feeding standards, which are seen above, are absolutely unimportant, for in no case can the nutritive value of a food-stuff 


\section{APPENDIX}

be measured without likelihood of a small error. The calculation may, in fact, be made with crude protein, if the feeding-stuffs composing the ration are not very rich in amides. Generally the cheapest amongst the foods which will serve to supplement the ration is chosen, and it is best to regard the market price in doing this, for the nutritive values of foods, as given in tables, are the average for whole countries at some particular time, and may not apply when the ration is being made up. In no case, though, are the standards in Table III to be treated as cast-iron; they are meant to enable the feeder to start with a well-tried average ration, and then he should find out what is most suitable for his own requirements. 


\section{SCIENTIFIC FEEDING OF ANIMALS}

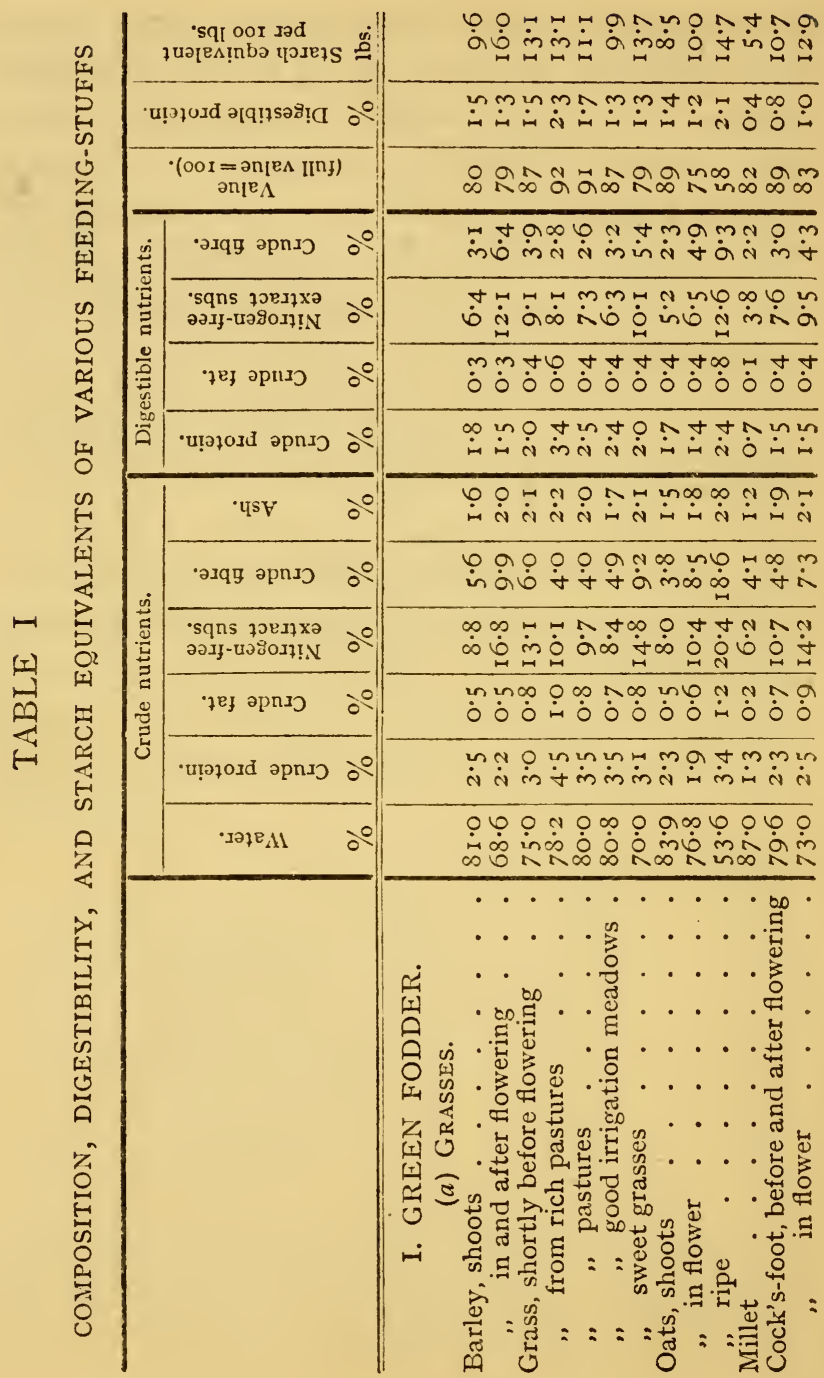




\section{TABLE I}

$m+\emptyset \leqslant+m \div ?$

0 \%

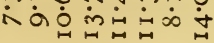

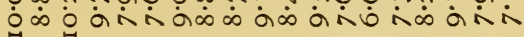
mo mam+no $\dot{0} \dot{0} \dot{\sim} \dot{\sim} \dot{\sim} \dot{\sim} \dot{0} \dot{\varphi}$ "艹

N $m$ in in a a ๙ૈศ๒ $\infty \infty \infty \times \infty \times$

I. $\dot{\mathrm{i}} \dot{\mathrm{n}} \dot{\mathrm{y}}$ in $\dot{\mathrm{m}} \dot{\mathrm{y}} \dot{\mathrm{m}} \dot{\mathrm{t}}$

" $\dot{\mathrm{N}} \dot{\mathrm{N}} \dot{\mathrm{m}} \dot{\mathrm{N}} \dot{\mathrm{N}} \dot{m} \dot{\mathrm{n}} \dot{\mathrm{N}} \dot{\mathrm{N}} \dot{\mathrm{n}} \dot{\mathrm{N}} \dot{\mathrm{m}} \dot{\mathrm{N}} \dot{\mathrm{N}} \dot{\mathrm{N}} \dot{\mathrm{N}} \dot{\mathrm{N}} \dot{\mathrm{H}}$

ก ก $+\infty \leqslant 0 \infty \div$ in $\dot{0} \dot{i} \dot{a} \dot{i}$ in $\dot{r}$

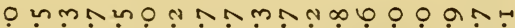
$\rightarrow$ $\dot{0}$ in $\dot{0} \dot{\theta} \dot{y}$ in in $\dot{y} \dot{\nabla} \dot{0}$ in $\dot{\theta} \dot{y}$ in $\dot{y}$ in in in $\dot{y}$

Nmmオ $m$ แn $n$ 0ं $\dot{0} \dot{0} \dot{0} \dot{0} \dot{0} \dot{0} \dot{0}$

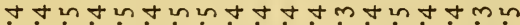
ó $\dot{0} \dot{0} \dot{0} \dot{0} \dot{0} \dot{0} \dot{0} \dot{0} \dot{0} \dot{0} \dot{0} \dot{0} \dot{0} \dot{0} \dot{0} \dot{0} \dot{0}$

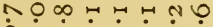
$\dot{0} \dot{\sim} \dot{\sim} \dot{\mathrm{i}} \dot{\mathrm{N}} \dot{\mathrm{N}} \dot{\sim} \dot{H}$

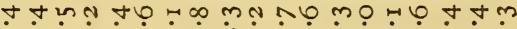

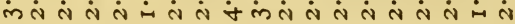

$\operatorname{lng} 0,0, \pi+4$ $\dot{\sim} \dot{\sim} \dot{\mathrm{n}} \dot{\mathrm{n}} \dot{\mathrm{n}} \dot{\mathrm{n}} \dot{\mathrm{n}} \dot{\mathrm{n}}$

œ +

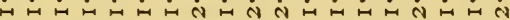

$0,1 \rightarrow 4 \sin$ in in $\dot{1} \dot{0} \dot{0} \dot{1} \dot{0}$

H⿻ in in in in in $\dot{0} \dot{\theta} \dot{+} \dot{\forall} \dot{i}$ in $\dot{0}$ in in in in in in

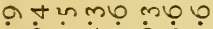
$\dot{\infty} \dot{0} \dot{\dot{y}} \dot{\dot{\theta}} \dot{0} \dot{\boldsymbol{i}}$ 4⿻

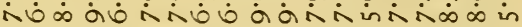

$+\ln \infty 090$ ? ல $\dot{0} \dot{0} \dot{0} \dot{\mathrm{r}} \dot{0} \dot{0} \dot{\mathrm{H}}$

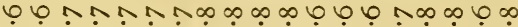
o $\dot{0} \dot{0} \dot{0} \dot{0} \dot{0} \dot{0} \dot{0} \dot{0} \dot{0} 0 \dot{0} 0 \dot{0} \dot{0} \dot{0} \dot{0} \dot{0}$

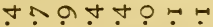
$\dot{\sim} \dot{\sim} \dot{\mathrm{N}} \dot{m} \dot{m} \dot{m} \dot{\mathrm{n}}$

mm+t

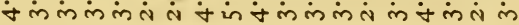

ก.

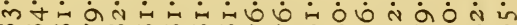

mas.

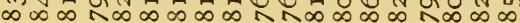

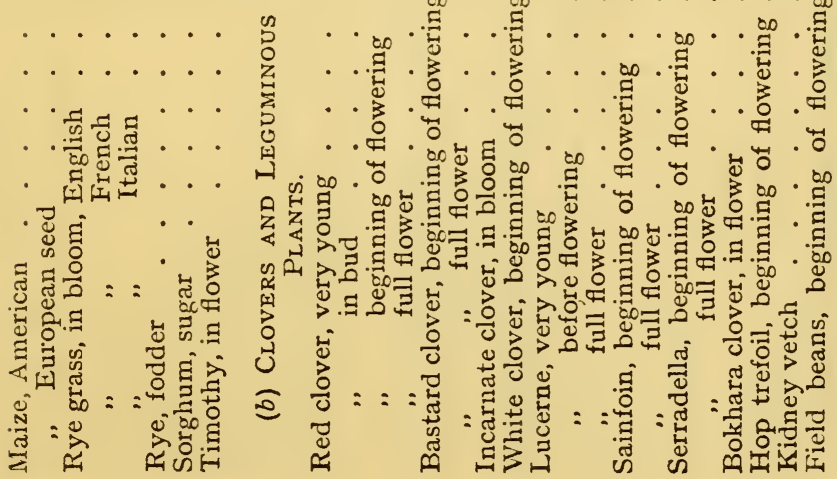




\section{SCIENTIFIC FEEDING OF ANIMALS}

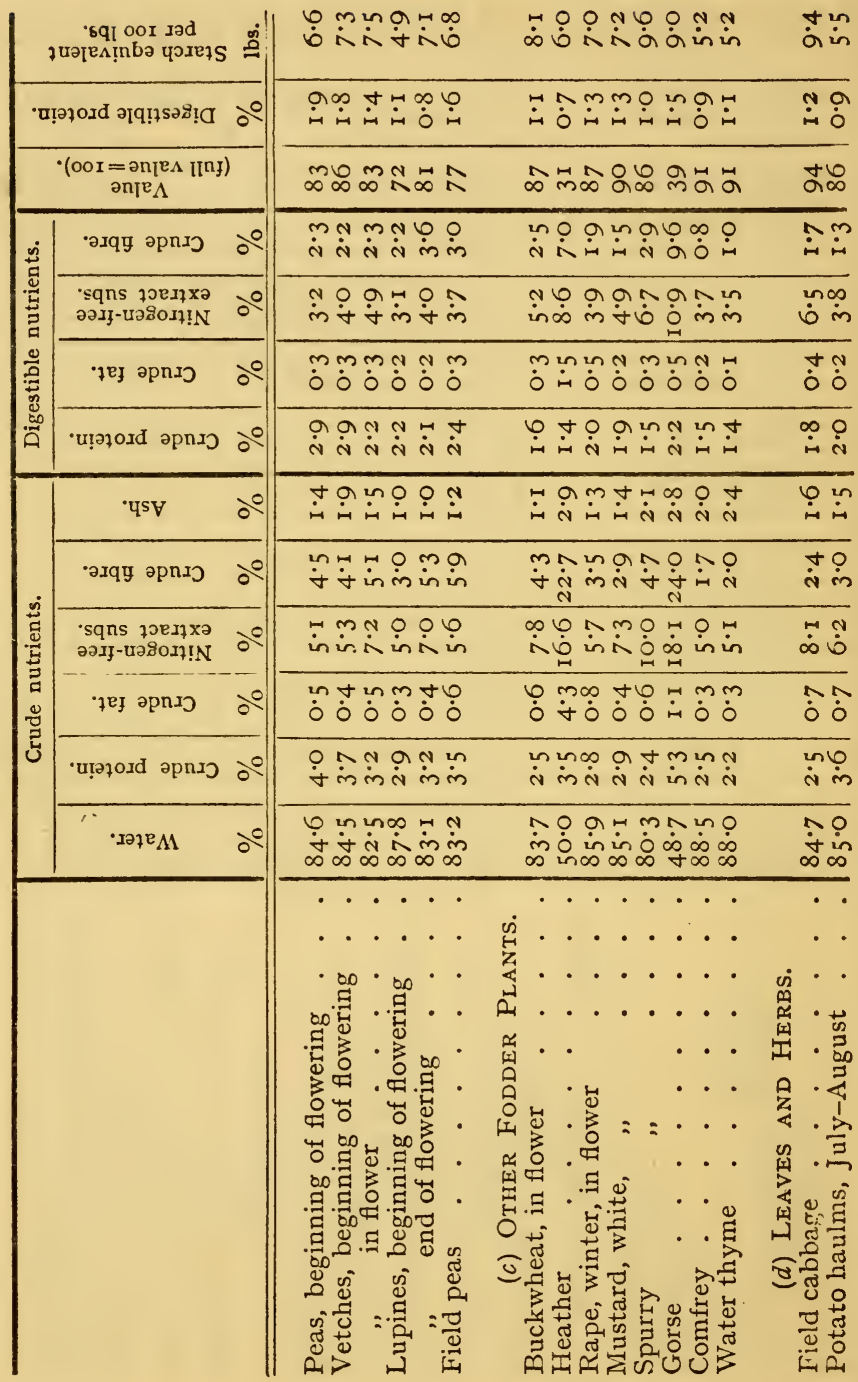




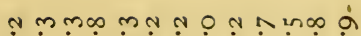

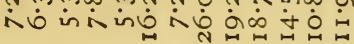

n.

$\dot{0}$ in $\dot{1} \dot{\infty} \dot{\infty} \dot{\infty} \dot{\infty} \dot{0} \dot{\alpha} \dot{1} \dot{a}$

0 t女

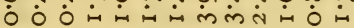

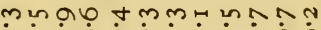

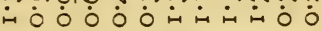

N

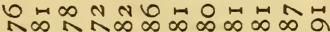

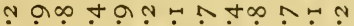

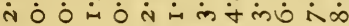

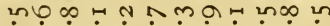

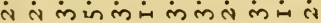

MN

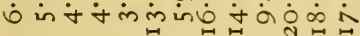

แก in in in in in in in in in

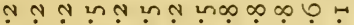
$\dot{0} \dot{0} \dot{0} \dot{0} \dot{0} \dot{0} \dot{0} \dot{\mathrm{n}} \dot{0} \dot{0} \dot{0} \dot{0}$

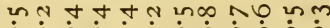
$\dot{0} \dot{0} \dot{0} \dot{0} \dot{0} \dot{\sim} \dot{0} \dot{0} \dot{0} \dot{0} \dot{0} \dot{0}$

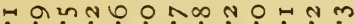

$\dot{\sim} \dot{\sim} \dot{\mathrm{N}} \dot{\mathrm{n}} \dot{\mathrm{N}} \dot{\mathrm{q}} \dot{\mathrm{y}} \dot{\mathrm{N}} \dot{\mathrm{N}} \dot{\mathrm{N}}$

$m 07+\infty$ ?

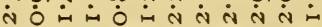

"

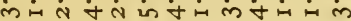

4 $\dot{0} \dot{0} \dot{\sim} \dot{\sim} \dot{\sim} \dot{\mathrm{N}} \dot{\sim} \dot{\mathrm{N}} \dot{\mathrm{N}}$ in $\dot{\mathrm{N}}$

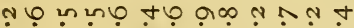

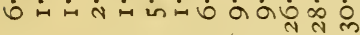

0 tนnnt女 in $+\dot{t} \dot{\infty}$ in $\dot{\forall} \dot{0}$ in in $\dot{0}$ in in

n.

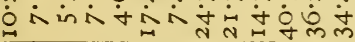
4ก: in in $\dot{\infty} \dot{0} \dot{0} \dot{0}$ in $\dot{+} \dot{0} \dot{0}$ o

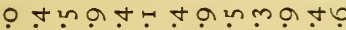

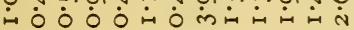

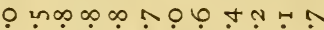

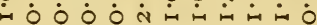

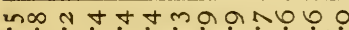

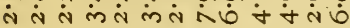

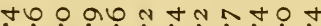

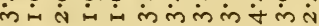

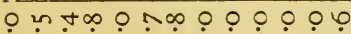

$\dot{1} \dot{0} \dot{\infty} \dot{\theta} \dot{\gamma}$ in in $\dot{i} \dot{0}$ in $\dot{0}$ in

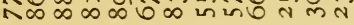

molomino m ml mo in $\dot{0} \dot{0} \dot{0} \dot{i}$ in $\dot{0} \dot{N}$ is $\dot{N}$ $\infty \infty \infty \wedge \infty N \infty \infty N$

Uै

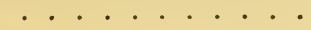

. . . . . . . . . . .

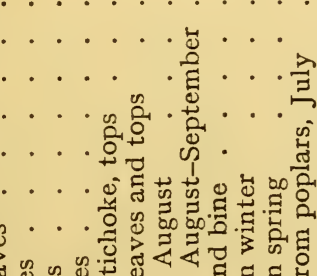

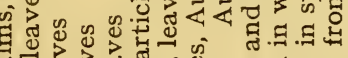
- $->>$ त $>$ क

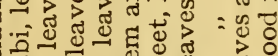
तु $\hat{\mathrm{A}}+\mathbf{0}$

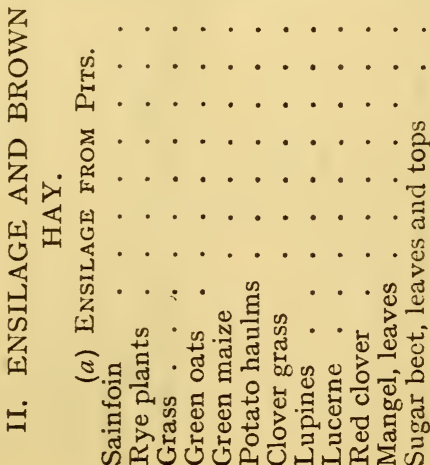




\section{SCIENTIFIC FEEDING OF ANIMALS}

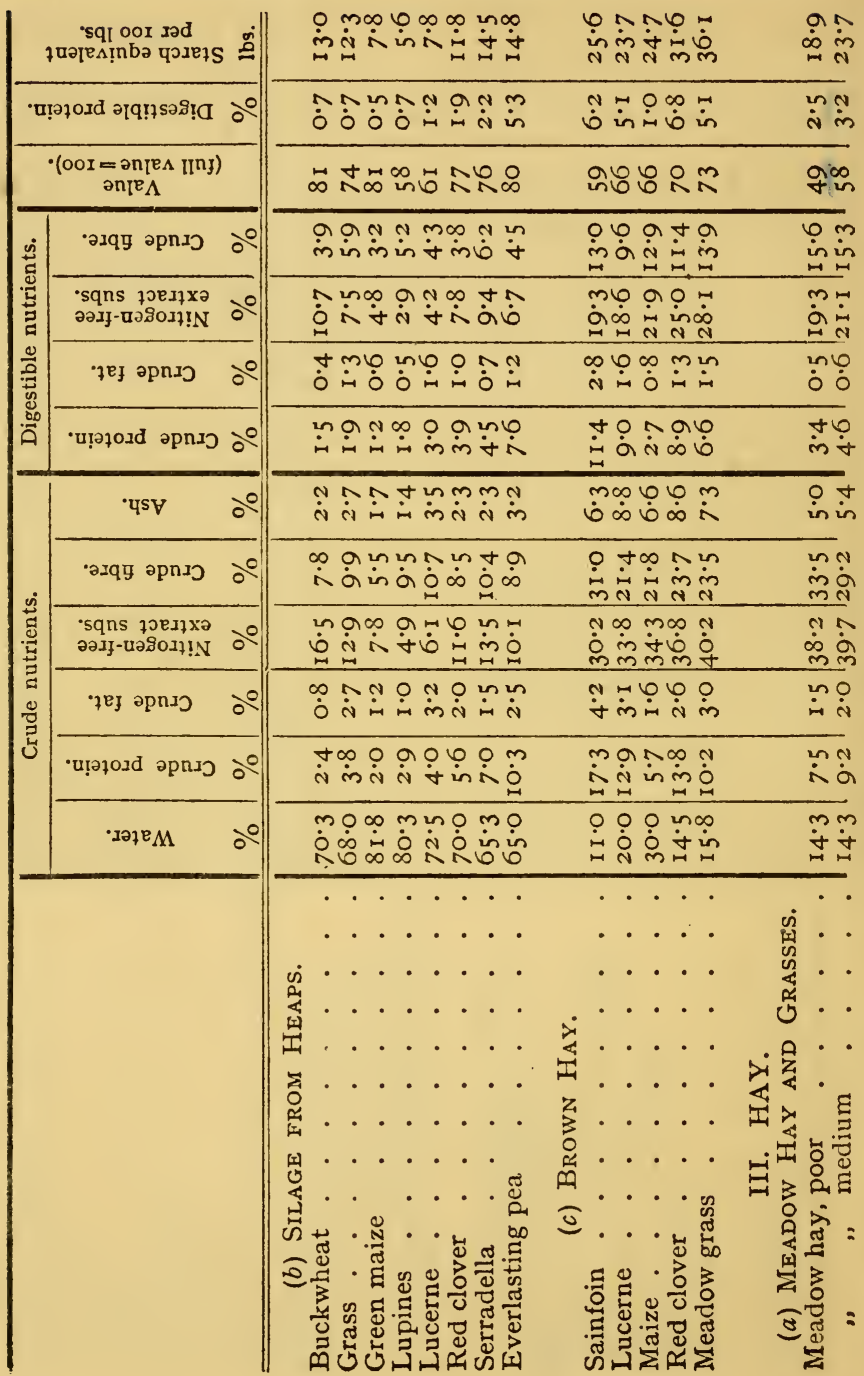




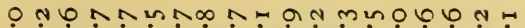

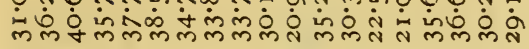

$\infty 0$ nio otntm 0.000 munanon

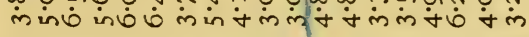

जั

$0, \infty$ N

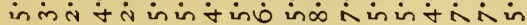

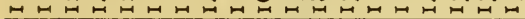

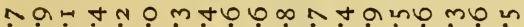

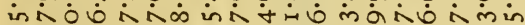

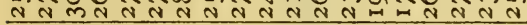

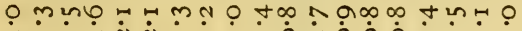

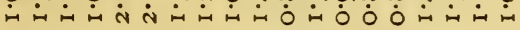

$\pi+4074 \div 0$,

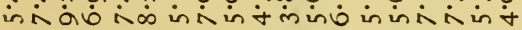

n?

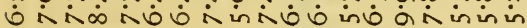

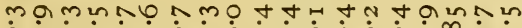

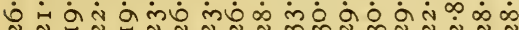

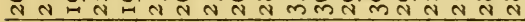

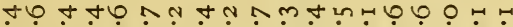

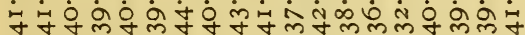
nno 0 , $\dot{\mathrm{N}} \dot{\mathrm{N}} \dot{m} \dot{\mathrm{m}} \dot{\mathrm{m}} \dot{\mathrm{N}} \dot{\mathrm{N}} \dot{\mathrm{N}} \dot{\mathrm{N}} \dot{\mathrm{N}} \dot{\mathrm{N}} \dot{\mathrm{N}} \dot{\mathrm{N}} \dot{\mathrm{n}} \dot{\mathrm{N}} \dot{\mathrm{N}} \dot{\mathrm{N}}$

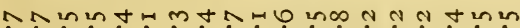

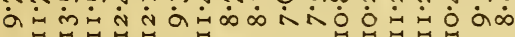
0000 no 0 No n tmmmmmm

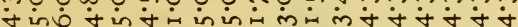

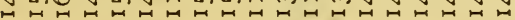

ก ᄂ

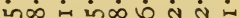
N $\mathrm{NmMN} N \mathrm{~N}$

0 in $\ln 0 \infty \mathrm{n} \infty \mathrm{n}$ $\dot{+}+$ in $\dot{1} \dot{+} \dot{0} \dot{i}$

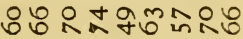

D.

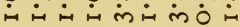

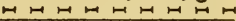

○ + in $\dot{0} \dot{0} \dot{\sim} \dot{\infty}$ in in

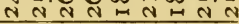

ONNHNMNH $\dot{\sim} \dot{\oplus} \dot{\sim} \dot{\mathrm{O}} \dot{\mathrm{n}} \dot{\mathrm{n}} \dot{\mathrm{N}}$

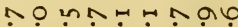
in $\dot{1} \dot{0} \dot{0} \dot{\text { i }} \dot{0} \dot{0}$ - mo o o monm in in $\dot{1} \dot{\wedge} \dot{\wedge} \dot{0} \dot{\circ}$

d. 으.

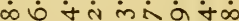

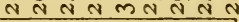

N"N is $\dot{m}$ in $\dot{m} \dot{m} \dot{q} \dot{v}$ mmmm

me d $\dot{N} \dot{N} \dot{N} \dot{m} \dot{N} \dot{N}$ in m minmonetr $\dot{i}$ is $\dot{m}$ in $\dot{1} \dot{b} \dot{y}$ in MHMHMHM ○ 0 un un 0 uno in in $\dot{0} \dot{0} \dot{0} \dot{0}$ in

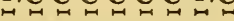

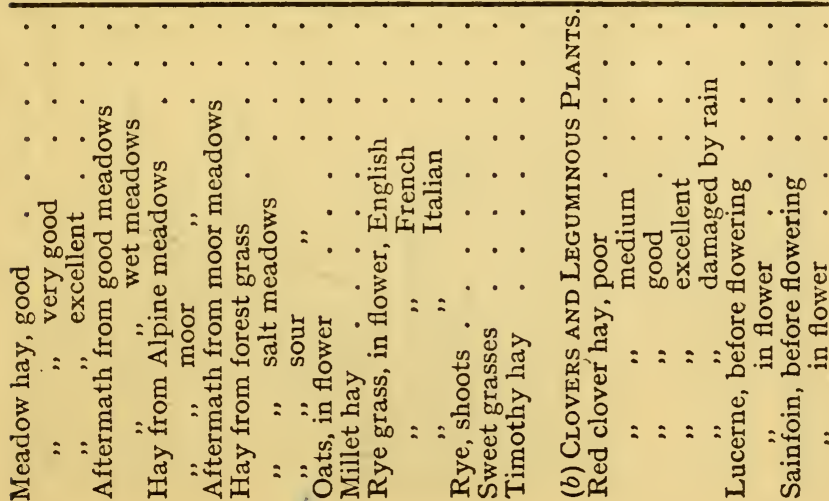




\section{SCIENTIFIC FEEDING OF ANIMALS}

\begin{tabular}{|c|c|c|}
\hline \multicolumn{2}{|c|}{ 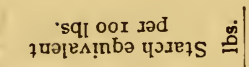 } & 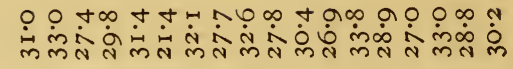 \\
\hline \multicolumn{2}{|c|}{ 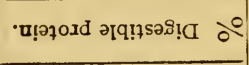 } & 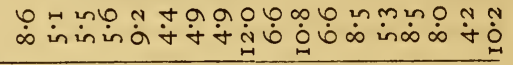 \\
\hline \multicolumn{2}{|r|}{ 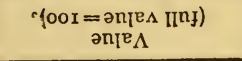 } & 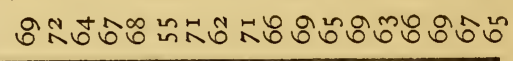 \\
\hline \multirow{4}{*}{ 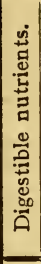 } & •xqg әрп्כ & 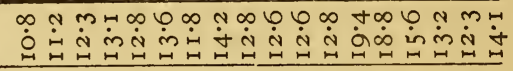 \\
\hline & 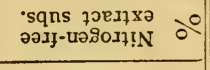 & 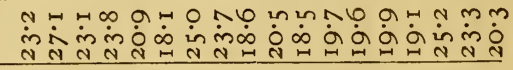 \\
\hline & ๆ э әрп्ว & 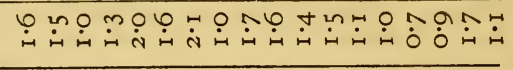 \\
\hline & 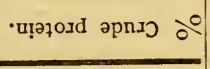 & 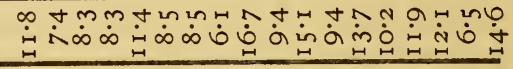 \\
\hline \multirow{6}{*}{ 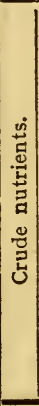 } & ' ५SV & 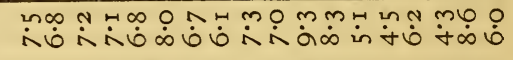 \\
\hline & •әхqg әрплכ & 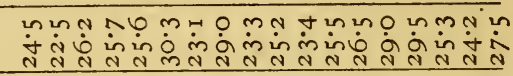 \\
\hline & 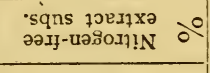 & 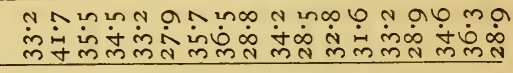 \\
\hline & 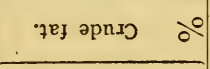 & 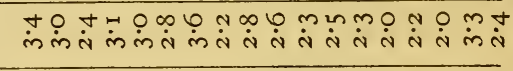 \\
\hline & 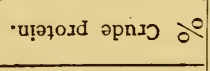 & 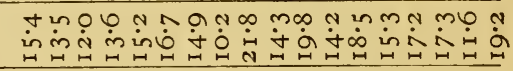 \\
\hline & - IәZRAI & 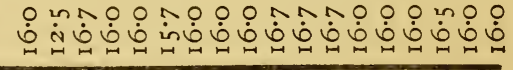 \\
\hline & & 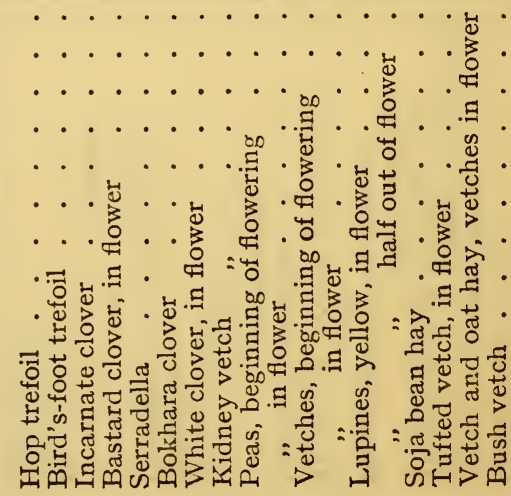 \\
\hline
\end{tabular}




\section{SCIENTIFIC FEEDING OF ANIMALS}

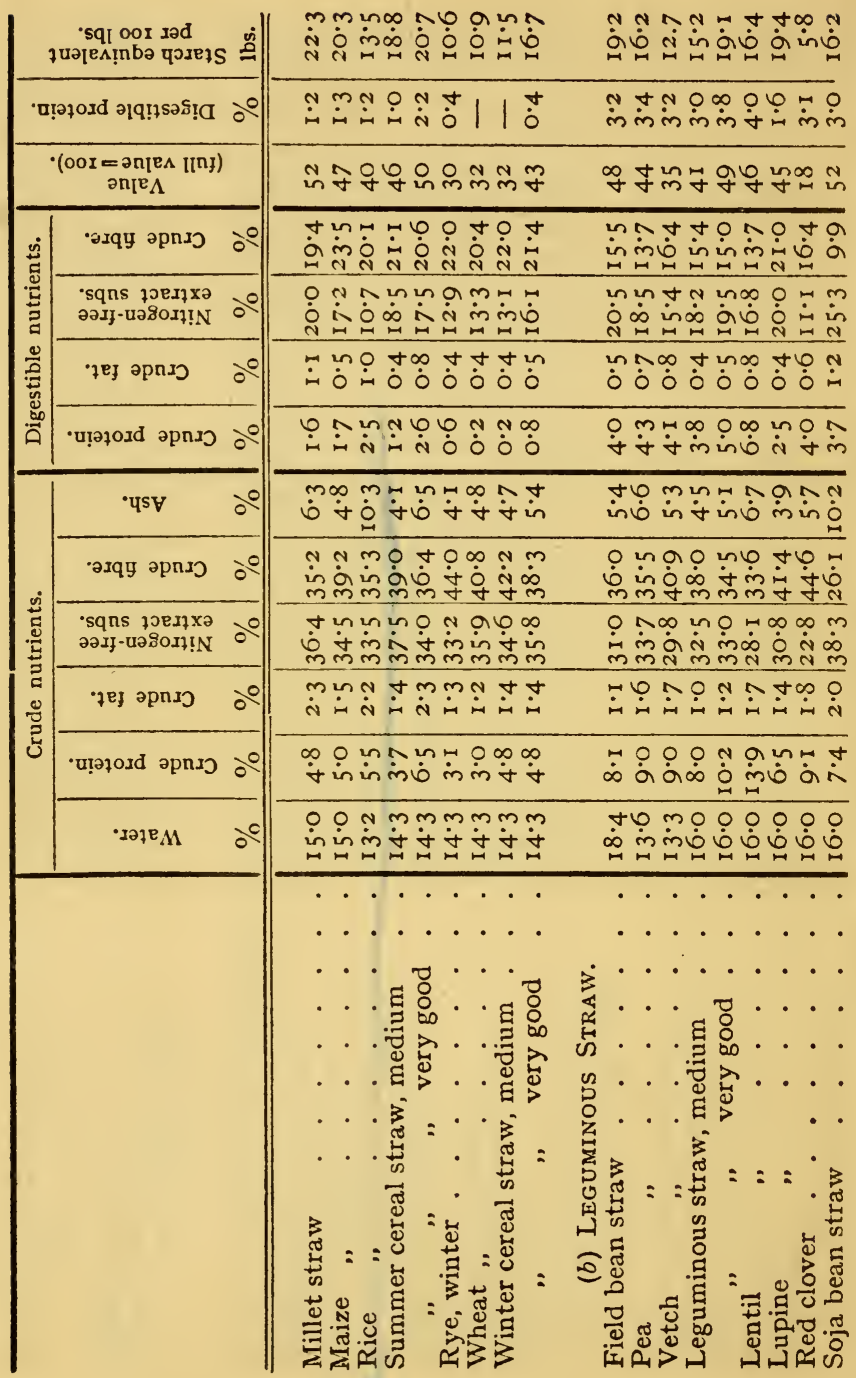


ก) ?

To not?

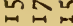

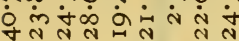

$\infty \div \rightarrow m+0 \div$

$\infty \emptyset 1$

แヘ

24
4

ก

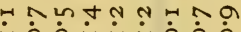

n ल

Im

$\dot{i} \dot{0}$

$\dot{A} \dot{0} \dot{0} \dot{H} \dot{H} \dot{0} \dot{0}$

ㄴ.

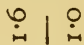

4.

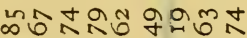

mำ $\mid$ ำำ

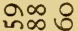

\begin{tabular}{|c|c|c|c|}
\hline 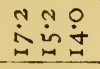 & 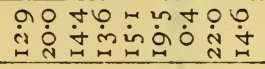 & 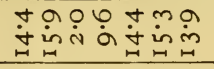 & $\ddot{m} \dot{m} \dot{n}$ \\
\hline 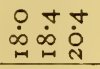 & 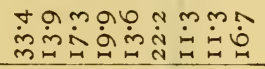 & 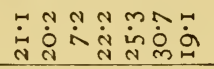 & $\begin{array}{l}\infty m 0 \\
\dot{y} \dot{\sim} \ddot{n} \\
\end{array}$ \\
\hline 我 un & 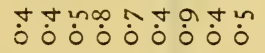 & 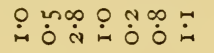 & 约 \\
\hline 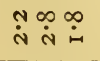 & 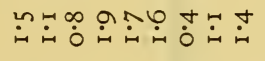 & in & تं \\
\hline in $\hat{\infty}$ in & 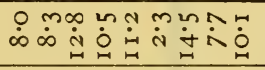 & 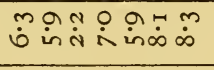 & $\stackrel{+\infty}{n} \underset{i}{n}$ in \\
\hline $\begin{array}{l}i \infty \\
\dot{m} \\
\dot{m}\end{array}$ & 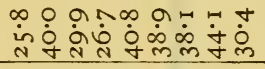 & i்trum & $\begin{array}{l}n \infty \\
\dot{m} \text { in }\end{array}$ \\
\hline 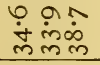 & 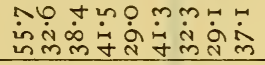 & 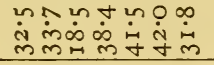 & $\begin{array}{l}+m 0 \\
\text { in் in } \\
m+m\end{array}$ \\
\hline 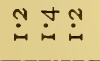 & 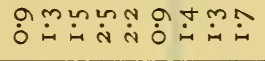 & 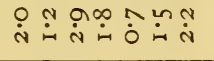 & تं山ें \\
\hline 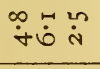 & 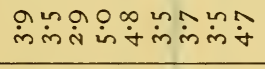 & 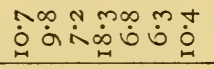 & $\begin{array}{l}0 \\
\dot{y} \dot{+} \dot{m}\end{array}$ \\
\hline 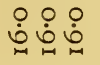 & 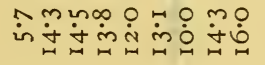 & 운 & 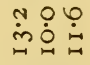 \\
\hline
\end{tabular}
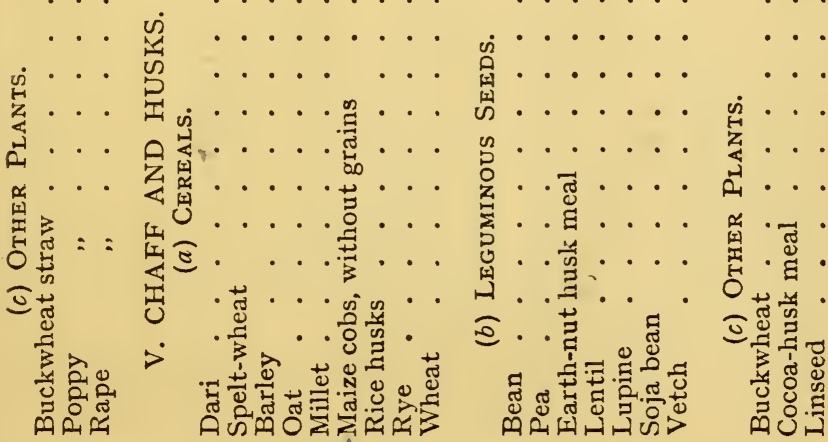


\section{SCIENTIFIC FEEDING OF ANIMALS}

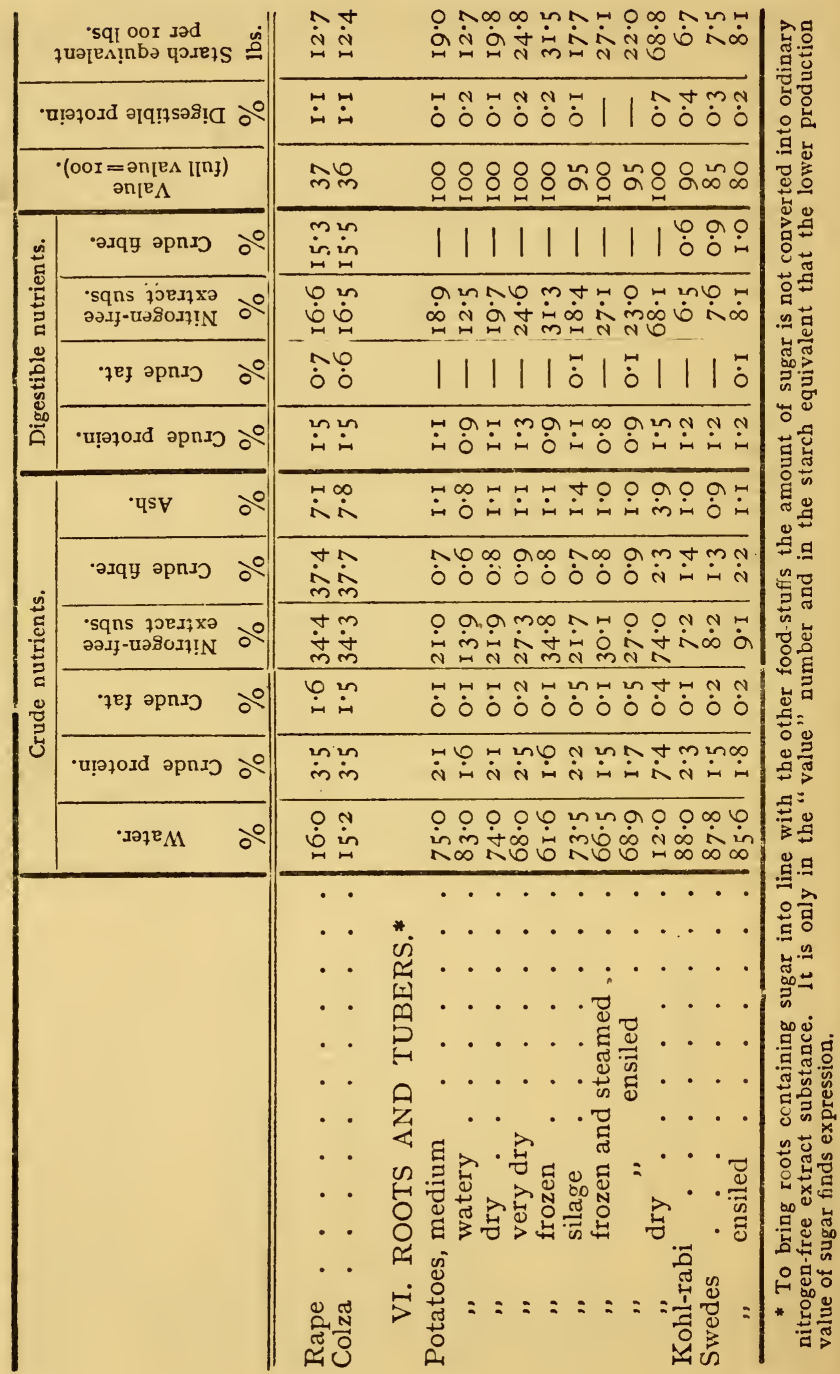




\section{TABLE I}

ก! ? + $\dot{\infty} \dot{\mu}$ in $\dot{1} \dot{\theta} \dot{+} \dot{\omega}$ in

オนחm ல்

$n \in+0 N N N$ n $\infty \infty N N N$

NmmmmN n

$\dot{0} \dot{0} \dot{0} \dot{0} \dot{0} \dot{0} \dot{0}$

ด แ

$\infty \underset{\sim}{\infty} \dot{0} \dot{0} \dot{\infty}$ in in

ஸि

$\infty$ a $0 \infty \emptyset 0$ o $\dot{0} \dot{0} \dot{0} \dot{0} \dot{0} \dot{0} \dot{0}$

ใด $\dot{\omega} \dot{\sim} \dot{\sim} \dot{0} \dot{i} \dot{0} \dot{0}$

$m+0 \infty 90 \mathrm{n} n$ $\dot{H} \dot{1} \dot{0} \dot{0} \dot{0} \dot{0} \dot{0}$

monl $\dot{\sigma}$ in $\dot{0} \dot{0} \dot{0} \dot{0}$ M ஸ்

กต

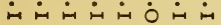

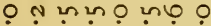
i $\dot{\text { i }} \dot{0} \dot{\infty}$ i $\dot{\text { in }}$ $\infty \infty \infty \infty \infty$ a $\infty$
NHmNO m

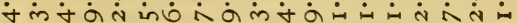

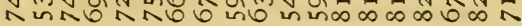

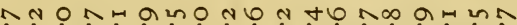

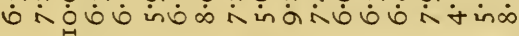

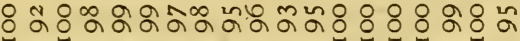

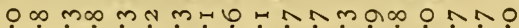

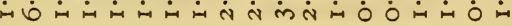

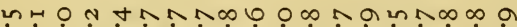
$\dot{0} \dot{\sim} \dot{0} \dot{\omega} \dot{\omega} \dot{\omega} \dot{0} \dot{0} \dot{0}$ in in $\dot{0}$ in $\dot{0}$ in in

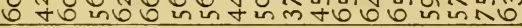

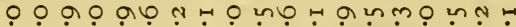

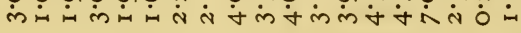

$n$ n n

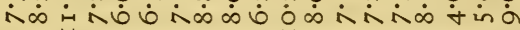
$\forall m \infty 0$ un $m \infty 0$, $\dot{\sim} \dot{N} \dot{H} \dot{N} \dot{N} \dot{N} \dot{N} \dot{N}$ m $m \dot{m} \dot{H} \dot{H} \dot{H} \dot{H} \dot{N}$

ด กำ in in is in $\dot{N} \dot{0}$ in $\dot{0} \dot{\infty}$ in $\dot{N} \dot{N} \dot{N} \dot{N} \dot{N} \dot{H}$

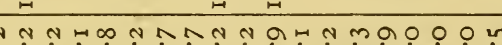

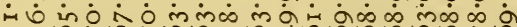

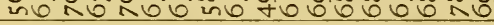

$\infty \forall n+\infty$ un $4 \infty$ a

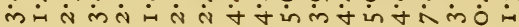

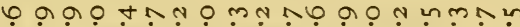

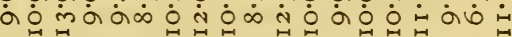

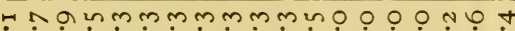

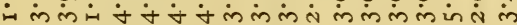

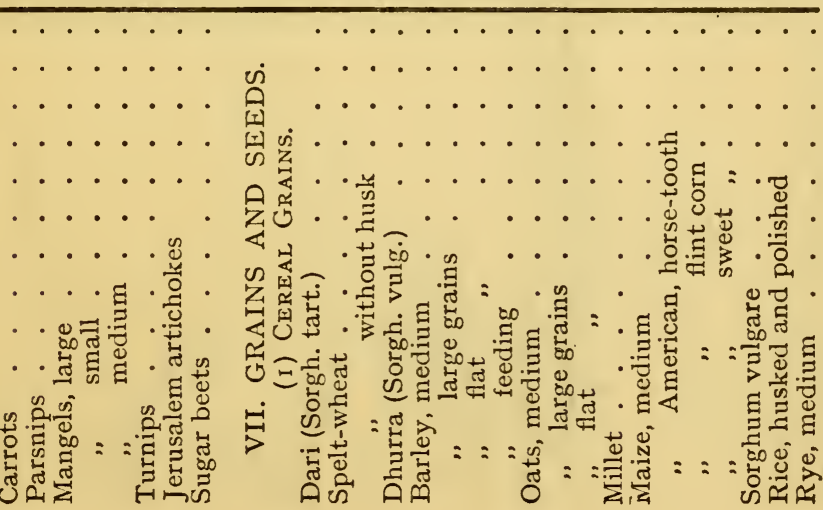




\section{SCIENTIFIC FEEDING OF ANIMALS}

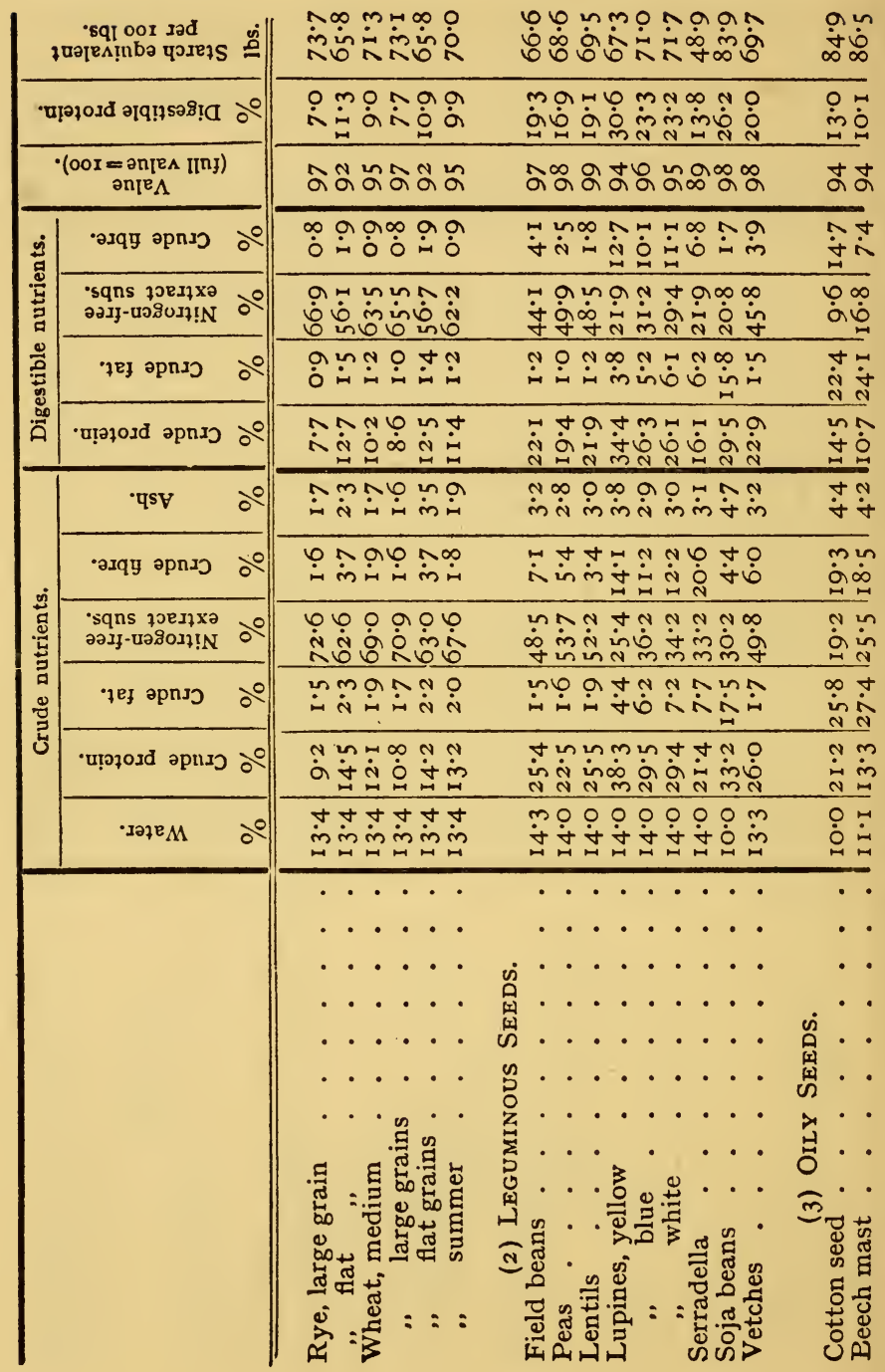




\section{TABLE I}

In N $\mathrm{Nm}$ N

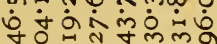
$\forall 0 \mapsto N \boxminus m m$

$0 \infty-6 \infty \infty \infty$

$+\dot{\sim} \dot{0}$ in mi

तथम

$\rightarrow \infty$

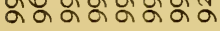

t $0 \% \infty$ in $\%$ t $t$

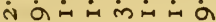

n

$\dot{0} \dot{\omega} \dot{\infty} \dot{\omega} \dot{N} \dot{\sim} \dot{\sim} \dot{\omega}$

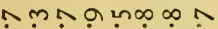

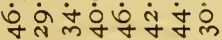

NAtao $+\infty$

$\dot{0}$ in $\dot{0}+\dot{0}$ in $\dot{\infty}$

N $\rightarrow-H \rightarrow$

$\infty$ N $\infty$ an

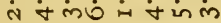

o 0 unm $9 \mathrm{~mm}$

$\dot{0}$ in in in in in $\dot{0}$

ต

4.

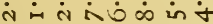
$\pi$ a d 4 C

ง

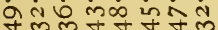

Na n 270 แn

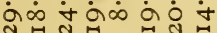

o $\dot{i} \dot{\infty} \dot{i} \dot{i} \dot{i}$ in
NAONmb mm

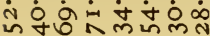

$\ln \infty \pi$ L

$\dot{i} \dot{\mathrm{N}} \dot{m} \dot{\mathrm{n}} \dot{\mathrm{N}} \dot{\mathrm{j}} \dot{\mathrm{j}}$

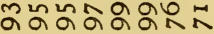

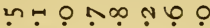

in $\dot{y} \dot{i}$ in $\dot{0} \dot{H} \dot{H}$

m! 느 $m+\infty$ ?

$\dot{v} \dot{v}$ in in $\dot{0} \dot{\infty} \dot{i}$

t $m$ Ln $m+n$

d

in in $\dot{0} \dot{i}$ is in

แก! $\dot{\infty} \dot{\mathrm{q}} \dot{+} \dot{\mathrm{n}} \dot{+} \dot{\mathrm{N}} \dot{\mathrm{N}}$

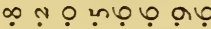

त $\rightarrow$ i

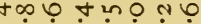
$\dot{\dagger} \dot{\omega} \dot{\omega} \dot{\omega} \dot{q} \dot{m} \dot{q}$

$\infty$ mio o n ? ४णें

0 t $m$ แ is $\dot{\mathrm{N}} \dot{+} \dot{i} \dot{i} \dot{\mathrm{N}}$ in in

$m m n \infty m 9 n$
in in in in $\dot{\nabla} \dot{0} \dot{\sim}$ $\rightarrow$ -

Ho o n n a

$\forall \dot{0}$ in in $\dot{0} \dot{0}$ in

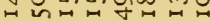

$\infty$ N in in $\dot{0} \dot{0}$ t in $\dot{0} \dot{0}$ n n⿺辶一兀

molo anmtnm

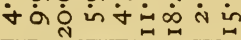

ㅁำ 4ก

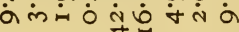
d. $\dot{0} \dot{0} \dot{\vec{\omega}} \dot{\infty} \dot{\sim} \dot{\sim} \dot{b}$ ง $+\infty+0$ ? $+\infty m$

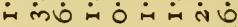
$œ+\forall \infty \mapsto \emptyset \mapsto \emptyset m$

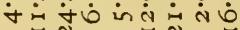
$\infty$ ? ก+

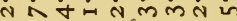

?

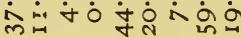
ง

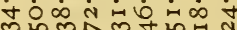
$\infty$ แ $\dot{+}+\infty \dot{n} \dot{\sim} \mathrm{N} \dot{\mathrm{N}}$

- $4 \infty 0 m \pi \infty n$
$\dot{\infty}$ in $\dot{m} \dot{\sim} \dot{i} \dot{m} \dot{i}$ $m$

lo ONONun m in $\dot{N} \dot{\sim} \dot{\nabla} \dot{N} \dot{n}$ in $\dot{0}$

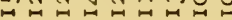
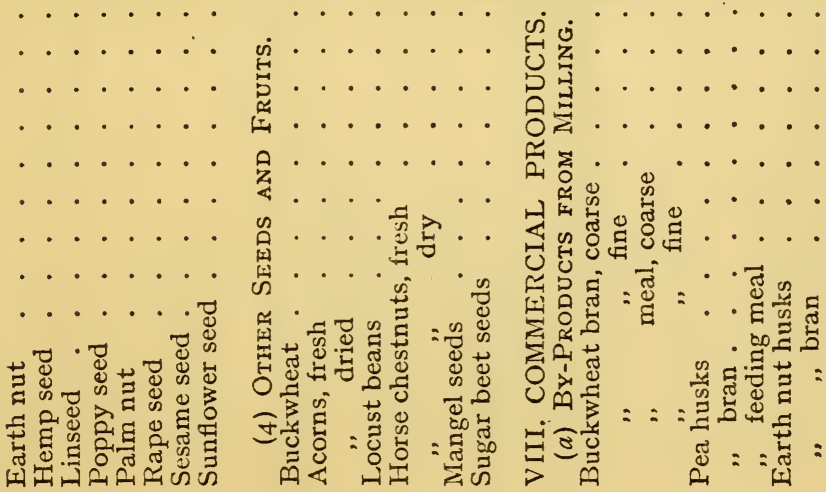


\section{SCIENTIFIC FEEDING OF ANIMALS}

\begin{tabular}{|c|c|c|c|c|}
\hline \multicolumn{2}{|c|}{ 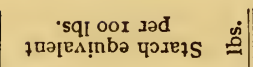 } & \multicolumn{3}{|c|}{ 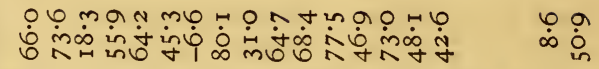 } \\
\hline \multicolumn{2}{|c|}{ 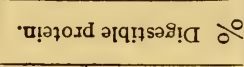 } & 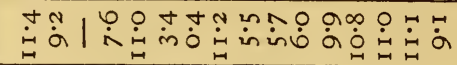 & & 1 \\
\hline \multicolumn{2}{|r|}{ 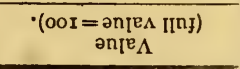 } & 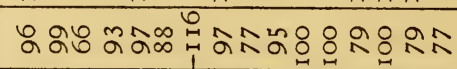 & & นุน \\
\hline \multirow{4}{*}{ 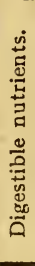 } & .әxqg әрnx & 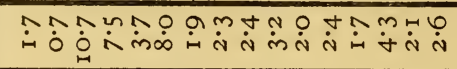 & & $\stackrel{N}{0}$ \\
\hline & 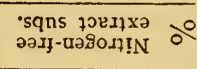 & 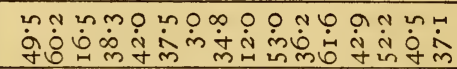 & & $\dot{\infty} \stackrel{\dot{\tau}}{n}$ \\
\hline & 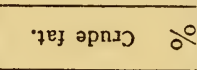 & 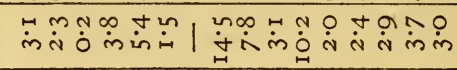 & & \\
\hline & 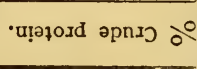 & 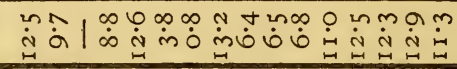 & & \\
\hline \multirow{6}{*}{ 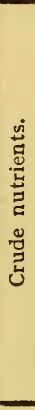 } & 'us & 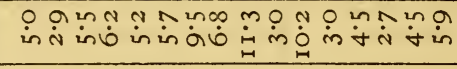 & & $\begin{array}{l}+ \text { in } \\
0 \text { in }\end{array}$ \\
\hline & - כ.वg әрп्र & 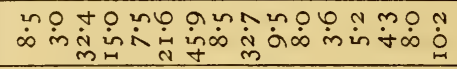 & & $i_{i \infty}^{\infty}$ \\
\hline & 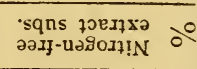 & 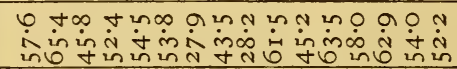 & & $\begin{array}{l}\operatorname{ma} \\
\dot{1} \dot{0} \\
\dot{H}\end{array}$ \\
\hline & .7е әрп्र & 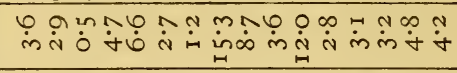 & & $1 \stackrel{+}{0}$ \\
\hline & -u!̣ozoxd opn כ כ & 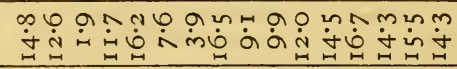 & & $\stackrel{\varphi}{\dot{0}}$ \\
\hline & 'дәре & 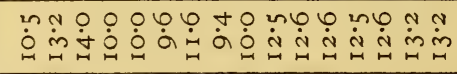 & & ○ \\
\hline & & 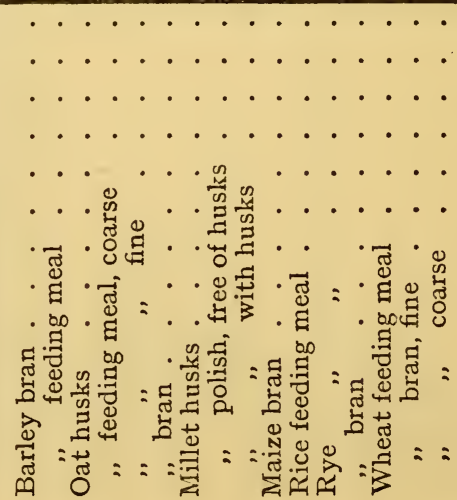 & 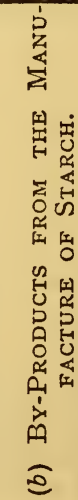 & 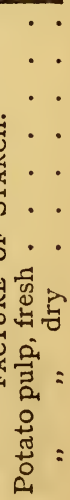 \\
\hline
\end{tabular}




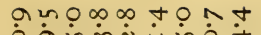

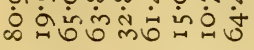

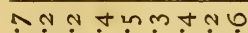
ind

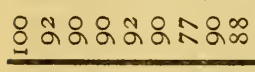

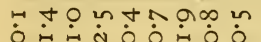

mњan-mo on

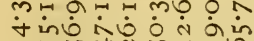

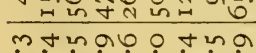
$\dot{4} \dot{4} \dot{\pi} \dot{i} \dot{H} \dot{0}$ +

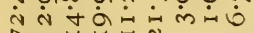

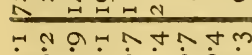

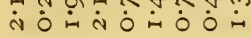
$+\infty$ mo

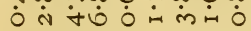

ก

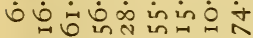
mbก in $\dot{i}$ in $\dot{\sim} \dot{\sim} \dot{\sim} \dot{\sim} \dot{0} \dot{i}$

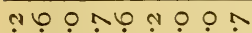

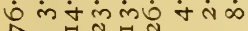
- Nom mo un! a of $n N \mapsto \infty$ in $n$

. . . . . . .$$
\text { (n) }
$$

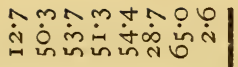

un $\rightarrow \infty$ an 0 un m

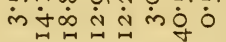

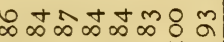

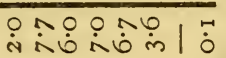
$00 m a n 0 m a n$ $\dot{0}$ in in $\dot{0} \dot{\mathrm{a}} \dot{\mathrm{y}} \dot{\mathrm{N}}$ 4 a $n \in A$ आण $\dot{\sim} \dot{0} \dot{0} \dot{i} \dot{\nabla} \dot{1}$ Nmo in in $\dot{0}$ in in $\dot{\nabla} \dot{v} \dot{0}$

$m$ n m $\dot{0} \dot{0} \dot{0} \dot{\forall} \dot{i} \dot{\forall} \dot{+}$ m. $\dot{0} \dot{0} \dot{0} \dot{\mathrm{N}} \dot{\mathrm{t}}$ 4. $\dot{\sim} \dot{\forall} \dot{N}$ in $\dot{0}$ in $\dot{0}$

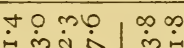
in

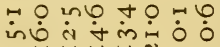

Nam monta


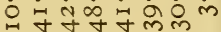
N ᄂ

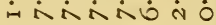

Non $\dot{\forall} \dot{1} \dot{\infty} \dot{0} \dot{0} \hat{0}$

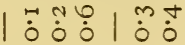

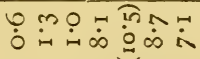

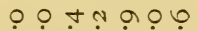
mins $\dot{\theta} \dot{1} \dot{0}$ $0 \infty \infty \cdots N$

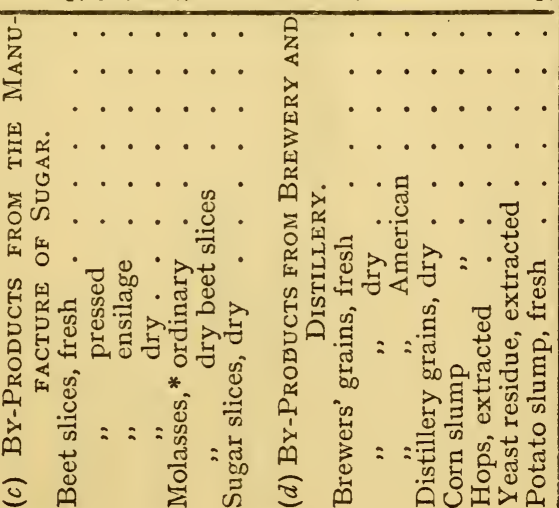




\section{SCIENTIFIC FEEDING OF ANIMALS}

\begin{tabular}{|c|c|c|c|}
\hline \multicolumn{2}{|c|}{ 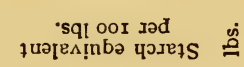 } & 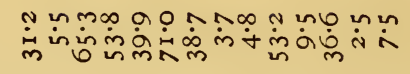 & $\dot{m} \dot{m} \dot{n}$ \\
\hline \multicolumn{2}{|c|}{ 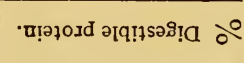 } & 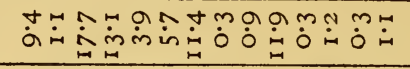 & \\
\hline \multicolumn{2}{|r|}{ 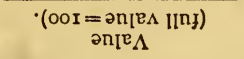 } & ᄋ̊ & + \\
\hline \multirow{4}{*}{ 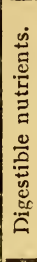 } & •əxqy әpnב & 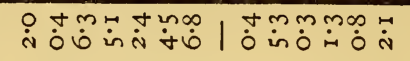 & \\
\hline & 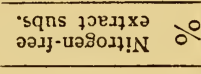 & 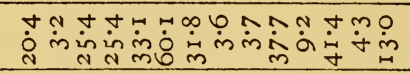 & $\dot{m}$ \\
\hline & 7еנ әрп्ว & 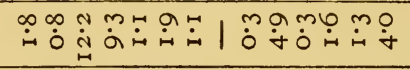 & $\ddot{6}$ \\
\hline & 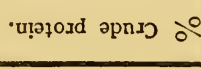 & 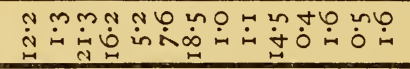 & $\stackrel{\mapsto}{\dot{\infty}}$ \\
\hline \multirow{6}{*}{ 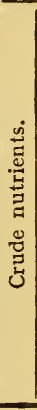 } & •"TSV & 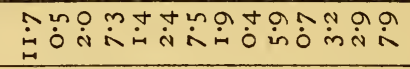 & \\
\hline & 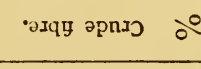 & 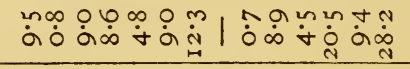 & 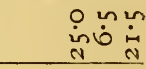 \\
\hline & 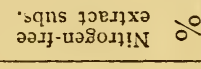 & 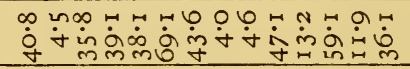 & 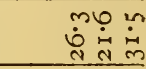 \\
\hline & - & 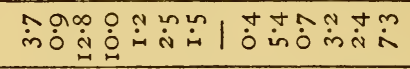 & ஜோ \\
\hline & 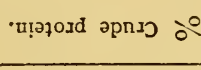 & 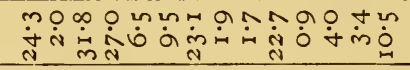 & $\begin{array}{l}\text { non } \\
\dot{4}+\dot{+} \infty \\
\end{array}$ \\
\hline & - دәңе & 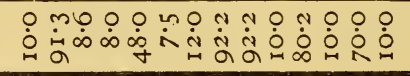 & in $\dot{0} \dot{\infty}$ \\
\hline & & 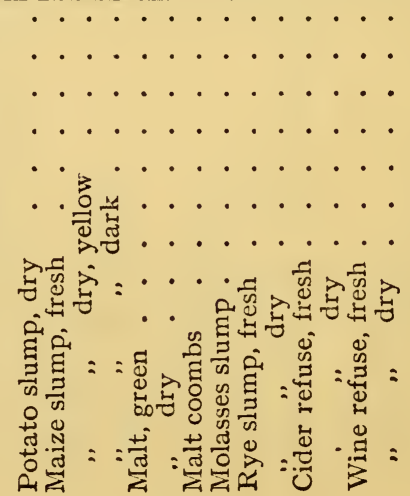 & 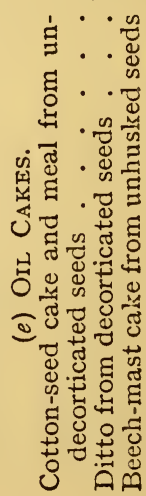 \\
\hline
\end{tabular}


ㄴ.

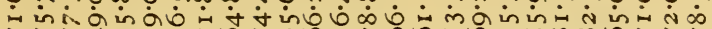

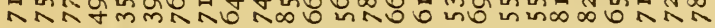

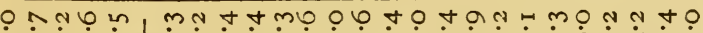

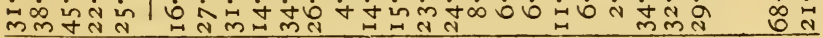

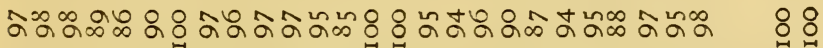

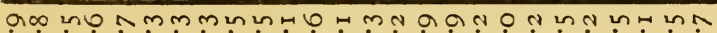

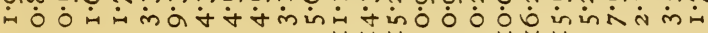

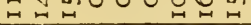

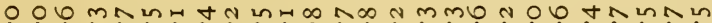

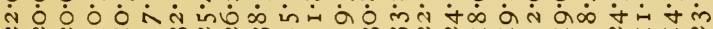

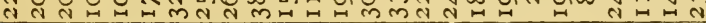

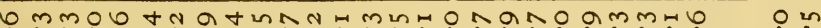

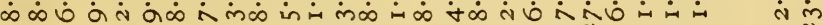

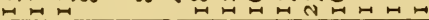

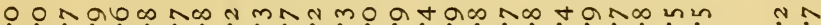

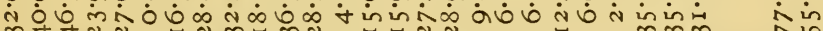

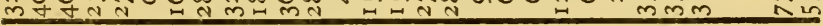

o แn

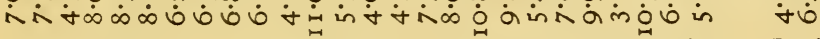

nata

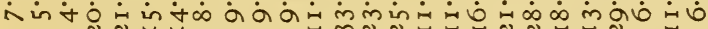
त $4 \pi$ H

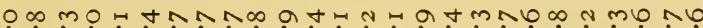

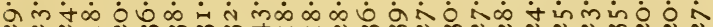

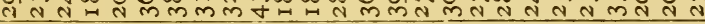

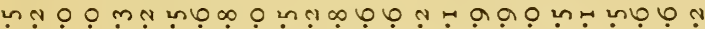

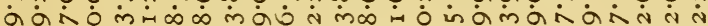

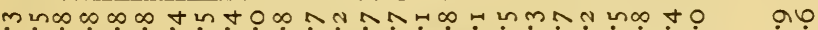

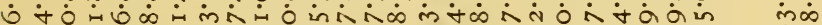

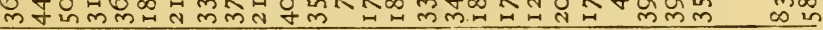

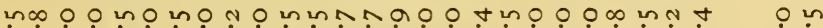

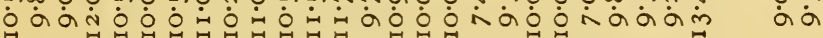

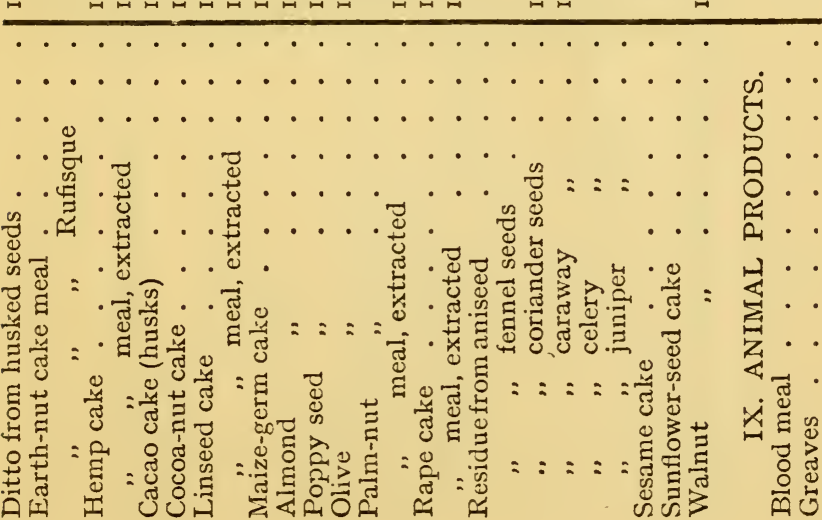




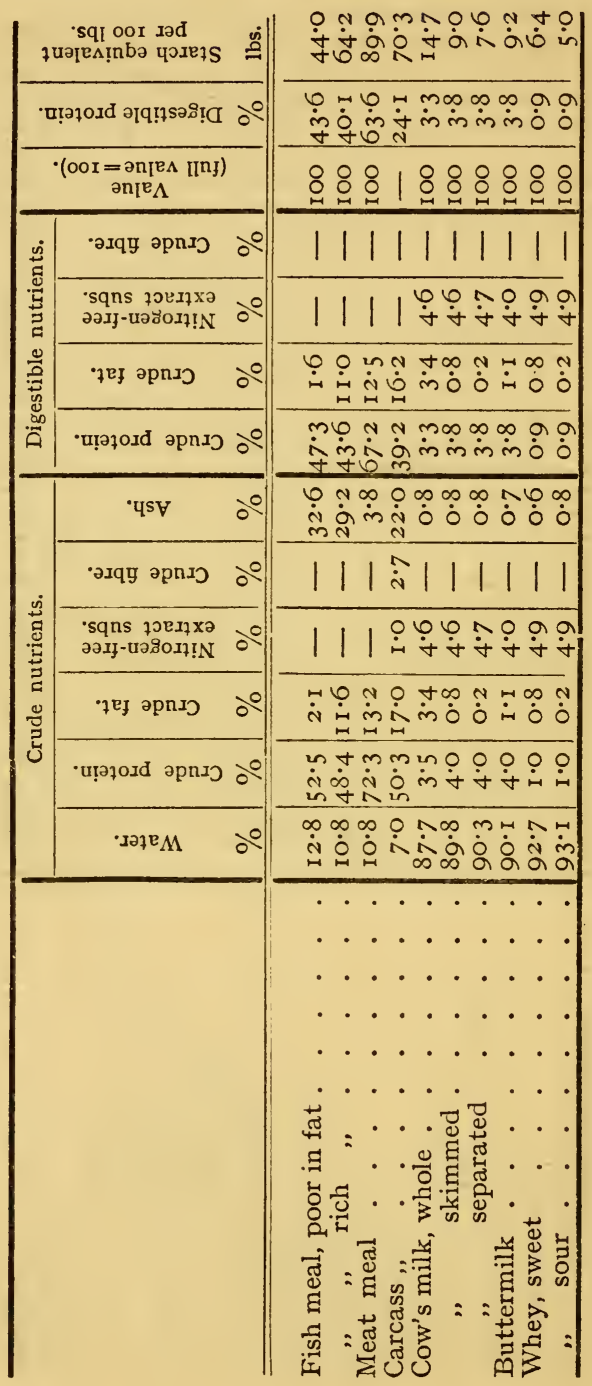


TABLE II

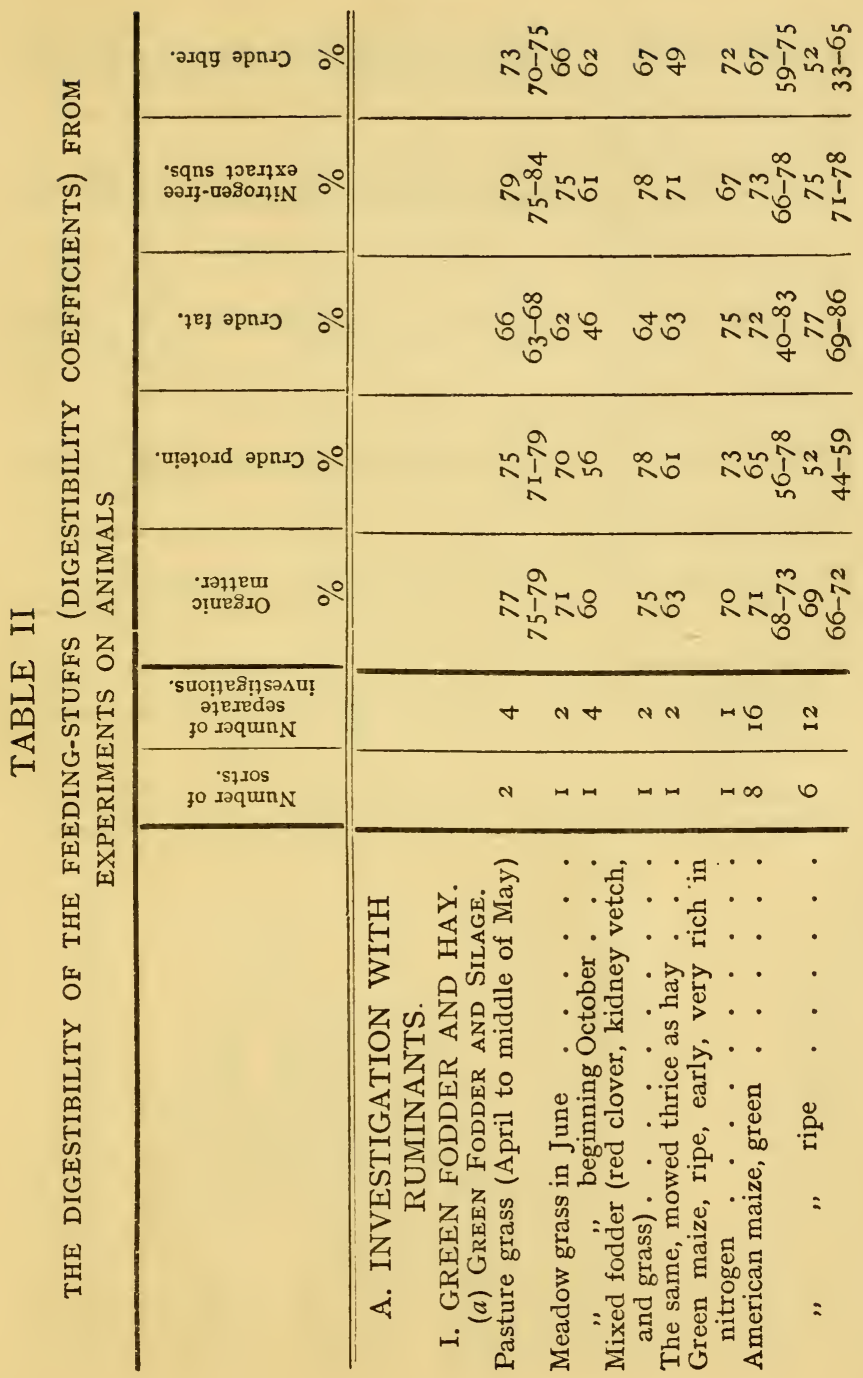




\section{SCIENTIFIC FEEDING OF ANIMALS}

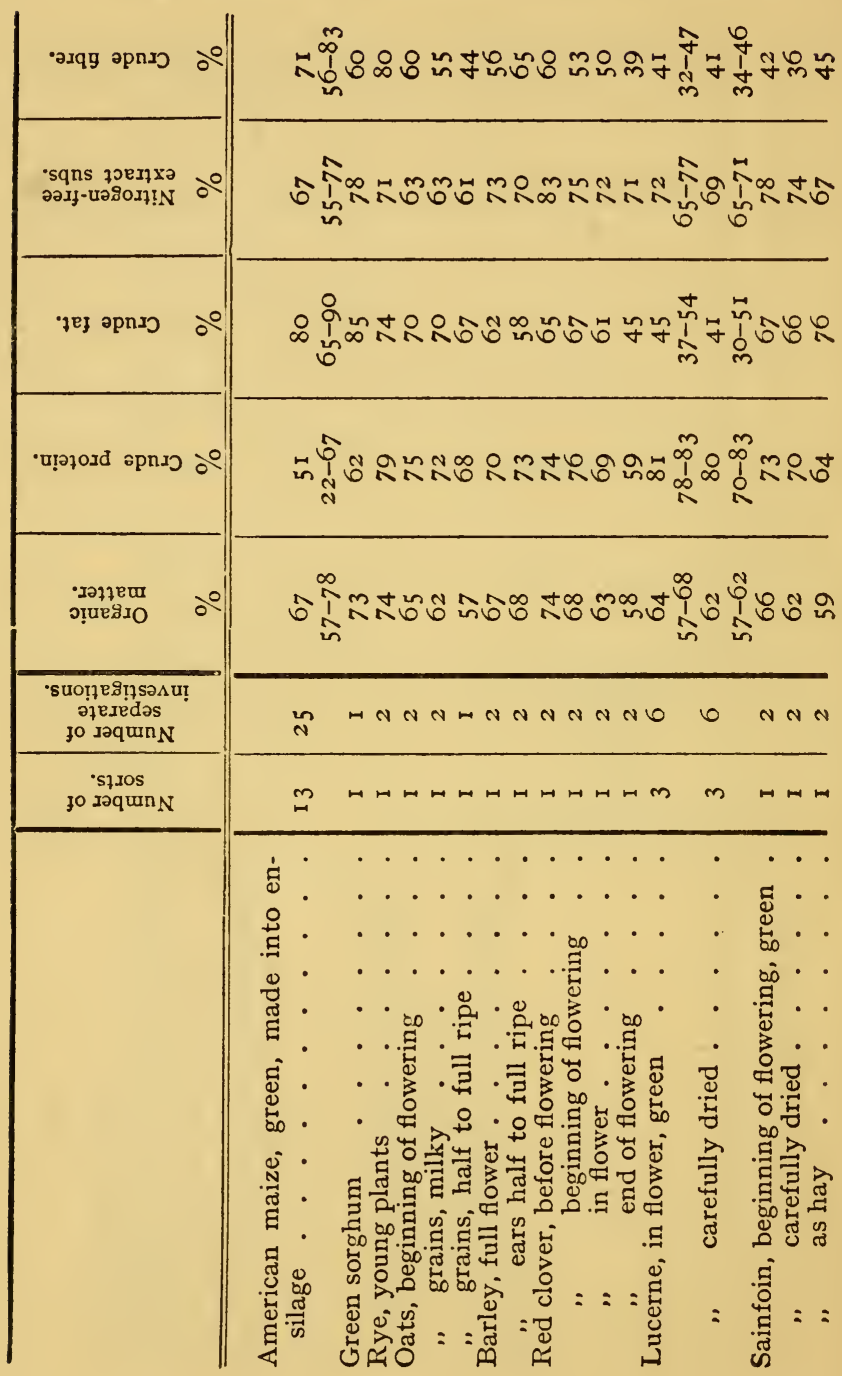




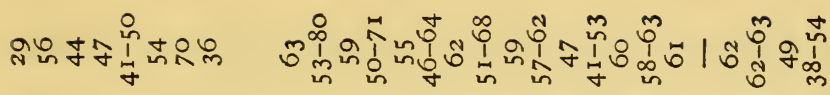

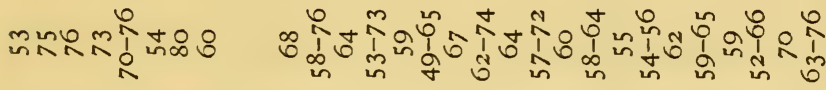

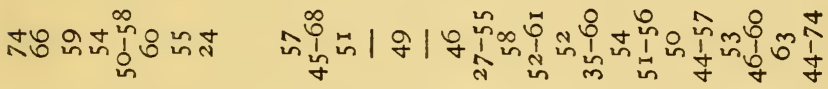

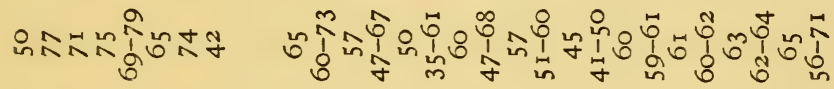

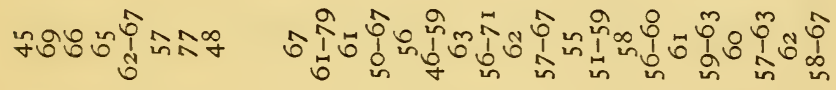

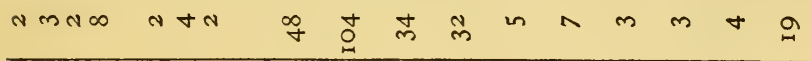

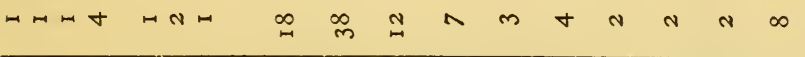

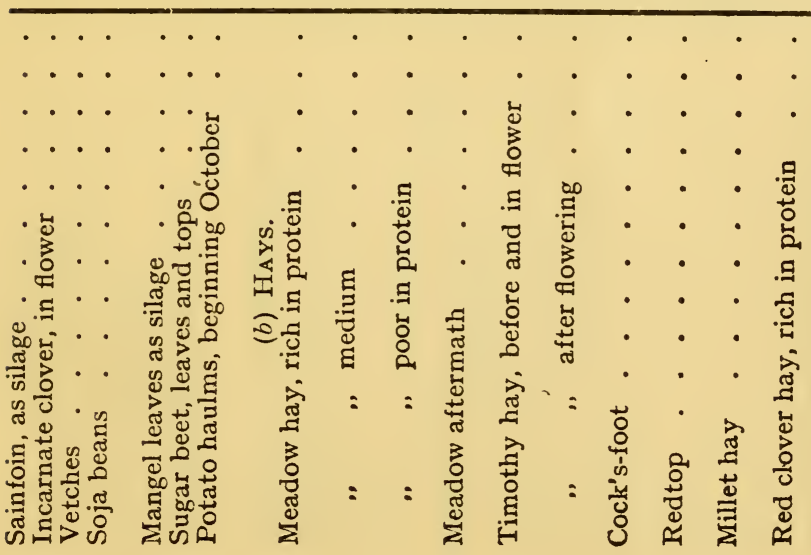




\section{SCIENTIFIC FEEDING OF ANIMALS}

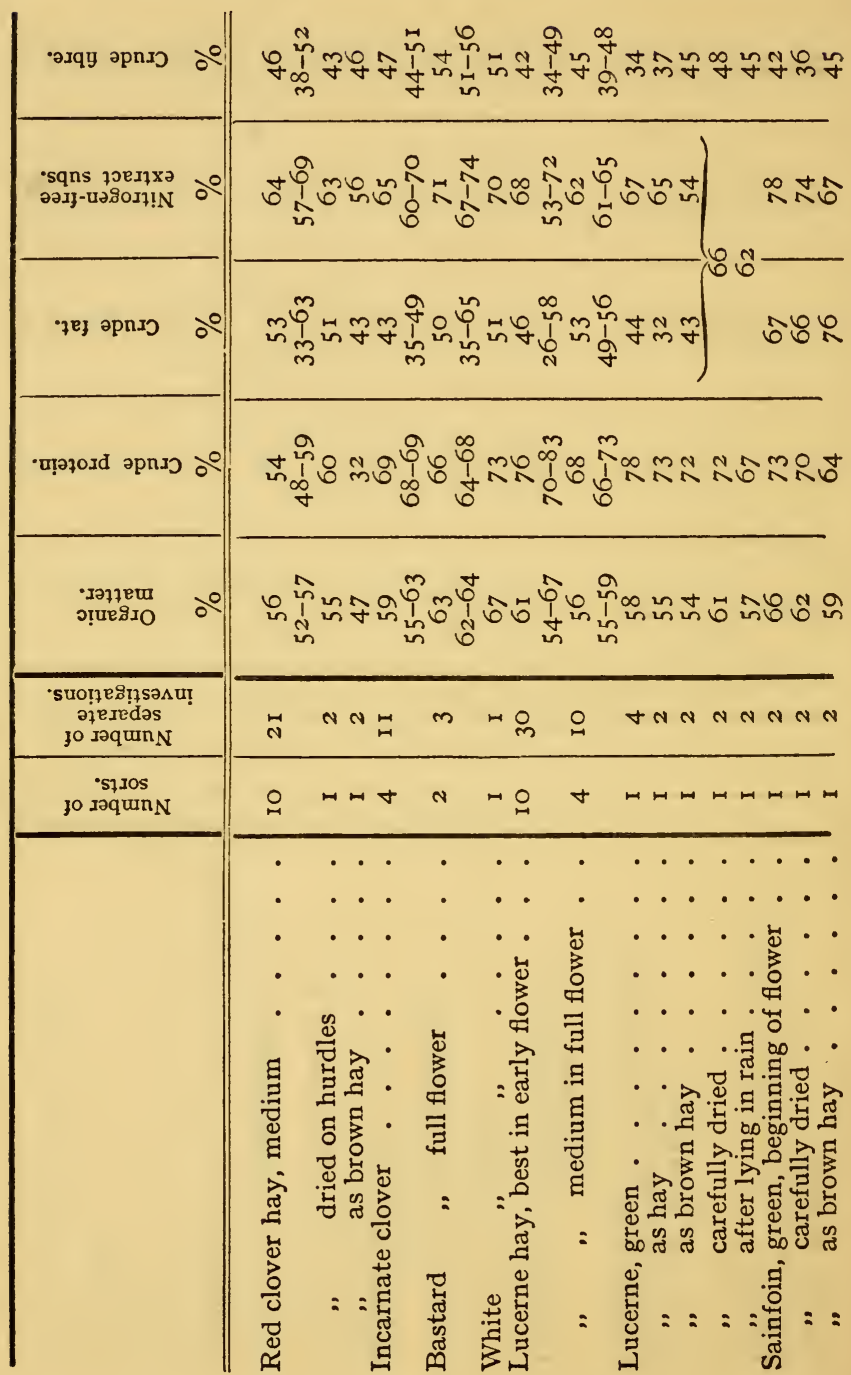




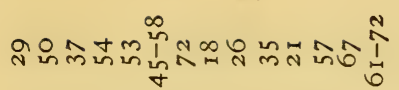

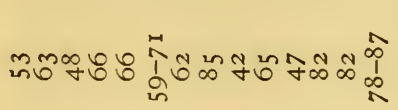

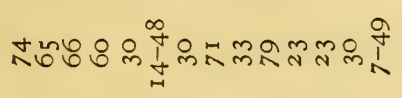

은

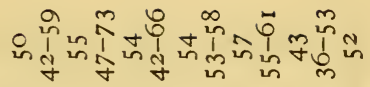

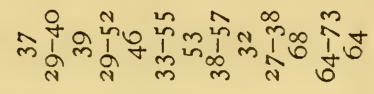
min

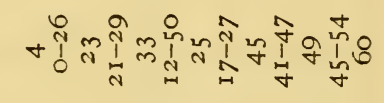

头

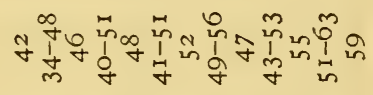

$4 h m b+46464 h t$ $\circ a m N \operatorname{man}$

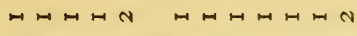
$n m N N m m$

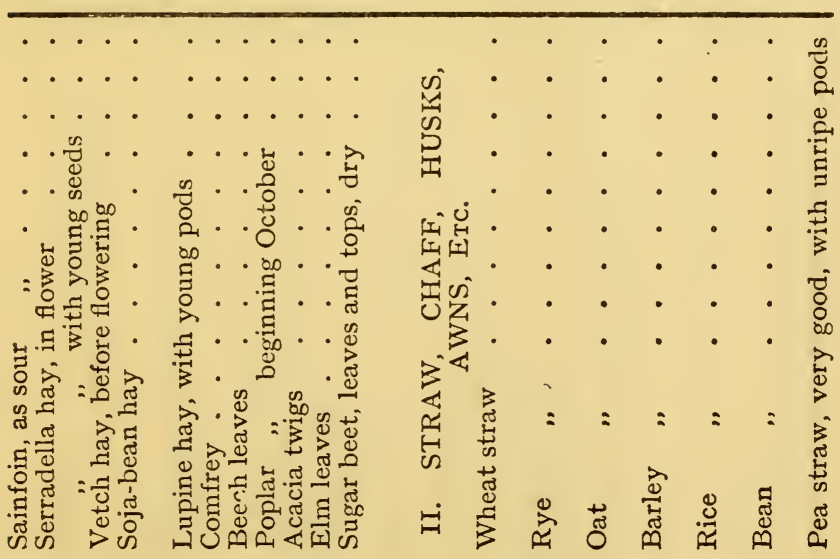




\section{SCIENTIFIC FEEDING OF ANIMALS}

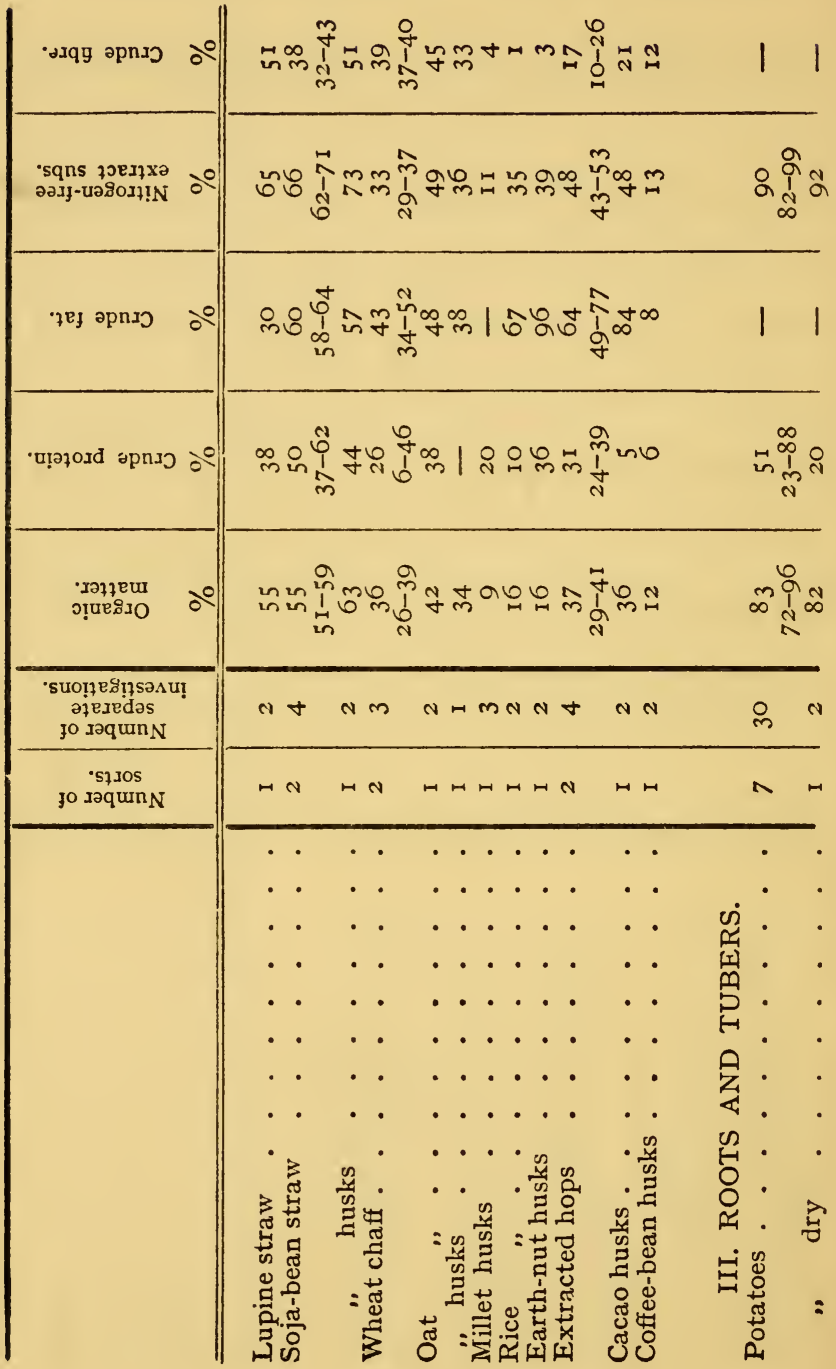




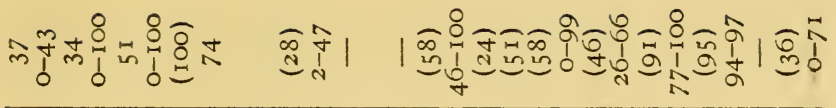

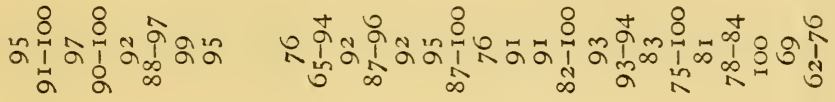

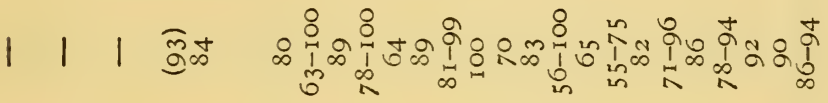

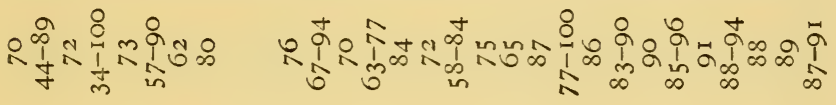

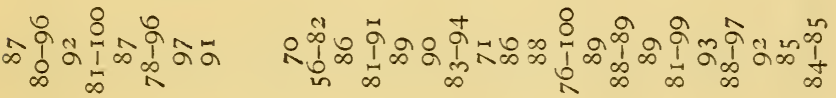

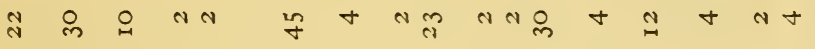

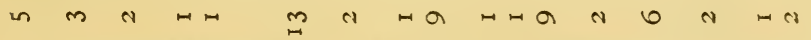

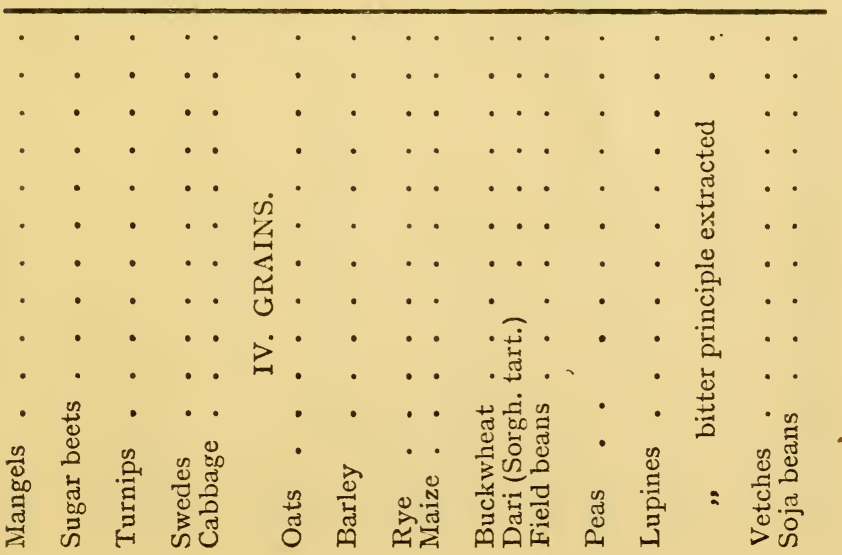




\section{SCIENTIFIC FEEDING OF ANIMALS}

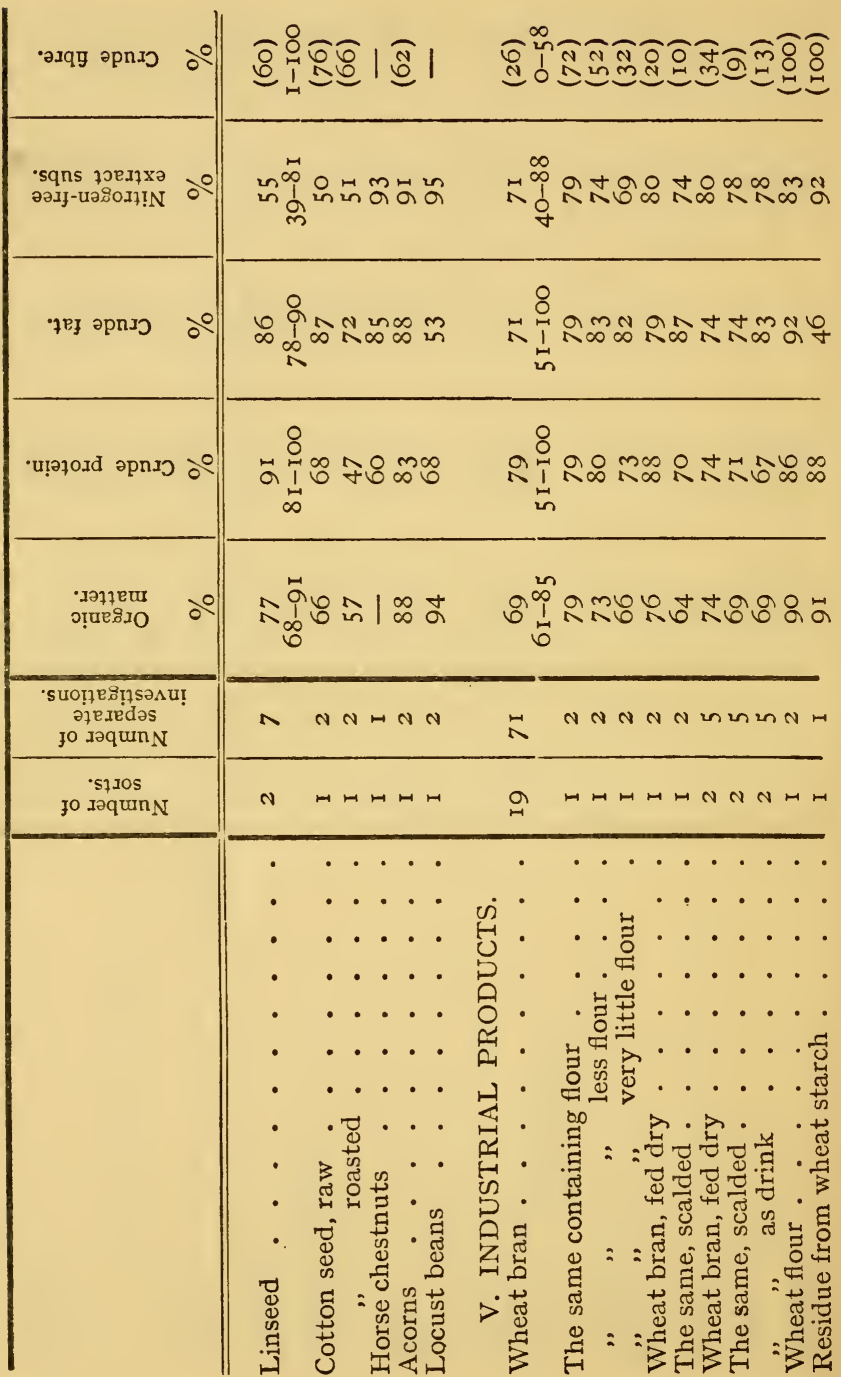




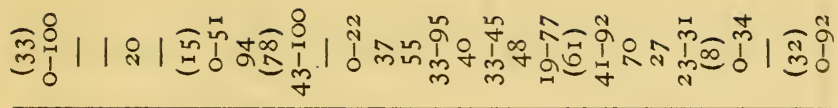

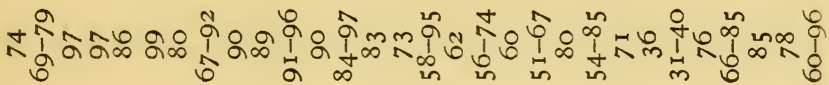

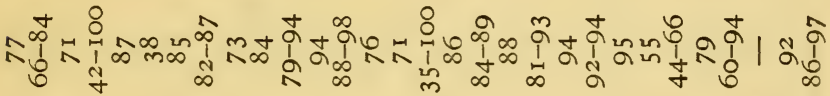

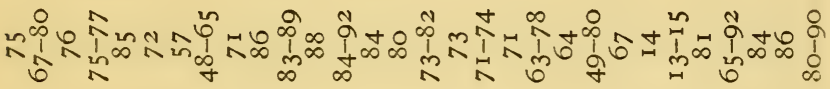

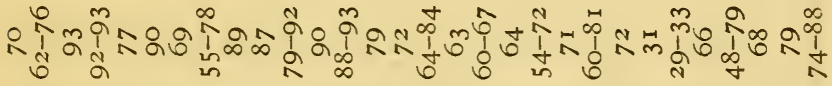

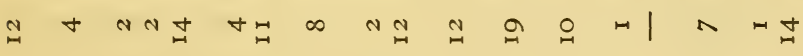

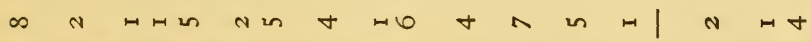

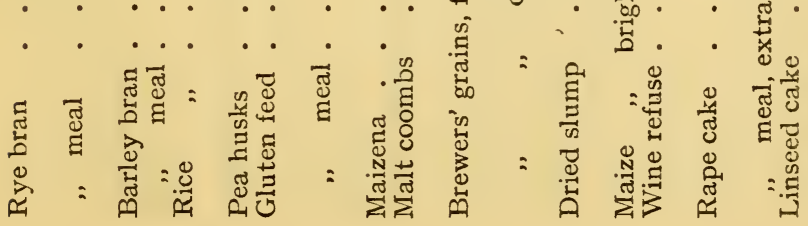




\section{SCIENTIFIC FEEDING OF ANIMALS}

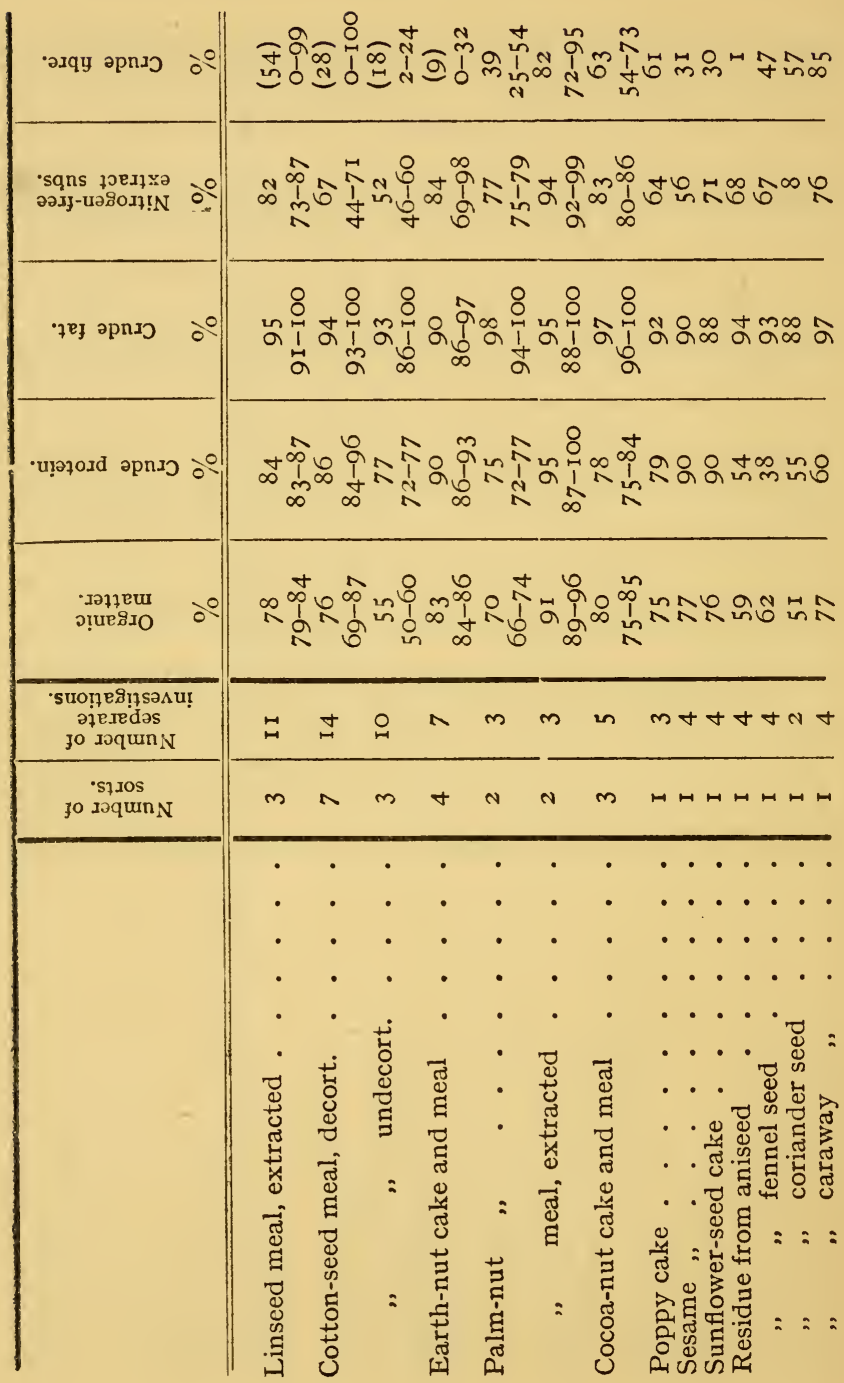




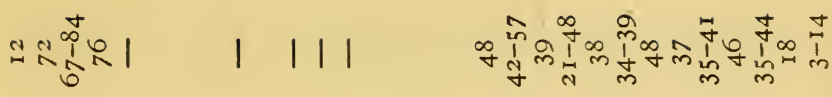

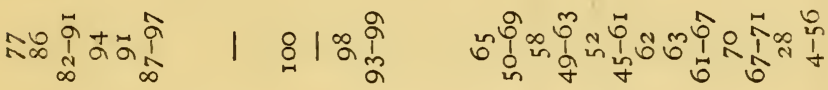

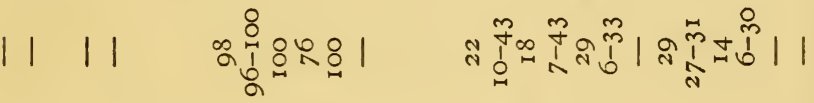

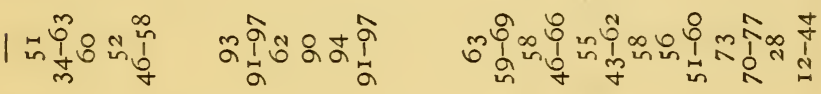

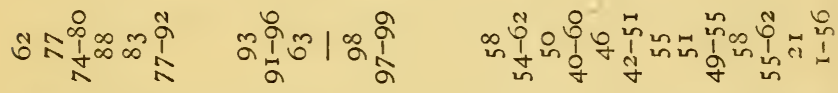

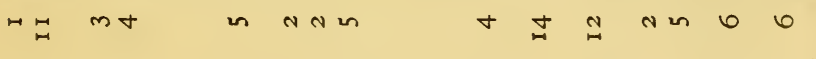

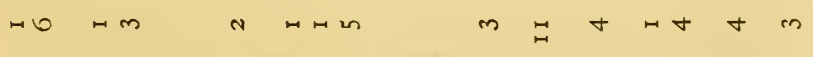

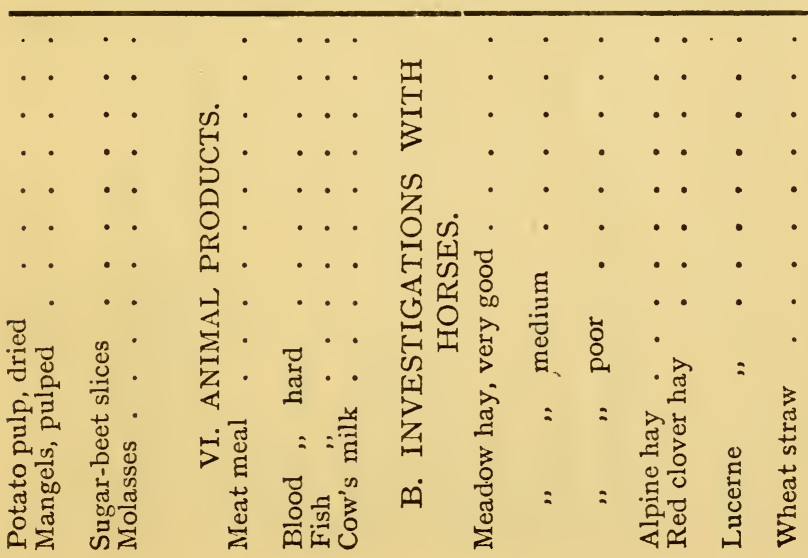




\section{SCIENTIFIC FEEDING OF ANIMALS}

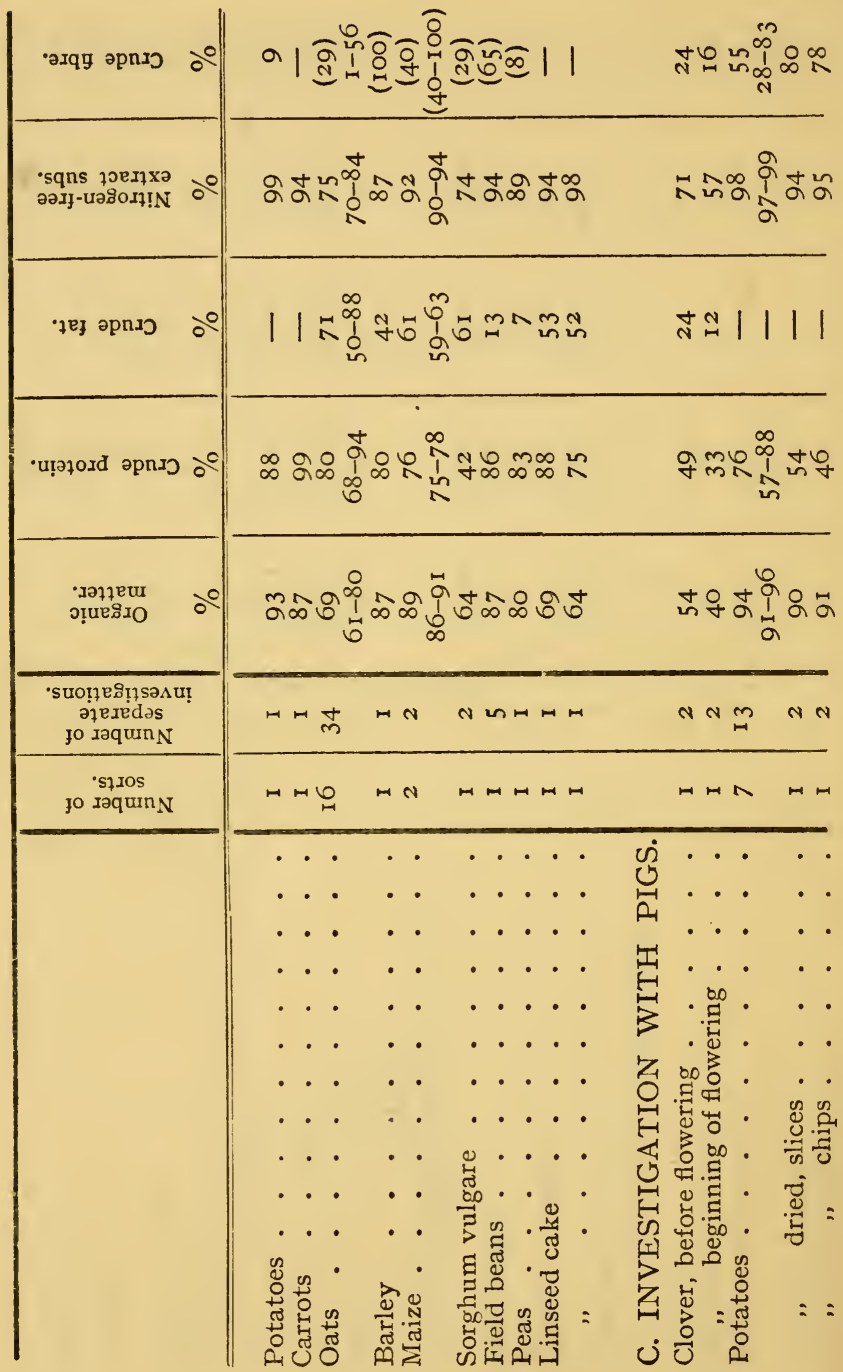




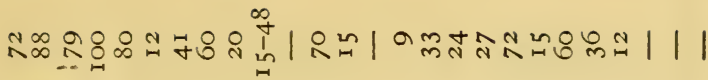

Й

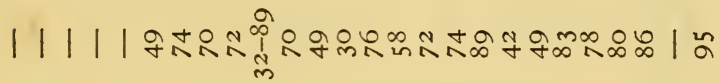

น⿻

นดำ

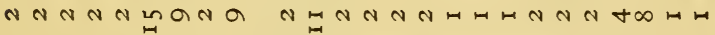

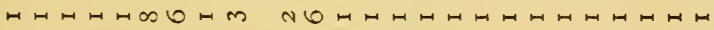

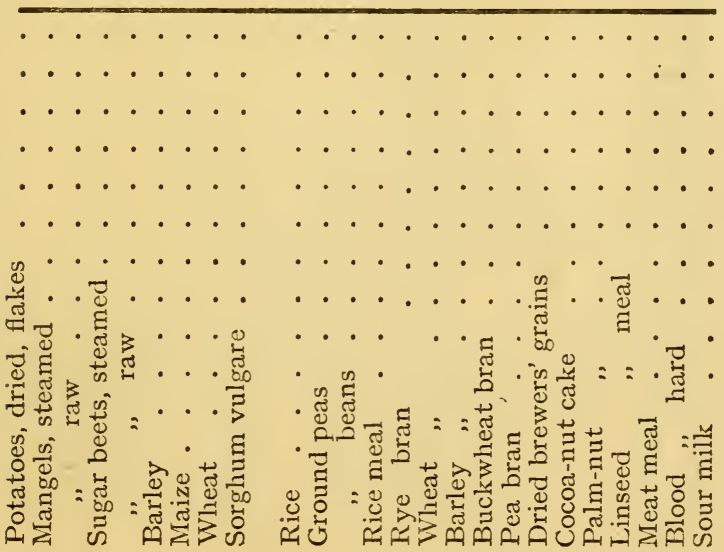




\section{SCIENTIFIC FEEDING OF ANIMALS}

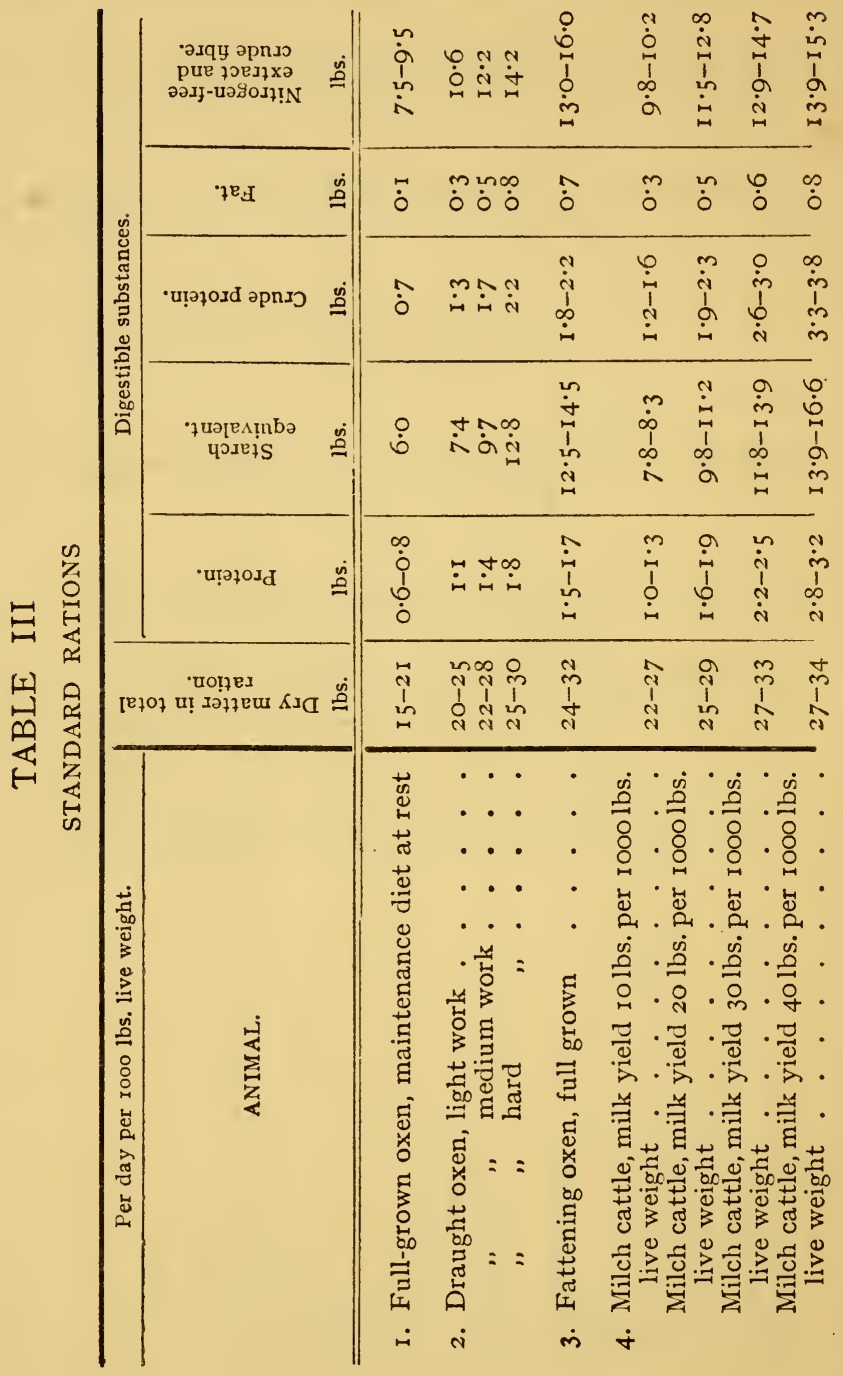




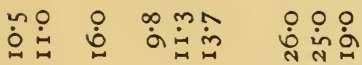

0 o $0 .+0 \quad$ a $\dot{m} \dot{m} \dot{\sim} \dot{\sim} \underset{\sim}{\dot{m}} \dot{m} \dot{m} \dot{\sim} \dot{\sim}$

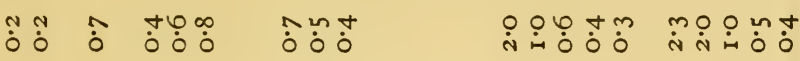

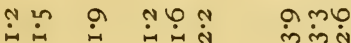

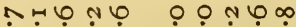

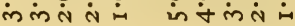

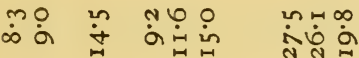

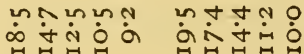

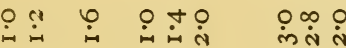

$\forall \infty m \infty$ un un, $N$ un $\dot{m} \dot{N} \dot{N} \dot{i} \dot{q} \dot{q} \dot{N} \dot{\sim} \dot{H}$

\begin{tabular}{|c|c|c|c|c|c|}
\hline 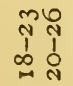 & $\frac{\text { aे }}{\text { I }}$ & 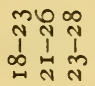 & 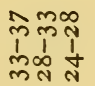 & 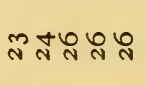 & mañ \\
\hline
\end{tabular}

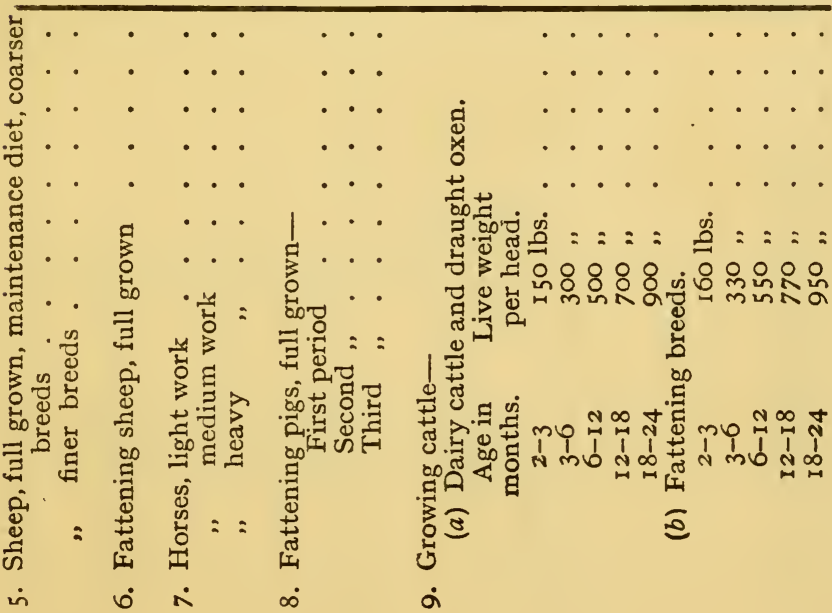




\section{SCIENTIFIC FEEDING OF ANIMALS}

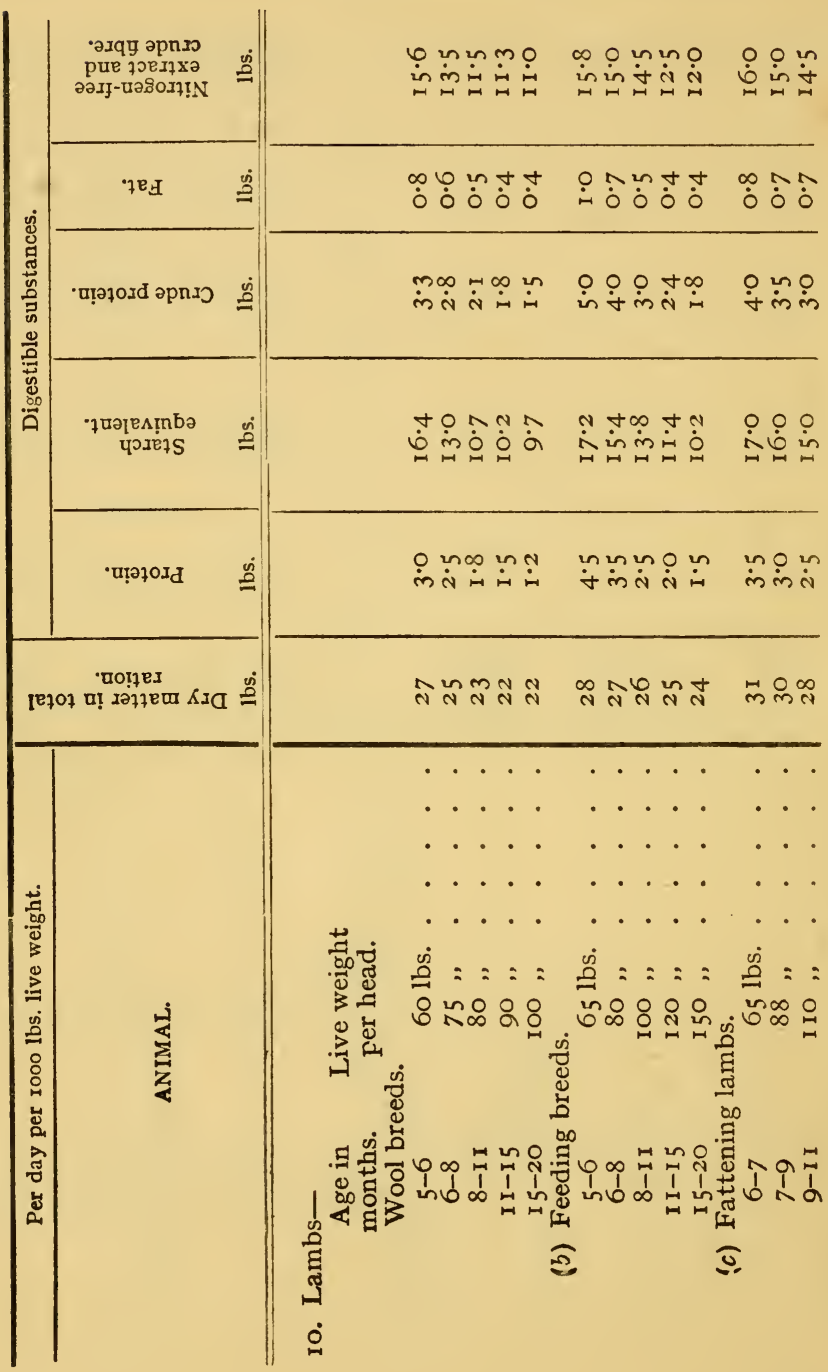




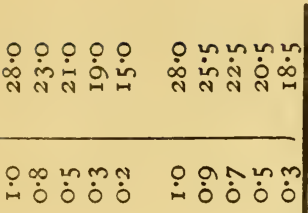

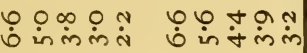

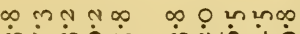
लित्र

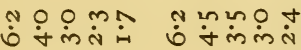

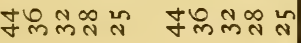

$\dot{0}=:=$ :

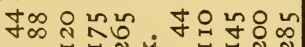
म्य

D.:

. . . . . .$$
\text { . } \cdot
$$$$
\text { . }
$$
कo

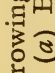

อ 



\section{INDEX}

\section{A}

Abomasum, I9

Absorption of nutrients, 26

Acid, lactic, 25, 39, 8I, I 27

Acorns, 190

Adulteration of feeding meals, I9I

- - oil cakes, 196

Age of animal, influence upon digestion, 33

- cow, influence upon milk production, 3I I

Air-dried material, 4

Albumin, 5

Albuminoid ratio, 232, 257

Albuminoids, 3

Albumoses, 23, 24, 59

Alcohol in distillery waste, 2 I 5

- - silage, 127

- - sweet mashes, I45

Alimentary canal, length of, in animals, 26

Almond cake, 204

Amides, 8

Amino acids, 8

Ammonium acetate, effect on milk production, 328

- - effect on protein metabolism, 66

Animal heat, 4I

Animals, composition of bodies, 254

Artichokes, I80

Artificial digestion, 30

- drying of feeding-stuffs, I 35
Ash, I 5

Asparagine, 8, 65

- and fat formation, 68

- influence on protein metabolism, 66

Availability, determination of, 30, 379

Available energy of food, 49, IO9

B

Bacon, influence of food on, 304 Bacteria, action of, in digestion, $21,24,37,87$

- and non-protein substances, 67

- in silage, 127

Barley, I 85, 192

— for horses, $28 \mathrm{I}$

— for pigs, I 86, 299

- meal, I93

Bastard clover, I64

Beech mast, I90

- nut cake, 203

Beef, feeding for, 256

Beet leaves, effect of feeding, 345

- - oxalic acid in, 167

- molasses, 208

- silage, 129

- slices, 207

Bile, 23

Blood, necessity of good supply, 272

- meal, 223

Body fat, determination of increase, 46 
Body fat from carbohydrates, 77 - - from food fat, 74, 82

- - - protein, 82

Body heat, loss dependent upon surface, 53

- temperature, $4 \mathrm{I}$

- tissue, determination of increase, 44

Bomb calorimeter, 48

Bones, diseases of, 97

Bran, adulteration of, I9I

- effects of, I94

- _ - on butter, 348

Breed and milk yield, 308

Brewers' grains, 214

- - dry, 2 I 5

Buckwheat, I66, I87

Butter fat, effect of food on, 333

Buttermilk, 220

Butyric acid formed by bacteria, 25, 127

\section{C}

Cabbage, feeding value of, I 68

Calf, Liebig's recipe for food of, I45, 29 I

Calorie, definition of, 48

Calves, feeding of, 289

- weaning of, 290, 292

Cane sugar, I4

- - in mangels, 135,174

- - in molasses, 208

Carbohydrates, 14, 83

- influence on butter fat, 334

Carcass meal, 222

Carrots, leaves of, 167

- value of, 176

Castor-oil seed cake, 204

Cattle powders, 224

Cellulose, composition of, I 3

Cereal grains, is 84

Cereals as fodder plants, I 62

Chaff, I 72

Chemical examination of foodstuffs, 3

Chlorine, effects of deficiency, 95

Chopping of straw, 137
Clover, influence of age, I 53

Clovers, composition of, I6 3

Coarse fodder, experiment with, 85

- - for horses, 279

Cocoa-nut cake, 199, 304, 348

— - meal, I99, 348

Coefficients, digestibility, 29, 279

Colostrum, 219, 289

Common salt, effects of, 95, 236

Composition of animal bodies, 254

Condiments, influence on digestibility of food, 40

Contamination of foods, II 8

Cooked food, value of, I4I

Cotton-seed cake meal, 196

- - - effect on pigs, 197. 304

Cows, and milk yield, 308

Crops for silage, I 25

Crude ash, 16

- fat, 12

- fibre, 12

- - and fat production, 88

- - increase in wet weather, 157

- - value as food, 80

Crushing of grain, 138

Cutin in crude fibre, 13

\section{D}

Diffusion slices, 207

Digested nutrients, the supply of energy from, 42

Digestibility coefficients, 29, 279

- depression of by carbohydrates, 36

- depression of by oil, 38

- depression raised by protein, 38

- determination of, 27

- influence of age on, 33

- trials, methods of conducting, 27

Digestion, artificial, 30 


\section{INDEX}

Digestion, defective, 33

- effect of work upon, 34

- extent of, 31

- influence of quantity of food upon, 35

- influence of mixing of food upon, 36

- influence of species of animal, 32

— of one-sided rations, 36

- processes of, 2 I

Digestive power of different breeds, 32

_ _ - individuals, 33

Distillery grains, 215

- waste or slump, 2 I 5

Dried blood, 223

- brewers' grains, 215

- slumps, 21 7

Drought, effect on plants, I 57 Dry matter, 4

Drying of samples of foodstuffs, 4

Durability of food-stuffs, I 20

Dynamic energy, 57

E

Earth-nut cake and meal, 197 Energy from fat, 107

- - nitrogen-free nutrients, 106

- - isolated nutrients, I Io

- - protein, 104, 106

- - starch, 107, 273

- metabolism, 48

- required for performance of work, I I I

- sources of, 104

- total, I IO

- units of, 48

- used in mastication and digestion, 57,87

Ensilage (see Silage)

Enzymes in digestive juices, 2 I

- properties of, 22

Epithelial cells in mammary gland, 307

Ether extract, 12
Excretion of waste products, 43

Exercise, benefits of, 298, 344

\section{F}

Fasting metabolism, 5 I

Fat, amount to be fed, 257,272

- determination of increase in body, 46

- from cane sugar, 80

- from carbohydrates, 77

- from crude fibre, 80

- from protein, 64,82

- heat value of, 70

— in food, 257

- influence on digestibility of food, 38

- influenced by food, 258

- in fasting, 54

Fats and oils, Io

- carbohydrates, 77

Fattening of grown animals, 254

- - ruminants, 26I

- ration, 256

Feeding, insufficient, 55

- loaves, manufacture of, I48

- of draught oxen, 273

- of horses, 275

- standards, 392

Feeding-stuffs, full-value, 90

Field beans, 188, 28!

Fish meal, 222

Flavour of milk, I 76,346

Flesh, composition of, 46

- increase of, 44

Flour mills, by-products from, I90

Fodder damaged by fumes, I 8

- - fungi, I I8

- - - moulds, I I9

- frozen, II9

- mastication of green, 88

- plants, influence of variety, I 54

- 154 of soil and manuring, I 55

Food, extra required for fat animals, 267 
Food fat, influence upon body fat, 76

- - influence upon secretion of milk, 321

Food for milch cattle, 338

- preparation for pigs, 305

- nutrients, 43,83

Foods, utilisation of complete, 82

Food-stuffs, effect of injurious, 338

- that damage milk, 346

- that improve milk, 347

Frequent milking, effect of, 3 I 3

Fruit sugar (see Levulose)

Full-value feeding-stuffs, 90

G

Gaseous products formed during digestion, 25

Gastric digestion, 23

Gastric juice, 23

Gelatine as food, 6I

Glucose, 14

Glutamine, 8

Gluten feed, 206

Glycerine, IO, I I

Grain, composition of, I80

- falsification of ground, I84

- influence of soil and manuring, 183

- losses on storage, I 3 I

- sprouting of, 182

Grape sugar (see Glucose)

Grass, influence of age, 150

Green food, care in use of, 158

- maize, I62

Grinding grain, $\mathrm{I} 38$

Group system in experiments on cows, 319

Growth of wool, 249

$\mathrm{H}$

Hay, I 50, I6I

Hay-making, I 22

Heat generated in fattening, 265

- loss of body, 52

- values, 48

Heating water for animals, 103
Hemp cake, 203

Henneberg's number, 65

Homco, or hominy feeding meal, 194

Hordenin, 2 I4

Horse chestnuts, 190

- inferior digestive power, 3 I

Horses, feeding of, 275

- maize for, 280

- oats for, 280

Hydrochloric acid in gastric juice, 23

- - heated with straw, 144

I

Incarnate clover, I 64

Incrusting material, 13, I4, I44

Indian corn (see Maize)

Insufficient feeding, 55

Internal work of body, I IO

Intestinal juice, 24

Intestine, bacteria in, 24

Investigations in groups, 240 , 319

- periods, 240, 317

Iron in food, 98

$\mathrm{J}$

Java bean, poison in, $\mathrm{I} 88$

$\mathrm{K}$

Kidney vetch, 164

Kohl-rabi, 176

- leaves, 167

\section{L}

Labour, hard, and nitrogen excretion, 105

Lactation, period of, 3 Io

Lactic acid, action on digestibility, 39

- - and fat, $8 \mathrm{I}$

- - in digestion, 25

- - in silage, 127

Lactose, I4

Lambs, feeding of, 294

- weaning of, 294

Leaves and twigs as fodder, 168

Lecithine, 8,98 
Leguminosæ as fodder crops, 163,165

Leguminous seeds, 187

Levulose, I4

Liebig's recipe, 145

Lignin in crude fibre, I 3

Lime, effect of deficiency, 96

- in feeding-stuffs, 98

- phosphate of, 223

Linoleic acid, 333

Linseed, 189

- cake, 200

Lipase in gastric juice, 23

Loss of heat from body, 52

Losses during keeping of mangels, 134

- - storage of grain, I3I

- in making hay, I 25

Lucerne, I64

Lupine plants as fodder, I 65

- - poison in, 165

- seeds, I 89

- - steeping, I 43

\section{M}

Magnesia, in animal body, 96

Maintenance ration, 58

- - for oxen at rest, 246

- - for sheep, 249

- - influence of body surface, 246

Maize, 186

- for horses, I86, 280

- for pigs, 187

- germ cake, 206

Malt, I 82

— coombs, 213

Malting of grains, 145

Mammary gland, 307

Mangel tops, 166

Mangels, food value of, I 75

- losses on storing, I 34

- properties of, 174

Manyplies, 19

Marsh-gas fermentation, 25

Mashes, sweet, 145

Meadow hay, I6I

— grass, I6I
Meals, feeding, 192

Meat meal, 22 I

Metabolism, definition of, 43

Methods of investigation in milk production, 317

Milch cows, feeding of, 306

Milk, 2 I 7

- composition of, 218

- formation of, 306

- sugar, I4

- yields, 308

Milking, influence of frequency of, 3 I I

Millet, 182

- polish, 193

Mineral hunger, 59

- substances, 15

- metabolism of, 94

_ — in milk, 343

Moistening of food, 140

Molasses, 208

- feeds, 2 10

- - adulteration of, 2 I I

- - water in, 212

- way to use, 2 II

Muscular energy, sources of, I04, 106

Mustard, white, 166

\section{$\mathrm{N}$}

Narrow and wide rations, 232

Nitrogen equilibrium, 6I

Nitrogen-free extract, I4

- nutrients as source of muscular energy, 106

- - diminish consumption of protein, 330

- - effect on metabolism, 6972,330

- - effect on milk production, 329

- - infiluence upon composition of butter, 334

Nitrogenous substances (see Protein)

Non-protein nitrogenous substances, 7,8 
Non-protein nitrogenous substances, effect on digestibility, 39

- - - effect on protein metabolism, 65

- - - effect on fat metabolism, 68

- - - effect on milk production, 327

Nutrient, definition of a, 43

- material, methods of investigation, 44

Nutrients, effect of, in food, 84

Nutritive ratio, 23I, 257

\section{O}

Oat cleanings, 193

— feed, 193

- grain, composition of, 182, I 85

- husks, II 7

- straw, I7I

Oats, I 84

— for cows, 337,348

- for horses, 185,280

- stimulating principle in, 214

- substitution of maize for, 280

Oil cake, adulteration of, 196

_ - feeding of, Ig6

- - old and new process, 195

- meal, I95

- mills, residues from, 195

Omasum, I9

Organic acids in food-stuffs, I 5

- matter, 16

Osteo-malacia, 97

\section{$\mathrm{P}$}

Palmitic acid, Io

Palm-nut cake, 199

- meal, 199

Pancreatic juice, 24

- - action of, 24

Passage of food through animal body, time required, 27

Pasture, benefit of, 298, 344

- grasses, 160
Pasture, importance in feeding pigs, 298

-influence of, on milk, 344

Peas, I 88

Pentosans, composition of, I? Pepsin in gastric juice, 23

Peptones, 23, 24, 59

Period of lactation, 310

Period system in experiments on cows, 317

Permanent pasture grasses, $16 \mathrm{c}$ Phaseolus lunatus, I 88

Phosphate of lime, 223

Phosphoric acid, deficiency, st

- - in feeding-stuffs, 98

Phytosterin, 333

Pig, power of digestibility, 32

Pigs, fattening of, 269

- feeding of growing, 296

- weaning of, 297

Plant, mineral substances in, I7

Poison from cotton seed, 197

- - lupine plants, 165

Poppy-seed cake, 202

Potash in animal body, 94

- - molasses, 209

Potato slump, 216

Potatoes, composition of, I 77

- cooking of, I 79

- dried, I80

- feeding of; 178

- steeping of, 142

Predigestion of foods, 146

Productive ration, 58

- value of nutrients, 86

Protein as source of muscular energy, 104

- crude, 7

- equilibrium, 6I

- hunger, 59

- influence upon digestibility, 38

_- - metabolism, 59

- part played in fasting by, 54

- pure, 7

Proteins, the, 5

Prussic acid, 163, I88

Psalterium, 19 
Ptyalin, in saliva, 22

Putrefaction of food in intestine, 87

\author{
Q
}

Quantity of food and milk production, 323

\section{$\mathrm{R}$}

Rape cake, 20I

- - meal, 202

Rations, calculation of, 354

- maintenance, 245, 248

- production, 256

- size of, 233

- narrow and wide, 232

Red clover, 163

Rennet in gastric juice, 23

Replacement of nutrients, 230

Respiration, increase due to excess of protein, 63

- calorimeter, 49

- chamber, 46

- collection of products of, 47

Reticulum, I9

Rice gluten, 206

- meal, 193

- slump, 206

Roasting of food-stuffs, 142

Roots, composition of, I 73

- feeding of, I74

- and tubers, losses during storage, I 32

Rumen, 19

Rumination, time required for, 34

Ruminants and non-protein, 66

Rye, I 86

— for horses, 28I

$\mathrm{S}$

Sainfoin, I64

Saliva, composition of, 23

- secretion of, 18

- work performed by, 22

Salt in animal body, 94

- supply of, 236
Sawdust, effect on digestion, 86,90

Seed grasses, 162

Separated milk, 220

Serradella, I 65

Sesame cake, 198

Shearing of fattening animals, 266

Sheep, composition of body of, 254

- feeding-stuffs for, 252

- maintenance ration for, 245

Silage, 125

- crops, 125

- quantities to be fed, I 28

Silo, character of losses in, 128

- construction, I26

- filling and covering, 126

Size of body and loss of heat, 53

Skim milk, 220

Slicing of roots, I 37

Soaking food, I40

Soda, in animal body, 94

Soja bean, 187

Solanine, 177

Sorghum, I63

Sour fodder, I 25

- - preparation of, 147

- milk, 220

Specific effects of food on milk, 334

Spurry, 346

Stall, temperature of, 265

Standard rations, 392

Starch as food for bacteria, 37

- energy from, IIO, 273

- equivalent, 92

- formation of fat from, 81

- residues from manufacture of, 204

Steaming of food, 146

Stearic acid, IO

Stomach of ruminant, I9

Straw, chopping of, I 37

— food value of cereal, I70

- - of leguminous, I 7 I

- treatment under pressure with soda lye, 144 
Steeping of potatoes in water, I 42

- of lupines in water, I43

Storage of cereal grains, I 30

- of meals, etc., I 32

- of roots and tubers, I 32

Sugar as food for bacteria, 37

- feeding of, 2 I 2

- from protein, 64

- beet as food, I75

- - leaves, I66

- - slices, 207

Suitableness of food, 232

Summer feeding of cows, 344

Sunflower-seed cake, 202

Swedish clover, I64

Sweet mashes, I 45

- mash for calves, I45

\section{$\mathrm{T}$}

Table for calculation of rations, 353

Tallow, I I

Temperature during fasting, 54

- in hay-stack, I 24

- influence of surroundings, I 53

— of body, $4 \mathrm{I}$

-- of stall, $52,244,265$

Thermic energy, 57

Total energy, 57

Trypsin, 24

Tubers, losses during storage of, I 32

'Turnips, I 76

Turnip leaves, 167

$\mathrm{U}$

Unit of energy, 48

- of work, I09

Urea, 43
Urine, waste products in, 43 Utilisable energy of nutrients, 48, 109

Utilisation of complete foods, 82

- of digested nutrients, 4I

- of energy in animal body, I09

\section{V ,}

Vermicular movements of intestine, 20

Vetches, 165

W

Waste products, composition of some, II 7

- - in respiration, 43

- oxidisable, 43

Water, I

- effects of excess of, IOI, 254

- in feeding-stuffs, 4

- of vegetation, IOI

- in body, uses of, 99

- warm drinking, IO2

Watering of animals, 237

Weaning calves, 290, 292

- lambs, 294

Weather, effect on fodder plants, 157

Weed seeds in grains, I9I

Weeds, injurious effects of, I 20

Wheat, I 86

Whey, 220

Wide and narrow rations, 232

Winter feeding of cows, 346

Wool, influence of food on, 249

- production of, 247

Work, effect upon digestion, 34

- influence upon milk production, 314

Working animals, feeding of, 271 

Webster Fanily thran of veternany Medicine Cummens solow of Vherinary inedicine at Tufus Whosin

200 Wontoro Road

North Guton, MA01536 
